\title{
SONGBIRD RESPONSE TO FOREST DISTURBANCE DUE TO UNCONVENTIONAL SHALE GAS DEVELOPMENT IN THE MARCELLUS-UTICA REGION: A MULTI-SCALE ANALYSIS
}

\author{
Laura S. Farwell \\ Dissertation submitted \\ to the Davis College of Agriculture, Natural Resources, and Design \\ at West Virginia University \\ in partial fulfillment of the requirements for the degree of \\ Doctor of Philosophy \\ in Forest Resource Science \\ Petra Bohall Wood, Ph.D., Chair \\ James T. Anderson, Ph.D. \\ Margaret C. Brittingham, Ph.D. \\ Donald J. Brown, Ph.D. \\ Brenden E. McNeil, Ph.D. \\ Division of Forestry and Natural Resources, \\ Wildlife and Fisheries Resources Program \\ Morgantown, West Virginia \\ 2018
}

Keywords: unconventional shale gas, fracking, forest fragmentation, songbird communities, avian guilds, land use change, Marcellus-Utica region, energy impacts

(c) 2018 Laura S. Farwell 


\section{ABSTRACT \\ Songbird response to forest disturbance due to unconventional shale gas development in the Marcellus-Utica region: a multi-scale analysis}

Laura S. Farwell

In this study, I evaluated impacts of unconventional shale gas development, or the combined use of horizontal drilling and hydraulic fracturing (i.e., fracking), on forest land cover and breeding songbirds in the Marcellus-Utica shale region. Since 2005, extraction of natural gas from the Marcellus-Utica shale has increased exponentially in the central Appalachians, an area of high conservation value for global biodiversity. Although there has been an increase in research on the effects of shale gas development in the region, the industry is still relatively new in the eastern U.S. and much is still unknown about biological and environmental impacts.

In Chapter 1, I summarize potential effects of unconventional shale gas development on regional forests, and review the literature on songbird responses to forest loss and fragmentation. I also outline the overall research objectives of this dissertation and provide a summary of chapter topics.

In Chapter 2, I evaluated the effects of shale gas development on a heavily forested, longterm study site in northern West Virginia, from 2008-2015. Construction of gas well pads and linear infrastructure contributed to an overall $4.5 \%$ loss in forest cover at the site, a $12.4 \%$ loss in core forest, and a $51.7 \%$ increase in forest edge density. I evaluated the relationship between land-cover metrics and species richness within three avian guilds: forest-interior, earlysuccessional, and synanthropic, in addition to abundances of 21 focal species. Land-cover impacts were evaluated at two spatial extents: a point-level within 100-m and 500-m buffers of each avian survey station, and a landscape-level across the study area (4,326 ha). Although I observed variability in species-specific responses, I found distinct trends in long-term response among the three avian guilds. Forest-interior species richness declined at all points across the site and at points impacted within $100 \mathrm{~m}$ by shale gas but did not change at unimpacted points. Earlysuccessional and synanthropic species richness increased at all points and at impacted points but did not change at unimpacted points.

In Chapter 3, I focused on spatial responses of focal songbird species to distance from shale gas development, at the same long-term study site in northern West Virginia (2008-2017). I found that more than half of the focal species evaluated showed sensitivity to distance from shale 
gas infrastructure. Several forest interior species occurred in higher abundances with increasing distance from shale gas, while a few forest interior gap specialists increased in abundance closer to shale gas. Early successional and synanthropic species generally occurred in higher abundances closer to shale gas. Interpolated distribution maps for four focal species helped visualize patterns of spatial response to shale gas development, over time.

In Chapter 4, I conducted a region-wide assessment of impacts of Marcellus-Utica shale gas development on forests and breeding songbirds in the central Appalachian region. I evaluated land cover and bird count data from 190 forested sites across the Marcellus-Utica region: 120 sites affected by shale gas development and 70 sites affected only by human development unrelated to shale gas. First, I quantified the footprint of shale gas infrastructure in forested landscapes and found that shale gas generally occupied a relatively small footprint on the landscape $(\bar{x}=2.7 \%)$, and that linear shale gas infrastructure accounted for greater forest loss and fragmentation than well pad development region. I then compared bird community assemblages at sites with and without shale gas development and found they did not differ, suggesting that at a broad scale, bird communities generally responded similarly to shale gas development and other types of human-caused forest disturbance. However, finer-resolution analyses of bird counts across gradients of forest cover and human development revealed some distinct patterns of songbird response relative to shale gas development: I observed lower species richness and abundance among forest interior birds relative to shale gas metrics, while early successional and synanthropic birds showed higher richness and abundance relative to shale gas development.

Lastly, in Chapter 5, I evaluated potential region-wide threshold responses in species abundance to distance from human development and percent forest/core forest cover, across the Marcellus-Utica shale region. My results supported the occurrence of some threshold avian responses to distance from shale gas development, and narrower threshold responses to the proportion of forest cover and core forest cover in landscapes altered by shale gas development.

These findings are consistent with other localized studies from the region, documenting decreasing abundance and diversity of forest interior birds and increasing numbers and diversity of disturbance-dependent and human adapted species, in landscapes altered by shale gas development. The results of this dissertation research suggest efforts to reduce forest fragmentation due to shale gas development may reduce negative impacts on native biological communities in the region, particularly for area-sensitive, forest interior species. 


\section{ACKNOWLEDGMENTS}

I have many people to thank for their support during my dissertation journey. First off, I thank Dr. Petra Wood, my graduate advisor and dissertation committee chair. Petra has been an extraordinarily kind and supportive mentor, and I have learned much from her not just in terms of ecology and research, but also in the value of collaboration and diplomacy in achieving conservation objectives. I sincerely thank Dr. Jim Anderson, Dr. Margaret Brittingham, Dr. Donald Brown, and Dr. Brenden McNeil for agreeing to serve on my graduate committee, for their collective wisdom and experience, helpful conversations during project design, and thoughtful feedback on early drafts of chapter manuscripts. I also thank Dr. Randy Dettmers and Dr. Todd Fearer for early input on study design, and Dr. George Merovich and Dr. Mike Strager for their excellent instruction in quantitative and spatial analyses.

I am grateful to the U.S. Fish and Wildlife Service for funding my research, and to the WV Cooperative Fish and Wildlife Research Unit, WVU Division of Forestry and Natural Resources, WV Department of Natural Resources, PA Department of Conservation and Natural Resources, PA Game Commission, WV Host Farms, Lantz Farm and Nature Preserve, and many private landowners for supporting this research and providing logistical support. Special thanks to Diane Pitcock, Bill Hughes, Dr. Lillie Langlois, and Ben Gamble for invaluable guidance and help in the field, and to Becky Nestor for her cheerful patience and master organizational skills.

I had the good fortune to work with exceptional graduate peers; I especially thank Dr. Jim Sheehan, Dr. Kyle Aldinger, Mack Frantz, Ryan Davis, Gretchen Nareff, and Eric Margenau for thoughtful discussions, friendship and advice. I am indebted to the field surveyors who braved inclement weather and treacherous terrain to gather data for this project: Dr. Doug Becker, Olivia DaRugna, Tasso Cocoves, Anna (Wiker) Therese, Lewis Lolya, Ryan Rock, Erin Eve, Justin Hill, Nathan Bowman, and Nick Glover. Special thanks to Sara Crayton for help with data entry.

Lastly, I could not have done any of this without the love and endless support of my husband, Jeff Anderson, who jumped headfirst into full-time parenting during our wild, wonderful Appalachian adventure. To my sons Kai and Cole - thank you for making me laugh every day and for being my greatest teachers. And finally, thank you to my parents Jim and Yoko Farwell, for always believing in me and teaching me the meaning of perseverance. がんばりました! 


\section{TABLE OF CONTENTS}

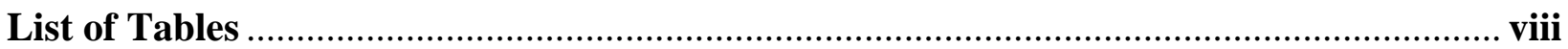

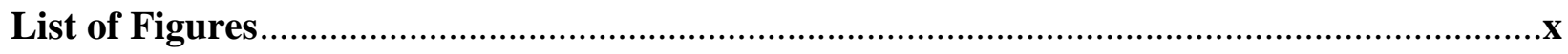

List of Appendices ........................................................................................................... x

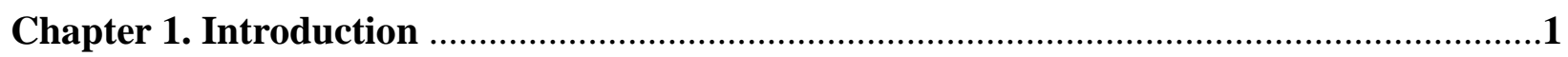

1. Impacts of Marcellus-Utica shale gas development on regional forests ................................1

2. Songbird response to forest loss and fragmentation............................................................

3. Research goals and summary of chapters .......................................................................

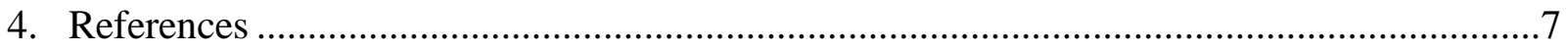

Chapter 2. Shale gas development effects on the songbird community in a central

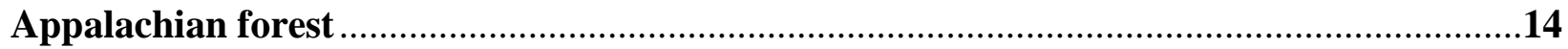

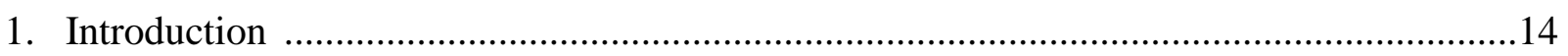

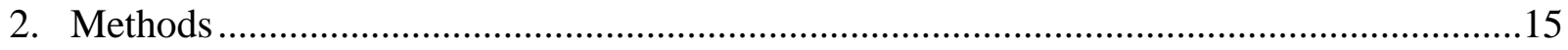

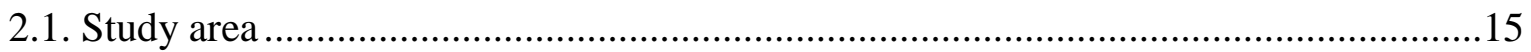

2.2. Land cover mapping and derivation of landscape metrics ..........................................16

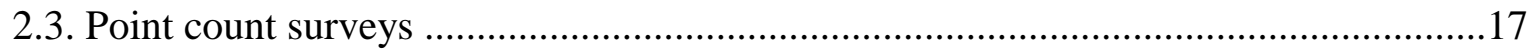

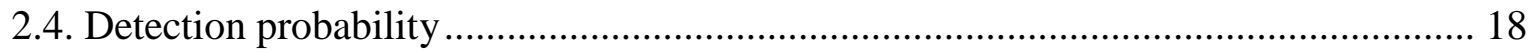

2.5. Avian guilds and focal species ...................................................................... 18

2.6. Data analysis.................................................................................................... 18

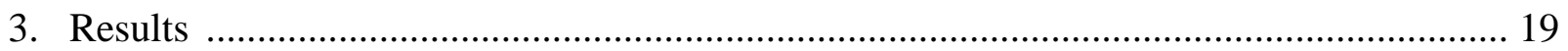

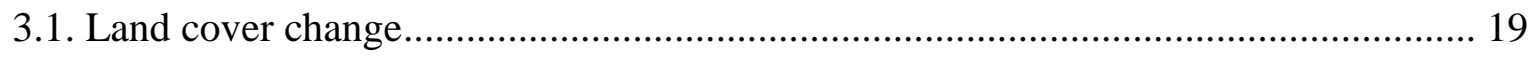

3.2. Avian guild responses ..................................................................................... 19

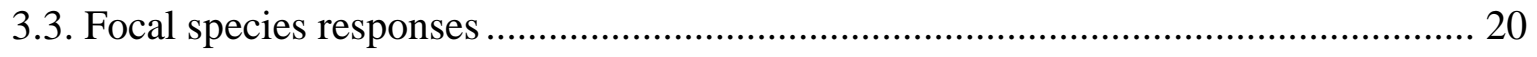

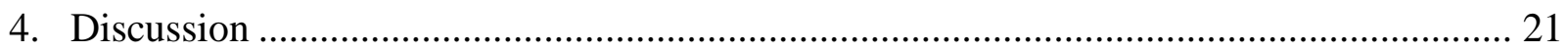

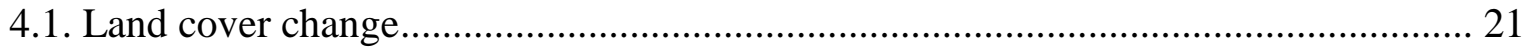

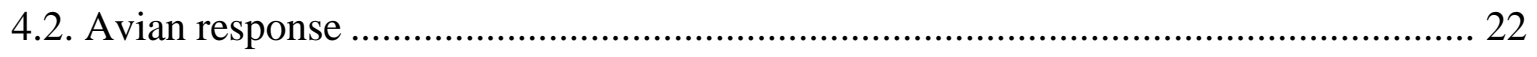

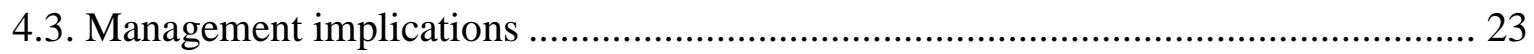

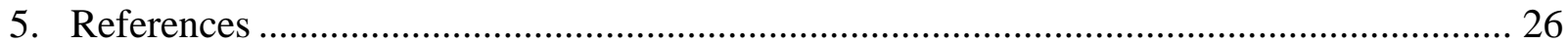


Chapter 3. Proximity to shale gas infrastructure affects breeding songbird abundance and

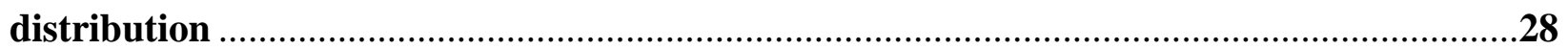

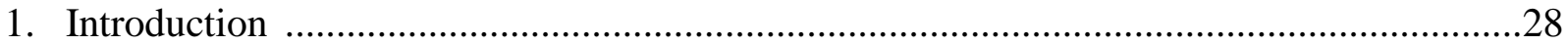

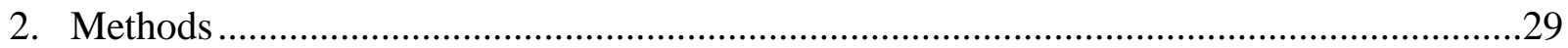

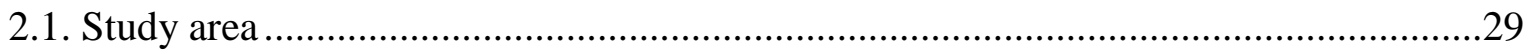

2.2. Land cover mapping and distance metrics ……………...............................................30

2.3. Avian surveys and detection probability ....................................................................30

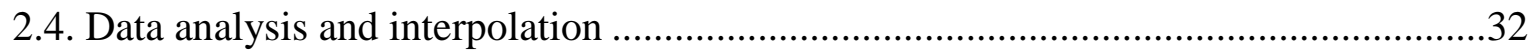

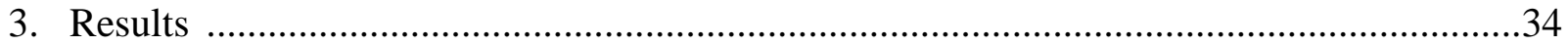

3.1. Avian response to distance from gas development .......................................................34

3.2. Focal species distribution probability maps …………………….................................

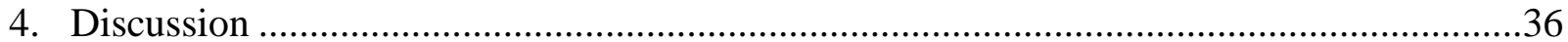

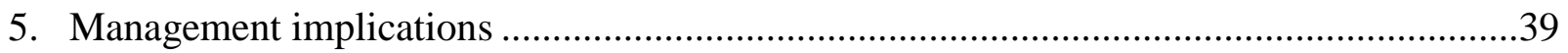

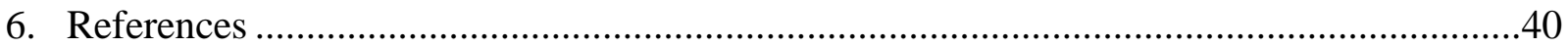

Chapter 4. Region-wide impacts of Marcellus-Utica shale gas development on forest

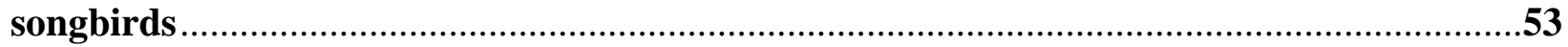

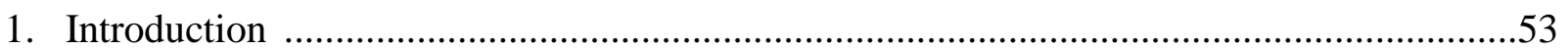

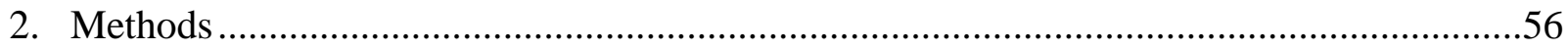

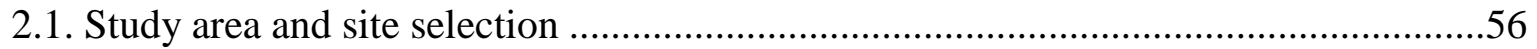

2.2. Land cover mapping and derivation of landscape metrics .........................................57

2.3. Avian surveys and detection probability ..................................................................61

2.4. Avian guilds and focal species ..............................................................................63

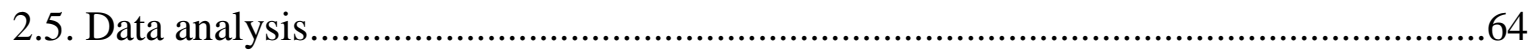

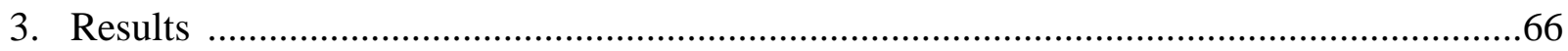

3.1. Land cover metrics and the footprint of shale gas.....................................................66

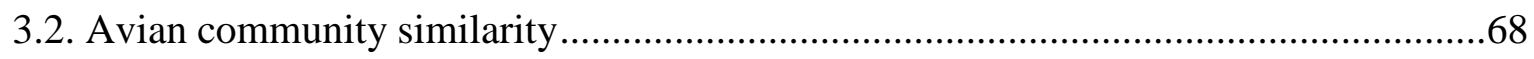

3.3. Avian guilds and focal species ......................................................................... 


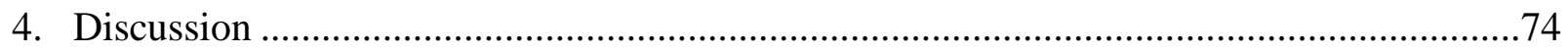

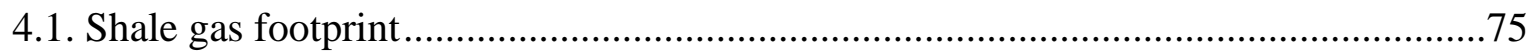

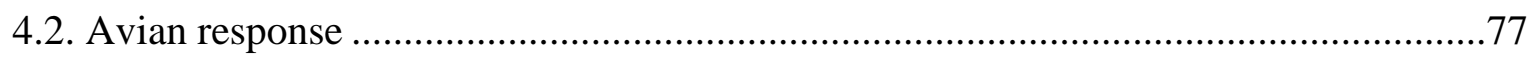

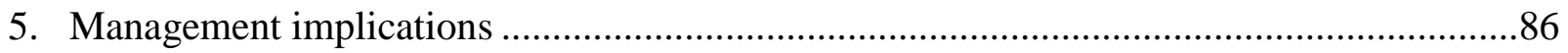

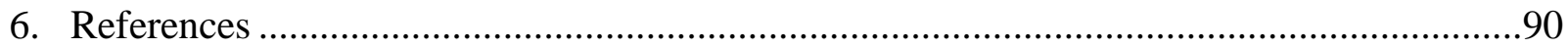

\section{Chapter 5. Threshold responses of songbirds within forested landscapes disturbed by} Marcellus-Utica shale gas development .......................................................................112

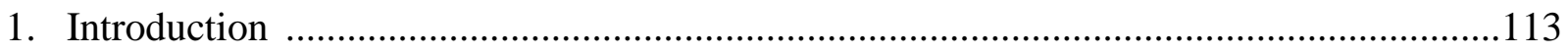

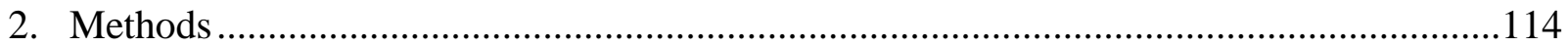

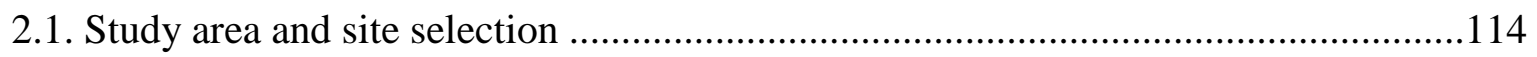

2.2. Distance and land cover metrics...................................................................115

2.3. Avian surveys and detection probability .......................................................116

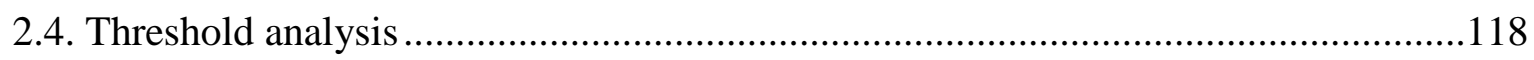

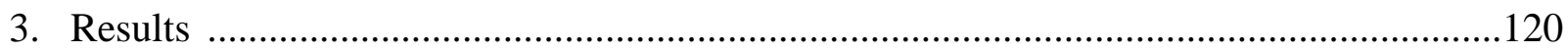

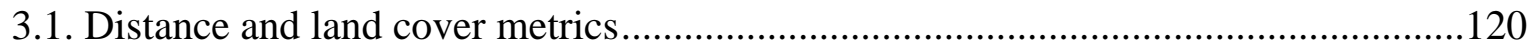

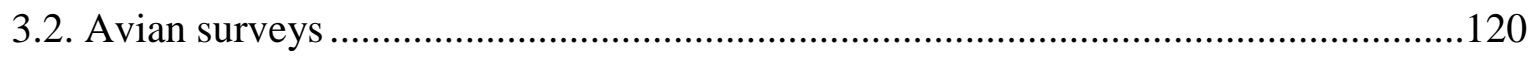

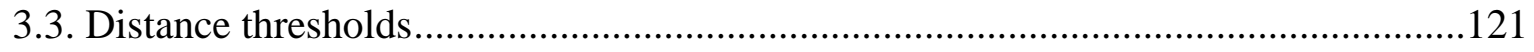

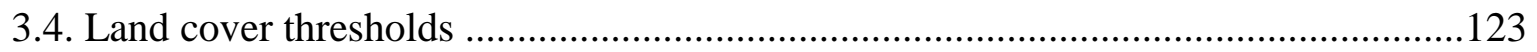

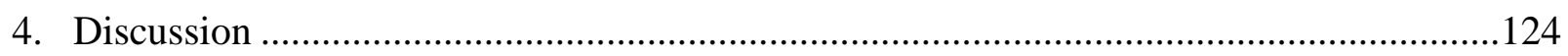

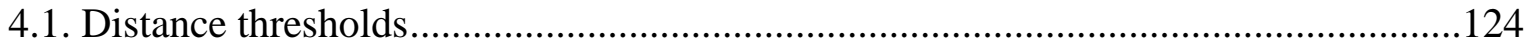

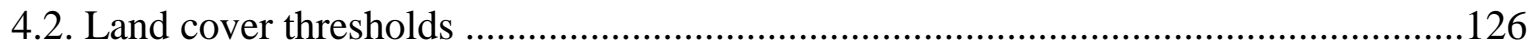

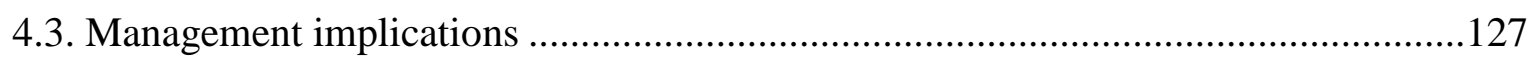

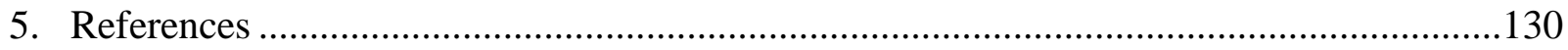




\section{LIST OF TABLES}

\section{CHAPTER 2.}

Table 1. Passerines and near-passerines surveyed at Lewis Wetzel Wildlife Management Area, West Virginia, from 2008-2015. Species were categorized into three guilds impacted by anthropogenic disturbance: forest interior, early successional, and synanthropic species. Birds with no assigned guild were excluded from analyses. Priority conservation species are shown in bold.

Table 2. Summary results of GLMMs relating avian guild species richness and point-level land cover metrics, after model-averaging. (See Appendix $\mathrm{C}$ for full model sets included in $\mathrm{AIC}_{\mathrm{c}}$ analysis.) 20

Table 3. Summary results of GLMMs relating forest interior focal bird abundances and pointlevel land cover metrics, after model-averaging. (See Appendix D for full model sets included in $\mathrm{AIC}_{\mathrm{c}}$ analysis.) 20

Table 4. Summary results of GLMMs relating early successional and synanthropic focal bird abundances and point-level land cover metrics, after model-averaging. (See Appendices E, F for full model sets included in $\mathrm{AIC}_{\mathrm{c}}$ analysis.).

\section{CHAPTER 3.}

Table 1. Relationships between species abundance and distance to shale gas, shown for all shale gas combined, and grouped separately by closest type of infrastructure: well pads v. linear infrastructure. Positive estimates indicate higher abundances with increasing distance from shale gas infrastructure. Significant responses are in bold $(\alpha=0.05)$

\section{CHAPTER 4.}

Table 1. Species detected during 2014-2015, grouped into three guilds potentially affected by human development: forest interior, early successional, and synanthropic species. Birds with no clear habitat guild were excluded from guild analyses. Focal species shown in bold. ...

Table 2. Summary results of generalized linear mixed models relating avian guild species richness with site-level land cover metrics ( $n=190$ sites), after model-averaging.

Table 3. Summary results of generalized linear mixed models relating habitat guild species richness with point-level land cover metrics ( $n=2,590$ points), after model-averaging... 104

Table 4. Summary results of generalized linear mixed models relating habitat guild species richness with point-level shale gas development metrics at gas sites only ( $n=1,612$ points), after model-averaging.... 


\section{CHAPTER 5.}

Table 1. Species included in threshold analyses, grouped into three guilds potentially impacted by human development: forest interior, early successional, and synanthropic species. Birds with no clear habitat guild were excluded from guild-specific analyses. Species of conservation concern shown in bold................................................................ 136

Table 2. Distance thresholds: negative $(\mathrm{Z}-)$ and positive $(\mathrm{Z}+)$ threshold responses $(\mathrm{CP}=$ change point) and 5-95\% change point quantiles, to distance $(\mathrm{m})$ to closest edge for all anthropogenic edge types combined, and grouped separately by closest edge type. Responses are filtered using only indicator taxa (purity and reliability $\geq 95 \%$ ). Results are listed for all species combined, by habitat guild, and for indictor species within each guild.

Table 3. Forest cover thresholds: negative $(\mathrm{Z}-)$ and positive $(\mathrm{Z}+)$ threshold responses $(\mathrm{CP}=$ change point) and 5-95\% CP quantiles, to forest and core forest cover within 1-km radius landscapes altered by shale gas development. Responses are filtered using only indicator taxa

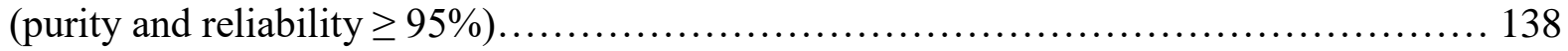




\section{LIST OF FIGURES}

\section{CHAPTER 2.}

Figure 1. Star represents location of study site (Lewis Wetzel Wildlife Management Area, West Virginia) in relation to the Marcellus shale formation, shaded in gray (from U.S. Energy Information Administration, updated 2/8/2015: http://www.eia.gov). Lower inset shows locations of 142 point count locations (black dots) within the extent of the focal study area (shown in white). Locations of completed unconventional shale gas wells (black crosses) at the study site and surrounding area are also shown (from West Virginia Geological and Economic Survey, updated 11/2015: http://www.wvgs.wvnet.edu).

Figure 2. Example of land cover disturbance associated with unconventional shale gas development. (a) Aerial photo of forest before development (National Agriculture Imagery Program, 2009); (b) following development of shale gas well pad and surrounding infrastructure (National Agriculture Imagery Program, 2014); (c) with spatially explicit digitization of disturbance features overlaid in white. Note expansion of pre-existing forest roads. Black dots inside white circles represent avian point count locations

Figure 3. Line graphs illustrating site-wide changes in land cover at the study area from 20082015: (a) percent forest cover; (b) percent core forest cover, (c) forest edge density in $\mathrm{m} / \mathrm{ha}$, and (d) percent of the landscape disturbed by shale gas development (dotted lines are linear trends obtained from ordinary least squares regression)....

Figure 4. Line graphs illustrating average annual species richness from 2008-2015, at points impacted by shale gas development within $100 \mathrm{~m}$ ("Gas") and points unimpacted within $100 \mathrm{~m}$ ("No Gas"), for species in three habitat guilds: (a) forest interior, (b) early successional, and (c) synanthropic (dotted lines indicate linear trends obtained from ordinary least squares regression)

Figure 5. Line graph illustrating average annual relative abundance of Cerulean Warblers from 2008-2015, at points impacted by shale gas development within $100 \mathrm{~m}$ ("Gas") and points unimpacted within $100 \mathrm{~m}$ ("No Gas") (dotted lines are linear trends obtained from ordinary least squares regression)

\section{CHAPTER 3.}

Figure 1. Example of a manually digitized land cover map for the study site, from 2012. Dots represent point count locations on ridges (black) and streams (blue). White star in the inset map represents the location of the study site; shaded red area shows the extent of the Marcellus shale formation.

Figure 2. Annual interpolated distribution probability maps for ovenbirds (Seiurus aurocapilla), based on indicator kriging. GLMMs showed ovenbirds occurred in higher abundance with increasing distance from both shale gas well pads $(P=0.03)$ and linear infrastructure $(P<$ 0.001). Darker red areas represent locations with higher indices of abundance. Shale gas infrastructure shown in black, for visual reference. 
Figure 3. Annual interpolated distribution probability maps for cerulean warblers (Setophaga cerulea), based on indicator kriging. GLMMs showed cerulean warblers had higher abundances in proximity to linear shale gas infrastructure $(P<0.001)$. Darker red areas represent locations with higher indices of abundance. Shale gas infrastructure shown in black, for visual reference..................................................................... 47

Figure 4. Annual interpolated distribution probability maps for indigo buntings (Passerina cyanea), based on indicator kriging. GLMMs showed indigo buntings occurred in higher abundances $(P=0.01)$ with increasing proximity to shale gas linear infrastructure, in particular. Darker red areas represent locations with higher index of abundance. Shale gas infrastructure shown in black, for visual reference............................................. 48

Figure 5. Annual interpolated distribution probability maps for brown-headed cowbirds, based on indicator kriging. GLMMs showed brown-headed cowbirds occurred in higher abundances with increasing proximity to both shale gas well pads $(P<0.001)$ and shale gas linear infrastructure $(P<0.001)$. Darker red areas represent locations with higher index of abundance. Shale gas infrastructure shown in black, for visual reference.

\section{CHAPTER 4.}

Figure 1. Map of study region. Sites were surveyed in 5 states: Pennsylvania, West Virginia, Ohio, Maryland, and New York. Black triangles represent shale gas sites, white dots represent non-gas sites. Extent of Marcellus shale play shaded in gray.

Figure 2. Land cover maps of 3 shale gas sites representing a gradient of forest cover: (a) low $37 \%$ forest, (b) moderate - $66 \%$ forest, and (c) high - $94 \%$ forest. Forest cover shown in green, shale gas infrastructure in red, non-gas development in black, agriculture in light green. White dots represent point count locations. Non-gas sites had similar gradients of forest cover and human development but had no shale gas development. 101

Figure 3. Site-level NMDS ordinations of sites (individual dots) based on avian community similarity, for (a) non-gas sites (bounded by white polygon) and shale gas sites (bounded by gray polygon); (b) shale gas sites with well pads on public lands (white polygon) versus private lands (gray polygon). Sites closer together in ordination space are more similar in overall species composition. For reference only, vectors labeled with large black text show the loadings of species richness within 3 avian guilds on the ordination axes: forest interior (FI), early successional (ES) and synanthropic (SYN). Vectors labeled with smaller gray text show the loadings of land cover: percent forest (FOREST), percent non-gas development (DEVELOP), and percent shale gas development (GAS). GAS was significant in (a) and non-significant in (b)

\section{CHAPTER 5.}

Figure 1. Map of study region. Sites were surveyed in 5 states: Pennsylvania, West Virginia, Ohio, Maryland, and New York. Black triangles represent shale gas sites, white dots represent non-gas sites. Extent of Marcellus shale play shaded in gray. 


\section{LIST OF APPENDICES}

\section{CHAPTER 2.}

Appendix A. Sources of imagery for the manual digitization of forest and non-forest cover.

Appendix B. Model sets included in $\mathrm{AIC}_{\mathrm{c}}$ analysis of detection probabilities using (1) time removal and (2) distance sampling. Models included intercept-only models as well as models incorporating survey-specific covariates.

Appendix C. Full model sets included in $\mathrm{AIC}_{\mathrm{c}}$ analysis of generalized linear mixed models relating guild species richness and land cover metrics.

Appendix D. Full model sets for forest interior focal species included in $\mathrm{AIC}_{\mathrm{c}}$ analysis of species-specific generalized linear mixed models relating focal bird abundances and land cover metrics

Appendix E. Full model sets for early successional focal species included in $\mathrm{AIC}_{\mathrm{c}}$ analysis of species-specific generalized linear mixed models relating focal bird abundances and land cover metrics. . . .25

Appendix F. Full model sets for synanthropic focal species included in $\mathrm{AIC}_{\mathrm{c}}$ analysis of speciesspecific generalized linear mixed models relating focal bird abundances and land cover metrics 25

\section{CHAPTER 3.}

Appendix A. Sources of imagery for manual digitization of forest and non-forest cover....50

Appendix B. Model sets included in AIC analysis of factors influencing detection probabilities using (1) time removal, and (2) distance sampling. Models include intercept-only models as well as models incorporating survey-specific covariates. Tree cover is percent forest cover within a 100 -m radius of each survey point

Appendix C. Cross validation of a subset of interpolated models (2008-2016), based on root mean square error (RMSE). Errors closer to zero indicate better fit between estimated and measured values 52

\section{CHAPTER 4.}

Appendix A. Model sets included in AIC analysis of factors influencing detection probabilities using (1) time removal, and (2) distance sampling. Models include intercept-only models as well as models incorporating survey-specific covariates. Tree cover is percent forest cover within a 100-m radius of each survey point 
Appendix B. Summary results of generalized linear mixed models relating forest interior focal species abundances with site-level land cover metrics $(n=190)$, after model-averaging....106

Appendix C. Summary results of generalized linear mixed models relating forest interior focal species abundances with point-level land cover metrics ( $n=2,590$ points), after model-

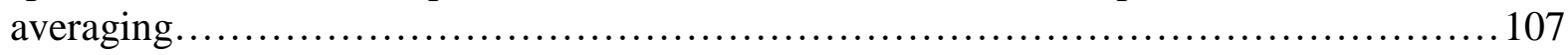

Appendix D. Summary results of generalized linear mixed models relating forest interior focal species abundances with point-level shale gas development metrics at gas sites only $(n=1,612$ points), after model-averaging .................................................. 108

Appendix E. Summary results of generalized linear mixed models relating early successional and synanthropic focal species abundances with site-level land cover metrics ( $n=190$ sites), after model-averaging.... 109

Appendix F. Summary results of generalized linear mixed models relating early successional and synanthropic focal species abundances with point-level land cover metrics ( $n=2,590$ points), after model-averaging. 110

Appendix G. Summary results of generalized linear mixed models relating early successional and synanthropic focal species abundances with point-level shale gas development metrics at gas sites only ( $n=1,612$ points), after model-averaging.

\section{CHAPTER 5.}

Appendix A. Model sets included in AIC analysis of factors influencing detection probabilities using (1) time removal, and (2) distance sampling. Models include intercept-only models as well as models incorporating survey-specific covariates. Tree cover is percent forest cover within a $100-\mathrm{m}$ radius of each survey point 


\section{CHAPTER 1. INTRODUCTION}

\section{Impacts of Marcellus-Utica shale gas development on regional forests}

The Marcellus-Utica shale basin in the central Appalachian region is the largest deposit of natural gas in the U.S., both in terms of area $\left(246,000 \mathrm{~km}^{2}\right)$ and technically recoverable gas volume (USEIA 2018). Advances in horizontal drilling and hydraulic fracturing technologies (i.e., fracking) in the early 2000s made the extraction of previously inaccessible natural gas trapped in shale formations economically feasible. This led to a boom in drilling for shale gas in the Marcellus-Utica shale region, with over 15,000 wells drilled from 2005-2016 (MCOR 2017). This form of energy development carries potential risks to human health, including contamination of air (Roy et al. 2014, Ziemkiewicz et al. 2014) and water resources (Jackson et al. 2013, Vidic et al. 2013), and noise and light pollution (Fisher et al. 2018. Ziemkiewicz et al. 2014, Hays et al. 2017).

There are also concerns regarding the consequences of land use change due to MarcellusUtica shale gas development for forest ecosystems and regional biodiversity (Kiviat 2013, Evans and Kiesecker 2014). In addition to the direct impacts of deforestation, habitat fragmentation, large-scale freshwater consumption (8-38 million liters per well), increased impervious surfaces, and noise and light disturbance, there are also potential secondary effects on forest ecosystems, including soil erosion, soil and water contamination, sedimentation of streams, increased human access/presence, and changes in biotic communities, among others (Francis et al. 2009, GWPC and ALL Consulting 2009, Kargbo et al. 2010, Brittingham et al. 2014, Souther et al. 2014, Latta et al. 2015). 
Recent studies of the impacts of shale gas development on forest cover in the eastern U.S. show that the industry is driving substantial land use change in the region. In Pennsylvania, an assessment of early trends in land cover change due to shale gas development found that wells occur primarily on privately owned lands (approximately 90\%), with the majority of pads drilled at low well densities of only 1-2 wells per pad (Drohan et al. 2012). As of June 2011, approximately $54-62 \%$ of well pads occur in areas dominated by agricultural land cover, while $38-45 \%$ of pads occur in forested lands, with many of these located in core forests (Drohan et al. 2012). In Arkansas, shale gas development cleared approximately $2 \%$ of natural forests in the Fayetteville shale region and created over 1,000 km of new forest edges (Moran et al. 2015). In two counties experiencing Marcellus-Utica shale gas development in Ohio and Pennsylvania, Donnelly et al. (2017) found that less than $1 \%$ of total forest for each county was lost but that the pattern of linear infrastructure development exacerbated forest fragmentation. In Lycoming County in Pennsylvania, pipelines had a greater impact on forest cover than well pads, both in terms of overall forest loss and forest fragmentation (Langlois et al. 2017). The ecological impacts of this development are likely to be disproportionate to the direct footprint of disturbance, due to increased edge and isolation effects associated with shale gas infrastructure in forest habitat (Pickell et al. 2014, Racicot et al. 2014).

Looking forward, Johnson et al. (2010) project that 64\% of future wells in Pennsylvania will be drilled in forested landscapes. These estimates raise concerns about potential threats to regional forests, given that 60,000 new wells are projected to be drilled on approximately 6,000 15,000 pads in Pennsylvania, by 2030 (Johnson et al. 2010). Each well pad installation occupies an average of 3.6 ha (1.3 ha per pad and 2.3 ha of associated infrastructure), and in forested landscapes, an additional 8.6 ha of adjacent lands may be impacted by edge effects (Johnson et 
al. 2010). If $64 \%$ of future well pads are installed in forests under a high development scenario with only 4 wells per pad (which is higher than the current average), upwards of 116,550 ha of forest habitat are likely to be impacted by shale gas development by 2030, in the state of Pennsylvania alone. In the broader Marcellus-Utica shale region, New York (which has a ban in place on unconventional gas drilling) and Ohio might experience similar patterns of well pad placement in agricultural versus forested areas to those in Pennsylvania, given that these states have similar patterns of land cover in their shale gas regions (Drohan et al. 2012). However, given that a higher overall percentage of West Virginia is forested, it would be expected to experience a higher percentage of forest loss and a lower percentage of agricultural lands lost compared with other states in the Marcellus-Utica region (Drohan et al. 2012).

It is also important to consider that shale gas development in this region is occurring within the context of a long history of anthropogenic forest disturbance and removal in the eastern U.S. The mixed mesophytic forests of Appalachia are almost entirely second growth, with the majority of forests regenerating since the implementation of forest management practices in the 1920s and 1930s (MacCleery 2011). The central Appalachian region has experienced and continues to experience forest loss and fragmentation due to agriculture, urban development, silviculture, coal mining, conventional oil and gas development, and most recently, wind farm development and shale gas exploration (Drummond and Loveland 2010, Evans and Kiesecker 2014). There are valid concerns about the long-term, cumulative effects of multiple anthropogenic stressors occurring in succession on a given landscape (Hegmann et al. 1999). In many cases, the combined effects of human-facilitated disturbances are greater than would be expected, because individual projects may interact synergistically to inhibit biological 
communities from recovering as they would to natural levels of disturbance (Paine et al. 1998, Brook et al. 2008).

\section{Songbird response to forest loss and fragmentation}

The central Appalachian region is also a region of high importance for global biodiversity (TNC 2018) and is considered a key conservation area for migratory birds (Rosenberg and Wells 2000, Rich et al. 2004, Steele et al. 2010, AMJV 2015). Forest loss and fragmentation are major threats to biodiversity (Wilcox \& Murphy 1985, Pimm and Askins 1995, Collinge 1996, Brooks et al. 2002, Riitters et al. 2002, Drummond and Loveland 2010), and have been implicated in population declines of forest birds (Askins et al. 1990, Robinson et al 1995, Boulinier et al. 2001, Donovan and Flather 2002, Pimm et al. 2006).

Anthropogenic disturbance of forests can lead directly to loss of suitable habitat, which is the leading cause of species extinctions in the U.S. (Czech et al. 2000). In addition to the total amount of habitat loss, the spatial pattern of forest removal is also important to consider because different configurations of remaining habitat can impact the ability of species to persist in altered landscapes (Trzcinski et al. 1999, Villard et al. 1999, Fahrig 2003, Mortelliti et al. 2010). Areasensitive species are negatively affected by decreased patch size (Andren 1994, Bender et al. 1998), with decreased rates of colonization (Hinsley et al. 1996), decreased species diversity (Blake and Karr 1987, Monkkonen et al. 2014), and crowding effects and creation of sink populations (Hagan et al. 1996, Monkkonen et al. 2014) in smaller, fragmented patches of habitat. Corridors and breaks in habitat may also be perceived as barriers and avoided by areasensitive species (Askins 1994, Murcia 1995, Bayne et al. 2005, Banks-Leite et al. 2010). Isolation of remaining habitat patches leads to increased mortality and lower reproductive 
success due to increased time and energy spent traveling outside of preferred habitat (Fahrig 2002), and can also lead to reduced gene flow among isolated populations - especially in species that have already experienced population declines (Haig et al. 1996, Lindsay et al. 2008, Coulon et al. 2010). Increased noise and light disturbance can also negatively affect foraging, reproduction, communication, and other behaviors important for fitness (Longcore and Rich 2006, Bayne et al. 2008, Francis et al. 2011, Kempenaers et al. 2010, Halfwerk et al. 2011). In addition to these direct impacts of forest loss and fragmentation, human disturbance of forested environments can also have indirect effects, including overall increases in human presence and activity (Aubad et al. 2010, Bayne and Dale 2011), increased rates of predation (Donovan et al. 1997, Jokimaki \& Huhta 2000, Chalfoun et al. 2002, Marzluff et al. 2004), interspecific competition (Nee and May 1992, Shochat et al. 2010, Farwell and Marzluff 2013), and nest parasitism (Brittingham and Temple 1983, Gates and Evans 1998, Howell et al. 2007) in isolated patches and along forest edges. Fragmented forests also see decreased abundance and diversity of forest interior species (Kroodsma 1982, Robbins et al. 1989, Parker et al. 2005, Wood et al. 2006) and increased abundance of habitat generalists (Carrara et al. 2015). Through this process of community turnover known as biotic homogenization, local habitat specialists are replaced with common habitat generalists (McKinney and Lockwood 1999). Biotic homogenization leads to loss of endemic species and the ecosystem services they provide, loss of regional ecological distinctness, and decreased functional and genetic biodiversity (McKinney and Lockwood 1999, Olden et al. 2004).

Conversely, forest loss and fragmentation may positively affect early successional species by increasing availability of non-forest habitat (Nee and May 1992, King and Byers 2002, Confer and Pascoe 2003, DeGraaf and Yamasaki 2003). However, while disturbance-dependent species 
are commonly thought to benefit from clearings and edge habitat created by anthropogenic disturbance, there is some indication that these areas are not always high quality habitat and may even serve as ecological traps (Weldon and Haddad 2005, Shipley et al. 2013, Strasser and Heath 2013).

\section{Research goals and summary of chapters}

There is growing evidence that the continuing expansion of Marcellus-Utica shale gas development is reducing regional forest cover and leaving remaining forests heavily fragmented (Drohan et al. 2012, Donnelly et al. 2017, Langlois et al. 2017). This is likely to have negative consequences for breeding populations of forest interior species, especially species such as the black-throated blue warbler (Setophaga caerulescens), whose breeding range overlaps significantly with the Marcellus-Utica shale basin (Johnson et al. 2010, Brittingham et al. 2014). In northern West Virginia, the Louisiana waterthrush (Parkesia motacilla) had lower rates of nest survival and productivity in areas disturbed by shale gas development, compared with undisturbed areas (Frantz et al. 2018). The Louisiana waterthrush is a species of conservation concern whose breeding range tightly overlaps the Marcellus-Utica shale region. Other recent localized studies of the impacts of conventional gas development in northeastern Pennsylvania (Thomas et al. 2014) and unconventional gas development in northcentral Pennsylvania (Barton et al. 2016, Langlois 2017) documented changes to avian communities, with decreases in forest interior species and increases in early-successional and human-adapted species.

Despite the recent increase in research on the environmental and biological effects of unconventional shale gas development, the rapid rate of shale gas development in the MarcellusUtica region has largely outpaced research and monitoring efforts (Kiviat 2013). Much is still 
unknown about environmental impacts (Souther et al. 2014), including long-term and regionwide impacts on forest cover and breeding birds. The goal of this dissertation is to address these knowledge gaps. In the second and third chapters, I used land cover and avian survey data from a long-term study site in northern West Virginia to evaluate how shale gas development altered forest cover at the site, and how proximity to shale gas development influenced breeding songbird abundances and spatial distributions. In the fourth chapter, I balance this long-term study from West Virginia with a region-wide, two-year 'snapshot' study of impacts of shale gas development on forest land cover and breeding songbird abundances, across the Marcellus-Utica shale region. In the fifth and final chapter, I used Threshold Indicator Taxa Analysis (TITAN; Baker and King 2010) to identify region-wide threshold responses in breeding songbird abundances to distance from shale gas development, and to overall forest and core forest cover in landscapes altered by shale gas development. The results of this dissertation add to a growing body of research documenting effects of shale gas development on forest land cover and avian communities, in a region experiencing rapid expansion of shale gas infrastructure.

\section{References}

AMJV (Appalachian Mountains Joint Venture). 2015. Priority Landbird Species. <http://amjv.org/documents/Priority_Landbird_Species.pdf> Accessed Aug 2015.

Andren, H. 1994. Effects of habitat fragmentation on birds and mammals in landscapes with different proportions of suitable habitat: a review. Oikos 71(3):355-366.

Askins, R.A., J.F. Lynch, and R. Greenburg. 1990. Population declines in migratory birds in eastern North America. Current Ornithology 7:1-57.

Askins, R.A. 1994. Open corridors in a heavily forested landscape: impact on shrubland and forest-interior birds. Wildlife Society Bulletin 22:339-347.

Aubad, J., P. Aragon, and M.A. Rodriguez. 2010. Human access and landscape structure effects on Andean forest bird richness. Acta Oecologica International Journal of Ecology 36(4):396402.

Baker, M.E., and R.S. King. 2010. A new method for detecting and interpreting biodiversity and ecological community thresholds. Methods in Ecology and Evolution 1:25-37. 
Banks-Leite, C., R.M. Ewers, and J.P. Metzger. 2010. Edge effects as the principal cause of area effects on birds in fragmented secondary forest. Oikos 119(6):918-926.

Barton, E.P., S.E. Pabian, and M.C. Brittingham. 2016. Bird community response to Marcellus shale gas development. Journal of Wildlife Management 80:1301-1313.

Bayne, E.M., S.L. Van Wilgenburg, S. Boutin, and K.A. Hobson. 2005. Modeling and fieldtesting of Ovenbird (Seiurus aurocapillus) responses to boreal forest dissection by energy sector development at multiple spatial scales. Landscape Ecology 20:203-216.

Bayne, E.M., L. Habib, and S. Boutin. 2008. Impacts of chronic anthropogenic noise from energy-sector activity on abundance of songbirds in the Boreal forest. Conservation Biology 22(5):1186-1193.

Bayne, E.M., and B.C. Dale. 2011. Effects of energy development on songbirds. In Naugle, D.E. (Ed.), Energy Development and Wildlife Conservation in Western North America. Island Press, Washington, D.C., pp. 95-114.

Bender, D.J., T.A. Contreras, and L. Fahrig. 1998. Habitat loss and population decline: a metaanalysis of the patch size effect. Ecology 79(2):517-533.

Blake, J.G., and J.R. Karr. 1987. Breeding birds of isolated woodlots: area and habitat relationships. Ecology 68:1724-1734.

Boulinier, T., J.D. Nichols, J.E. Hines, J.R. Sauer, C.H. Flather, and K.H. Pollock. 2001. Forest fragmentation and bird community dynamics: inference at regional scales. Ecology 82(4):1159-1169.

Brittingham, M.C., and S.A. Temple. 1983. Have cowbirds caused forest songbirds to decline? BioScience 33(1):31-35.

Brittingham, M.C., K.O. Maloney, A.M. Farag, D.D. Harper, and Z.H. Bowen. 2014. Ecological Risks of Shale Oil and Gas Development to Wildlife, Aquatic Resources and their Habitats. Environmental Science and Technology 48(19):11034-11047.

Brook, B.W., N.S. Sodhi, C.J.A. Bradshaw. 2008. Synergies among extinction drivers under global change. Trends in Ecology and Evolution 23:453-460.

Brooks, T.M., R.A. Mettermeier, C.G. Mittermeier, G.A.B. da Fonseca, A.B. Rylands, W.R. Konstant, P. Flick, J. Pilgrim, S. Oldfield, G. Magin, and C. Hilton-Taylor. 2002. Habitat loss and extinction in the hotspots of biodiversity. Conservation Biology 16(4):909-923.

Carrara, E., V. Arroyo-Rodriguez, J.H. Vega-Rivera, J.E. Schondube, S.M. de Freitas, and L. Fahrig. 2015. Impact of landscape composition and configuration on forest specialist and generalist bird species in fragmented Lacandona rainforest, Mexico. Biological Conservation 184:117-126.

Chalfoun, A.D., F.R. Thompson, M.J. Ratnaswamy. 2002. Nest predators and fragmentation: a review and meta-analysis. Conservation Biology 16:306-18

Collinge, S.K. 1996. Ecological consequences of habitat fragmentation: implications for landscape architecture and planning. Landscape and Urban Planning 36:59-77

Confer, J.L., and S.M. Pascoe. 2003. Avian communities on utility rights-of-ways and other managed shrublands in the northeastern United States. Forest Ecology and Management 185:193-205. 
Coulon, A., J.W. Fitzpatrick, R. Bowman, and I.J. Lovette. 2010. Effects of habitat fragmentation on effective dispersal of Florida Scrub-Jays. Conservation Biology 24:10801088.

Czech, B., P.R. Krausman, and P.K. Devers. 2000. Economic associations among causes of species endangerment in the United States. Bioscience 50(7):593-601.

DeGraaf, R.M., and M. Yamasaki. 2003. Options for managing early-successional forest and shrubland bird habitats in the northeastern United States. Forest Ecology and Management 185:179-191.

Donnelly, S., I.C. Wilson, and J.O. Appiah. 2017. Comparing land change from shale gas infrastructure development in neighboring Utica and Marcellus regions, 2006-2015. Journal of Land Use Science 12:338-350.

Donovan, T.M., P.W. Jones, E.M. Annand, and F.R. Thompson. 1997. Variation in local-scale edge effects: mechanisms and landscape context. Ecology 78(7):2064-2075.

Donovan, T.M., and C.H. Flather. 2002. Relationships among North American songbird trends, habitat fragmentation, and landscape occupancy. Ecological Applications 12:364-374.

Drummond, M.A., and T.R. Loveland. 2010. Land-use pressure and a transition to forest-cover loss in the Eastern United States. BioScience 60:286-298.

Evans, J.S., and J.M. Kiesecker. 2014. Shale gas, wind and water: assessing the potential cumulative impacts of energy development on ecosystem services within the Marcellus play. PLoS One 9:e89210

Fisher, M.P., A. Mayer, K. Vollet, E.L. Hill, and E.N. Haynes. 2018. Psychosocial implications of unconventional natural gas development: quality of life in Ohio's Guernsey and Noble Counties. Journal of Environmental Psychology 55:90-98.

Fahrig, L. 2002. Effect of habitat fragmentation on the extinction threshold: a synthesis. Ecological Applications 12:346-53.

Fahrig, L. 2003. Effects of habitat fragmentation on biodiversity. Annual Review of Ecology Evolution and Systematics 34:487-515.

Farwell, L.S., and J.M. Marzluff. 2013. A new bully on the block: does urbanization promote Bewick's wren aggressive exclusion of Pacific wrens? Biological Conservation 161:128141.

Francis, C.D., C.P. Ortega, and A. Cruz. 2009. Noise pollution changes avian communities and species interactions. Current Biology 19(16):1415-1419.

Francis, C.D., J. Paritsis, C.P. Ortega, and A. Cruz. 2011. Landscape patterns of avian habitat use and nest success are affected by chronic gaswell compressor noise. Landscape Ecology 26:1269-1280.

Frantz, M.W., P.B. Wood, J. Sheehan, and G.A. George. 2018. Demographic response of Louisiana waterthrush, a stream obligate songbird of conservation concern, to shale gas development. Condor 120(2):265-282.

Gates, J.E., and D.R. Evans. 1998. Cowbirds breeding in the central Appalachians: spatial and temporal patterns and habitat selection. Ecological Applications 8(1):27-40. 
GWPC (Ground Water Protection Council) and ALL Consulting. 2009. Modern shale gas development in the United States: a primer. Report commissioned by the United States Department of Energy, Office of Fossil Energy and National Energy Technology Laboratory. [Online] <http://www.netl.doe.gov/technologies/oilgas/publications/epreports/shale_gas_primer_2009.pdf> Accessed Jan 2015.

Haig, S.M., R. Bowman, and T.D. Mullins. 1996. Population structure of red-cockaded woodpeckers in south Florida: RAPDs revisited. Molecular Ecology 5(6):725-734.

Halfwerk, W., L.J.M. Holleman, C.M. Lessells, and H. Slabbekoom. 2011. Negative impact of traffic noise on avian reproductive success. Journal of Applied Ecology 48(1):210-219.

Hays, J., M. McCawley, and S.B.C. Shonkoff. 2017. Public health implications of environmental noise associated with unconventional oil and gas development. Science of the Total Environment 580:448-456.

Hegmann, G., C. Cocklin, R. Creasey, S. Dupuis, A. Kennedy, L. Kingsley, W. Ross, H. Spaling, and D. Stalker. 1999. Cumulative Effects Assessment Practitioners Guide. AXYS Environmental Consulting Ltd. and the CEA Working Group for the Canadian Environmental Assessment Agency, Hull, Quebec, Canada.

Hinsley, S.A., R. Pakeman, P.E. Bellamy, and I. Newton. 1996. Influences of habitat fragmentation on bird species distributions and regional population sizes. Proceedings of the Royal Society B: Biological Sciences 263:307-313.

Howell, C.A., W.D. Dijak, and F.R. Thompson. 2007. Landscape context and selection for forest edge by breeding brown-headed cowbirds. Landscape Ecology 22(2):273-284.

Jackson, R.B., A. Vengosh, T.H. Darrah, N.R. Warner, A. Down, R.J. Poreda, S.G. Osborn, K.G. Zhao, and J.D. Karr. Increased stray gas abundance in a subset of drinking water wells near Marcellus shale gas extraction. Proceedings of the National Academy of Sciences of the United States of America 110(28):11250-11255.

Johnson, N., T. Gagnolet, R. Ralls, E. Zimmerman, B. Eichelberger, C. Tracey, G. Kreitler, S. Orndorff, J. Tomlinson, S. Bearer, and S. Sargent. 2010. Pennsylvania energy impacts assessment, report 1: Marcellus shale natural gas and wind. The Nature Conservancy, Pennsylvania Chapter, Harrisburg, PA. <http://www.nature.org/media/pa/tnc_energy_analysis.pdf > Accessed Jan 2015.

Jokimaki,J., and E. Huhta. 2000. Artificial nest predation and abundance of birds along an urban gradient. Condor 102:838-847.

Kargbo, D.M., R.G. Wilhelm, and D.J. Campbell. 2010. Natural gas plays in the Marcellus shale: challenges and potential opportunities. Environmental Science and Technology 44(15):56795684.

Kempenaers, B., P. Borgstrom, P. Loes, E. Schlicht, and M. Valcu. 2010. Artificial night lighting affects dawn song, extra-pair siring success, and lay date in songbirds. Current Biology 20:1735-1739.

King, D.I., and B.E. Byers. 2002. An evaluation of powerline rights-of-way as habitat for earlysuccessional shrubland birds. Wildlife Society Bulletin 30:868-874. 
Kiviat, E. 2013. Risks to biodiversity from hydraulic fracturing for natural gas in the Marcellus and Utica shales. In: Schlesinger, W.H., Ostfeld, R.S. (Eds.), Year in Ecology and Conservation Biology. Annals of the New York Academy of Sciences 1286:1-14.

Kroodsma, R.L. 1982. Edge effect on breeding forest birds along a power-line corridor. Journal of Applied Ecology 19:361-70.

Langlois, L.A. 2017. Effects of Marcellus shale gas infrastructure on forest fragmentation and bird communities in northcentral Pennsylvania. Dissertation, Pennsylvania State University, State College, USA.

Langlois, L.A., P.J. Drohan, and M.C. Brittingham. 2017. Linear infrastructure drives habitat conversion and forest fragmentation associated with Marcellus shale gas development in a forested landscape. Journal of Environmental Management 197:167-176.

Latta, S.C., L.C. Marshall, M.W. Frantz, and J.D. Toms. 2015. Evidence from two shale regions that a riparian songbird accumulates metals associated with hydraulic fracturing. Ecosphere 6(9):art.144.

Lindsay, D.L., K.R. Barr, R.F. Lance, S.A. Tweddale, T.J. Hayden, and P.L. Leberg. 2008. Habitat fragmentation and genetic diversity of an endangered, migratory songbird, the golden-cheeked warbler (Dendroica chrysoparia). Molecular Ecology 17(9):212-2133.

Longcore, T., and C. Rich. 2004. Ecological light pollution. Frontiers in Ecology and the Environment 2(4):191-198.

MacCleery, D.W. 2011. American forests: a history of resiliency and recovery. The Forest History Society, Durham, NC.

Marzluff, J.M., J.J. Millspaugh, P. Hurvitz, M.S. Handcock. 2004. Relating resources to a probabilistic measure of space use: forest fragments and Steller's Jays. Ecology 85:1411-27

McKinney, M.L., and J.L. Lockwood. 1999. Biotic homogenization: a few winners replacing many losers in the next mass extinction. Trends in Ecology and Evolution 14(11):450-453.

MCOR (Marcellus Center for Outreach and Research). 2017. Tri-state unconventional shale wells drilled by year (PA, WV, OH). $<$ http://www.marcellus.psu.edu/resources/images/tristate-static-2016.jpg> Accessed Dec 2017.

Monkkonen, M., A. Rajasarkka, and P. Lampila. 2014. Isolation, patch size and matrix effects on bird assemblages in forest reserves. Biodiversity Conservation 23:3287-3300.

Moran, M.D., A.B. Cox, R.L. Wells, C.C. Benichou, and M.R. McClung. 2015. Habitat loss and modification due to gas development in the Fayetteville Shale. Environmental Management 55:1276-1284.

Mortelliti, A., S. Fagiani, and C. Battisti. 2010. Independent effects of habitat loss, habitat fragmentation and structural connectivity on forest-dependent birds. Diversity and Distributions 16(6):941-951.

Murcia, C. 1995. Edge effects in fragmented forests: implications for conservation. Trends in Ecology and Evolution 10:58-62.

Nee, S., and R.M. May. 1992. Dynamics of metapopulations: habitat destruction and competitive coexistence. Journal of Animal Ecology 61:37-40. 
Olden, J.D., N. LeRoy Poff, M.R. Douglas, M.E. Douglas, and K.D. Fausch. 2004. Ecological and evolutionary consequences of biotic homogenization. Trends in Ecology and Evolution 19(1):18-24.

Paine, R.T., M.J. Tegner, and E.A. Johnson. 1998. Compounded perturbations yield ecological surprises. Ecosystems 1:535-545.

Parker, T.H., B.M. Stansberry, C.D. Becker, and P.S. Gipson. 2005. Edge and area effects on the occurrence of migrant forest songbirds. Conservation Biology 19(4):1157-1167.

Pickell, P., S. Gergel, N. Coops, and D. Andison. 2014. Monitoring forest change in landscapes undergoing rapid energy development: challenges and new perspectives. Land 3:617-638.

Pimm, S.L., and R.A. Askins. 1995. Forest losses predict bird extinctions in Eastern North America. Proceedings of the National Academy of Sciences U.S.A. 92(20):9343-9347.

Pimm, S.L, P. Raven, A. Peterson, C.H. Sekercioglu, and P.R. Ehrlich. 2006. Human impacts on the rates of recent, present, and future bird extinctions. Proceedings of the National Academy of Sciences of the United States of America 103:10941-10946.

Racicot, A., V. Babin-Roussel, J.-F. Dauphinais, J.S. Joly, P. Noel, and C. Lavoie. 2014. A framework to predict the impacts of shale gas infrastructures on the forest fragmentation of an agroforest region. Environmental Management 53:1023-1033.

Rich, T.D., C.J. Beardmore, H. Berlanga, P.J. Blancher, M.S.W. Bradstreet, G.S. Butcher, D.W. Demarest, E.H. Dunn, W.C. Hunter, E.E. Inigo-Elias, J.A. Kennedy, A.M. Martell, A.O. Panjabi, D.N. Pashley, K.V. Rosenberg, C.M. Rustay, J.S. Wendt, and T.C. Will. 2004. Partners in Flight North American landbird conservation plan. Cornell Lab of Ornithology, Ithaca, New York, USA.

Riitters, K.H., J.D. Wickham, R.V. O’Neill, K.B. Jones, E.R. Smith, J.W. Coulston, T.G. Wade, and J.H. Smith. 2002. Fragmentation of continental United States forests. Ecosystems 5:815822.

Robbins, C.S., D.K. Dawson, and B.A. Dowell. 1989. Habitat area requirements of breeding forest birds of the Middle Atlantic States. Wildlife Monographs 103:3-34.

Robinson, S.K., F.R. Thompson, T.M. Donovan, D.R. Whitehead, and J. Faaborg. 1995. Regional forest fragmentation and the nesting success of migratory birds. Science 267:19871990.

Rosenberg, K.V., and J.V. Wells. 2000. Global perspectives on neotropical migratory bird conservation in the Northeast: long-term responsibility versus immediate concern. USDA Forest Service Proceedings RMRS-P-16.

Roy, A.A., P.J. Adams, and A.L. Robinson. Air pollutant emissions from the development, production, and processing of Marcellus Shale natural gas. Journal of the Air and Waste Management Association 64(1):19-37.

Shipley, A.A., M.T. Murphy, and A.H. Elzinga. 2013. Residential edges as ecological traps: post-fledging survival of a ground-nesting passerine in a forested urban park. Auk 130(3):501-511.

Shochat, E., S.B. Lerman, J.M. Anderies, P.S. Warren, S.H. Faeth, and C.H. Nilon. 2010. Invasion, competition, and biodiversity loss in urban ecosystems. Bioscience 60:199-208. 
Souther, S, M.W. Tingley, V.D. Popescu, D.T.S. Hayman, M.E. Ryan, T.A. Graves, B. Harth, and K. Terrell. 2014. Biotic impacts of energy development from shale: research priorities and knowledge gaps. Frontiers in Ecology and the Environment 12(6):330-338.

Steele, M.A., M.C. Brittingham, T.J. Maret, and J.F. Merritt. 2010. Terrestrial vertebrates of Pennsylvania: a complete guide to species of conservation concern. Johns Hopkins University Press, Baltimore, Maryland, USA.

Strasser, E.H., and J.A. Heath. 2013. Reproductive failure of a human-tolerant species, the American kestrel, is associated with stress and human disturbance. Journal of Applied Ecology 50(4):912-919.

Thomas, E.H., M.C. Brittingham, and S.H. Stoleson. 2014. Conventional oil and gas development alters forest songbird communities. Journal of Wildlife Management 78(2):293-306.

TNC (The Nature Conservancy). 2018. Central Appalachians: nature's last stronghold. $<$ https://www.nature.org/ourinitiatives/regions/northamerica/areas/centralappalachians/index. htm> Accessed Apr 2018.

Trzcinski, M.K., L. Fahrig, and G. Merriam. 1999. Independent effects of forest cover and fragmentation on the distribution of forest breeding birds. Ecological Applications 9(2):586593.

USEIA (U.S. Energy Information Administration. 2018. Annual energy outlook. <https://www.eia.gov/outlooks/aeo/> Accessed Apr 2018.

Vidic, R.D., S.L. Brantley, J.M. Vandenbossche, D. Yoxtheimer, and J.D. Abad. Impact of shale gas development on regional water quality. Science 340(6134):art.1235009.

Villard, M., M.K. Trzcinski, and G. Merriam. 1999. Fragmentation effects on forest birds: relative influence of woodland cover and configuration on landscape occupancy. Conservation Biology 13(4):774-783.

Weldon, A.J., and N.M. Haddad. 2005. The effects of patch shape on indigo buntings: evidence for an ecological trap. Ecology 86(6)1422-1431.

Wilcox, B.A., and D.D. Murphy. 1985. Conservation strategy: the effects of fragmentation on extinction. American Naturalist 125(6):879-887.

Wood, P.B., S.B. Bosworth, and R. Dettmers. 2006. Cerulean Warbler abundance and occurrence relative to large-scale edge and habitat characteristics. Condor 108:154-165.

Ziemkiewicz, P., J.D. Quaranta, and M. McCawley. 2014. Practical measures for reducing the risk of environmental contamination in shale energy production. Environmental Science: Processes and Impacts 16(7):1692-1699. 


\title{
Shale gas development effects on the songbird community in a central Appalachian forest
}

\author{
Laura S. Farwell ${ }^{\mathrm{a}, *}$, Petra B. Wood ${ }^{\mathrm{b}}$, James Sheehan ${ }^{\mathrm{a}}$, Gregory A. George ${ }^{\mathrm{a}, 1}$ \\ a West Virginia Cooperative Fish and Wildife Research Unit, Davis College, School of Natural Resources, West Virginia University, P.O. Box 6125, Morgantown, WV, USA \\ ${ }^{\mathrm{b}}$ U.S. Geological Survey, West Virginia Cooperative Fish and Wildlife Research Unit, West Virginia University, P.O. Box 6125, Morgantown, WV, USA
}

\section{A R T I C L E I N F O}

\section{Article history:}

Received 1 April 2016

Received in revised form 18 June 2016

Accepted 21 June 2016

Available online $\mathrm{xxxx}$

\section{Keywords:}

Energy impacts

Hydraulic fracturing

Marcellus-Utica

Land-use change

Forest fragmentation

Avian guilds

\begin{abstract}
A B S T R A C T
In the last decade, unconventional drilling for natural gas from the Marcellus-Utica shale has increased exponentially in the central Appalachians. This heavily forested region contains important breeding habitat for many neotropical migratory songbirds, including several species of conservation concern. Our goal was to examine effects of unconventional gas development on forest habitat and breeding songbirds at a predominantly forested site from 2008 to 2015. Construction of gas well pads and infrastructure (e.g., roads, pipelines) contributed to an overall $4.5 \%$ loss in forest cover at the site, a $12.4 \%$ loss in core forest, and a $51.7 \%$ increase in forest edge density. We evaluated the relationship between land-cover metrics and species richness within three avian guilds: forestinterior, early-successional, and synanthropic, in addition to abundances of 21 focal species. Land-cover impacts were evaluated at two spatial extents: a point-level within 100-m and 500-m buffers of each avian survey station, and a landscape-level across the study area (4326 ha). Although we observed variability in species-specific responses, we found distinct trends in long-term response among the three avian guilds. Forest-interior guild richness declined at all points across the site and at points impacted within $100 \mathrm{~m}$ by shale gas but did not change at unimpacted points. Early-successional and synanthropic guild richness increased at all points and at impacted points. Our results suggest that shale gas development has the potential to fragment regional forests and alter avian communities, and that efforts to minimize new development in core forests will reduce negative impacts to forest dependent species.
\end{abstract}

(c) 2016 Elsevier Ltd. All rights reserved.

\section{Introduction}

The combined use of advanced horizontal drilling techniques and highvolume hydraulic fracturing (i.e., fracking) has increased access to large reserves of unconventional gas trapped in deep shale formations, which were previously considered inaccessible and uneconomical (Johnson et al., 2010). In contrast with conventional drilling for shallow gas deposits, unconventional gas development occurs at a much larger scale both in terms of land use and water consumption (Brittingham et al., 2014). Spurred by technological advances and energy demands, the rapid expansion of drilling for unconventional gas has largely outpaced research on potential environmental and biotic impacts in the United States (Kiviat, 2013; Souther et al., 2014) and in other countries (EIA, 2015).

Over the last decade, unconventional drilling for natural gas from the Marcellus-Utica shale has increased exponentially in the central Appalachian region (EIA, 2012), with 111 wells on the landscape in 2005, and approximately 14,022 wells by the end of 2015 (MCOR, 2016). While

\footnotetext{
* Corresponding author.

E-mail address: Isfarwell@mix.wvu.edu (L.S. Farwell).

1 Current address: Department of Biology, Delaware Valley University, Doylestown, PA, USA.
}

drilling in the Marcellus-Utica region has occurred in both forested and agricultural landscapes, the majority of future wells are projected to be drilled on forested lands, many of which lie in large areas of undisturbed forest (Johnson et al., 2010). The rapid expansion of shale gas wells and extensive linear infrastructure (roads and pipelines) has the potential to reduce regional forest cover and to leave remaining forests heavily fragmented (Drohan et al., 2012).

The Marcellus-Utica region is an area also known for its mature forests and diverse flora and fauna (Hinkle et al., 1993). It is considered a key conservation area for forest songbirds, and comprises important breeding habitat for many neotropical migrants, including several species of conservation concern (AMJV, 2015). Forest loss and fragmentation pose serious threats to biodiversity (Pimm and Askins, 1995; Collinge, 1996; Brooks et al., 2002), and are considered major drivers of population declines of forest birds (Robinson et al., 1995; Boulinier et al., 2001). There is growing concern that the rapid expansion of shale gas development will increase impacts of forest loss and fragmentation on breeding birds in the Marcellus-Utica region, particularly in previously intact forests (Kiviat, 2013; Brittingham et al., 2014). In addition to the direct impacts of deforestation, fragmentation, large-scale freshwater consumption (3-5 million gallons per well), increased impervious surfaces, and noise and light pollution, unconventional gas 
development poses potential secondary impacts on forest ecosystems and wildlife, including soil and water contamination, sedimentation of streams, increased human activity, and altered biotic communities and interactions (Kiviat, 2013; Souther et al., 2014), all of which may have auxiliary effects on avian assemblages.

Terrestrial birds are often used to assess how complex communities respond to human-modified landscapes, and are effective biological indicators of environmental degradation (Bradford et al., 1999; O'Connell et al., 2000). Birds also exhibit a wide range of habitat associations and space-use behaviors, and can reveal a diversity of responses to land use change (Leonard et al., 2008). To date, few studies have directly quantified impacts of unconventional oil and gas development on birds, and even fewer have focused on effects of forest disturbance associated with unconventional gas development on birds. In the boreal forests of Alberta, Canada, ovenbirds exhibited a threshold response to seismic line density and their territories did not cross seismic lines (Bayne et al., 2005; see Table 1 for scientific names of all species), and abundance of forest songbirds decreased near active compressor stations (Bayne et al., 2008). Other studies of unconventional oil and gas impacts on birds have primarily occurred in the western U.S., with a focus on sagebrush obligate species (Gilbert and Chalfoun, 2011; Blickley and Patricelli, 2012; Mutter et al., 2015), grassland birds (Thompson et al., 2015), and noise impacts of compressor stations in northwestern New Mexico (Francis et al., 2009, 2011). While there has been an increase in interest and research on the effects of unconventional oil and gas development on birds and other wildlife in the eastern U.S., this method of extraction is still relatively new in the region and much is still unknown about region-specific effects on forest ecosystems (Kiviat, 2013; Souther et al., 2014).

We monitored annual breeding bird abundances and changes in land cover associated with shale gas development at a long-term study site in northern West Virginia, to evaluate potential biological impacts. The specific objectives of our study were to (1) quantify the effects of shale gas development on forest cover at the site, both in terms of forest loss and fragmentation, and (2) determine if changes in species richness and relative abundance of songbirds reflect sensitivity to forest disturbance associated with unconventional gas development. Quantifying how breeding songbirds respond to this changing landscape is a valuable first step in developing spatially explicit management strategies to mitigate potential negative effects of ongoing unconventional gas development in forested landscapes.

\section{Methods}

\subsection{Study area}

Lewis Wetzel Wildlife Management Area (LWWMA) overlays the Marcellus and Utica shale gas basins in northwestern West Virginia

Table 1

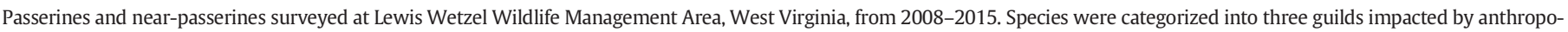

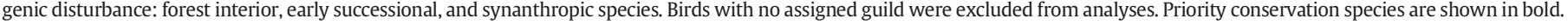

\begin{tabular}{|c|c|c|c|}
\hline Forest interior & Early successional & Synanthropic & No assigned guild \\
\hline Acadian flycatcher ${ }^{1}$ & Brown thrasher ${ }^{1}$ & American goldfinch & Black-billed cuckoo \\
\hline Empidonax virescens & Toxostoma rufum & Spinus tristis & Coccyzus erythropthalmus \\
\hline American redstart & Blue-winged warbler ${ }^{1,2}$ & American robin & Blue-gray gnatcatcher \\
\hline Setophaga ruticilla & Vermivora cyanoptera & Turdus migratorius & Polioptila caerulea \\
\hline Black-and-white warbler ${ }^{1}$ & Common yellowthroat & Baltimore oriole & Carolina chickadee \\
\hline Mniotilta varia & Geothlypis trichas & Icterus galbula & Poecile carolinensis \\
\hline Black-throated green warbler & Eastern bluebird & Blue jay & Cedar waxwing \\
\hline Setophaga virens & Sialia sialis & Cyanocitta cristata & Bombycilla cedrorum \\
\hline Blue-headed vireo & Eastern towhee $^{1}$ & Brown-headed cowbird & Downy woodpecker \\
\hline Vireo solitarius & Pipilo erythrophthalmus & Molothrus ater & Picoides pubescens \\
\hline Brown creeper & Field sparrow ${ }^{1}$ & Carolina wren & Great-crested flycatcher \\
\hline Certhia americana & Spizella pusilla & Thryothorus ludovicianus & Myiarchus crinitus \\
\hline Cerulean warbler ${ }^{1,2,3}$ & Golden-winged warbler ${ }^{1,2,3}$ & Chipping sparrow & Northern flicker \\
\hline Setophaga cerulea & Vermivora chrysoptera & Spizella passerina & Colaptes auratus \\
\hline Eastern wood peewee $^{1}$ & Gray catbird & Eastern phoebe & Northern parula \\
\hline Contopus virens & Dumetella carolinensis & Sayornis phoebe & Setophaga americana \\
\hline Hairy woodpecker & Indigo bunting $^{1}$ & European starling & Red-bellied woodpecker \\
\hline Picoides villosus & Passerina cyanea & Sturnus vulgaris & Melanerpes carolinus \\
\hline Hooded warbler ${ }^{1}$ & Orchard oriole & Mourning dove & Ruby-throated hummingbird \\
\hline Setophaga citrina & Icterus spurius & Zenaida macroura & Archilochus colubris \\
\hline Kentucky warbler ${ }^{1,2}$ & Prairie warbler $^{1,2}$ & Northern cardinal & Summer tanager \\
\hline Geothlypis formosa & Setophaga discolor & Cardinalis cardinalis & Piranga rubra \\
\hline Louisiana waterthrush ${ }^{1}$ & White-eyed vireo & Song sparrow & Tufted titmouse \\
\hline Parkesia motacilla & Vireo griseus & Melospiza melodia & Baeolophus bicolor \\
\hline Ovenbird & Willow flycatcher & & White-breasted nuthatch \\
\hline Seiurus aurocapilla & Empidonax traillii & & Sitta carolinensis \\
\hline Pileated woodpecker & Yellow-breasted chat ${ }^{1}$ & & Yellow warbler \\
\hline Dryocopus pileatus & Icteria virens & & Setophaga petechia \\
\hline Red-eyed vireo & & & Yellow-billed cuckoo \\
\hline Vireo olivaceus & & & Coccyzus americanus \\
\hline Rose-breasted grosbeak & & & Yellow-throated vireo \\
\hline Pheucticus ludovicianus & & & Vireo flavifrons \\
\hline \multicolumn{4}{|l|}{ Scarlet tanager ${ }^{1}$} \\
\hline \multicolumn{4}{|l|}{ Piranga olivacea } \\
\hline \multicolumn{4}{|l|}{ Wood thrush $^{1,2}$} \\
\hline \multicolumn{4}{|l|}{ Hylocichla mustelina } \\
\hline \multicolumn{4}{|l|}{ Worm-eating warbler ${ }^{1,2}$} \\
\hline \multicolumn{4}{|l|}{ Helmitheros vermivorum } \\
\hline \multicolumn{4}{|l|}{ Yellow-throated warbler ${ }^{1}$} \\
\hline \multicolumn{4}{|l|}{ Setophaga dominica } \\
\hline
\end{tabular}


(Fig. 1). The site lies in the Permian Hills subdivision of the Western Allegheny Plateau ecoregion, and covers 6521 ha. The Permian Hills are known for their rugged topography, characterized by steep ridges and narrow stream valleys. The site is predominantly forested with mature, second-growth Appalachian oak and mixed mesophytic forests, with elevations of 221-480 m.

The first unconventional gas well at the study site was developed in 2007, with gas production rising dramatically at LWWMA and the surrounding region from 2008 to 2015 (WVGES, 2015). The site also has a history of conventional oil and gas development; however, we excluded from our study the 2195-ha section of LWWMA that contains the majority of older, shallow gas wells at the site. We focused on the remaining two-thirds of the LWWMA (4326 ha), which also contains older and narrow forest access roads, a powerline right-of-way, small openings maintained for wildlife, and recent timber harvests, most of which were present at the beginning of the study. Unconventional gas development activities included removal of timber for new drilling sites, the building of well pads, widening of existing roads and pipelines, and construction of new roads and pipelines (we refer to all of these unconventional gas development activities as "shale gas" throughout the rest of the paper). Shale gas related activities resulted in the majority of forest loss and fragmentation over the study period (see Results section). At the start of the study in 2008, the site was $95.3 \%$ forested.

\subsection{Land cover mapping and derivation of landscape metrics}

We manually digitized annual changes in forest cover from 2008 to 2015, using a sequence of leaf-off and leaf-on aerial imagery (WV SAMB 2003, NAIP 2007, NAIP 2011, NAIP 2014) and satellite imagery (Landsat 7, Quickbird 2009; see Appendix A for a list of image sources), as well as personal knowledge of disturbance events at the site. We accessed public gas well records (WVDEP, 2015) to verify target shale

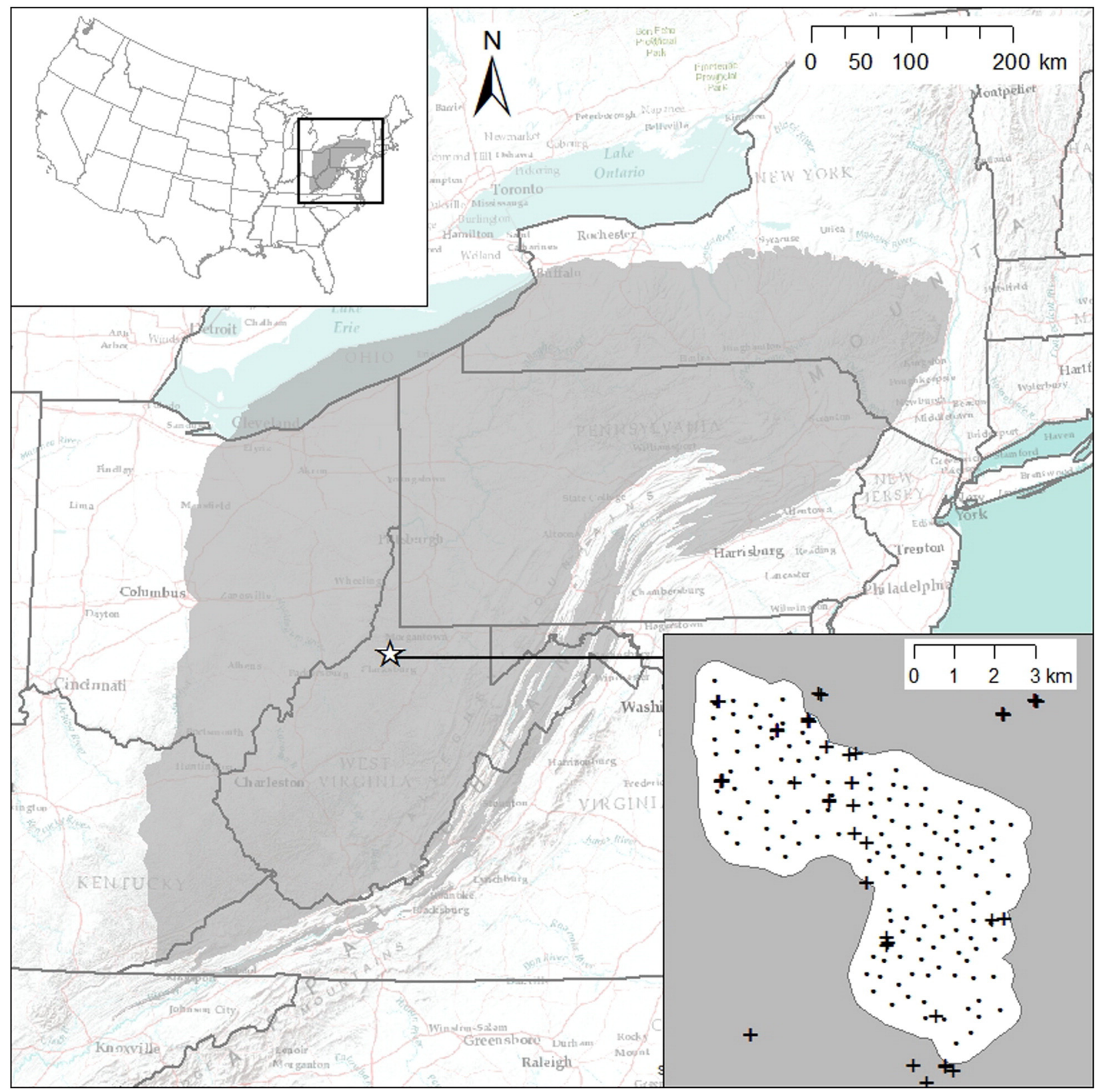

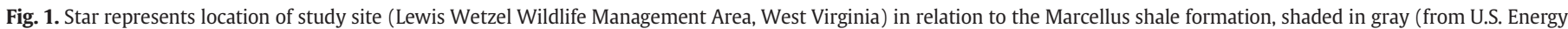

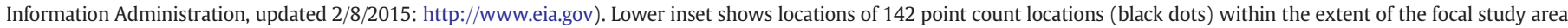

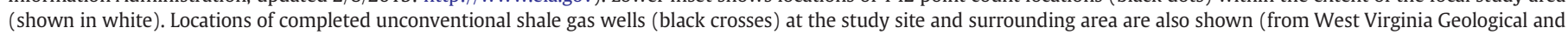
Economic Survey, updated 11/2015: http://www.wvgs.wvnet.edu). 
formations and drilling start dates. We digitally mapped all impacts using a GIS (Fig. 2), then specified which breeding seasons were affected and whether each impact was related to shale gas (well pads, new or widening of roads and pipelines) or unrelated (even-aged timber harvests). Pre-existing impacts were also digitized and classified, and were treated as baseline disturbance. Three partial harvests (113 ha combined total) that occurred prior to 2008 were classed as baseline forest rather than harvests because most of the canopy trees were retained, which generally results in relatively minimal changes to this forest bird community (Sheehan et al., 2014).

We converted annual vector maps to $1-\mathrm{m}$ resolution raster land cover grids, and used FRAGSTATS v.4 (McGarigal et al., 2012) to assess site-wide changes in annual land cover and forest edge density. We calculated the percent of the study site covered in forest, shale gas, evenaged timber harvests, and core forest (areas of forest $>100 \mathrm{~m}$ from any forest edge). We selected a 100-m depth of edge based on its widespread use to quantify edge influence (Robbins et al., 1989; Howell et al., 2007; Johnson et al., 2010; Drohan et al., 2012; Becker et al., 2015). Lastly, we calculated forest edge density, or the aggregate lengths of all forest edges ( $\mathrm{m}$ ) divided by the total landscape area (ha). Because forest edges associated with timber harvests have lower structural contrast and fewer negative effects on area-sensitive species in forested landscapes than other, more static types of edge (Schmiegelow et al., 1997; Hansen and Rotella, 2000), we weighted forest edges with harvests at 0.5 , and all other types of forest edge (primarily with shale gas) at 1.0, following McGarigal (2015) and previous studies (Rempel et al., 2007; Purcell et al., 2012). For core area and edge density calculations, artificial edges created by the study area boundary were excluded.

To evaluate both the effects of local patch characteristics and landscape context on avian responses at the point-level, we selected two spatial extents for land cover metrics. We used a $100-\mathrm{m}$ radius area (3.14 ha) to represent a local extent surrounding each survey point, and a 500-m radius area ( $78.5 \mathrm{ha}$ ) to represent a neighborhood or intermediate landscape extent (Desrochers et al., 2010). At the 100-m extent, we selected forest edge density $\left(\right.$ Edge $_{100 \mathrm{~m}}$ ) as a measure of local forest fragmentation, and percent of landscape occupied by shale gas and infrastructure ( $\mathrm{pGAS}_{100 \mathrm{~m}}$ ) as a measure of local forest loss directly associated with the footprint of shale gas. At the 500-m extent, we selected percent forest cover ( $\mathrm{pFOR}_{500 \mathrm{~m}}$ ) as a measure of broader forest context. We selected these landscape metrics to assess whether species appear to respond more strongly to forest configuration and gas impacts at a local scale or to overall forest cover at a broader spatial extent (Wiens et al., 1997; Smith et al., 2011).

We used overlapping, concentric circles (i.e., non-independent) primarily because we were not interested in bird responses at two independent distances from each survey, but rather across entire landscapes within two spatial extents (Desrochers et al., 2010). There was also minimal overlap in area; the smaller 3.14 ha circle overlapped only $4 \%$ of the larger 78.5 radius circle. We assessed collinearity among all three landscape metrics with pairwise Pearson correlations, since measures of habitat fragmentation are frequently correlated with measures of habitat amount, even across scales (Fahrig, 2003; Battin and Lawler, 2006). Our values were $\pm 0.43-0.47$, below a cut-off of \pm 0.5 suggested as an indicator of high collinearity (Booth et al., 1994). We also examined variance inflation factors (VIFs) for the three landscape metrics using the package 'car' (Fox and Weisberg, 2011) in program $\mathrm{R}$ version 3.1.1 ( $\mathrm{R}$ Core Team, 2014). Iterative addition of individual variables to generalized linear models did not cause marked increases in VIFs of other model variables, and all three landscape metrics maintained VIFs below 1.5 in all models, indicating they can be evaluated as non-proxy variables in subsequent analyses (Booth et al., 1994; Zuur et al., 2009).

\subsection{Point count surveys}

During 2008-2015, we conducted avian point count surveys (Bibby et al., 1992) at 142 sampling points placed systematically throughout the study area (Fig. 1); 87 points were along ridges and 55 points along $50.4 \mathrm{~km}$ of $1 \mathrm{st}$ - and 2nd-order tributary streams. To minimize counting individual birds at more than one station, we placed points a minimum distance of $250 \mathrm{~m}$ apart.

Observers conducted 10-minute surveys at each point, recording all birds detected by sight or sound. We conducted two surveys at each point from mid-May to late June annually, between sunrise and $4 \mathrm{~h}$ after sunrise to coincide with peak singing activity (Ralph et al., 1995). Surveys were not conducted when wind or environmental conditions interfered with audibility or visibility of birds. If there was active drilling or construction near a survey point, we resurveyed on a subsequent day when activity had stopped or subsided. There was only one point in 2014 that we were unable to survey due to constant shale gas noise interference. We conducted a total of 2270 surveys from 2008 to 2015, and used maximum detections at each point from within-year visits in analyses $(n=1135)$.

Detections were recorded in 7 time intervals $(0-2,>2-3,>3-4$, $>4-5,>5-6,>6-7,>7-10 \mathrm{~min})$ and four distance intervals $(0-25 \mathrm{~m}$, $>25-50 \mathrm{~m},>50-100 \mathrm{~m},>100 \mathrm{~m}$ ), to allow for estimation of detection probabilities using a combined time removal and distance sampling approach (Sólymos et al., 2013), and to allow for comparison with other studies (Ralph et al., 1995). Multiple observers conducted surveys each year of the study with observer overlap between years; 5 of 29 observers completed $61.5 \%$ of counts. All observers were experienced in bird identification and distance estimation and also completed training in both prior to conducting counts. We varied the order in which stations were visited and the observers conducting surveys over withinseason visits, to minimize any systematic biases due to time of day and observer skill.
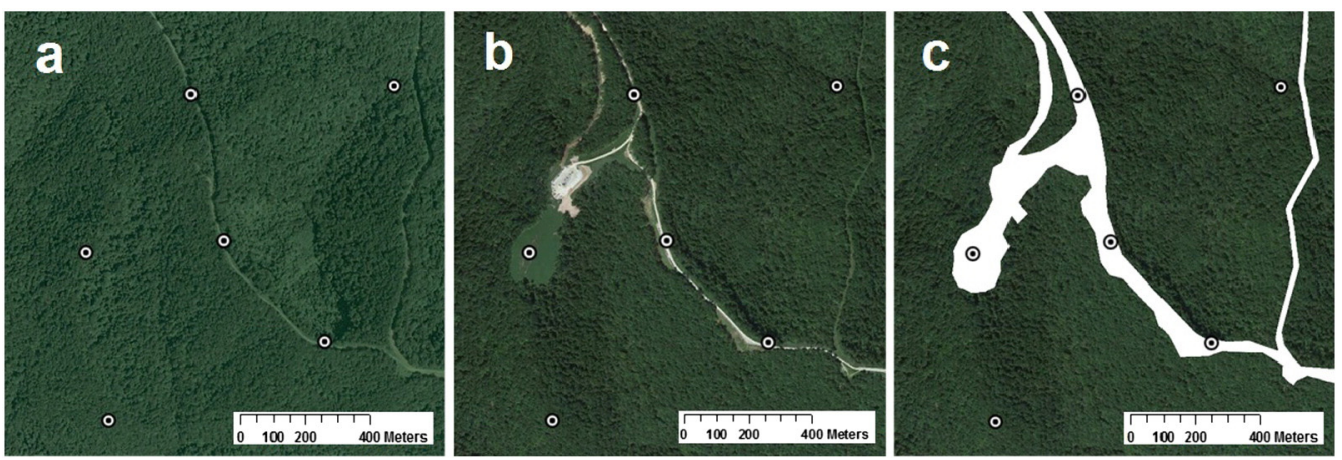

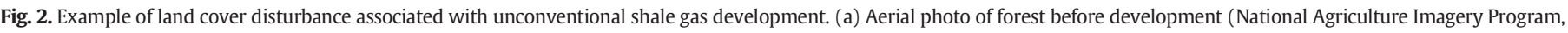

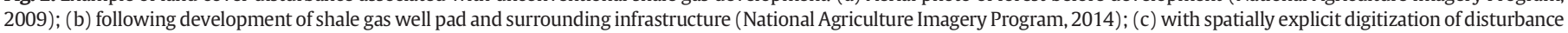
features overlaid in white. Note expansion of pre-existing forest roads. Black dots inside white circles represent avian point count locations. 


\subsection{Detection probability}

To account for species-specific differences in detection probabilities, we used the QPAD approach (Sólymos et al., 2013), which combines time removal and distance sampling methods to estimate $p$ (availability) and $q$ (perceptibility). The approach provides conditional maximum likelihood estimates for the two components of detectability, and accounts for detection error using survey-specific covariates likely to affect abundance and detection (Sólymos et al., 2013).

We included serial date, time since sunrise, and quadratic terms of each as survey-specific covariates of availability, since numbers of birds singing and rates of singing are influenced by time of day and survey date (Ralph et al., 1995). We included observer as a survey-specific covariate of perceptibility to account for potential differences in observer skill, as well as percent forest cover within $100 \mathrm{~m}$ because foliage affects amplitude reduction, with sounds attenuating at shorter distances in forested settings (Huisman and Attenborough, 1991). Percent forest cover within $100 \mathrm{~m}$ of each sample point was calculated using our 1$\mathrm{m}$ resolution annual land cover grids and FRAGSTATS v.4 (McGarigal et al., 2012).

We used the package 'detect' (Sólymos et al., 2016) in program $\mathrm{R}$ version 3.1.1 (R Core Team, 2014) to calculate species-specific detection probabilities based on maximum detections from two within-year visits, during 10 min surveys ( 7 time intervals) and within a 50-m radius ( 2 distance intervals). Although using the maximum count at a point within a season helps to reduce observer effects and false zeros, we used counts within a 50-m radius to further minimize observer effects (Ralph et al., 1995) and potential inconsistencies in distance estimation (Alldredge et al., 2007). We fit count data for each species to nine removal and four distance models (including intercept only models; see Appendix B for full models). The best-fitting models for each species were then used to calculate custom offsets to account for detectability in subsequent analyses (see Data analysis section).

\subsection{Avian guilds and focal species}

To test general trends in avian community response to changes in land cover associated with shale gas, we classified birds a priori into three habitat guilds of interest (Table 1) based on breeding biology of regional bird species (Ehrlich et al., 1988) and previous guild studies from the region (Whitcomb et al., 1981; O'Connell et al., 2000; McDermott and Wood, 2009; Thomas et al., 2014). Forest interior birds ( $n=20$ ) were species most commonly found in large tracts of mature forest in the region; this included species associated with small openings and canopy gaps within core forests. Early successional birds $(n=14)$ were species associated with young forests, recently disturbed edges, and areas dominated by shrubby, heterogeneous vegetation. Synanthropic birds $(n=13)$ were species that exhibit a symbiotic relationship with humans, and are known to capitalize on increased resources associated with human disturbance (Johnston, 2001; Marzluff, 2005).

For analyses, we excluded non-breeding migrants, species detected only once during the eight-year study, and birds not adequately sampled by point counts (i.e., gamebirds and other non-passerines, primarily aerial species such as swallows, and species that range over large areas, such as raptors, crows, and ravens). Of the remaining 62 passerine and near-passerine species detected, $74 \%$ were classified into guilds; the remaining $26 \%$ did not fit clearly into any of the three guilds of interest, and were omitted from further analysis (Table 1). We modeled guild species richness as a community-level measure of response to land cover metrics, based on the total number of species detected at each point across two within-year visits.

We also examined responses of 21 focal species to shale gas. We selected our focal species from among the most commonly detected, to ensure sufficient abundance to test for a response across disturbance gradients. We also selected species to represent a range of resource needs and space-use behaviors. We included eleven forest interior (Table 3), five early successional, and five synanthropic species (Table 4); more forest birds were included due to conservation concern about impacts of shale gas on area-sensitive, forest interior dependent species in the Marcellus-Utica region (Kiviat, 2013; Brittingham et al., 2014). Of the eleven forest interior birds selected, eight are listed as regional conservation priority species by the Appalachian Mountains Joint Venture (AMJV, 2015), four are birds of conservation concern on the U.S. Fish and Wildlife Service National List (USFWS, 2008), and one species, the cerulean warbler, is a focal species of high conservation priority and is also listed as vulnerable on the IUCN Red List (IUCN, 2015; see Table 1). We used abundance per point per year as a measure of each focal species response, based on maximum detections from withinyear visits corrected for detection probabilities.

\subsection{Data analysis}

To evaluate general trends in land cover change at the site across the eight-year study, we modeled annual site-wide land cover metrics (percent forest cover, percent core forest, percent shale gas cover, and forest edge density) using Gaussian generalized linear models (GLMs). We also used GLMs with a Poisson distribution and a log link to evaluate three general trends in guild species richness and cerulean warbler abundance: (1) across all points over time, (2) only at points impacted by shale gas disturbance at a local extent ( pGAS $_{100 \mathrm{~m}}>0$ ), and (3) only at unimpacted points ( pGAS $\left._{100 \mathrm{~m}}=0\right)$. We considered differences significant at $p \leq 0.10$. Use of a higher alpha level is justified when studying conservation issues to avoid making a Type II error (Askins et al., 1990). For ease of graphical interpretation, we plotted line graphs of site-wide land cover metrics by year, as well as annual averages of guild species richness and cerulean warbler abundance at impacted versus unimpacted points, over time. We plotted best-fit linear trend lines on each graph to simply illustrate the general slope and direction of longterm trends, using ordinary least squares regression

To relate avian responses directly to point-level land cover metrics (Edge $_{100 \mathrm{~m}}, \mathrm{pGAS}_{100 \mathrm{~m}}, \mathrm{pFOR}_{500 \mathrm{~m}}$ ), we used generalized linear mixed models (GLMMs) with a Poisson distribution and a log link. We included year and point as random effects to account for variation associated with repeated measures over space and time (Zuur et al., 2009). Logarithms of correction factors for detection error were applied as offsets in count models for focal species (Sólymos et al., 2013). Before conducting statistical analyses, we evaluated our data and found they were neither overdispersed nor zero-inflated (Zuur et al., 2010). Blue jay counts were the single exception, with slight zero-inflation. After comparing log-likelihood ratios for Poisson, zero-inflated Poisson, and negative binomial blue jay models, we found the Poisson model was the best fit. For all species, we initially modeled both linear and quadratic terms of land cover metrics to evaluate potential linear and nonlinear responses. However, inclusion of quadratic terms increased model nonconvergence, resulted in higher model $\mathrm{AIC}_{\mathrm{c}}$ scores for the majority of species, and we found evidence of linear responses in the few species that also showed a quadratic response. Thus, we included only linear terms in final models.

Lastly, we used Akaike's information criterion with a second-order bias correction $\left(\mathrm{AIC}_{\mathrm{c}}\right)$ to evaluate and summarize GLMM results. Because our intent was to determine which point-level land cover metrics exerted the most influence on guild species richness and focal species abundances, and not to rank individual models or find the "best" model, we used a model-averaging approach (Burnham and Anderson, 1998; Mazerolle, 2006). We calculated model-averaged parameter estimates and $85 \%$ unconditional confidence intervals (Arnold, 2010), and determined the relative importance of each landscape metric by summing the $\mathrm{AIC}_{\mathrm{c}}$ weights across the models containing that term in the full model set (Burnham and Anderson, 1998).

Data exploration and statistical analyses were performed in $\mathrm{R}$ version 3.1.1 (R Core Team, 2014). We used the package "Ime4" (Bates 
et al., 2015) for GLMMs, "glmmADMB" (Skaug et al., 2006) for testing a zero-inflated Poisson GLMM for blue jays, and "AICcmodavg" (Mazerolle, 2016) for calculating $\mathrm{AIC}_{\mathrm{c}}$ values, model averaged parameter estimates, and relative importance values.

\section{Results}

\subsection{Land cover change}

Forest cover decreased across the study area by $4.5 \%$ (193.4 ha), dropping from $95.3 \%$ forest cover in 2008 to $90.8 \%$ in 2015, and had a consistent negative trend over the eight-year period (Fig. $3 \mathrm{a} ; F_{1,6}=$ $54.11, p<0.001)$. The total amount of core forest area at the site decreased by $12.4 \%$ ( $533.7 \mathrm{ha}$ ), dropping from $66.1 \%$ in 2008 to $53.7 \%$ in 2015 (Fig. 3b; $F_{1,6}=81.84, p<0.001$ ). At the same time, we observed a $51.7 \%$ increase in forest edge density, which expanded from $36.0 \mathrm{~m} /$ ha in 2008 to $54.7 \mathrm{~m} /$ ha in 2015 (Fig. 3c; $F_{1,6}=71.71, p<0.001$ ).

Site-wide annual increases in forest loss and fragmentation were largely due to shale gas, which increased from $0.4 \%$ cover in 2008 to $3.9 \%$ of total land cover in 2015 (Fig. 3d; $F_{1,6}=95.40, p<0.001$ ). Linear features comprised the majority of gas-related development at the site, with pipelines and access roads altering 2.4\% of total land cover in 2015. Drilling sites for gas wells (well pads, fluid impoundments, storage areas, and associated buffers) made up the remaining $1.5 \%$ of shale gas disturbance. Although some new shale gas development overlapped or expanded pre-existing disturbances (e.g., older forest roads, fields, timber cuts), $83.1 \%$ of shale gas development at the site resulted in direct loss of forest. The site also experienced a $1.5 \%$ increase in area impacted by timber harvests, which occurred between the 2010 and 2011 breeding seasons, and consisted of moderate intensity harvests with green-tree retention which did not result in complete loss of canopy cover.

At the point level, the percentage of point count locations directly impacted by the footprint of shale gas within $100 \mathrm{~m}\left(\mathrm{pGAS}_{100 \mathrm{~m}}>0\right)$ rose by $31.0 \%$, increasing from $12.0 \%$ of points $(n=17)$ impacted in 2008, 21.8\% $(n=31)$ in 2009 and $2010,26.8 \%(n=38)$ in 2011, $33.8 \%(n=48)$ in 2012, 40.8\% ( $n=58)$ in 2013 and 2014, and ending with $43.0 \%$ of points $(n=61)$ impacted in 2015 . In contrast, the percentage of points directly impacted by even-aged timber harvests within $100 \mathrm{~m}$ rose by $3.6 \%$, increasing from $7.0 \%$ of points $(n=10)$ impacted in 2008 to $10.6 \%$ of points $(n=15)$ impacted in 2015 .

\subsection{Avian guild responses}

We observed some year-to-year variation in landscape-level trends of guild species richness over the eight-year study (Fig. 4). However, despite inter-annual variability, all three guilds showed distinct patterns of long-term response across the study site.

Forest interior guild species richness decreased over time across all points $\left(\chi_{(1, N=1135)}^{2}=2.74, p=0.098\right)$ and at points impacted by shale gas within $100 \mathrm{~m}$ (Fig. $\left.\left.4 \mathrm{a} ; \chi^{2}{ }_{(1, N}=341\right)=18.45, p<0.001\right)$, but did not change at points unimpacted by shale gas $\left(\chi_{(1, N=794)}^{2}=\right.$ $1.16, p=0.28)$. During the first three years of the study (2008-2010), we detected higher forest interior species richness at points impacted by shale gas; however this trend reversed in 2011, with consistently fewer forest interior species detected at impacted points during 2011-2015.

Conversely, early successional guild species richness increased over time across all points $\left(\chi_{(1, N=1135)}^{2}=12.10, p<0.001\right)$, and at points impacted by shale gas within $100 \mathrm{~m}$ (Fig. $4 \mathrm{~b} ; \chi_{(1, N=341)}^{2}=8.42$, $p=0.004)$, but did not change at points unimpacted by shale gas $\left(\chi_{(1, N=794)}^{2}=0.39, p=0.53\right)$. The early successional guild had consistently higher richness at points impacted by shale gas compared to unimpacted points, across years.

Synanthropic guild species richness also significantly increased over time across all points $\left(\chi_{(1, N=1135)}^{2}=41.63, p<0.001\right)$ and at points
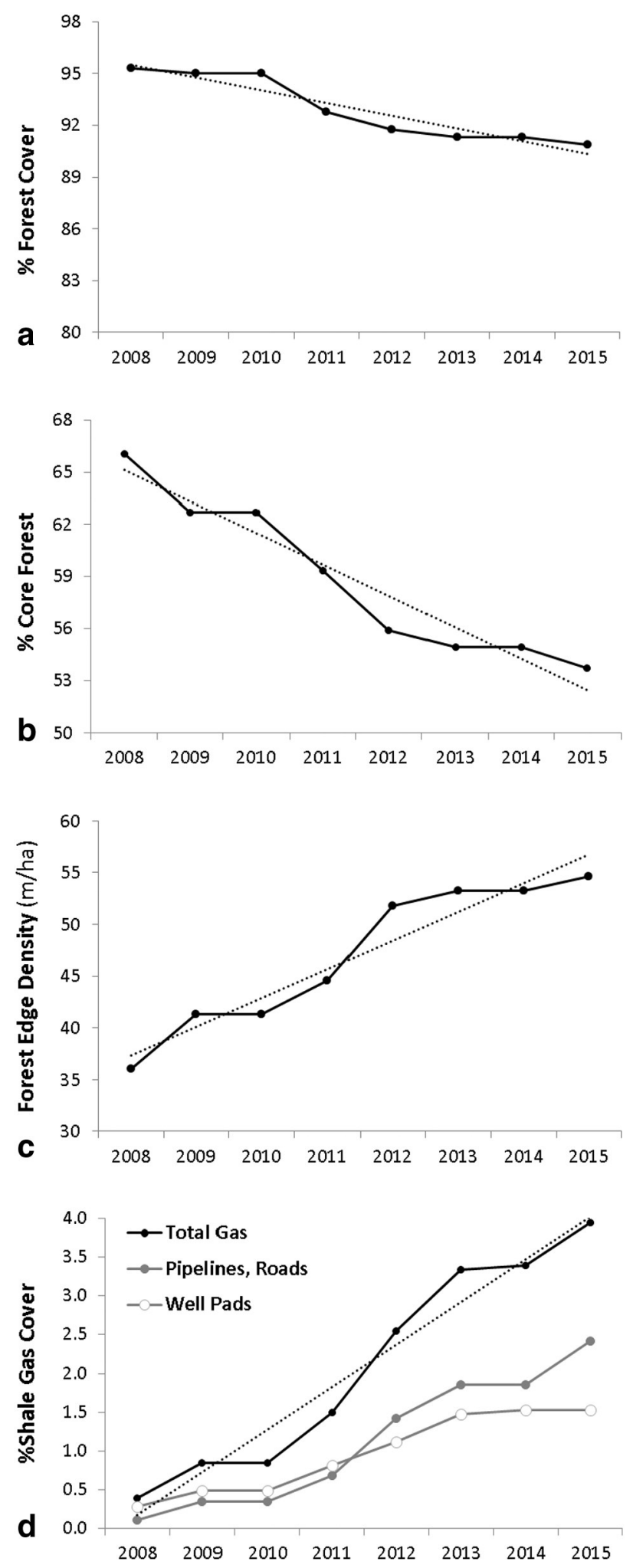

Fig. 3. Line graphs illustrating site-wide changes in land cover at the study area from 2008 to 2015: (a) percent forest cover; (b) percent core forest cover, (c) forest edge density in $\mathrm{m} / \mathrm{ha}$, and (d) percent of the landscape disturbed by shale gas development (dotted lines are linear trends obtained from ordinary least squares regression).

impacted by shale gas (Fig. $\left.4 c ; \chi^{2}{ }_{(1, N}=341\right)=24.54, p<0.001$ ), but did not show a significant change at points unimpacted by shale gas $\left(\chi^{2}(1, N=794)=0.39, p=0.53\right)$. The synanthropic guild also had consistently higher species richness at impacted points than at unimpacted points. 

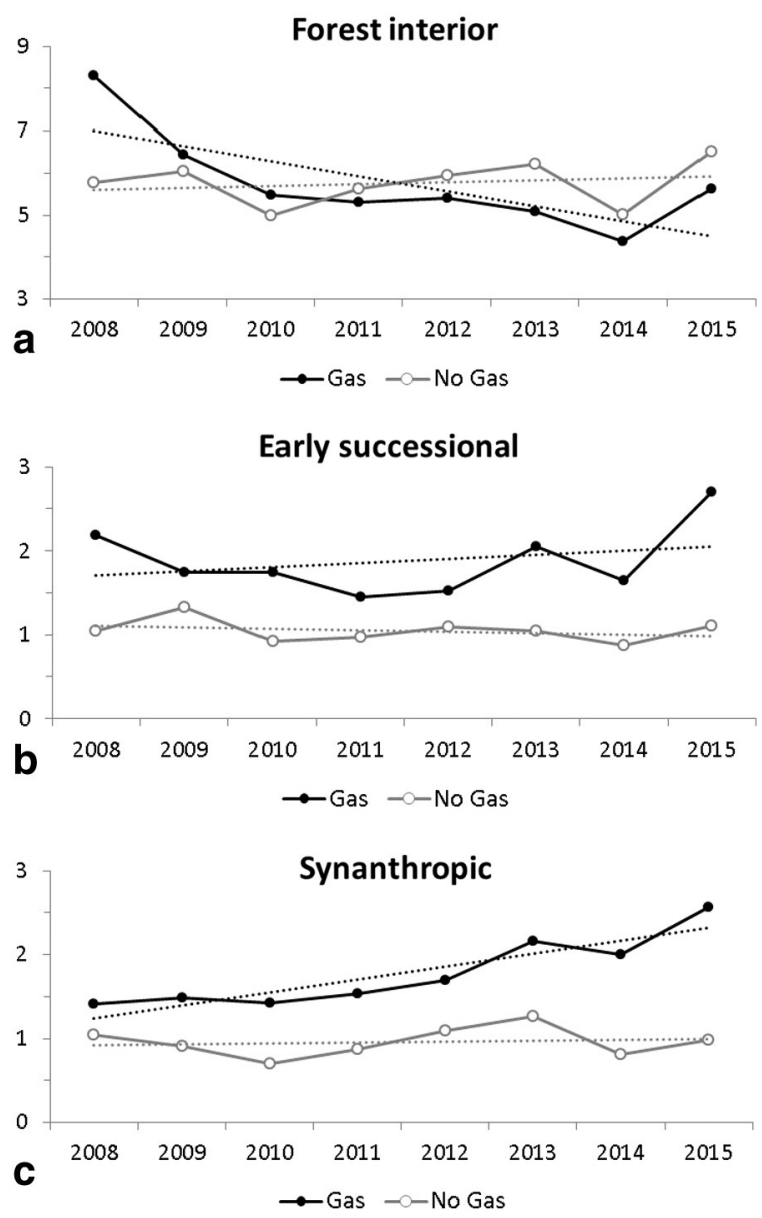

Fig. 4. Line graphs illustrating average annual species richness from 2008 to 2015 , at points impacted by shale gas development within $100 \mathrm{~m}$ ("Gas") and points unimpacted within 100 m ("No Gas"), for species in three habitat guilds: (a) forest interior, (b) early successional, and (c) synanthropic (dotted lines indicate linear trends obtained from ordinary least squares regression)

Model-averaged results of GLMMs directly relating guild species richness to point-level land cover metrics revealed similar trends, with all three guilds exhibiting distinct patterns of response to predictor variables (Table 2). For the forest interior guild, species richness was negatively related to shale gas cover within a local extent $(100 \mathrm{~m})$ and positively related to forest cover within a neighborhood extent $(500 \mathrm{~m})$. Shale gas was the most important predictor of species richness with a relative importance value of 1.00 , followed closely by percent forest cover ( 0.94 relative importance). Edge density at a local extent had comparatively low relative importance $(0.28)$, and confidence intervals for this parameter estimate included zero.

Table 2

Summary results of GLMMs relating avian guild species richness and point-level land cover metrics, after model-averaging. (See Appendix $C$ for full model sets included in AIC analysis.)

\begin{tabular}{llcll}
\hline Avian guild & Parameter & Estimate & $\begin{array}{l}\text { Confidence } \\
\text { interval }\end{array}$ & $\begin{array}{l}\text { Relative } \\
\text { importance }\end{array}$ \\
\hline \multirow{3}{*}{ Forest interior guild } & Edge $_{100 \mathrm{~m}}$ & 0.01 & $(-0.02,0.04)$ & 0.28 \\
& pGAS $_{100 \mathrm{~m}}$ & -0.08 & $(-0.11,-0.05)$ & 1.00 \\
& pFOR $_{500 \mathrm{~m}}$ & 0.06 & $(0.03,0.08)$ & 0.94 \\
& Edge $_{100 \mathrm{~m}}$ & 0.53 & $(0.46,0.61)$ & 1.00 \\
Early successional guild & pGAS $_{100 \mathrm{~m}}$ & 0.002 & $(-0.05,0.05)$ & 0.27 \\
& pFOR $_{500 \mathrm{~m}}$ & -0.05 & $(-0.11,0.02)$ & 0.40 \\
Synanthropic guild & Edge $_{100 \mathrm{~m}}$ & 0.25 & $(0.20,0.30)$ & 0.99 \\
& pGAS $_{100 \mathrm{~m}}$ & 0.11 & $(0.07,0.15)$ & 0.99 \\
& pFOR $_{500 \mathrm{~m}}$ & -0.11 & $(-0.16,-0.06)$ & 0.97 \\
\hline
\end{tabular}

* $85 \%$ unconditional confidence intervals provided, following Arnold (2010).
Conversely, early successional guild species richness showed a strong positive response to edge density at a local extent and it was the most important predictor of species richness, with a relative importance value of 1.00. Importance values for percent forest cover $(0.40)$ and shale gas cover (0.27) were comparatively low, and confidence intervals for these parameter estimates included zero.

For the synanthropic guild, species richness was positively related to edge density and shale gas cover at a local extent, and negatively related to forest cover at a neighborhood extent. All three predictor variables had similar relative importance values (0.97-0.99).

\subsection{Focal species responses}

Model-averaged results from GLMMs relating focal species abundances to land cover metrics were generally consistent with overall guild species richness trends. However, there were clear speciesspecific differences and variability in responses among guild members, particularly among forest interior species (Tables 3, 4).

For forest interior focal species (Table 3 ), four species showed consistent negative responses to shale gas at a local extent, and also had high relative importance values for shale gas: hooded warbler (0.82), Kentucky warbler (0.95), red-eyed vireo (0.92), and worm-eating warbler (0.99). There was weaker evidence that Acadian flycatcher, American redstart, black-and-white warbler, ovenbird, and wood thrush were negatively impacted by shale gas. Relative importance of shale gas was low to moderate for these species $(0.30-0.52)$, and confidence intervals for shale gas parameter estimates for these species included zero. Relative importance of forest cover was moderate to high for five forest interior species: Kentucky warbler (0.68), ovenbird (1.00), red-eyed vireo (0.74), scarlet tanager (0.77), and wood thrush

\section{Table 3}

Summary results of GLMMs relating forest interior focal bird abundances and point-level land cover metrics, after model-averaging. (See Appendix D for full model sets included in $\mathrm{AIC}_{\mathrm{c}}$ analysis.)

\begin{tabular}{|c|c|c|c|c|}
\hline & Parameter & Estimate & $\begin{array}{l}\text { Confidence } \\
\text { interval }^{*}\end{array}$ & $\begin{array}{l}\text { Relative } \\
\text { importance }\end{array}$ \\
\hline \multirow{3}{*}{ Acadian flycatcher } & Edge $_{100 \mathrm{~m}}$ & -0.06 & $(-0.28,0.17)$ & 0.30 \\
\hline & pGAS $_{100 \mathrm{~m}}$ & -0.19 & $(-0.38,0.00)$ & 0.52 \\
\hline & $\mathrm{pFOR}_{500 \mathrm{~m}}$ & 0.004 & $(-0.15,0.16)$ & 0.28 \\
\hline \multirow{3}{*}{ American redstart } & Edge $_{100 \mathrm{~m}}$ & 0.12 & $(0.02,0.22)$ & 0.63 \\
\hline & $\mathrm{pGAS}_{100 \mathrm{~m}}$ & -0.08 & $(-0.18,0.02)$ & 0.45 \\
\hline & $\mathrm{pFOR}_{500 \mathrm{~m}}$ & 0.04 & $(-0.05,0.12)$ & 0.31 \\
\hline \multirow{3}{*}{ Black-and-white warbler } & Edge $_{100 \mathrm{~m}}$ & 0.05 & $(-0.03,0.12)$ & 0.36 \\
\hline & $\mathrm{pGAS}_{100 \mathrm{~m}}$ & -0.07 & $(-0.15,0.02)$ & 0.43 \\
\hline & $\mathrm{pFOR}_{500 \mathrm{~m}}$ & -0.01 & $(-0.09,0.06)$ & 0.28 \\
\hline \multirow{3}{*}{ Cerulean warbler } & Edge $_{100 ~ m}$ & 0.14 & $(0.03,0.24)$ & 0.68 \\
\hline & $\mathrm{pGAS}_{100 \mathrm{~m}}$ & -0.03 & $(-0.13,0.07)$ & 0.30 \\
\hline & $\mathrm{pFOR}_{500 \mathrm{~m}}$ & -0.04 & $(-0.14,0.07)$ & 0.30 \\
\hline \multirow{3}{*}{ Hooded warbler } & Edge $_{100 \mathrm{~m}}$ & 0.06 & $(-0.02,0.13)$ & 0.41 \\
\hline & pGAS $_{100 \mathrm{~m}}$ & -0.11 & $(-0.19,-0.04)$ & 0.82 \\
\hline & $\mathrm{pFOR}_{500 \mathrm{~m}}$ & -0.01 & $(-0.08,0.07)$ & 0.28 \\
\hline \multirow{3}{*}{ Kentucky warbler } & Edge $_{100 \mathrm{~m}}$ & 0.28 & $(0.07,0.49)$ & 0.70 \\
\hline & $\mathrm{pGAS}_{100 \mathrm{~m}}$ & -0.57 & $(-0.91,-0.23)$ & 0.95 \\
\hline & $\mathrm{pFOR}_{500 \mathrm{~m}}$ & 0.28 & $(0.06,0.51)$ & 0.68 \\
\hline \multirow{3}{*}{ Ovenbird } & Edge $_{100 \mathrm{~m}}$ & -0.34 & $(-0.47,-0.21)$ & 1.00 \\
\hline & $\mathrm{pGAS}_{100 \mathrm{~m}}$ & -0.16 & $(-0.33,0.01)$ & 0.51 \\
\hline & $\mathrm{pFOR}_{500 \mathrm{~m}}$ & 0.33 & $(0.2,0.46)$ & 1.00 \\
\hline \multirow{3}{*}{ Red-eyed vireo } & Edge $_{100 ~ m}$ & -0.04 & $(-0.09,0.01)$ & 0.41 \\
\hline & pGAS $_{100 \mathrm{~m}}$ & -0.11 & $(-0.17,-0.05)$ & 0.92 \\
\hline & $\mathrm{pFOR}_{500 \mathrm{~m}}$ & 0.07 & $(0.02,0.13)$ & 0.74 \\
\hline \multirow{3}{*}{ Scarlet tanager } & Edge $_{100 ~ m}$ & -0.01 & $(-0.07,0.06)$ & 0.28 \\
\hline & pGAS $_{100 \mathrm{~m}}$ & -0.03 & $(-0.1,0.04)$ & 0.31 \\
\hline & $\mathrm{pFOR}_{500 \mathrm{~m}}$ & 0.09 & $(0.03,0.16)$ & 0.77 \\
\hline \multirow{3}{*}{ Wood thrush } & Edge $_{100 \mathrm{~m}}$ & -0.07 & $(-0.16,0.02)$ & 0.42 \\
\hline & pGAS $_{100 \mathrm{~m}}$ & -0.06 & $(-0.16,0.03)$ & 0.38 \\
\hline & $\mathrm{pFOR}_{500 \mathrm{~m}}$ & 0.11 & $(0.02,0.19)$ & 0.62 \\
\hline \multirow{3}{*}{ Worm-eating warbler } & Edge $_{100 \mathrm{~m}}$ & -0.28 & $(-0.49,-0.08)$ & 0.72 \\
\hline & $\mathrm{pGAS}_{100 \mathrm{~m}}$ & -0.65 & $(-0.99,-0.31)$ & 0.99 \\
\hline & $\mathrm{pFOR}_{500 \mathrm{~m}}$ & -0.02 & $(-0.19,0.16)$ & 0.27 \\
\hline
\end{tabular}

* 85\% unconditional confidence intervals provided, following Arnold (2010). 
Table 4

Summary results of GLMMs relating early successional and synanthropic focal bird abundances and point-level land cover metrics, after model-averaging. (See Appendices E, F for full model sets included in $\mathrm{AIC}_{\mathrm{c}}$ analysis.)

\begin{tabular}{|c|c|c|c|c|}
\hline & Parameter & Estimate & $\begin{array}{l}\text { Confidence } \\
\text { interval }^{*}\end{array}$ & $\begin{array}{l}\text { Relative } \\
\text { importance }\end{array}$ \\
\hline \multicolumn{5}{|l|}{ Early successional species: } \\
\hline \multirow[t]{3}{*}{ Blue-winged warbler } & Edge $_{100 \mathrm{~m}}$ & 0.60 & $(0.37,0.84)$ & 1.00 \\
\hline & $\mathrm{pGAS}_{100 \mathrm{~m}}$ & -0.31 & $(-0.55,-0.07)$ & 0.75 \\
\hline & $\mathrm{pFOR}_{500 \mathrm{~m}}$ & 0.03 & $(-0.22,0.28)$ & 0.28 \\
\hline \multirow[t]{3}{*}{ Common yellowthroat } & Edge $_{100 \mathrm{~m}}$ & 1.02 & $(0.84,1.19)$ & 1.00 \\
\hline & pGAS $_{100 \mathrm{~m}}$ & 0.07 & $(-0.05,0.19)$ & 0.33 \\
\hline & $\mathrm{pFOR}_{500 \mathrm{~m}}$ & -0.02 & $(-0.18,0.14)$ & 0.27 \\
\hline \multirow[t]{3}{*}{ Eastern towhee } & Edge $_{100 \mathrm{~m}}$ & 0.26 & $(0.19,0.33)$ & 1.00 \\
\hline & $\mathrm{pGAS}_{100 \mathrm{~m}}$ & -0.05 & $(-0.11,0.01)$ & 0.42 \\
\hline & $\mathrm{pFOR}_{500 \mathrm{~m}}$ & 0.03 & $(-0.04,0.1)$ & 0.31 \\
\hline \multirow[t]{3}{*}{ Field sparrow } & Edge $_{100 \mathrm{~m}}$ & 1.31 & $(0.85,1.77)$ & 1.00 \\
\hline & $\mathrm{pGAS}_{100 \mathrm{~m}}$ & 0.07 & $(-0.2,0.34)$ & 0.29 \\
\hline & $\mathrm{pFOR}_{500 \mathrm{~m}}$ & -0.74 & $(-1.13,-0.35)$ & 0.92 \\
\hline \multirow[t]{3}{*}{ Indigo bunting } & Edge $_{100 \mathrm{~m}}$ & 0.79 & $(0.66,0.93)$ & 1.00 \\
\hline & $\mathrm{pGAS}_{100 \mathrm{~m}}$ & 0.06 & $(-0.03,0.15)$ & 0.38 \\
\hline & $\mathrm{pFOR}_{500 \mathrm{~m}}$ & -0.21 & $(-0.33,-0.09)$ & 0.89 \\
\hline \multicolumn{5}{|l|}{ Synanthropic species: } \\
\hline \multirow[t]{3}{*}{ American robin } & Edge $_{100 ~ m}$ & 0.22 & $(0.16,0.28)$ & 0.99 \\
\hline & $\mathrm{pGAS}_{100 \mathrm{~m}}$ & 0.05 & $(0.03,0.08)$ & 0.35 \\
\hline & $\mathrm{pFOR}_{500 \mathrm{~m}}$ & -0.10 & $(-0.17,-0.02)$ & 0.54 \\
\hline \multirow[t]{3}{*}{ Blue jay } & Edge $_{100 ~ m}$ & -0.33 & $(-0.37,-0.29)$ & 1.00 \\
\hline & $\mathrm{pGAS}_{100 \mathrm{~m}}$ & 0.13 & $(0.11,0.15)$ & 0.66 \\
\hline & $\mathrm{pFOR}_{500 \mathrm{~m}}$ & 0.10 & $(0.06,0.14)$ & 0.40 \\
\hline \multirow[t]{3}{*}{ Brown-headed cowbird } & Edge $_{100 ~ m}$ & 0.61 & $(0.43,0.79)$ & 1.00 \\
\hline & $\mathrm{pGAS}_{100 \mathrm{~m}}$ & 0.36 & $(0.25,0.47)$ & 1.00 \\
\hline & $\mathrm{pFOR}_{500 \mathrm{~m}}$ & -0.20 & $(-0.35,-0.04)$ & 0.65 \\
\hline \multirow[t]{3}{*}{ Chipping sparrow } & Edge $_{100 \mathrm{~m}}$ & 0.83 & $(0.64,1.02)$ & 1.00 \\
\hline & pGAS $_{100 \mathrm{~m}}$ & 0.30 & $(0.19,0.4)$ & 1.00 \\
\hline & $\mathrm{pFOR}_{500 \mathrm{~m}}$ & -0.11 & $(-0.27,0.04)$ & 0.38 \\
\hline \multirow[t]{3}{*}{ Northern cardinal } & Edge $_{100 \mathrm{~m}}$ & 0.25 & $(0.18,0.31)$ & 0.98 \\
\hline & $\mathrm{pGAS}_{100 \mathrm{~m}}$ & -0.08 & $(-0.17,0.01)$ & 0.39 \\
\hline & $\mathrm{pFOR}_{500 \mathrm{~m}}$ & -0.02 & $(-0.05,0.02)$ & 0.28 \\
\hline
\end{tabular}

* $85 \%$ unconditional confidence intervals provided, following Arnold (2010).

(0.62), all of which responded positively to percent forest cover at a neighborhood extent $(500 \mathrm{~m})$. Relative importance of edge density was moderate to high for American redstart (0.63), cerulean warbler (0.68), and Kentucky warbler (0.70), all of which responded positively to edges, and ovenbird (1.00) and worm-eating warbler (0.72), both of which showed negative responses to edge. For Acadian flycatcher and black-and-white warbler, confidence intervals for all parameter estimates included zero, which suggests the predictor variables either had no effect or highly variable effects on these two forest interior species. Cerulean warbler, a forest interior species of high conservation priority (Table 1), showed an overall $34.8 \%$ decline in abundance over the eight-year study, dropping from an average annual relative abundance of 0.90 in 2008 to 0.59 in 2015. GLMs of cerulean warbler abundance over time showed these declines were significant across all points $\left(\chi_{(1, N=1135)}^{2}=33.08, p<0.001\right)$, at points impacted by gas within $100 \mathrm{~m}$ (Fig. $\left.5 ; \chi_{(1, N=341)}^{2}=20.93, p<0.001\right)$, and at unimpacted points $\left(\chi_{(1, N=794)}^{2}=23.42, p<0.001\right)$.

Among early successional focal species (Table 4), local edge density was the most important predictor for abundances of all five species, which showed positive responses to edge density within $100 \mathrm{~m}$. Forest cover at a neighborhood extent also had high relative importance values for field sparrow (0.92) and indigo bunting (0.89), both of which responded negatively to percent forest within $500 \mathrm{~m}$. Shale gas cover within $100 \mathrm{~m}$ was only an important predictor for blue-winged warbler (0.75), which showed a negative response to shale gas.

For the synanthropic focal species (Table 4), edge density had high relative importance values for all five focal species $(0.98-1.00)$, with American robin, brown-headed cowbird, chipping sparrow, and northern cardinal showing a positive response to edges; blue jay was the only focal synanthropic species that showed a negative response in

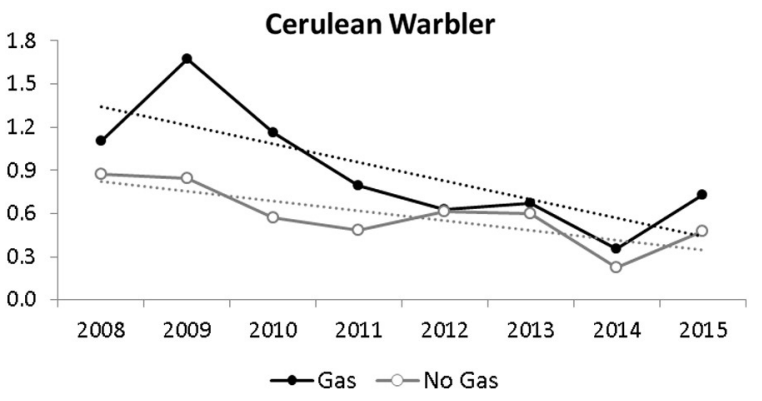

Fig. 5. Line graph illustrating average annual relative abundance of Cerulean Warblers from 2008 to 2015, at points impacted by shale gas development within 100 m ("Gas") and points unimpacted within $100 \mathrm{~m}$ ("No Gas") (dotted lines are linear trends obtained from ordinary least squares regression).

abundance to edge density. Shale gas was another important predictor for brown-headed cowbird and chipping sparrow; both had relative importance values of 1.00. These two species, in addition to American robin and blue jay, showed a positive response in abundance to shale gas at a local extent. Brown-headed cowbirds, in particular, showed steep increases; they were detected at $2.1 \%$ of points $(n=3)$ at the start of the study in 2008 , and at $27.5 \%$ of points $(n=39)$ by the end of the study in 2015 . Although percent forest cover within $500 \mathrm{~m}$ had lower relative importance values for synanthropic species compared with local edge density and shale gas, American robin (0.54) and brown-headed cowbird (0.65) responded negatively to neighborhood forest cover, while blue jay (0.40) was the only focal synanthropic species to show a positive response to forest cover.

\section{Discussion}

As unconventional shale gas development continues to expand in the Marcellus-Utica shale region, there is a need for increased understanding of potential biological impacts, particularly in core forest areas. Here we have provided a region-specific, eight-year case study of the impacts of shale gas development on predominantly mature forest habitat and breeding songbirds, at a long-term study site in the central Appalachian region.

\subsection{Land cover change}

Shale gas development altered forest configuration at our study site over time, primarily through the process of forest fragmentation. The removal of forest cover for drilling pads and new pipelines, in particular, dissected much of what was previously continuous, uninterrupted core forest. Although the site only experienced an overall loss of $4.5 \%$ forest cover, the $51.7 \%$ increase in edge density and $12.4 \%$ loss of core forest suggest that even at a relatively small footprint of forest removal, edge effects appear to exacerbate impacts of unconventional shale gas development on forest ecosystems.

Increasing rates of forest loss and fragmentation associated with shale gas development are of particular concern in the Marcellus-Utica region, given that this area contains some of the largest expanses of core forest remaining in the eastern U.S., and much of the development is occurring in previously intact forests (Johnson et al., 2010; Drohan et al., 2012). Preliminary analyses of existing shale gas disturbance combined with projections of future development suggest that shale gas is already driving substantial land use change, and will continue to significantly alter forested landscapes in the central Appalachian region for decades to come (Johnson et al., 2010; Drohan et al., 2012; EIA, 2012; Evans and Kiesecker, 2014). The potential for cumulative effects of multiple anthropogenic disturbances is also high in the central Appalachian region (Johnson et al., 2010; Kiviat, 2013), due to forest loss associated with other industries (e.g., agriculture, urban development, silviculture, coal mining, conventional gas, and wind energy development). Forest 
loss and fragmentation have been implicated in declines of multiple bird species of conservation concern in Pennsylvania and West Virginia, including wood thrush and cerulean warbler, among others (Wood et al., 2006; Steele et al., 2010). Species most likely to be at risk are those with ranges that closely overlap the Marcellus-Utica shale gas basin, and which are additionally vulnerable due to small population sizes, restricted ranges, narrow habitat requirements, and/or specific sensitivities to disturbance (Johnson et al., 2010, Brittingham et al., 2014).

Although shale gas comprised the majority of forest disturbance during our study, a $1.5 \%$ increase in area impacted by even-aged timber harvests also affected forest cover at the site. However, there are several indications that forest disturbance associated with shale gas was the main driver of negative impacts to forest interior species. First, few overall points had harvests within $100 \mathrm{~m}$, with only 5 points impacted by new timber harvests over the eight-year period, compared with 44 points impacted by new shale gas development. Second, the forest interior guild showed declines prior to 2011, the year when new harvests occurred, and only showed significant declines at points impacted by shale gas within $100 \mathrm{~m}$ (Fig. 4a). Lastly, fragmentation generally has fewer negative effects on forest interior species in landscapes where regenerating timber harvests form a dynamic mosaic with surrounding forests, compared with forests interrupted by more permanent disturbances (Schmiegelow et al., 1997; Hansen and Rotella, 2000; Lichstein et al., 2002). Shale gas well pads are covered with a thick layer of crushed limestone and compacted gravel to support the weight of heavy machinery and drilling rigs. Buffer areas surrounding these well pads and extensive networks of shale gas pipelines are typically seeded with non-native grasses and clover, and are maintained by mowing and/or application of herbicides. Thus, shale gas constitutes a relatively long-term impact on the landscape, given that well pads can be redrilled for multiple well bores, and forest regeneration is suppressed for the lifespan of active wells. In contrast, timber harvests created less severe land cover transitions, with retention and regeneration of native vegetation and in many cases residual trees, post-harvest (Sheehan et al., 2014).

\subsection{Avian response}

Although we observed variability in species-specific responses, we found trends in both avian community- and species-level responses that indicate sensitivity to shale gas development, at our long-term study site. We observed general patterns of decline in the forest interior guild, moderate increases in the early successional guild, and overall gains in the synanthropic guild. To the best of our knowledge, there are no published studies investigating forest fragmentation effects of shale gas development on wildlife in the eastern U.S. However, our findings are consistent with patterns of avian community response to other sources of anthropogenic disturbance in regional core forests, including exurban development (Lumpkin and Pearson, 2013), mountaintop removal coal mining (Becker et al., 2015), and conventional (shallow) gas development (Thomas et al., 2014).

Declines in forest interior species richness across the site, particularly at points impacted by shale gas development, and the negative response in species richness and several forest interior focal species abundances to shale gas cover within $100 \mathrm{~m}$ are of concern. The hooded warbler is a species of conservation priority regionally (AMJV, 2015), and worm-eating warbler and Kentucky warbler are species of high conservation priority both regionally (AMJV, 2015) and nationally (USFWS, 2008). The lack of a clear response to forest edge density within the forest interior guild may reflect the highly variable responses to edge we observed among our forest interior focal species. Within large areas of mature forest, the relatively small clear-cuts for well pad construction and corridors cut for pipelines may mimic natural canopy openings (Buchanan and Hart, 2012). That at least initially may attract forest interior species known to prefer canopy gaps (e.g., American redstart, black-and-white warbler, cerulean warbler; Perkins and Wood, 2014). This is consistent with our observed trend of initially greater forest interior guild species richness at points impacted by shale gas within $100 \mathrm{~m}$. The reversal of this trend during the last five years of the study suggests a redistribution of forest interior species away from points impacted by shale gas. It is possible that gas-related gaps over time prove to be suboptimal habitat for forest interior gap specialists, and may function as ecological traps as suggested for other anthropogenic forest disturbances (Weldon and Haddad, 2005; Boves et al., 2013). Examples of this would be forest interior gap species establishing breeding territories along pipeline corridors, only to experience increased rates of nest predation and parasitism by species that travel along linear disturbances (Brittingham and Temple, 1983; Chalfoun et al., 2002), or nesting near well pads or compressor stations and experiencing nest failure from excessive noise (Francis et al., 2009; Schroeder et al., 2012).

Conversely, disturbance-dependent, early successional species are commonly thought to benefit from clearings and edge habitat created by anthropogenic disturbance (Askins, 1994; McDermott and Wood, 2009). We observed an increasing trend in early successional guild species richness across our study site with an increase in shale gas development, and species richness was consistently higher at points impacted by shale gas compared with unimpacted points. Although we did not observe a clear point-level response to shale gas cover at either the guild or species levels, the strong positive response of both guild richness and species abundance to forest edge density may reflect an attraction to pipeline corridors, which create a high ratio of edge compared to the overall footprint of shale gas cover. This may in part be due to increased prey availability; linear corridors have been shown to act as windbreaks which collect large numbers of insects, particularly on the leeward side (Lewis, 1970; Whitaker et al., 2000). Although early successional species generally appeared to benefit from increased edge density likely in response to increasing shale gas development at the site, blue-winged warbler, an early successional species of high conservation concern both regionally (AMJV, 2015) and nationally (USFWS, 2008), showed a fairly strong negative response to shale gas cover.

The synanthropic guild showed the most significant gains from expanding shale gas, both at a landscape and a local spatial extent. At the community level, synanthropic guild species richness showed a significantly increasing trend across the site over time, increased specifically in areas impacted by shale gas but not in unimpacted areas, and also showed a positive response to percent shale gas cover within $100 \mathrm{~m}$. At the species level, four of five synanthropic focal species tested responded positively to point-level shale gas cover, including American robin, blue jay, brown-headed cowbird, and chipping sparrow. All four species are habitat generalists known to benefit from increased resources associated with human development (Johnston, 2001). Increasing abundances of brown-headed cowbirds pose a specific threat to forest birds in fragmented forests (Brittingham and Temple, 1983; Howell et al., 2007); this nest parasite has been implicated in declines of several songbird species of conservation concern (Eckrich et al., 1999; Kus, 1999; DeCapita, 2000). Brown-headed cowbirds increased primarily at points impacted by shale gas; however, they also were detected in undisturbed areas of forest in later years where they did not occur at the beginning of the study. European starlings are another synanthropic species that pose a potential problem for other species, since they may negatively impact native cavity-nesting birds through aggressive competition for limited nest sites (Koenig, 2003). Although European starlings were rarely detected during our study, it is worth noting that they were not known to occur at the site until two flocks were observed during point counts in 2013, and one flock in 2014; all three flocks were detected within $100 \mathrm{~m}$ of a shale gas well pad or pipeline.

The direct mechanism most likely driving the general patterns we observed in avian response to shale gas is habitat conversion. This includes the direct loss of mature forest on which many forest interior 
species rely (Becker et al., 2015), coupled with an increase in open spaces and forest edges avoided by area-sensitive species (Askins, 1994; Banks-Leite et al., 2010). At the same time, shale gas development creates linear corridors and edge environments that benefit early successional and synanthropic species, leading to biotic homogenization (McKinney and Lockwood, 1999). Another direct mechanism potentially driving songbird response to shale gas development is noise pollution (Kempenaers et al., 2010; Halfwerk et al., 2011). During active phases of drilling and hydraulic fracturing, operations typically run $24 \mathrm{~h}$ per day until well completion, which requires lights surrounding well pads at night and high volumes of truck traffic to transport water, sand, and chemicals (Kiviat, 2013). These activities create acute noise impacts that can last from weeks to months, depending on the number of wells being drilled at any given time on the landscape (Brittingham et al., 2014). Compressor stations that move gas through pipelines also run $24 \mathrm{~h}$ per day, and are a source of long-term, chronic noise (Francis et al., 2011). Noise pollution poses a particular problem for animals that rely on acoustic communication, since acoustic signals play an important role in mate selection, parent-offspring communication, and predator-prey interactions (Rabin et al., 2003). The declines we observed in red-eyed vireo abundance in response to increasing shale gas disturbance were consistent with findings from a study in Alberta, Canada, which found that red-eyed vireos occurred in lower abundances near noisy gas compressor facilities compared with quiet facilities (Bayne et al., 2008).

A related indirect mechanism potentially affecting avian responses in forested landscapes fragmented by shale gas development is overall increased human access and activity (Bayne and Dale, 2011). Some of the interannual variability we observed in avian response was likely driven by differing levels of shale gas-related activity across years. The study site experienced noticeable 'pulses' of drilling activity, typified by higher volumes of truck traffic, increased human presence, and greater overall noise levels, which likely impacted breeding songbirds at the site (Ingelfinger and Anderson, 2004). Although we did not directly monitor drilling activity or traffic volume, field personnel noted steady levels of shale gas-related activity at the site during the 2008-2014 breeding seasons, with levels of drilling and truck traffic reaching relatively high intensities in 2011 and 2013-2014. These anecdotal patterns of overall increased human presence and drilling activity correspond with the general patterns of decline we observed in forest interior guild species richness and abundance of forest interior focal species such as the cerulean warbler. Conversely, the 2015 breeding season was comparatively quiet with little gas-related activity and no drilling; that year we observed increases in species richness across avian guilds.

While our ability to draw inferences about the broader region is limited because we sampled only one site over time, we would expect other predominantly forested systems in the region to experience similar patterns of forest change and avian response. Repeating this study in other areas within the Marcellus-Utica shale region would broaden our understanding of region-wide impacts. Additionally, our study was limited to species richness and abundance; studies incorporating demographic parameters such as reproductive success and survivorship are still needed. Further investigations could focus on spatial redistributions of species in response to specific types of shale gas infrastructure (e.g., well pads versus pipelines), and on specific mechanisms driving observed patterns of avian response to shale gas such as noise impact studies and nest monitoring for brood parasitism.

Site-wide declines in cerulean warbler abundance over the eightyear study (Fig. 5) are of particular concern given that this is a species of global conservation concern (IUCN, 2015). Based on regional declines of 3.1\% per year across the Appalachian Mountains from 2003 to 2013 (Sauer et al., 2014), we estimate that cerulean warblers declined regionally by $19.8 \%$ from 2008 to 2015 , a rate $15.0 \%$ lower than the $34.8 \%$ decline we observed at our study site over the same eight-year period. The majority of the core breeding range of this species overlies the
Marcellus-Utica shale gas basin, and our long-term study site (LWWMA) was designated as a globally Important Bird Area for cerulean warblers in 2010 (National Audubon Society, 2013). One driver of cerulean warbler declines is the extensive loss and fragmentation of forests within their breeding range (Hamel et al., 2004). The steep declines we observed across our long-term study site suggest that shale gas development may be increasing pressures on this species of high conservation concern, and that further research is warranted.

\subsection{Management implications}

Our results suggest that although shale gas development has the potential to negatively impact forest ecosystems by reducing overall forest cover, forest fragmentation and reduction of core forest habitat are the greater potential impacts. Even given the relatively small amount of forest cover lost at our study site due to shale gas development, the larger increase in forest edge density and reduction of core forest habitat suggests the footprint of well pads and pipelines is magnified by associated edge effects, particularly for vulnerable species. The use of guild analyses helped reveal general patterns of songbird response to shale gas development among species with overlapping habitat associations, which might not have been clear had we only evaluated individual species responses, and which may be useful for managers trying to mitigate impacts for multiple species (Verner, 1984). However, the diversity of responses among our focal species, particularly within the forest interior guild, underscores the importance of also considering speciesspecific responses across multiple spatial extents, particularly when species of conservation concern are involved.

The extensive horizontal reach ( $1.5 \mathrm{~km}$ or more) of unconventional gas wells allows some flexibility in placement of pads and infrastructure in relation to target gas basins (Johnson et al., 2010). Given this flexibility, strategies for mitigation of negative impacts to sensitive species could be incorporated into site planning (Evans and Kiesecker, 2014). Because many forest interior species decline with even small amounts of forest cover lost in the landscape (Becker et al., 2015), placement of pipeline corridors and access roads around the periphery of larger tracts of mature forest would help maintain core forest habitat for bird species and other taxa associated with interior forests (Askins, 1994). Concentration of well pads along existing road and pipeline networks, and reduction of new well pad construction by drilling multiple bores on existing well pads would further minimize impacts to core forest habitat (Johnson et al., 2010; Thompson et al., 2015). At the same time, implementation of integrated vegetation management practices along pipeline and well pad borders, by creating 'feathered' cut-back borders along hard forest edges (Bramble et al., 1994) and promoting establishment of native vegetation which biologically suppresses tree growth while providing heterogeneous structure (De Blois et al., 2004) may decrease barrier effects for forest interior species, while increasing suitable habitat for early successional birds (Yahner et al., 2004). Planning the timing of construction, drilling, and mowing or spraying of pipeline corridors to avoid critical nesting periods could potentially reduce impacts on breeding birds. Lastly, monitoring the effectiveness of mitigation efforts is a critical step towards improved understanding of how to minimize negative impacts of shale gas development on wildlife in forested systems of the Marcellus-Utica region, and perhaps in other forested shale gas regions world-wide.

\section{Acknowledgments}

West Virginia Division of Natural Resources provided access to the study area and Wheeling Jesuit University provided access to field housing. This research was funded by NETL Department of Energy, West Virginia Division of Natural Resources, and U.S. Fish and Wildlife Service. We thank the many graduate students and field assistants who collected data over the eight-year study. Special thanks to Mack Frantz, Kyle Aldinger, Ryan Davis, Gretchen Nareff, Eric Margenau, and Jeff Anderson 
for project feedback and manuscript editing. James Anderson, Margaret Brittingham, Donald Brown, Brenden McNeil, and three anonymous reviewers provided helpful comments on an earlier version of this manuscript. Any use of trade, firm, or product names is for descriptive purposes only and does not imply endorsement by the U.S. Government.

\section{Appendix A. Sources of imagery for the manual digitization of forest and non-forest cover.}

\begin{tabular}{llll}
\hline Year & Platform & Season & Source \\
\hline & & & West Virginia Statewide Addressing and Mapping \\
2003 & Aerial & Leaf-off & Board (SAMB) project \\
2007 & Aerial & Leaf-on & USDA National Agricultural Imagery Project (NAIP) \\
2008 & Satellite & Leaf-on & Landsat 7 \\
2009 & Satellite & Leaf-on & Quickbird \\
2010 & Satellite & Leaf-on & Landsat 7 \\
2011 & Aerial & Leaf-on & USDA National Agricultural Imagery Project (NAIP) \\
2014 & Aerial & Leaf-on & USDA National Agricultural Imagery Project (NAIP) \\
\hline
\end{tabular}

Appendix B. Model sets included in $\mathrm{AIC}_{\mathrm{c}}$ analysis of detection probabilities using (1) time removal and (2) distance sampling. Models included intercept-only models as well as models incorporating survey-specific covariates.

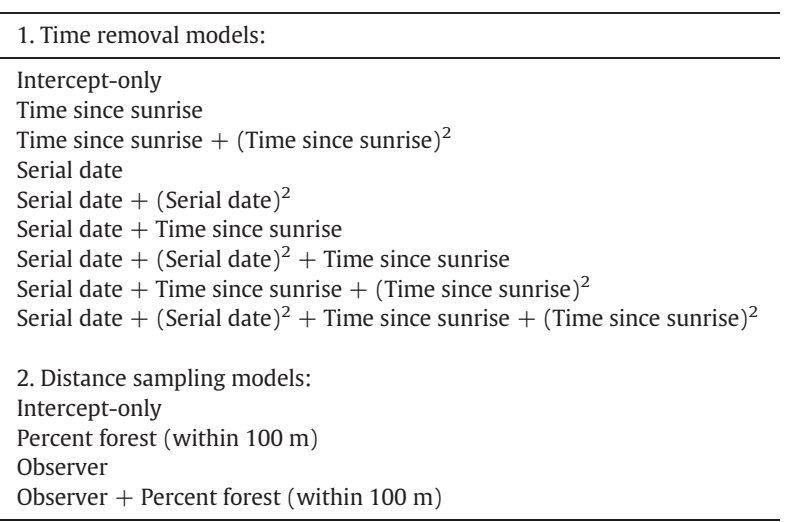

Appendix C. Full model sets included in $\mathrm{AIC}_{\mathrm{c}}$ analysis of generalized linear mixed models relating guild species richness and land cover metrics.

\begin{tabular}{|c|c|c|c|c|c|}
\hline Avian guild & Model & $\mathrm{k}$ & LL & $\Delta \mathrm{AIC}_{\mathrm{C}}$ & $w$ \\
\hline \multirow{14}{*}{ Forest interior guild } & $\mathrm{pGAS}_{100 \mathrm{~m}}, \mathrm{pFOR}_{500 \mathrm{~m}}$ & 5 & -2445.47 & 0.00 & 0.68 \\
\hline & Edge $_{100 \mathrm{~m}}, \mathrm{pGAS}_{100 \mathrm{~m}}$ & & & & \\
\hline & $\mathrm{pFOR}_{500 \mathrm{~m}}$ & 6 & -2445.41 & 1.91 & 0.26 \\
\hline & $\mathrm{pGAS}_{100 \mathrm{~m}}$ & 4 & -2449.20 & 5.45 & 0.04 \\
\hline & Edge $_{100 \mathrm{~m}}, \mathrm{pGAS}_{100 \mathrm{~m}}$ & 5 & -2449.14 & 7.35 & 0.02 \\
\hline & $\mathrm{pFOR}_{500 \mathrm{~m}}$ & 4 & -2452.67 & 12.38 & 0.00 \\
\hline & Edge $_{100 \mathrm{~m}}, \mathrm{pFOR}_{500 \mathrm{~m}}$ & 5 & -2452.22 & 13.50 & 0.00 \\
\hline & Edge $_{100 \mathrm{~m}}$ & 4 & -2460.54 & 28.12 & 0.00 \\
\hline & Null & 3 & -2464.22 & 33.47 & 0.00 \\
\hline & Edge $_{100 \mathrm{~m}}$ & 4 & -1439.74 & 0.00 & 0.44 \\
\hline & Edge $_{100 \mathrm{~m}}, \mathrm{pFOR}_{500 \mathrm{~m}}$ & 5 & -1439.16 & 0.84 & 0.29 \\
\hline & Edge $_{100 \mathrm{~m}}, \mathrm{pGAS}_{100 \mathrm{~m}}$ & 5 & -1439.72 & 1.96 & 0.16 \\
\hline & Edge $_{100 \mathrm{~m}}, \mathrm{pGAS}_{100 \mathrm{~m}}$, & 6 & -1439.14 & 2.84 & 0.11 \\
\hline & $\mathrm{pGAS}_{100 \mathrm{~m}}, \mathrm{pFOR}_{500 \mathrm{~m}}$ & 5 & -1481.58 & 85.70 & 0.00 \\
\hline \multirow{2}{*}{$\begin{array}{l}\text { Early successional } \\
\text { guild }\end{array}$} & $\mathrm{pFOR}_{500 \mathrm{~m}}$ & 4 & -1483.38 & 87.27 & 0.00 \\
\hline & $\mathrm{pGAS}_{100 \mathrm{~m}}$ & 4 & -1484.74 & 90.00 & 0.00 \\
\hline
\end{tabular}

\begin{tabular}{llrrrr} 
(continued) & & & & & \\
\hline Avian guild & Model & $\mathrm{k}$ & $\mathrm{LL}$ & $\Delta \mathrm{AIC}_{\mathrm{C}}$ & $w$ \\
\hline & Null & 3 & -1489.76 & 98.02 & 0.00 \\
& Edge $_{100 \mathrm{~m}}$, pGAS $_{100 \mathrm{~m}}$, & & & & \\
& pFOR $_{500 \mathrm{~m}}$ & 6 & -1519.17 & 0.00 & 0.97 \\
& Edge $_{100 \mathrm{~m}}, \mathrm{pGAS}_{100 \mathrm{~m}}$ & 5 & -1523.97 & 7.57 & 0.02 \\
& Edge $_{100 \mathrm{~m}}, \mathrm{pFOR}_{500 \mathrm{~m}}$ & 5 & -1525.69 & 11.01 & 0.00 \\
& Edge $_{100 \mathrm{~m}}$ & 4 & -1534.74 & 27.10 & 0.00 \\
& pGAS $_{100 \mathrm{~m}}$, pFOR $_{500 \mathrm{~m}}$ & 5 & -1544.04 & 47.72 & 0.00 \\
& pGAS $_{100 \mathrm{~m}}$ & 4 & -1553.65 & 64.92 & 0.00 \\
& pFOR $_{500 \mathrm{~m}}$ & 4 & -1556.32 & 70.26 & 0.00 \\
Synanthropic guild & Null & 3 & -1577.09 & 109.78 & 0.00 \\
\hline
\end{tabular}

Appendix D. Full model sets for forest interior focal species included in $\mathrm{AIC}_{\mathrm{c}}$ analysis of species-specific generalized linear mixed models relating focal bird abundances and land cover metrics.

\begin{tabular}{|c|c|c|c|c|c|}
\hline $\begin{array}{l}\text { Forest interior } \\
\text { species }\end{array}$ & Model & $\mathrm{k}$ & LL & $\triangle \mathrm{AIC}_{\mathrm{C}}$ & $w$ \\
\hline \multirow[t]{8}{*}{ Acadian flycatcher } & $\mathrm{pGAS}_{100 \mathrm{~m}}$ & 4 & -793.16 & 0.00 & 0.27 \\
\hline & Null & 3 & -794.36 & 0.38 & 0.23 \\
\hline & Edge $_{100 \mathrm{~m}}$ & 4 & -793.99 & 1.67 & 0.12 \\
\hline & $\mathrm{pGAS}_{100 \mathrm{~m}}, \mathrm{pFOR}_{500 \mathrm{~m}}$ & 5 & -793.12 & 1.95 & 0.10 \\
\hline & Edge $_{100 \mathrm{~m}}, \mathrm{pGAS}_{100 \mathrm{~m}}$ & 5 & -793.16 & 2.02 & 0.10 \\
\hline & $\mathrm{pFOR}_{500 \mathrm{~m}}$ & 4 & -794.24 & 2.17 & 0.09 \\
\hline & Edge $_{100 \mathrm{~m}}, \mathrm{pFOR}_{500 \mathrm{~m}}$ & 5 & -793.96 & 3.63 & 0.04 \\
\hline & $\begin{array}{l}\text { Edge }_{100 \mathrm{~m}}, \text { pGAS }_{100 \mathrm{~m}} \\
\text { pFOR }_{500 \mathrm{~m}}\end{array}$ & 6 & -793.12 & 3.97 & 0.04 \\
\hline \multirow[t]{8}{*}{ American redstart } & Edge $_{100 \mathrm{~m}}, \mathrm{pGAS}_{100 \mathrm{~m}}$ & 5 & -1123.94 & 0.00 & 0.24 \\
\hline & Edge $_{100 \mathrm{~m}}$ & 4 & -1125.18 & 0.46 & 0.19 \\
\hline & Null & 3 & -1126.22 & 0.54 & 0.18 \\
\hline & Edge $_{100 \mathrm{~m}}, \mathrm{pFOR}_{500 \mathrm{~m}}$ & 5 & -1124.65 & 1.44 & 0.11 \\
\hline & $\begin{array}{l}\text { Edge }_{100 \mathrm{~m}}, \mathrm{pGAS}_{100 \mathrm{~m}} \\
\text { pFOR }_{500 \mathrm{~m}}\end{array}$ & 6 & -1123.82 & 1.79 & 0.10 \\
\hline & $\mathrm{pGAS}_{100 \mathrm{~m}}$ & 4 & -1125.96 & 2.03 & 0.09 \\
\hline & $\mathrm{pFOR}_{500 \mathrm{~m}}$ & 4 & -1126.14 & 2.39 & 0.07 \\
\hline & $\mathrm{pGAS}_{100 \mathrm{~m}}, \mathrm{pFOR}_{500 \mathrm{~m}}$ & 5 & -1125.96 & 4.05 & 0.03 \\
\hline \multirow{8}{*}{$\begin{array}{l}\text { Black-and-white } \\
\text { warbler }\end{array}$} & Null & 3 & -917.00 & 0.00 & 0.28 \\
\hline & $\mathrm{pGAS}_{100 \mathrm{~m}}$ & 4 & -916.51 & 1.04 & 0.17 \\
\hline & Edge $_{100 \mathrm{~m}}, \mathrm{pGAS}_{100 \mathrm{~m}}$ & 5 & -915.74 & 1.51 & 0.13 \\
\hline & Edge $_{100 \mathrm{~m}}$ & 4 & -916.76 & 1.54 & 0.13 \\
\hline & $\mathrm{pFOR}_{500 \mathrm{~m}}$ & 4 & -916.98 & 1.98 & 0.11 \\
\hline & $\mathrm{pGAS}_{100 \mathrm{~m}}, \mathrm{pFOR}_{500 \mathrm{~m}}$ & 5 & -916.29 & 2.62 & 0.08 \\
\hline & $\begin{array}{l}\text { Edge }_{100 \mathrm{~m}}, \text { pGAS }_{100 \mathrm{~m}} \\
\text { pFOR }_{500 \mathrm{~m}}\end{array}$ & 6 & -915.69 & 3.43 & 0.05 \\
\hline & Edge $_{100 \mathrm{~m}}, \mathrm{pFOR}_{500 \mathrm{~m}}$ & 5 & -916.75 & 3.54 & 0.05 \\
\hline \multirow[t]{8}{*}{ Cerulean warbler } & Edge $_{100 \mathrm{~m}}$ & 4 & -953.23 & 0.00 & 0.34 \\
\hline & Null & 3 & -955.03 & 1.58 & 0.15 \\
\hline & Edge $_{100 \mathrm{~m}}, \mathrm{pGAS}_{100 \mathrm{~m}}$ & 5 & -953.02 & 1.59 & 0.15 \\
\hline & Edge $_{100 \mathrm{~m}}, \mathrm{pFOR}_{500 \mathrm{~m}}$ & 5 & -953.21 & 1.97 & 0.13 \\
\hline & $\mathrm{pFOR}_{500 \mathrm{~m}}$ & 4 & -954.65 & 2.83 & 0.08 \\
\hline & $\begin{array}{l}\text { Edge }_{100 \mathrm{~m}}, \mathrm{pGAS}_{100 \mathrm{~m}} \\
\text { pFOR }_{500 \mathrm{~m}}\end{array}$ & 6 & -952.90 & 3.38 & 0.06 \\
\hline & $\mathrm{pGAS}_{100 \mathrm{~m}}$ & 4 & -955.01 & 3.56 & 0.06 \\
\hline & $\mathrm{pGAS}_{100 \mathrm{~m}}, \mathrm{pFOR}_{500 \mathrm{~m}}$ & 5 & -954.63 & 4.80 & 0.03 \\
\hline \multirow[t]{8}{*}{ Hooded warbler } & $\mathrm{pGAS}_{100 \mathrm{~m}}$ & 4 & -1163.26 & 0.00 & 0.33 \\
\hline & Edge $_{100 \mathrm{~m}}, \mathrm{pGAS}_{100 \mathrm{~m}}$ & 5 & -1162.47 & 0.43 & 0.26 \\
\hline & $\mathrm{pGAS}_{100 \mathrm{~m}}, \mathrm{pFOR}_{500 \mathrm{~m}}$ & 5 & -1163.17 & 1.83 & 0.13 \\
\hline & $\begin{array}{l}\text { Edge }_{100 \mathrm{~m}}, \mathrm{pGAS}_{100 \mathrm{~m}} \\
\text { pFOR }_{500 \mathrm{~m}}\end{array}$ & 6 & -1162.47 & 2.45 & 0.10 \\
\hline & Null & 3 & -1165.57 & 2.59 & 0.09 \\
\hline & $\mathrm{pFOR}_{500 \mathrm{~m}}$ & 4 & -1165.39 & 4.24 & 0.04 \\
\hline & Edge $_{100 \mathrm{~m}}$ & 4 & -1165.56 & 4.59 & 0.03 \\
\hline & Edge $_{100 \mathrm{~m}}, \mathrm{pFOR}_{500 \mathrm{~m}}$ & 5 & -1165.30 & 6.09 & 0.02 \\
\hline \multirow[t]{8}{*}{ Kentucky warbler } & $\begin{array}{l}\text { Edge }_{100 \mathrm{~m}}, \mathrm{pGAS}_{100 \mathrm{~m}} \\
\text { pFOR }_{500 \mathrm{~m}}\end{array}$ & 6 & -442.77 & 0.00 & 0.50 \\
\hline & Edge $_{100 \mathrm{~m}}, \mathrm{pGAS}_{100 \mathrm{~m}}$ & 5 & -444.76 & 1.96 & 0.19 \\
\hline & $\mathrm{pGAS}_{100 \mathrm{~m}}, \mathrm{pFOR}_{500 \mathrm{~m}}$ & 5 & -445.09 & 2.61 & 0.14 \\
\hline & $\mathrm{pGAS}_{100 \mathrm{~m}}$ & 4 & -446.13 & 2.68 & 0.13 \\
\hline & $\mathrm{pFOR}_{500 \mathrm{~m}}$ & 4 & -447.65 & 5.71 & 0.03 \\
\hline & Edge $_{100 \mathrm{~m}}, \mathrm{pFOR}_{500 \mathrm{~m}}$ & 5 & -447.27 & 6.97 & 0.02 \\
\hline & Null & 3 & -451.26 & 10.92 & 0.00 \\
\hline & Edge $_{100 \mathrm{~m}}$ & 4 & -451.19 & 12.79 & 0.00 \\
\hline
\end{tabular}


(continued)

\begin{tabular}{|c|c|c|c|c|c|}
\hline $\begin{array}{l}\text { Forest interior } \\
\text { species }\end{array}$ & Model & $\mathrm{k}$ & LL & $\triangle \mathrm{AIC}_{\mathrm{C}}$ & $w$ \\
\hline \multirow[t]{8}{*}{ Ovenbird } & $\begin{array}{l}\text { Edge }_{100 \mathrm{~m}}, \text { pGAS }_{100 \mathrm{~m}} \\
\text { pFOR }_{500 \mathrm{~m}}\end{array}$ & 6 & -851.40 & 0.00 & 0.50 \\
\hline & Edge $_{100 \mathrm{~m}}, \mathrm{pFOR}_{500 \mathrm{~m}}$ & 5 & -852.43 & 0.03 & 0.49 \\
\hline & $\mathrm{pGAS}_{100 \mathrm{~m}}, \mathrm{pFOR}_{500 \mathrm{~m}}$ & 5 & -857.35 & 9.88 & 0.00 \\
\hline & Edge $_{100 \mathrm{~m}}, \mathrm{pGAS}_{100 \mathrm{~m}}$ & 5 & -858.09 & 11.35 & 0.00 \\
\hline & Edge $_{100 \mathrm{~m}}$ & 4 & -861.94 & 17.05 & 0.00 \\
\hline & $\mathrm{pFOR}_{500 \mathrm{~m}}$ & 4 & -862.30 & 17.76 & 0.00 \\
\hline & $\mathrm{pGAS}_{100 \mathrm{~m}}$ & 4 & -867.04 & 27.24 & 0.00 \\
\hline & Null & 3 & -883.61 & 58.37 & 0.00 \\
\hline \multirow[t]{8}{*}{ Red-eyed vireo } & $\mathrm{pGAS}_{100 \mathrm{~m}}, \mathrm{pFOR}_{500 \mathrm{~m}}$ & 5 & -1325.81 & 0.00 & 0.44 \\
\hline & $\begin{array}{l}\text { Edge }_{100 \mathrm{~m}}, \mathrm{pGAS}_{100 \mathrm{~m}} \\
\text { pFOR }_{500 \mathrm{~m}}\end{array}$ & 6 & -1325.46 & 1.30 & 0.23 \\
\hline & Edge $_{100 \mathrm{~m}}, \mathrm{pGAS}_{100 \mathrm{~m}}$ & 5 & -1327.05 & 2.48 & 0.13 \\
\hline & $\mathrm{pGAS}_{100 \mathrm{~m}}$ & 4 & -1328.07 & 2.50 & 0.13 \\
\hline & Edge $_{100 \mathrm{~m}}, \mathrm{pFOR}_{500 \mathrm{~m}}$ & 5 & -1328.06 & 4.50 & 0.05 \\
\hline & $\mathrm{pFOR}_{500 \mathrm{~m}}$ & 4 & -1329.58 & 5.51 & 0.03 \\
\hline & Edge $_{100 \mathrm{~m}}$ & 4 & -1331.50 & 9.36 & 0.00 \\
\hline & Null & 3 & -1336.73 & 17.80 & 0.00 \\
\hline \multirow[t]{8}{*}{ Scarlet tanager } & $\mathrm{pFOR}_{500 \mathrm{~m}}$ & 4 & -1071.08 & 0.00 & 0.41 \\
\hline & $\mathrm{pGAS}_{100 \mathrm{~m}}, \mathrm{pFOR}_{500 \mathrm{~m}}$ & 5 & -1071.03 & 1.91 & 0.16 \\
\hline & Edge $_{100 \mathrm{~m}}, \mathrm{pFOR}_{500 \mathrm{~m}}$ & 5 & -1071.08 & 2.02 & 0.15 \\
\hline & Null & 3 & -1073.69 & 3.21 & 0.08 \\
\hline & $\mathrm{pGAS}_{100 \mathrm{~m}}$ & 4 & -1072.82 & 3.47 & 0.07 \\
\hline & $\begin{array}{l}\text { Edge }_{100 \mathrm{~m}}, \text { pGAS }_{100 \mathrm{~m}} \\
\text { pFOR }_{500 \mathrm{~m}}\end{array}$ & 6 & -1071.02 & 3.91 & 0.06 \\
\hline & Edge $_{100 ~ m}$ & 4 & -1073.22 & 4.27 & 0.05 \\
\hline & Edge $_{100 \mathrm{~m}}, \mathrm{pGAS}_{100 \mathrm{~m}}$ & 5 & -1072.73 & 5.30 & 0.03 \\
\hline \multirow[t]{8}{*}{ Wood thrush } & $\mathrm{pFOR}_{500 \mathrm{~m}}$ & 4 & -1073.42 & 0.00 & 0.27 \\
\hline & Edge $_{100 \mathrm{~m}}, \mathrm{pFOR}_{500 \mathrm{~m}}$ & 5 & -1072.95 & 1.08 & 0.16 \\
\hline & $\mathrm{pGAS}_{100 \mathrm{~m}}, \mathrm{pFOR}_{500 \mathrm{~m}}$ & 5 & -1073.11 & 1.41 & 0.13 \\
\hline & Edge $_{100 ~ m}$ & 4 & -1074.21 & 1.59 & 0.12 \\
\hline & $\mathrm{pGAS}_{100 \mathrm{~m}}$ & 4 & -1074.33 & 1.82 & 0.11 \\
\hline & Null & 3 & -1075.72 & 2.59 & 0.07 \\
\hline & Edge $_{100 \mathrm{~m}}, \mathrm{pGAS}_{100 \mathrm{~m}}$ & 5 & -1073.71 & 2.61 & 0.07 \\
\hline & $\begin{array}{l}\text { Edge }_{100 \mathrm{~m}}, \mathrm{pGAS}_{100 \mathrm{~m}} \\
\text { pFOR }_{500 \mathrm{~m}}\end{array}$ & 6 & -1072.83 & 2.86 & 0.06 \\
\hline \multirow{8}{*}{$\begin{array}{l}\text { Worm-eating } \\
\text { warbler }\end{array}$} & Edge $_{100 \mathrm{~m}}, \mathrm{pGAS}_{100 \mathrm{~m}}$ & 5 & -579.74 & 0.00 & 0.51 \\
\hline & $\mathrm{pGAS}_{100 \mathrm{~m}}$ & 4 & -581.65 & 1.80 & 0.21 \\
\hline & $\begin{array}{l}\text { Edge }_{100 \mathrm{~m}}, \mathrm{pGAS}_{100 \mathrm{~m}} \\
\text { pFOR }_{500 \mathrm{~m}}\end{array}$ & 6 & -579.71 & 1.96 & 0.19 \\
\hline & $\mathrm{pGAS}_{100 \mathrm{~m}}, \mathrm{pFOR}_{500 \mathrm{~m}}$ & 5 & -581.64 & 3.80 & 0.08 \\
\hline & Edge $_{100 \mathrm{~m}}$ & 4 & -585.06 & 8.63 & 0.01 \\
\hline & Edge $_{100 \mathrm{~m}}, \mathrm{pFOR}_{500 \mathrm{~m}}$ & 5 & -584.78 & 10.09 & 0.00 \\
\hline & $\mathrm{pFOR}_{500 \mathrm{~m}}$ & 4 & -591.58 & 21.66 & 0.00 \\
\hline & Null & 3 & -593.77 & 24.03 & 0.00 \\
\hline
\end{tabular}

Appendix E. Full model sets for early successional focal species included in AIC $_{\mathrm{c}}$ analysis of species-specific generalized linear mixed models relating focal bird abundances and land cover metrics.

\begin{tabular}{|c|c|c|c|c|c|}
\hline $\begin{array}{l}\text { Early successional } \\
\text { species }\end{array}$ & Model & $\mathrm{k}$ & LL & $\Delta \mathrm{AIC}_{\mathrm{c}}$ & $w$ \\
\hline \multirow[t]{8}{*}{ Blue-winged warbler } & Edge $_{100 \mathrm{~m}}, \mathrm{pGAS}_{100 \mathrm{~m}}$ & 5 & -345.71 & 0.00 & 0.55 \\
\hline & $\begin{array}{l}\text { Edge }_{100 \mathrm{~m}}, \text { pGAS }_{100 \mathrm{~m}}, \\
\text { pFOR }_{500 \mathrm{~m}}\end{array}$ & 6 & -345.71 & 2.02 & 0.20 \\
\hline & Edge $_{100 \mathrm{~m}}$ & 4 & -347.91 & 2.37 & 0.17 \\
\hline & Edge $_{100 ~ m}, \mathrm{pFOR}_{500 \mathrm{~m}}$ & 5 & -347.69 & 3.95 & 0.08 \\
\hline & Null & 3 & -353.88 & 12.31 & 0.00 \\
\hline & $\mathrm{pFOR}_{500 \mathrm{~m}}$ & 4 & -353.56 & 13.68 & 0.00 \\
\hline & $\mathrm{pGAS}_{100 \mathrm{~m}}$ & 4 & -353.81 & 14.18 & 0.00 \\
\hline & $\mathrm{pGAS}_{100 \mathrm{~m}}, \mathrm{pFOR}_{500 \mathrm{~m}}$ & 5 & -353.23 & 15.04 & 0.00 \\
\hline \multirow{8}{*}{$\begin{array}{l}\text { Common } \\
\text { yellowthroat }\end{array}$} & Edge $_{100 \mathrm{~m}}$ & 4 & -416.68 & 0.00 & 0.48 \\
\hline & Edge $_{100 \mathrm{~m}}, \mathrm{pGAS}_{100 \mathrm{~m}}$ & 5 & -416.35 & 1.36 & 0.24 \\
\hline & Edge $_{100 \mathrm{~m}}, \mathrm{pFOR}_{500 \mathrm{~m}}$ & 5 & -416.63 & 1.93 & 0.18 \\
\hline & $\begin{array}{l}\text { Edge }_{100 \mathrm{~m}}, \text { pGAS }_{100 \mathrm{~m}} \\
\text { pFOR }_{500 \mathrm{~m}}\end{array}$ & 6 & -416.35 & 3.38 & 0.09 \\
\hline & $\mathrm{pGAS}_{100 \mathrm{~m}}$ & 4 & -449.73 & 66.12 & 0.00 \\
\hline & $\mathrm{pGAS}_{100 \mathrm{~m}}, \mathrm{pFOR}_{500 \mathrm{~m}}$ & 5 & -448.85 & 66.37 & 0.00 \\
\hline & $\mathrm{pFOR}_{500 \mathrm{~m}}$ & 4 & -452.05 & 70.75 & 0.00 \\
\hline & Null & 3 & -456.00 & 76.63 & 0.00 \\
\hline
\end{tabular}

(continued)

\begin{tabular}{|c|c|c|c|c|c|}
\hline $\begin{array}{l}\text { Early successional } \\
\text { species }\end{array}$ & Model & $\mathrm{k}$ & LL & $\Delta \mathrm{AIC}_{\mathrm{c}}$ & $w$ \\
\hline \multirow[t]{8}{*}{ Eastern towhee } & Edge $_{100 \mathrm{~m}}$ & 4 & -1204.66 & 0.00 & 0.39 \\
\hline & Edge $_{100 \mathrm{~m}}, \mathrm{pGAS}_{100 \mathrm{~m}}$ & 5 & -1203.90 & 0.51 & 0.30 \\
\hline & Edge $_{100 \mathrm{~m}}, \mathrm{pFOR}_{500 \mathrm{~m}}$ & 5 & -1204.34 & 1.37 & 0.19 \\
\hline & $\begin{array}{l}\text { Edge }_{100 \mathrm{~m}}, \mathrm{pGAS}_{100 \mathrm{~m}} \text {, } \\
\text { pFOR }_{500 \mathrm{~m}}\end{array}$ & 6 & -1203.82 & 2.36 & 0.12 \\
\hline & $\mathrm{pFOR}_{500 \mathrm{~m}}$ & 4 & -1218.44 & 27.57 & 0.00 \\
\hline & Null & 3 & -1219.60 & 27.87 & 0.00 \\
\hline & $\mathrm{pGAS}_{100 \mathrm{~m}}$ & 4 & -1219.13 & 28.95 & 0.00 \\
\hline & pGAS $_{100 \mathrm{~m}}, \mathrm{pFOR}_{500 \mathrm{~m}}$ & 5 & -1218.39 & 29.48 & 0.00 \\
\hline \multirow[t]{8}{*}{ Field sparrow } & Edge $_{100 \mathrm{~m}}, \mathrm{pFOR}_{500 \mathrm{~m}}$ & 5 & -164.07 & 0.00 & 0.67 \\
\hline & $\begin{array}{l}\text { Edge }_{100 \mathrm{~m}}, \mathrm{pGAS}_{100 \mathrm{~m}} \text {, } \\
\text { pFOR }_{500 \mathrm{~m}}\end{array}$ & 6 & -164.03 & 1.95 & 0.25 \\
\hline & Edge $_{100 \mathrm{~m}}$ & 4 & -167.87 & 5.58 & 0.04 \\
\hline & Edge $_{100 \mathrm{~m}}, \mathrm{pGAS}_{100 \mathrm{~m}}$ & 5 & -166.97 & 5.81 & 0.04 \\
\hline & $\mathrm{pFOR}_{500 \mathrm{~m}}$ & 4 & -171.15 & 12.15 & 0.00 \\
\hline & $\mathrm{pGAS}_{100 \mathrm{~m}}, \mathrm{pFOR}_{500 \mathrm{~m}}$ & 5 & -170.87 & 13.59 & 0.00 \\
\hline & pGAS $_{100 \mathrm{~m}}$ & 4 & -173.17 & 16.18 & 0.00 \\
\hline & Null & 3 & -175.02 & 17.87 & 0.00 \\
\hline \multirow[t]{8}{*}{ Indigo bunting } & Edge $_{100 \mathrm{~m}}, \mathrm{pFOR}_{500 \mathrm{~m}}$ & 5 & -732.29 & 0.00 & 0.58 \\
\hline & $\begin{array}{l}\text { Edge }_{100 \mathrm{~m}}, \mathrm{pGAS}_{100 \mathrm{~m}} \text {, } \\
\text { pFOR }_{500 \mathrm{~m}}\end{array}$ & 6 & -731.91 & 1.26 & 0.31 \\
\hline & Edge $_{100 \mathrm{~m}}, \mathrm{pGAS}_{100 \mathrm{~m}}$ & 5 & -734.44 & 4.30 & 0.07 \\
\hline & Edge $_{100 \mathrm{~m}}$ & 4 & -736.01 & 5.42 & 0.04 \\
\hline & $\mathrm{pGAS}_{100 \mathrm{~m}}, \mathrm{pFOR}_{500 \mathrm{~m}}$ & 5 & -766.48 & 68.38 & 0.00 \\
\hline & $\mathrm{pFOR}_{500 \mathrm{~m}}$ & 4 & -768.76 & 70.92 & 0.00 \\
\hline & $\mathrm{pGAS}_{100 \mathrm{~m}}$ & 4 & -774.08 & 81.56 & 0.00 \\
\hline & Null & 3 & -784.13 & 99.66 & 0.00 \\
\hline
\end{tabular}

Appendix F. Full model sets for synanthropic focal species included in AIC $_{c}$ analysis of species-specific generalized linear mixed models relating focal bird abundances and land cover metrics.

\begin{tabular}{|c|c|c|c|c|c|}
\hline Synanthropic species & Model & $\mathrm{k}$ & LL & $\Delta \mathrm{AIC}_{\mathrm{c}}$ & $w$ \\
\hline \multirow[t]{8}{*}{ American robin } & Edge $_{100 \mathrm{~m}}, \mathrm{pFOR}_{500 \mathrm{~m}}$ & 5 & -905.80 & 0.00 & 0.37 \\
\hline & Edge $_{100 \mathrm{~m}}$ & 4 & -907.12 & 0.62 & 0.27 \\
\hline & Edge $_{100 \mathrm{~m}}, \mathrm{pGAS}_{100 \mathrm{~m}}$ & 5 & -906.47 & 1.35 & 0.19 \\
\hline & $\begin{array}{l}\text { Edge }_{100 \mathrm{~m}}, \text { pGAS }_{100 \mathrm{~m}} \\
\text { pFOR }_{500 \mathrm{~m}}\end{array}$ & 6 & -905.63 & 1.69 & 0.16 \\
\hline & $\mathrm{pGAS}_{100 \mathrm{~m}}, \mathrm{pFOR}_{500 \mathrm{~m}}$ & 5 & -910.30 & 9.00 & 0.00 \\
\hline & $\mathrm{pFOR}_{500 \mathrm{~m}}$ & 4 & -911.36 & 9.11 & 0.00 \\
\hline & pGAS $_{100 \mathrm{~m}}$ & 4 & -912.57 & 11.51 & 0.00 \\
\hline & Null & 3 & -916.38 & 17.13 & 0.00 \\
\hline \multirow[t]{8}{*}{ Blue jay } & Edge $_{100 \mathrm{~m}}, \mathrm{pGAS}_{100 \mathrm{~m}}$ & 5 & -687.18 & 0.00 & 0.36 \\
\hline & $\begin{array}{l}\text { Edge }_{100 \mathrm{~m}}, \text { pGAS }_{100 \mathrm{~m}} \\
\text { pFOR }_{500 \mathrm{~m}}\end{array}$ & 6 & -686.37 & 0.40 & 0.30 \\
\hline & Edge $_{100 ~ m}$ & 4 & -688.63 & 0.88 & 0.23 \\
\hline & Edge $_{100 \mathrm{~m}}, \mathrm{pFOR}_{500 \mathrm{~m}}$ & 5 & -688.45 & 2.54 & 0.10 \\
\hline & $\mathrm{pFOR}_{500 \mathrm{~m}}$ & 4 & -693.38 & 10.38 & 0.00 \\
\hline & $\mathrm{pGAS}_{100 \mathrm{~m}}, \mathrm{pFOR}_{500 \mathrm{~m}}$ & 5 & -692.69 & 11.01 & 0.00 \\
\hline & Null & 3 & -695.68 & 12.96 & 0.00 \\
\hline & $\mathrm{pGAS}_{100 \mathrm{~m}}$ & 4 & -695.68 & 14.97 & 0.00 \\
\hline \multirow[t]{8}{*}{$\begin{array}{l}\text { Brown-headed } \\
\text { cowbird }\end{array}$} & $\begin{array}{l}\text { Edge }_{100 \mathrm{~m}}, \text { pGAS }_{100 \mathrm{~m}}, \\
\text { pFOR }_{500 \mathrm{~m}}\end{array}$ & 6 & -448.05 & 0.00 & 0.65 \\
\hline & Edge $_{100 \mathrm{~m}}, \mathrm{pGAS}_{100 \mathrm{~m}}$ & 5 & -449.67 & 1.22 & 0.35 \\
\hline & $\mathrm{Edge}_{100 \mathrm{~m}}, \mathrm{pFOR}_{500 \mathrm{~m}}$ & 5 & -457.17 & 16.23 & 0.00 \\
\hline & $\mathrm{pGAS}_{100 \mathrm{~m}}, \mathrm{pFOR}_{500 \mathrm{~m}}$ & 5 & -460.12 & 22.12 & 0.00 \\
\hline & $\mathrm{pGAS}_{100 \mathrm{~m}}$ & 4 & -464.05 & 27.97 & 0.00 \\
\hline & Edge $_{100 \mathrm{~m}}$ & 4 & -464.82 & 29.51 & 0.00 \\
\hline & $\mathrm{pFOR}_{500 \mathrm{~m}}$ & 4 & -471.71 & 43.29 & 0.00 \\
\hline & Null & 3 & -488.03 & 73.91 & 0.00 \\
\hline \multirow[t]{8}{*}{ Chipping sparrow } & Edge $_{100 \mathrm{~m}}, \mathrm{pGAS}_{100 \mathrm{~m}}$ & 5 & -358.60 & 0.00 & 0.62 \\
\hline & $\begin{array}{l}\text { Edge }_{100 \mathrm{~m}}, \mathrm{pGAS}_{100 \mathrm{~m}} \\
\text { pFOR }_{500 \mathrm{~m}}\end{array}$ & 6 & -358.07 & 0.97 & 0.38 \\
\hline & Edge $_{100 \mathrm{~m}}, \mathrm{pFOR}_{500 \mathrm{~m}}$ & 5 & -364.37 & 11.56 & 0.00 \\
\hline & Edge $_{100 \mathrm{~m}}$ & 4 & -368.24 & 17.28 & 0.00 \\
\hline & $\mathrm{pGAS}_{100 \mathrm{~m}}, \mathrm{pFOR}_{500 \mathrm{~m}}$ & 5 & -378.94 & 40.69 & 0.00 \\
\hline & $\mathrm{pGAS}_{100 \mathrm{~m}}$ & 4 & -381.90 & 44.59 & 0.00 \\
\hline & $\mathrm{pFOR}_{500 \mathrm{~m}}$ & 4 & -388.05 & 56.89 & 0.00 \\
\hline & Null & 3 & -401.55 & 81.87 & 0.00 \\
\hline
\end{tabular}


(continued)

\begin{tabular}{llllrl}
\hline Synanthropic species & Model & $\mathrm{k}$ & $\mathrm{LL}$ & \multicolumn{1}{c}{$\Delta \mathrm{AIC}_{\mathrm{c}}$} & $w$ \\
\hline \multirow{2}{*}{ Northern cardinal } & Edge $_{100 \mathrm{~m}}$ & 4 & -701.93 & 0.00 & 0.44 \\
& Edge $_{100 \mathrm{~m}}$, pGAS $_{100 \mathrm{~m}}$ & 5 & -701.39 & 0.93 & 0.28 \\
& Edge $_{100 \mathrm{~m}}, \mathrm{pFOR}_{500 \mathrm{~m}}$ & 5 & -701.93 & 2.02 & 0.16 \\
& Edge $_{100 \mathrm{~m}}$, pGAS $_{100 \mathrm{~m}}$, & 6 & -701.32 & 2.82 & 0.11 \\
& pFOR $_{500 \mathrm{~m}}$ & & & & \\
& Null & 3 & -707.19 & 8.50 & 0.01 \\
& pFOR $_{500 \mathrm{~m}}$ & 4 & -706.24 & 8.61 & 0.01 \\
& pGAS $_{100 \mathrm{~m}}$ & 4 & -707.10 & 10.35 & 0.00 \\
& pGAS $_{100 \mathrm{~m}}$, pFOR $_{500 \mathrm{~m}}$ & 5 & -706.22 & 10.59 & 0.00 \\
\hline
\end{tabular}

\section{References}

Alldredge, M.W., Simons, T.R., Pollock, K.H., 2007. A field evaluation of distance measurement error in auditory avian point count surveys. J. Wildl. Manag. 71 (8), 2759-2766.

AMJV (Appalachian Mountains Joint Venture), 2015. Priority Landbird Species. [Online] http://amjv.org/documents/Priority_Landbird_Species.pdf.

Arnold, T.W., 2010. Uninformative parameters and model selection using Akaike's Information Criterion. J. Wildl. Manag. 74 (6), 1175-1178.

Askins, R.A., 1994. Open corridors in a heavily forested landscape: impact on shrubland and forest-interior birds. Wildl. Soc. Bull. 22 (2), 339-347.

Askins, R.A., Lynch, J.F., Greenberg, R., 1990. Population declines in migratory birds in eastern North America. Curr. Ornithol. 7, 1-57.

Banks-Leite, C., Ewers, R.M., Metzger, J.P., 2010. Edge effects as the principal cause of area effects on birds in fragmented secondary forest. Oikos 119 (6), 918-926.

Bates, D., Maechler, M., Bolker, B., Walker, S., 2015. Fitting linear mixed-effects models using lme4. J. Stat. Softw. 67 (1), 1-48.

Battin, J., Lawler, J.J., 2006. Cross-scale correlations and the design and analysis of avian habitat selection studies. Condor 108, 59-70.

Bayne, E.M., Dale, B.C., 2011. Effects of energy development on songbirds. In: Naugle, D.E. (Ed.), Energy Development and Wildlife Conservation in Western North America. Island Press, Washington, D.C., pp. 95-114.

Bayne, E.M., Habib, L., Boutin, S., 2008. Impacts of chronic anthropogenic noise from energy-sector activity on abundance of songbirds in the boreal forest. Conserv. Biol. 22 (5), 1186-1193.

Bayne, E.M., Van Wilgenburg, S.L., Boutin, S., Hobson, K.A., 2005. Modeling and fieldtesting of ovenbird (Seiurus aurocapillus) responses to boreal forest dissection by energy sector development at multiple spatial scales. Landsc. Ecol. 20, 203-216.

Becker, D.A., Wood, P.B., Strager, M.P., Mazzarella, C., 2015. Impacts of mountaintop mining on terrestrial ecosystem integrity: identifying landscape thresholds for avian species in the central Appalachians, United States. Landsc. Ecol. 30, 339-356.

Bibby, C.J., Burgess, N.D., Hill, D.A., 1992. Bird Census Techniques. Academic Press, London, UK.

Blickley, J.L., Patricelli, G.L., 2012. Potential acoustic masking of Greater Sage-grouse (Centrocercus urophasianus) display components by chronic industrial noise. Ornithol. Monogr. 74, 23-35.

Booth, G.D., Niccolucci, M.J., Schuster, E.G., 1994. Identifying proxy sets in multiple linear regression: an aid to better coefficient interpretation. Research Paper INT-470. U.S. Department of Agriculture, Forest Service, Intermountain Research Station, Ogden, Utah.

Boulinier, T., Nichols, J.D., Hines, J.E., Sauer, J.R., Flather, C.H., Pollock, K.H., 2001. Forest fragmentation and bird community dynamics: inference at regional scales. Ecology 82 (4), 1159-1169.

Boves, T.J., Buehler, D.A., Sheehan, J., Wood, P.B., Rodewald, A.D., Larkin, J.L., Keyser, P.D., Newell, F.L., George, G.A., Bakermans, M.H., Evans, A., Beachy, T.A., McDermott, M.E., Perkins, K.A., White, M., Wigley, T.B., 2013. Emulating natural disturbances for declining late-successional species: a case study of the consequences for cerulean warblers (Setophaga cerulean). PLoS ONE 8 (1), e52107.

Bradford, D.F., Franson, A.C., Neale, A.C., Heggem, D.T., Miller, G.F., Caterbury, G.E., 1999. Bird species assemblages as indicators of biological integrity in Great Basin rangeland. Environ. Monit. Assess. 49, 1-22.

Bramble, W.C., Yahner, R.H., Byrnes, W.R., 1994. Nesting of breeding birds on an electric utility right-of-way. J. Arboric. 20 (2), 124-129.

Brittingham, M.C., Temple, S.A., 1983. Have cowbirds caused forest songbirds to decline? Bioscience 33 (1), 31-35.

Brittingham, M.C., Maloney, K.O., Farag, A.M., Harper, D.D., Bowen, Z.H., 2014. Ecological risks of shale oil and gas development to wildlife, aquatic resources and their habitats. Environ. Sci. Technol. 48 (19), 11034-11047.

Brooks, T.M., Mettermeier, R.A., Mittermeier, C.G., da Fonseca, G.A.B., Rylands, A.B., Konstant, W.R., Flick, P., Pilgrim, J., Oldfield, S., Magin, G., Hilton-Taylor, C., 2002. Habitat loss and extinction in the hotspots of biodiversity. Conserv. Biol. 16 (4), 909-923.

Buchanan, M.L., Hart, J.L., 2012. Canopy disturbance history of old-growth Quercus alba sites in the eastern United States: examination of long-term trends and broad-scale patterns. For. Ecol. Manag. 267, 28-39.

Burnham, K.P., Anderson, D.R., 1998. Model Selection and Inference: A Practical Information-Theoretic Approach. Springer-Verlag, New York.

Chalfoun, A.D., Thompson, F.R., Ratnaswamy, M.J., 2002. Nest predators and fragmentation: a review and meta-analysis. Conserv. Biol. 16, 306-318.

Collinge, S.K., 1996. Ecological consequences of habitat fragmentation: implications for landscape architecture and planning. Landsc. Urban Plan. 36, 59-77.
De Blois, S., Brisson, J., Bouchard, A., 2004. Herbaceous covers to control tree invasion in rights-of-way: ecological concepts and applications. Environ. Manag. 33 (5), 606-619.

DeCapita, M.E., 2000. Brown-headed cowbird control on Kirtland's warbler nesting areas in Michigan, 1972-1995. In: Smith, J.N.M., Cook, T.L., Rothstein, S.I., Robinson, S.K., Sealy, S.G. (Eds.), Ecology and Management of Cowbirds and Their Hosts: Studies in the Conservation of North American Passerine Birds. University of Texas Press, Austin, TX, pp. 333-341.

Desrochers, A., Renaud, C., Hochachka, W.M., Cadman, M., 2010. Area-sensitivity by forest songbirds: theoretical and practical implications of scale-dependency. Ecography 33, 921-931.

Drohan, P.J., Brittingham, M.C., Bishop, J., 2012. Early trends in landcover change and forest fragmentation due to shale-gas development in Pennsylvania: a potential outcome for the northcentral Appalachians. Environ. Manag. 49, 1061-1075.

Eckrich, G.H., Koloszar, J.A., Goering, M.D., 1999. Effective landscape management of brown-headed cowbirds at Fort Hood, Texas. Stud. Avian Biol. 18, 267-274.

Ehrlich, P.R., Dobkin, D.S., Wheye, D., 1988. The Birder's Handbook: A Field Guide to the Natural History of North American Birds. Simon \& Schuster, New York.

EIA (Energy Information Administration), 2012. Annual Energy Outlook. U.S. Department of Energy, Washington, DC ([Online] http://www.eia.gov/forecasts/archive/aeo/pdf/ 0383(2012).pdf).

EIA (Energy Information Administration), 2015. World Shale Resource Assessments. U.S. Department of Energy, Washington, DC ([Online] http://www.eia.gov/analysis/ studies/worldshalegas).

Evans, J.S., Kiesecker, J.M., 2014. Shale gas, wind and water: assessing the potential cumulative impacts of energy development on ecosystem services within the Marcellus play. PLoS ONE 9 (2), e89210.

Fahrig, L., 2003. Effects of habitat fragmentation on biodiversity. Annu. Rev. Ecol. Evol. Syst. 34, 487-515.

Fox, J., Weisberg, S., 2011. An $\{\mathrm{R}\}$ Companion to Applied Regression. second ed. Sage Publications, Thousand Oaks, CA.

Francis, C.D., Ortega, C.P., Cruz, A., 2009. Noise pollution changes avian communities and species interactions. Curr. Biol. 19, 1415-1419.

Francis, C.D., Paritsis, J., Ortega, C.P., Cruz, A., 2011. Landscape patterns of avian habitat use and nest success are affected by chronic gaswell compressor noise. Landsc. Ecol. 26, 1269-1280.

Gilbert, M.M., Chalfoun, A.D., 2011. Energy development affects populations of sagebrush songbirds in Wyoming. J. Wildl. Manag. 75 (4), 816-824.

Halfwerk, W., Holleman, L.J.M., Lessells, C.M., Slabbekoom, H., 2011. Negative impact of traffic noise on avian reproductive success. J. Appl. Ecol. 48 (1), 210-219.

Hamel, P.B., Dawson, D.K., Keyser, P.D., 2004. How can we learn more about the cerulean warbler (Dendroica cerulean). Auk 121 (1), 7-14.

Hansen, A.J., Rotella, J.J., 2000. Bird responses to forest fragmentation. In: Knight, R.L., Smith, F.W., Buskirk, S.W., Romme, W.H., Baker, W.L. (Eds.), Forest Fragmentation in the Southern Rocky Mountains. University Press of Colorado, Boulder, pp. 201-219.

Hinkle, C.R., McComb, W.C., Safely, J.M., Schmalzer, P.A., 1993. Mixed mesophytic forests In: Martin, W.H., Boyce, S.G., Echternacht, A.C. (Eds.), Biodiversity of the Southeastern United States: Upland Terrestrial Communities. John Wiley and Sons, Inc., New York, pp. 203-253.

Howell, C.A., Dijak, W.D., Thompson, F.R., 2007. Landscape context and selection for forest edge by breeding brown-headed cowbirds. Landsc. Ecol. 22 (2), 273-284.

Huisman, W.H.T., Attenborough, K., 1991. Reverberation and attenuation in a pine forest. J. Acoust. Soc. Am. 90, 2664-2677.

Ingelfinger, F., Anderson, S., 2004. Passerine response to roads associated with natural gas extraction in a sagebrush steppe habitat. West. N. Am. Naturalist 64, 385-395.

IUCN (International Union for Conservation of Nature), 2015. The IUCN Red List of Threatened Species, v. 2015-3. [Online] http://www.iucnredlist.org (Accessed Feb.2, 2016)

Johnson, N., Gagnolet, T., Ralls, R., Zimmerman, E., Eichelberger, B., Tracey, C., Kreitler, G. Orndorff, S., Tomlinson, J., Bearer, S., Sargent, S., 2010. Pennsylvania Energy Impacts Assessment, Report 1: Marcellus Shale Natural Gas and Wind. The Nature Conservancy, Pennsylvania Chapter, Harrisburg, PA ([Online] http://www.nature.org/media/pa/ tnc_energy_analysis.pdf).

Johnston, R.F., 2001. Synanthropic birds of North America. In: Marzluff, J.M., Bowman, R. Donnelly, R. (Eds.), Avian Ecology and Conservation in an Urbanizing World. Kluwer Academic Publishers, Norwell, MA, pp. 49-68.

Kempenaers, B., Borgstrom, P., Loes, P., Schlicht, E., Valcu, M., 2010. Artificial night lighting affects dawn song, extra-pair siring success, and lay date in songbirds. Curr. Biol. 20 1735-1739.

Kiviat, E., 2013. Risks to biodiversity from hydraulic fracturing for natural gas in the Marcellus and Utica shales. In: Schlesinger, W.H., Ostfeld, R.S. (Eds.), Year in Ecology and Conservation Biology. Annals of the New York Academy of Sciences 1286, pp. 1-14.

Koenig, W.D., 2003. European starlings and their effect on native cavity-nesting birds. Conserv. Biol. 17 (4), 1134-1140.

Kus, B.E., 1999. Impacts of brown-headed cowbird parasitism on productivity of the endangered Least Bell's Vireo. Stud. Avian Biol. 18, 160-166.

Leonard, T.D., Taylor, P.D., Warkentin, I.G., 2008. Landscape structure and spatial scale affect space use by songbirds in naturally patchy and harvested boreal forests. Condor 110 (3), 467-481.

Lewis, T., 1970. Patterns of distribution of insects near a windbreak of tall trees. Ann. Appl. Biol. 65 (2), 213-220.

Lichstein, J.W., Simons, T.R., Franzreb, K.E., 2002. Landscape effects on breeding songbird abundance in managed forests. Ecol. Appl. 12 (3), 836-857.

Lumpkin, H.A., Pearson, S.M., 2013. Effects of exurban development and temperature on bird species in the southern Appalachians. Conserv. Biol. 27 (5), 1069-1078.

Marzluff, J.M., 2005. Island biogeography for an urbanizing world: how extinction and colonization may determine biological diversity in human-dominated landscapes. Urban Ecosyst. 8 (2), 157-177. 
Mazerolle, M.J., 2006. Improving data analysis in herpetology: using Akaike's Information Criterion (AIC) to assess the strength of biological hypotheses. Amphibia-Reptilia 27, $169-180$.

Mazerolle, M.J., 2016. AICcmodavg: model selection and multimodel inference based on (Q)AIC(c). $\mathrm{R}$ package version 2.0-4. http://CRAN.R-project.org/package= AICcmodavg.

McDermott, M.E., Wood, P.B., 2009. Short- and long-term implications of clearcut and two-age silviculture for conservation of breeding forest birds in the central Appalachians, USA. Biol. Conserv. 142 (1), 212-220.

McGarigal, K., 2015. FRAGSTATS Help. University of Massachusetts, Amherst, Amherst MA ([Online] http://www.umass.edu/landeco/research/fragstats/documents/ fragstats.help.4.2.pdf).

McGarigal, K., Cushman, S.A., Ene, E., 2012. FRAGSTATS v4: Spatial Pattern Analysis Program for Categorical and Continuous Maps. University of Massachusetts, Amherst ([Online] http://www.umass.edu/landeco/research/fragstats/fragstats.html).

McKinney, M.L., Lockwood, J.L., 1999. Biotic homogenization: a few winners replacing many losers in the next mass extinction. Trends Ecol. Evol. 14 (11), 450-453.

MCOR (Marcellus Center for Outreach and Research), 2016. Tri-State Unconventional Shale Wells (PA, WV, OH). [Online] http://www.marcellus.psu.edu/resources/maps. php (Last updated December 31, 2015. Accessed Mar.15, 2016).

Mutter, M., Pavlacky, D.C., Van Lanen, N.J., Grenyer, R., 2015. Evaluating the impact of gas extraction infrastructure on the occupancy of sagebrush-obligate songbirds. Ecol. Appl. 25 (5), 1175-1186.

National Audubon Society, 2013. Important Bird Area Reports: Lewis Wetzel Wildlife Management Area. [Online] http://netapp.audubon.org/IBA/Reports/3447.

O'Connell, T.J., Jackson, L.E., Brooks, R.P., 2000. Bird guilds as indicators of ecological condition in the central Appalachians. Ecol. Appl. 10, 1706-1721.

Perkins, K.A., Wood, P.B., 2014. Selection of forest canopy gaps by male cerulean warblers in West Virginia. Wilson J. Ornithol. 126 (2), 288-297.

Pimm, S.L., Askins, R.A., 1995. Forest losses predict bird extinctions in Eastern North America. Proc. Natl. Acad. Sci. U. S. A. 92 (20), 9343-9347.

Purcell, K.L., Thompson, C.M., Drynan, D.A., 2012. Response of brown creepers to elevation and forest edges in the southern Sierra Nevada, California. Condor 114 (1), 185-196.

R Core Team, 2014. R: A Language and Environment for Statistical Computing. R Foundation for Statistical Computing, Vienna, Austria ([Online] http://www.Rproject.org/).

Rabin, L.A., McCowan, B., Hooper, S.L., Owings, D.H., 2003. Anthropogenic noise and its ef fect on animal communication: an interface between comparative psychology and conservation biology. Int. J. Comp. Psychol. 16, 172-192.

Ralph, C.J., Droege, S., Sauer, J.R., 1995. Managing and monitoring birds using poin counts: standards and applications. In: Ralph, C.J., Sauer, J.R., Droege, S. (Eds.), Monitoring Bird Populations by Point Counts. Gen.Tech.Rep.PSW-GTR-149. U.S. Department of Agriculture, Forest Service, Pacific Southwest Research Station, Albany, California, pp. 161-168.

Rempel, R.S., Baker, J., Elkie, P.C., Gluck, M.J., Jackson, J., Kushneriuk, R.S., Moore, T., Perera, A.H., 2007. Forest policy scenario analysis: sensitivity of songbird community to changes in forest cover amount and configuration. Avian Conserv. Ecol. 2 (1), 5

Robbins, C.S., Dawson, D.K., Dowell, B.A., 1989. Habitat area requirements of breeding forest birds of the Middle Atlantic States. Wildl. Monogr. 103, 3-34.

Robinson, S.K., Thompson III, F.R., Donovan, T.M., Whitehead, D.R., Faaborg, J., 1995. Regional forest fragmentation and the nesting success of migratory birds. Science 267, 1987-1990.

Sauer, J.R., Hines, J.E., Fallon, J.E., Pardieck, K.L., Ziolkowski, D.J., Link, W.A., 2014. The North American Breeding Bird Survey, Results and Analysis 1966-2013 version 01.30.2015. USGS Patuxent Wildlife Research Center, Laurel, Maryland ([Online] http://www. mbr-pwrc.usgs.gov/bbs/. Accessed Mar.15, 2016)

Schmiegelow, F.K.A., Machtans, C.S., Hannon, S.J., 1997. Are boreal birds resilient to forest fragmentation? An experimental study of short-term community responses. Ecology 78 (6), 1914-1932.

Schroeder, J., Nakagawa, S., Cleasby, I.R., Burke, T., 2012. Passerine birds breeding under chronic noise experience reduced fitness. PLoS One 7 (7), e39200.
Sheehan, J., Wood, P.B., Buehler, D.A., Keyser, P.D., Larkin, J.L., Rodewald, A.D., Wigley, T.B., Boves, T.J., George, G.A., Bakermans, M.H., Beachy, T.A., Evans, A., McDermott, M.E., Newell, F.L., Perkins, K.A., White, M., 2014. Avian response to timber harvesting applied experimentally to manage cerulean warbler breeding populations. For. Ecol. Manag. 321, 5-18.

Skaug, H., Fournier, D., Nielsen, A., 2006. glmmADMB: generalized linear mixed models using AD Model Builder. R package version 0.3. http://glmmadmb.r-forge.r-project. org.

Smith, A.C., Fahrig, L., Francis, C.M., 2011. Landscape size affects the relative importance of habitat amount, habitat fragmentation, and matrix quality on forest birds. Ecography 31 (1), 103-113.

Sólymos, P., Matsuoka, S.M., Bayne, E.M., Lele, S.R., Fontaine, P., Cummings, S.G., Stralberg, D., Schmiegelow, F.K.A., Song, S.J., 2013. Calibrating indices of avian density from nonstandardized survey data: making the most of a messy situation. Methods Ecol. Evol. 4 (11), 1047-1058

Sólymos, P., Moreno, M., Lele, S.R., 2016. Detect: analyzing wildlife data with detection error. R package version 0.4-0. https://CRAN.R-project.org/package=detect.

Souther, S., Tingley, M.W., Popescu, V.D., Hayman, D.T.S., Ryan, M.E., Graves, T.A., Harth, B. Terrell, K., 2014. Biotic impacts of energy development from shale: research priorities and knowledge gaps. Front. Ecol. Environ. 12 (6), 330-338.

Steele, M.A., Brittingham, M.C., Maret, T.J., Merritt, J.F., 2010. Terrestrial Vertebrates of Pennsylvania: A Complete Guide to Species of Conservation Concern. Johns Hopkins University Press, Baltimore, MD.

Thomas, E.H., Brittingham, M.C., Stoleson, S.H., 2014. Conventional oil and gas development alters forest songbird communities. J. Wildl. Manag. 78 (2), 293-306.

Thompson, S.J., Johnson, D.H., Niemuth, N.D., Ribic, C.A., 2015. Avoidance of unconventional oil wells and roads exacerbates habitat loss for grassland birds in the North American great plains. Biol. Conserv. 192, 82-90.

U.S. Fish and Wildlife Service, 2008. Birds of Conservation Concern 2008. United States Department of Interior, Fish and Wildlife Service, Division of Migratory Bird Management, Arlington, Virginia ([Online] http://www.fws.gov/migratorybirds/).

Verner, J., 1984. The guild concept applied to management of bird populations. Environ. Manag. 8, 1-13.

Weldon, A.J., Haddad, N.M., 2005. The effects of patch shape on indigo buntings: evidence for an ecological trap. Ecology 86 (6), 1422-1431.

Whitaker, D.M., Carroll, A.L., Montevecchi, W.A., 2000. Elevated numbers of flying insects and insectivorous birds in riparian buffer strips. Can. J. Zool. 78 (5), 740-747.

Whitcomb, R.F., Robbins, C.S., Lynch, J.F., Klimkiewicz, B.L., Bystrak, D., 1981. Effects of forest fragmentation on avifauna of the eastern deciduous forest. In: Burgess, R.L., Sharpe, D.M. (Eds.), Forest Island Dynamics in Man-dominated Landscapes. Springer-Verlag, New York, pp. 125-206.

Wiens, J.A., Rotenberry, J.T., Van Horne, B., 1997. Habitat occupancy patterns of North American shrubsteppe birds: the effects of spatial scale. Oikos 48 (2), 132-147.

Wood, P.B., Bosworth, S., Dettmers, R., 2006. Cerulean warbler abundance and occurrence relative to large-scale edge and habitat characteristics. Condor 108, 154-165.

WVDEP (West Virginia Department of Environmental Protection), 2015n. Oil and Gas Permits. [Online] https://apps.dep.wv.gov/oog/permitsearch_new.cfm.

WVGES (West Virginia Geological and Economic Survey), 2015. WV Marcellus Shale Wells: Completed, Permitted, and Cancelled Episodes. [Online] http://www.wvgs. wvnet.edu/www/datastat/devshales.htm.

Yahner, R.H., Ross, B.D., Yahner, R.T., Hutnik, R.J., Liscinsky, S.A., 2004. Long-term effects of rights-of-way maintenance via the wire-border zone method on bird nesting ecology. J. Arboric. 30 (5), 288-294.

Zuur, A.F., Ieno, E.N., Elphick, C.S., 2010. A protocol for data exploration to avoid common statistical problems. Methods Ecol. Evol. 1, 3-14.

Zuur, A.F., Ieno, E.N., Walker, N.J., Saveliev, A.A., Smith, G.M., 2009. Mixed Effects Models and Extensions in Ecology with R. Springer, New York. 


\section{CHAPTER 3. \\ PROXIMITY TO SHALE GAS INFRASTRUCTURE AFFECTS BREEDING SONGBIRD ABUNDANCE AND DISTRIBUTION}

\section{Introduction}

The Marcellus-Utica shale region has seen a boom in drilling for unconventional shale gas in the last decade, due to advances in horizontal drilling and hydraulic fracturing technologies (i.e., fracking; USEIA 2018). Although this method of extracting natural gas from deep shale formations is relatively novel in the central Appalachian region, there is growing evidence that forest loss and fragmentation associated with unconventional shale gas development is negatively impacting interior forests in the region (Drohan et al. 2012, Langlois et al. 2017) and altering the composition of avian communities (Barton et al. 2014, Farwell et al. 2016, Langlois 2017). Understanding how animals react spatially to unconventional shale gas infrastructure within forested environments is a key step in predicting how wildlife populations will respond to large-scale land use change, driven by this emerging form of energy development.

Although unconventional shale gas development occupies a relatively small overall footprint on the landscape, much of the development is occurring in core forest areas and pipelines and access roads, in particular, are causing extensive forest fragmentation (Farwell et al. 2016, Langlois et al. 2017, Farwell et al. 2018-in review). Recent studies have shown that unconventional shale gas development is negatively affecting abundance and diversity of areasensitive, forest interior birds (Barton et al. 2016, Farwell et al. 2016, Langlois 2017), as well as reproductive success of a forest interior, riparian obligate species (Frantz et al. 2018). At the same time, some early successional and synanthropic species appear to benefit from forest disturbance due to shale gas development (Barton et al. 2016, Farwell et al. 2016, Langlois 2017). To complicate the issue further, some forest interior species are naturally drawn to small 
canopy openings, and clearings and edge habitat created by anthropogenic disturbance can mimic natural canopy openings and then function as ecological traps (Battin 2004, Weldon and Haddad 2005, Boves et al. 2013).

To evaluate spatial responses of breeding songbirds to forest disturbance due to shale gas development, we assessed the relationship between bird abundances and distance from shale gas infrastructure, at a long-term study site in northern West Virginia. We also created annual interpolated distribution maps for four focal species, to visualize the spatial relationship between bird abundances and locations of shale gas infrastructure. Our objective was to determine if proximity to shale gas development influenced patterns in songbird abundance and species distributions across the landscape. Our results will help quantify the spatial impacts of unconventional shale gas infrastructure on birds, and may help define spatially explicit management objectives for species in landscapes undergoing shale gas development.

\section{Methods}

\subsection{Study area}

Lewis Wetzel Wildlife Management Area (LWWMA) is located in northern West Virginia and overlies the Marcellus and Utica shale gas basins (Fig. 1). Approximately two-thirds of the LWWMA surface area (4,326 ha) was selected for study, with work focusing on the majority of ridges and $50.4 \mathrm{~km}$ of $1^{\text {st }}$-and $2^{\text {nd }}$-order tributary streams (Fig. 1). Unconventional shale gas development began at the site in 2007 and expanded steadily from 2008 to 2015. Although activity has slowed at the site with no new wells drilled since 2014, existing wells continue to produce gas at the site, and a large permitted well pad area and access road were cleared in 2015. As of 2017, the site remains predominantly (90.0\%) forested, but has been heavily fragmented 
by the construction of gas well pads and, to a greater extent, by the proliferation of new pipeline corridors (Farwell et al. 2016).

\subsection{Land cover mapping and distance metrics}

We mapped annual changes in land cover at the site from 2008 to 2017, using a combination of leaf-off and leaf-on aerial imagery (see Appendix A for a list of image sources). Changes in land cover were manually digitized in a GIS on an annual basis and categorized according to type of disturbance. For analyses in this paper we focused on land cover changes driven by unconventional shale gas development because they were the primary drivers of change at the site and categorized these into impacts associated with drilling sites or "well pads" (i.e., pads, buffers, fluid impoundments, storage areas), versus linear forms of infrastructure (i.e., pipelines, new and expanded access roads). We then calculated distances from avian sampling points to nearest shale gas development annually, using the 'near' function in ArcGIS 10.4 (ESRI 2016). We also specified the type of nearest shale gas infrastructure, with separate categories for development associated with well pads versus linear infrastructure.

\subsection{Avian surveys and detection probability}

From 2008 to 2017, we conducted standard, 10-min avian point count surveys (Bibby et al. $1992)$ at 142 survey stations located on ridges $(n=87)$ and along streams $(n=55)$. We placed stations systematically in a GIS along the tops of ridges and along streams, at approximately 250 m intervals (Fig. 1). This minimum distance between points was selected to avoid counting individual birds at more than one station. Each point was typically surveyed twice per breeding season, although we were unable to conduct second within-season surveys at four points due to noise interference and were unable to survey one point at all in 2014, due to constant noise from 
construction and drilling. We conducted a total of 2,834 surveys during 2008-2017 and used maximum counts from within-year visits $(n=1,419)$ to minimize observer effects and false zeros (Ralph et al. 1995). We also restricted our data to observations within a 50-m radius to further reduce observer effects and potential inconsistencies in distance estimation (Alldredge et al. 2007). Over the course of the study, 35 observers proficient in regional bird identification and distance estimation conducted surveys; 13 conducted surveys in multiple years and five observers completed $60.1 \%$ of all counts.

We conducted surveys between 18 May and 5 July, from sunrise until $4 \mathrm{~h}$ after sunrise on mornings with suitable weather and environmental conditions. First detections of birds were recorded within 7 time intervals $(0-2,>2-3,>3-4,>4-5,>5-6,>6-7,>7-10 \mathrm{~min})$ and 2 distance bands $(0-25,>25-50)$, for estimation of detection probability using a combined removal and distance sampling method (Sólymos et al. 2013). This method provides conditional likelihood estimates for availability and perceptibility, the two components of detectability (Sólymos et al. 2013). We included serial date, time-since-sunrise, and quadratic terms of each as survey-level covariates potentially influencing availability (probability that a bird will sing). We included observer experience level (on a scale of 1-5) and tree cover surrounding each point as survey-level covariates potentially influencing perceptibility (probability that a bird will be detected if it sings). Tree cover was measured as percent forest cover within 100-m radius buffers of each point and was calculated in Fragstats v. 4 (McGarigal et al. 2012) using annual land cover maps.

Excluding non-breeding migrants and species only observed once during the 10-year study, we detected a total of 79 species of passerines and near-passerines within $50 \mathrm{~m}$ of our sampling points. Based on trial-and-error, and as shown in Sólymos et al. (2013), we found that 
approximately 75 detections were sufficient to run detection probability models and subsequent analyses. Of the 36 species with $\geq 75$ detections, 27 were passerines that fell within three avian habitat guilds likely to be affected by human development (Thomas et al. 2014, Farwell et al. 2016). Forest interior birds are typically found in large areas of mature forest $(n=16)$, early successional birds prefer recently disturbed, shrubby habitat $(n=6)$, and synanthropic birds thrive in human-modified environments $(n=5)$. These were the 26 focal species included in our analyses, many of which are species of high conservation priority (Table 1).

\subsection{Data analysis and interpolation}

For each focal species, we fitted 9 removal models and 4 distance sampling models, including intercept-only models (Appendix B), using the package 'detect' (Sólymos et al. 2016) in program $\mathrm{R}$ version 3.4.1 (R Core Team 2017). Fitted models with lowest AIC values were selected for each species and used to calculate correction factors to account for detection probability (Sólymos et al. 2013). To relate focal species abundances to distance from shale gas development, we used generalized linear mixed models (GLMM) with a Poisson distribution and $\log$ link, in the R program package 'lme4' (Bates et al. 2015). During exploratory data analysis, we checked abundance data for overdispersion and zero-inflation (Zuur et al. 2010). Blue jays (see Table 1 for scientific names of species) were the only species with slight zero-inflation; a comparison of log-likelihood ratios revealed negative binomial models were a better fit than Poisson models, so for blue jays we used a negative binomial distribution (White and Bennetts 1996). We included point and year as random effects, to account for variation associated with repeated measures (Zuur et al. 2009) and applied species-specific correction factors for detection error as custom offsets (Sólymos et al. 2013). 
To visualize and compare examples of species distributions across the study area relative to locations of shale gas development, we derived spatially continuous distribution probability maps for four focal species in GIS, using a kriging approach. We selected four species representing a range of habitat preferences and resource needs (Ehrlich et al. 1988, Rodewald 2015). Ovenbirds are an area-sensitive species that breeds in extensive, closed-canopy forests with open understory and deep leaf litter. Cerulean warblers are also associated with large areas of mature forest but are known to prefer small canopy gaps and openings within extensive forests (Wood et al. 2006, Boves et al. 2013). Indigo buntings are an early successional species typically found in shrubby, weedy habitats between forests and open areas. Brown-headed cowbirds are synanthropic nest parasites that are attracted to human disturbances and linear corridors, in particular (Gates and Evans 1998, Howell et al. 2007), and have been implicated in declines of species of conservation concern (Eckrich et al. 1999, Kus 1999, DeCapita 2000).

Kriging is a family of regionalized variable interpolation techniques based on regression against observed values of surrounding data points, weighted according to spatial covariance values (Li and Heap 2008). Indicator kriging (IK) is a non-parametric approach that transforms continuous data to binary values that indicate membership to classes, based on observed values within a defined neighborhood (Li and Heap 2008). Although IK is often used in ecological studies because it does not assume normality, a disadvantage of IK is that it cannot be used to generate predictive maps of species abundance (Walker et al. 2007). Rather, IK maps species distributions based on probability species occurrence data. Probability of occurrence maps are not suitable for accurate estimation of animal densities, but can still be used as indices of relative abundance to evaluate patterns of species distributions (Walker et al. 2007, Melles et al. 2011, Polakowska et al. 2012). During preliminary, exploratory data analysis of abundance data from 
2008-2016, we compared performance of IK with two other interpolation methods: ordinary kriging and inverse distance weighting ( $\mathrm{Li}$ and Heap 2008, Abdi and Nandipati 2009). However, we found that IK consistently out-performed the other two interpolation methods evaluated, and thus used IK to interpolate distribution probability maps for focal species (see Appendix C for cross-validation results from the three interpolation methods).

\section{Results}

\subsection{Avian response to distance from gas development}

Over the ten-year study period, shale gas development steadily expanded at the study site and encroached on interior forest habitat. At the start of the study in 2008, the mean distance from avian sampling points to the closest shale gas development was $901.8 \mathrm{~m}$ (range $=0.0-2645.5 \mathrm{~m})$, and only $12 \%$ of points fell within $100 \mathrm{~m}$ of shale gas infrastructure. Ten years later in 2017 , the mean distance to closest shale gas dropped to $333.7 \mathrm{~m}($ range $=0.0-2026.6 \mathrm{~m})$ and $43 \%$ of points fell within $100 \mathrm{~m}$ of shale gas infrastructure.

Within the forest interior guild, eight of 16 focal species evaluated showed a significant response to distance from shale gas development (Table 1). Black-throated green warblers, ovenbirds, and red-eyed vireos occurred in higher numbers with increasing distance from all types of shale gas infrastructure, while hooded warblers increased further from well pads and wood thrushes increased further from linear infrastructure. Conversely, three forest interior species showed a negative response to distance from gas, indicating they occurred in higher numbers closer to development. Eastern wood pewees occurred in higher numbers near all types of shale gas development, while American redstarts had higher abundances near gas well pads and cerulean warblers had higher abundances near linear infrastructure. 
Within the early successional guild, only two of six species evaluated showed a significant response to distance from gas: common yellowthroats were more abundant near all types of shale gas development, while indigo buntings had higher abundances closer to linear infrastructure, specifically. Within the synanthropic guild, four of five human-adapted species we evaluated showed significant responses to distance from gas. Three species occurred in higher abundances closer to all three categories of shale gas development tested. Only blue jays showed a positive response, and had higher abundances with increasing distance from gas infrastructure.

\subsection{Focal species distribution probability maps}

Since the start of the study in 2008 , ovenbirds occurred in high concentrations in the leastdisturbed areas of forest in the eastern and southern regions of the study area (Fig. 2). In 2009, with the construction of a network of well pads, pipelines and access roads in the southern portion of the site, ovenbirds began to shift away from these disturbances. Although we observed year-to-year variation, this general pattern of spatial response continued throughout the course of the study; as shale gas infrastructure continued to expand across the site, ovenbirds typically occurred in highest concentrations in forested areas furthest from development. By the end of the study period in 2017, there is a visible pattern of ovenbird avoidance of shale gas infrastructure at the site. This spatial pattern of response is supported by our statistical models, which showed higher numbers of ovenbirds relative to increasing distance from both shale gas well pads ( $P=$ $0.03)$ and linear infrastructure $(P<0.001)$.

In contrast, cerulean warblers showed a less distinct pattern of spatial response to locations of shale gas infrastructure, over time (Fig. 3). Like ovenbirds, cerulean warblers initially occurred in some of the least disturbed areas of forest at the site. Unlike ovenbirds, however, cerulean warblers also appear more likely to occur in concentrated abundances near shale gas 
development. Starting in 2009, cerulean warblers began to occur in higher abundances near linear shale gas infrastructure, in particular. Again, this is consistent with our statistical models, which showed higher abundances of cerulean warblers closer to pipelines and access roads $(P<$ 0.001), but not gas well pads $(P=0.62)$.

Conversely, at the start of the study in 2008 indigo buntings occurred in high concentrations in the most disturbed areas of forest, in the northern and western regions of the study area (Fig. 4). However, starting in 2009 indigo buntings made their way into the southern portion of the study site, following new shale gas construction. Before much of the linear shale gas infrastructure was constructed at the site, indigo buntings were distributed across most of the site. As linear infrastructure expanded at the site, however, they began gravitating toward it. Throughout the remaining years of the study, indigo buntings clearly occurred in highest concentrations around linear shale gas infrastructure. The spatial distribution of indigo buntings is also supported by statistical models, which showed higher abundances of indigo buntings with increasing proximity to linear shale gas infrastructure $(P=0.01)$.

Lastly, brown-headed cowbirds were only detected at three points at the start of the study in 2008, but their abundance and spatial distribution increased across the site with the expansion of shale gas development (Fig. 5). Brown-headed cowbirds showed a clear pattern of spatial attraction to areas disturbed by shale gas development consistent with higher abundances near both well pads $(P<0.0001)$ and linear infrastructure $(P<0.0001)$.

\section{Discussion}

More than half of the species we evaluated were sensitive to proximity to shale gas development, and among these we found more negative than positive responses to distance from 
gas infrastructure. A previous study at this site demonstrated that forest interior guild species richness declined over time at points impacted by shale gas development within $100 \mathrm{~m}$, and that forest interior guild richness was negatively related to percent shale gas cover within $100 \mathrm{~m}$ (Farwell et al. 2016). Most forest interior focal species in the previous study also occurred in lower abundances relative to percent shale gas cover and forest edge density within $100 \mathrm{~m}$ (Farwell et al. 2016). Our results are consistent with this pattern of response among several forest interior focal species, however here we demonstrate that forest interior birds are not just responding to changes in overall habitat amount and configuration within buffers of each sampling point, but are also showing a direct spatial response to distance from shale gas infrastructure. Thus, shale gas development is not just affecting overall avian abundance and community composition but is also altering species distributions across impacted landscapes.

In the previous study, there was also considerable variation in species-specific responses within the forest interior guild, with some forest interior gap specialists showing a positive response to forest edge density within $100 \mathrm{~m}$ (Farwell et al. 2016). The higher abundances we observed among forest interior gap specialists (i.e., American redstarts, cerulean warblers, and eastern wood pewees) in proximity to gas development offers additional evidence that the relatively small canopy openings created by shale gas infrastructure may mimic natural canopy openings and attract these species (Buchanan and Hart 2012, Perkins and Wood 2014).

Our results also indicate that some early successional and synanthropic species show a spatial pattern of attraction to shale gas infrastructure. However, we observed more synanthropic species than early successional species with a clear positive relationship with proximity to shale gas development (both well pads and linear infrastructure). Farwell et al. (2016) also did not find a positive relationship between early successional species abundances and shale gas cover within 
$100 \mathrm{~m}$, at this study site. However, they observed increased abundances of early successional birds relative to increasing forest edge density surrounding sampling points. Our results are consistent with their hypothesis that there is a particular attraction among early successional species to linear infrastructure, which creates a high ratio of edge compared to the footprint of development (Farwell et al. 2016).

Our findings are also consistent with other recent studies of impacts of unconventional shale gas development on breeding birds in the Marcellus shale region, which documented lower abundances of forest interior species and higher abundances of early successional and synanthropic species closer to shale gas well pads (Barton et al. 2016) and pipelines (Langlois 2017) in forests of northcentral Pennsylvania. The patterns we observed are also similar to patterns of songbird response to other comparable forms of anthropogenic forest disturbance. Forest interior birds generally responded negatively to mountaintop mining in the central Appalachians, while early successional birds responded positively and interior edge species showed mixed responses (Becker et al. 2015). In northwestern Pennsylvania, forest interior birds were less abundant at conventional oil and gas well sites compared with reference sites, while early successional and synanthropic species were more abundant (Thomas et al. 2014). Exurban development in the southern Appalachians negatively affected occurrence of forest interior species, and had limited positive effects on shrubland and edge-associated species (Lumpkin and Pearson 2013). In the boreal forests of western Canada, ovenbirds showed a threshold response to seismic line density, and their territories did not cross seismic lines (Bayne et al. 2005).

Our findings underscore the importance of further research on avian demographic rates in areas impacted by shale gas development. Our analyses were limited to species abundance data, but species abundance is not always an accurate measure of habitat quality (Van Horne 1983). 
Forest interior gap specialists such as cerulean warblers occurred in higher numbers near shale gas development, but still showed overall declines in abundance across the site over time (Farwell et al. 2016), which suggests shale gas infrastructure may be functioning as ecological traps (Weldon and Haddad 2005, Boves et al. 2013). This hypothesis is also supported by our finding that human-adapted habitat generalists occurred in higher abundances near shale gas infrastructure, including nest-parasitic brown-headed cowbirds.

\section{Management implications}

Changes in wildlife abundance and diversity in proximity to human development have been well-documented for many forms of development and infrastructure (Benitez-Lopez et al. 2010, Rayner et al. 2015, Richardson et al. 2017). However, the unconventional shale gas industry represents a relatively novel form of energy development and forest disturbance in the central Appalachian region. Here we add to a growing body of research indicating the rapid expansion of shale gas infrastructure in the Marcellus-Utica shale region is affecting forest ecosystems and altering native biological communities. This is not a trivial issue, given the considerable number of new pipelines currently approved or under review for construction (FERC 2018), many of which will bisect remaining areas of interior forest in the central Appalachian region and spur additional development of new well pads, gathering lines, and access roads. Our results suggest efforts to avoid shale gas infrastructure development in core forest areas of high conservation value will help mitigate negative impacts to native songbird communities, in a region with high value for global biodiversity (Gillian and Kiviat 2012, Kiviat 2013). 


\section{Acknowledgments}

This research was funded by the NETL Department of Energy, West Virginia Division of Natural Resources, and U.S. Fish and Wildlife Service. West Virginia Division of Natural Resources granted access to the study area, Wheeling Jesuit University provided access to field housing, and West Virginia Cooperative Fish and Wildlife Research unit provided field vehicles. We thank the many graduate students and field surveyors who collected data over the ten-year study, especially Jim Sheehan and Mack Frantz. Special thanks to Donald Brown, Mike Strager, and Brenden McNeil for input on study design and project feedback. Any use of trade, firm, or product names is for descriptive purposes only and does not imply endorsement by the U.S.

Government.

\section{References}

Abdi, A., and A. Nandipati. 2009. Bird diversity modeling using geostatistics and GIS. $12^{\text {th }}$ AGILE International Conference on Geographic Information Science, $20 \mathrm{pp}$.

Alldredge, M.W., T.R Simons, and K.H. Pollock. 2007. A field evaluation of distance measurement error in auditory avian point count surveys. Journal of Wildlife Management 71(8):2759-2766.

Barton, E.P., S.E. Pabian, and M.C. Brittingham. 2016. Bird community response to Marcellus shale gas development. Journal of Wildlife Management 80:1301-1313.

Bates, D., M. Maechler, B. Bolker, and S. Walker. 2015. Fitting linear mixed-effects models using lme4. Journal of Statistical Software 67(1):1-48.

Battin, J. 2004. When good animals love bad habitats: ecological traps and the conservation of animal populations. Conservation Biology 18(6):1482-1491.

Bayne, E.M., S.L. Van Wilgenburg, S. Boutin, and K.A. Hobson. 2005. Modeling and fieldtesting of Ovenbird (Seiurus aurocapillus) responses to boreal forest dissection by energy sector development at multiple spatial scales. Landscape Ecology 20:203-216.

Becker, D.A., P.B. Wood, M.P. Strager, and C. Mazzarella. 2015. Impacts of mountaintop mining on terrestrial ecosystem integrity: identifying landscape thresholds for avian species in the central Appalachians, United States. Landscape Ecology 30:339-356.

Benítez-López, A., R. Alkemade, and P.A. Verweij. 2010. The impacts of roads and other infrastructure on mammal and bird populations: a meta-analysis. Biological Conservation 143:1307-1316.

Bibby, C.J., N.D. Burgess, and D.A. Hill. 1992. Bird Census Techniques. Academic Press, London, UK. 
Boves, T.J., D.A. Buehler, J. Sheehan, P.B. Wood, A.D. Rodewald, J.L. Larkin, P.D. Keyser, F.L. Newell, G.A. George, M.H. Bakermans, A. Evans, T.A. Beachy, M.E. McDermott, K.A. Perkins, M. White, and T.B. Wigley. 2013. Emulating natural disturbances for declining latesuccessional species: a case study of the consequences for Cerulean Warblers (Setophaga cerulea). PLoS ONE 8(1):e52107.

Buchanan, M.L., and J.L. Hart. 2012. Canopy disturbance history of old-growth Quercus alba sites in the eastern United States: examination of long-term trends and broad-scale patterns. Forest Ecology and Management 267:28-39.

DeCapita, M.E. 2000. Brown-headed cowbird control on Kirtland's warbler nesting areas in Michigan, 1972-1995. Pages 333-341 in J.N.M. Smith, T.L. Cook, S.I. Rothstein, S.K. Robinson, and S.G. Sealy (Eds.). Ecology and management of cowbirds and their hosts: studies in the conservation of North American passerine birds. University of Texas Press, Austin, Texas, USA.

Drohan, P.J., M.C. Brittingham, and J. Bishop. 2012. Early trends in landcover change and forest fragmentation due to shale-gas development in Pennsylvania: a potential outcome for the northcentral Appalachians. Environmental Management 49:1061-1075.

Eckrich, G.H., J.A. Koloszar, and M.D. Goering. 1999. Effective landscape management of brown-headed cowbirds at Fort Hood, Texas. Studies in Avian Biology 18:267-274.

Ehrlich, P.R., D.S. Dobkin, and D. Wheye. 1988. The Birder's Handbook: a Field Guide to the Natural History of North American Birds. Simon \& Schuster, New York.

ESRI (Environmental Research Systems Institute). 2016. ArcGIS Desktop: Release 10.4. Redlands, CA, USA.

Farwell, L.S., P.B. Wood, J. Sheehan, and G.A. George. 2016. Shale gas development effects on the songbird community in a central Appalachian forest. Biological Conservation 201:78-91.

Farwell, L.S., P.B. Wood, R. Dettmers, and M.C. Brittingham. 2018 (in review). Region-wide impacts of Marcellus-Utica shale gas development on forest songbirds.

FERC (Federal Energy Regulatory Commission). 2018. Approved major natural gas pipeline projects. < https://www.ferc.gov/industries/gas/indus-act/pipelines/approved-projects.asp> Accessed May 2018.

Frantz, M.W., P.B. Wood, J. Sheehan, and G.A. George. 2018. Demographic response of Louisiana waterthrush, a stream obligate songbird of conservation concern, to shale gas development. Condor 120(2):265-282.

Gates, J.E., and D.R. Evans. 1998. Cowbirds breeding in the central Appalachians: spatial and temporal patterns and habitat selection. Ecological Applications 8(1):27-40.

Gillen, J.L., and E. Kiviat. 2012. Hydraulic fracturing threats to species with restricted geographic ranges in the Eastern United States. Environmental Practice 14:320-331.

Howell, C.A., W.D. Dijak, and F.R. Thompson. 2007. Landscape context and selection for forest edge by breeding brown-headed cowbirds. Landscape Ecology 22(2):273-284.

Kiviat, E. 2013. Risks to biodiversity from hydraulic fracturing for natural gas in the Marcellus and Utica shales. Annals of the New York Academy of Sciences 1286:1-14. 
Kus, B.E. 1999. Impacts of brown-headed cowbird parasitism on productivity of the endangered Least Bell's Vireo. Studies in Avian Biology 18:160-166.

Langlois, L.A. 2017. Effects of Marcellus shale gas infrastructure on forest fragmentation and bird communities in northcentral Pennsylvania. Dissertation, Pennsylvania State University, State College, USA.

Langlois, L.A., P.J. Drohan, and M.C. Brittingham. 2017. Linear infrastructure drives habitat conversion and forest fragmentation associated with Marcellus shale gas development in a forested landscape. Journal of Environmental Management 197:167-176.

Li, J., and A.D. Heap. 2008. A Review of Spatial Interpolation Methods for Environmental Scientists. Geoscience Australia, Record 2008/23, 137 pp.

Lumpkin, H.A., and S.M. Pearson. 2013. Effects of exurban development and temperature on bird species in the southern Appalachians. Conservation Biology 27(5):1069-1078.

McGarigal, K., S.A. Cushman, and E. Ene. 2012. FRAGSTATS v4: Spatial Pattern Analysis Program for Categorical and Continuous Maps. University of Massachusetts, Amherst. Amherst, MA. <http://www.umass.edu/landeco/research/fragstats/fragstats.html> Accessed Jul 2017.

Melles, S.J, M.-J. Fortin, K. Lindsay, and D. Badzinski. 2011. Expanding northward: influence of climate change, forest connectivity, and population processes on a threatened species' range shift. Global Change Biology 17:17-31.

Perkins, K.A., and P.B. Wood. 2014. Selection of forest canopy gaps by male cerulean warblers in West Virginia. Wilson Journal of Ornithology 126:288-297.

Polakowska, A.E., M.-J. Fortin, and A. Couturier. 2012. Quantifying the spatial relationship between bird species' distributions and landscape feature boundaries in southern Ontario, Canada. Landscape Ecology 27:1481-1493.

Ralph, C.J., S. Droege, and J.R. Sauer. 1995. Managing and monitoring birds using point counts: standards and applications. In: Ralph, C.J., J.R. Sauer, and S. Droege (Eds.), Monitoring bird populations by point counts. Gen.Tech.Rep.PSW-GTR-149. Albany, California: U.S. Department of Agriculture, Forest Service, Pacific Southwest Research Station, pp.161-168.

Rayner, L., K. Ikin, M.J. Evans, P. Gibbons, D.B. Lindenmayer, and A.D. Manning. 2015. Avifauna and urban encroachment in time and space. Diversity and Distributions 21(4):428440.

Richardson, M.L., B.A. Wilson, D.A.S. Aiuto, J.E. Crosby, A. Alonso, F. Dallmeier, and G.K. Golinski. 2017. A review of the impact of pipelines and power lines on biodiversity and strategies for mitigation. Biodiversity and Conservation 26(8):1801-1815.

Rodewald, P.G. (Ed.). 2015. The birds of North America. Cornell Laboratory of Ornithology, Ithaca, New York, USA.

Sólymos, P., S.M. Matsuoka, E.M. Bayne, S.R. Lele, P. Fontaine, S.G. Cummings, D. Stralberg, F.K.A. Schmiegelow, and S.J. Song. 2013. Calibrating indices of avian density from nonstandardized survey data: making the most of a messy situation. Methods in Ecology and Evolution 4:1047-1058 
Sólymos, P., M. Moreno, and S.R. Lele. 2016. detect: Analyzing wildlife data with detection error. R package version 0.4-0.

Thomas, E.H., M.C. Brittingham, and S.H. Stoleson. 2014. Conventional oil and gas development alters forest songbird communities. Journal of Wildlife Management 78:293306.

USEIA (U.S. Energy Information Administration). 2018. Annual energy outlook. <https://www.eia.gov/outlooks/aeo/> Accessed Feb 2018.

Van Horne, B. 1983. Density as a misleading indicator of habitat quality. Journal of Wildlife Management 47:893-901.

Walker, J.S., R.C. Balling, J.M. Briggs, M. Katti, P.S. Warren, and E.A. Wentz. 2008. Birds of a feather: Interpolating distribution patterns of urban birds. Computers, Environment and Urban Systems 32(1):19-28.

Weldon, A.J., and N.M. Haddad. 2005. The effects of patch shape on indigo buntings: evidence for an ecological trap. Ecology 86(6):1422-1431.

White, G.C., and R.E. Bennetts. 1996. Analysis of frequency count data using the negative binomial distribution. Ecology 77:2549-2557.

Wood, P.B., S. Bosworth, and R. Dettmers. 2006. Cerulean warbler abundance and occurrence relative to large-scale edge and habitat characteristics. Condor 108:154-165.

Zuur, A.F., E.N. Ieno, N.J. Walker, A.A. Saveliev, and G.M. Smith. 2009. Mixed Effects Models and Extensions in Ecology with R. Springer, New York.

Zuur, A.F., E.N. Ieno, and C.S. Elphick. 2010. A protocol for data exploration to avoid common statistical problems. Methods in Ecology and Evolution 1:3-14. 
Figure 1. Example of a manually digitized land cover map for the study site, from 2012. Dots represent point count locations on ridges (black) and streams (blue). White star in the inset map represents the location of the study site; shaded red area shows the extent of the Marcellus shale formation.

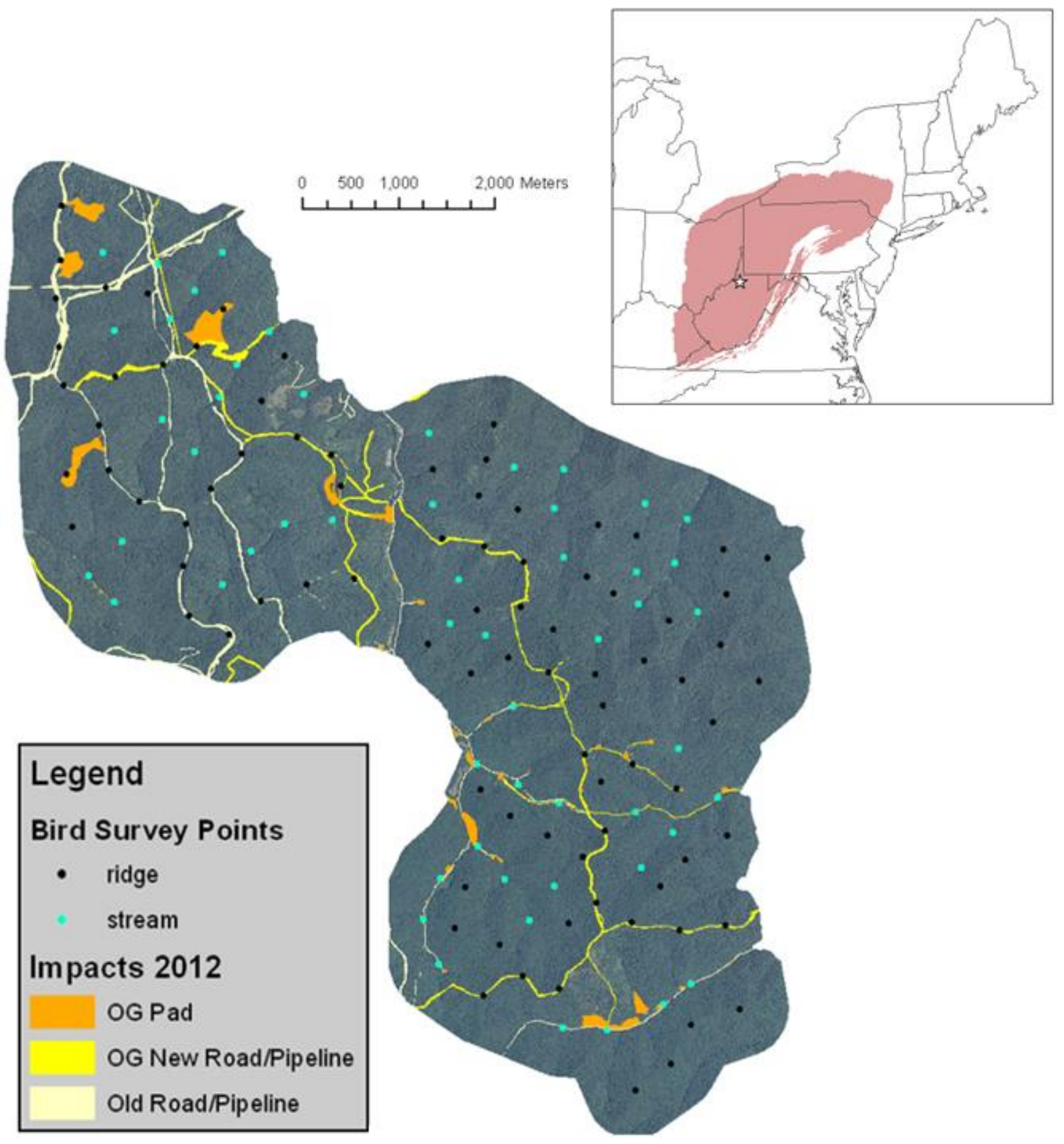


Table 1. Relationships between species abundance and distance to shale gas, shown for all shale gas combined, and grouped separately by closest type of infrastructure: gas well pads v. linear gas infrastructure. Positive estimates indicate higher abundances with increasing distance from shale gas. Significant responses are in bold $(\alpha=0.05)$.

\begin{tabular}{|c|c|c|c|c|c|c|c|c|c|c|c|c|c|}
\hline \multirow[b]{2}{*}{ Habitat guild } & \multirow[b]{2}{*}{ Species } & \multicolumn{4}{|c|}{ All shale gas combined } & \multicolumn{4}{|c|}{ Gas well pads } & \multicolumn{4}{|c|}{ Linear gas infrastructure } \\
\hline & & Est. & SE & $z$ & $P$ & Est. & SE & $z$ & $P$ & Est. & SE & $z$ & $P$ \\
\hline $\begin{array}{l}\text { Forest } \\
\text { interior }\end{array}$ & $\begin{array}{l}\text { Acadian flycatcher } \\
\text { Empidonax virescens }\end{array}$ & 0.01 & 0.07 & 0.19 & 0.85 & 0.004 & 0.14 & 0.03 & 0.97 & 0.05 & 0.08 & 0.66 & 0.51 \\
\hline \multirow[t]{15}{*}{ guild } & $\begin{array}{l}\text { American redstart } \\
\text { Setophaga ruticilla }\end{array}$ & -0.09 & 0.05 & -1.71 & 0.09 & -0.23 & 0.08 & -2.70 & 0.01 & -0.03 & 0.06 & -0.41 & 0.68 \\
\hline & $\begin{array}{l}\text { Black-and-white warbler' } \\
\text { Setophaga caerulescens }\end{array}$ & -0.05 & 0.05 & -1.02 & 0.31 & 0.06 & 0.06 & 1.07 & 0.28 & -0.12 & 0.06 & -1.84 & 0.07 \\
\hline & $\begin{array}{l}\text { Black-throated green warbler } \\
\text { Setophaga virens }\end{array}$ & 0.20 & 0.10 & 2.04 & 0.04 & 0.12 & 0.18 & 0.68 & 0.50 & 0.14 & 0.10 & 1.34 & 0.18 \\
\hline & $\begin{array}{l}\text { Blue-headed vireo } \\
\text { Vireo solitarius }\end{array}$ & 0.04 & 0.09 & 0.38 & 0.70 & -0.11 & 0.17 & -0.69 & 0.49 & -0.03 & 0.11 & -0.23 & 0.82 \\
\hline & $\begin{array}{l}\text { Cerulean warbler } \\
\text { Setophaga cerulea }\end{array}$ & -0.19 & 0.06 & -3.01 & 0.003 & -0.05 & 0.09 & -0.50 & 0.62 & -0.20 & 0.08 & -2.63 & 0.01 \\
\hline & $\begin{array}{l}\text { Eastern wood pewee } \\
\text { Contopus virens }\end{array}$ & -0.27 & 0.09 & -2.94 & 0.003 & -0.33 & 0.15 & -2.19 & 0.03 & -0.22 & 0.10 & -2.11 & 0.03 \\
\hline & $\begin{array}{l}\text { Hooded warbler } \\
\text { Setophaga citrina }\end{array}$ & 0.05 & 0.04 & 1.33 & 0.18 & 0.12 & 0.05 & 2.48 & 0.01 & -0.03 & 0.05 & -0.63 & 0.53 \\
\hline & $\begin{array}{l}\text { Kentucky warbler } \\
\text { Geothlypis formosa }\end{array}$ & -0.07 & 0.10 & -0.72 & 0.47 & -0.17 & 0.17 & -0.99 & 0.32 & 0.07 & 0.11 & 0.64 & 0.52 \\
\hline & $\begin{array}{l}\text { Louisiana waterthrush }{ }^{1} \\
\text { Parkesia motacilla }\end{array}$ & -0.11 & 0.11 & -0.98 & 0.33 & -0.33 & 0.18 & -1.84 & 0.07 & -0.03 & 0.14 & -0.20 & 0.85 \\
\hline & $\begin{array}{l}\text { Ovenbird } \\
\text { Seinurus aurocapilla }\end{array}$ & 0.25 & 0.06 & 4.11 & $<0.001$ & 0.18 & 0.08 & 2.23 & 0.03 & 0.30 & 0.08 & 3.56 & $<0.001$ \\
\hline & $\begin{array}{l}\text { Red-eyed vireo } \\
\text { Vireo olivaceus }\end{array}$ & 0.07 & 0.03 & 2.61 & 0.01 & 0.10 & 0.04 & 2.61 & 0.01 & 0.10 & 0.03 & 2.78 & 0.01 \\
\hline & $\begin{array}{l}\text { Rose-breasted grosbeak } \\
\text { Phencticus hidoviciamus }\end{array}$ & 0.09 & 0.07 & 1.25 & 0.21 & 0.16 & 0.10 & 1.63 & 0.10 & 0.03 & 0.08 & 0.32 & 0.75 \\
\hline & $\begin{array}{l}\text { Scarlet tanager } \\
\text { Piranga olivacea }\end{array}$ & 0.02 & 0.04 & 0.54 & 0.59 & 0.10 & 0.05 & 1.88 & 0.06 & 0.003 & 0.05 & 0.06 & 0.95 \\
\hline & $\begin{array}{l}\text { Wood thrush }{ }^{1,2,3} \\
\text { Hylocichla mustelina }\end{array}$ & 0.08 & 0.05 & 1.57 & 0.12 & -0.03 & 0.07 & -0.53 & 0.60 & 0.18 & 0.06 & 2.94 & 0.003 \\
\hline & $\begin{array}{l}\text { Worm-eating warbler }{ }^{1,2} \\
\text { Helmitheros vermivorum }\end{array}$ & 0.05 & 0.09 & 0.55 & 0.58 & -0.04 & 0.11 & -0.37 & 0.71 & 0.12 & 0.11 & 1.15 & 0.25 \\
\hline $\begin{array}{l}\text { Early } \\
\text { successional }\end{array}$ & $\begin{array}{l}\text { Blue-winged warbler }{ }^{1,2} \\
\text { Vermivor a cyanoptera }\end{array}$ & -0.10 & 0.13 & -0.76 & 0.45 & -0.15 & 0.21 & -0.72 & 0.47 & -0.23 & 0.19 & -1.22 & 0.22 \\
\hline \multirow[t]{5}{*}{ guild } & $\begin{array}{l}\text { Common yellowthroat } \\
\text { Geothhypis trichas }\end{array}$ & -0.54 & 0.12 & -4.45 & $<0.001$ & -0.71 & 0.24 & -2.98 & 0.003 & -0.49 & 0.16 & -3.05 & 0.002 \\
\hline & $\begin{array}{l}\text { Eastern towhee } \\
\text { Pipilo erythrophthalmus }\end{array}$ & -0.02 & 0.05 & -0.36 & 0.72 & 0.01 & 0.08 & 0.19 & 0.85 & -0.05 & 0.05 & -0.95 & 0.34 \\
\hline & $\begin{array}{l}\text { Field sparrow }{ }^{1} \\
\text { Spizella pusilla }\end{array}$ & -0.12 & 0.17 & -0.69 & 0.49 & -0.17 & 0.15 & -1.17 & 0.24 & -0.30 & 0.20 & -1.48 & 0.14 \\
\hline & $\begin{array}{l}\text { Gray catbird } \\
\text { Dumetella carolinensis }\end{array}$ & -0.22 & 0.35 & -0.62 & 0.54 & -0.22 & 0.35 & -0.62 & 0.54 & 0.03 & 0.49 & 0.06 & 0.95 \\
\hline & $\begin{array}{l}\text { Indigo bunting } \\
\text { Passerina cyanea }\end{array}$ & -0.19 & 0.08 & -2.52 & 0.01 & -0.16 & 0.14 & -1.11 & 0.27 & -0.25 & 0.10 & -2.48 & 0.01 \\
\hline \multirow[t]{5}{*}{$\begin{array}{l}\text { Synanthropic } \\
\text { guild }\end{array}$} & $\begin{array}{l}\text { American robin } \\
\text { Turdus migratorius }\end{array}$ & -0.26 & 0.08 & -3.25 & 0.001 & -0.31 & 0.13 & -2.50 & 0.01 & -0.21 & 0.10 & -2.22 & 0.03 \\
\hline & $\begin{array}{l}\text { Blue jay } \\
\text { Cyanocitfa cristata }\end{array}$ & 0.18 & 0.07 & 2.51 & 0.01 & 0.20 & 0.07 & 2.99 & 0.003 & 0.19 & 0.07 & 2.80 & 0.01 \\
\hline & $\begin{array}{l}\text { Brown-headed cowbird } \\
\text { Molothrus ater }\end{array}$ & -0.85 & 0.17 & -4.94 & $<0.001$ & -1.12 & 0.16 & -7.16 & $<0.001$ & -0.94 & 0.20 & -4.79 & $<0.001$ \\
\hline & $\begin{array}{l}\text { Chipping sparrow } \\
\text { Spizella passerina }\end{array}$ & -0.92 & 0.17 & -5.53 & $<0.001$ & -0.83 & 0.33 & -2.55 & 0.01 & -0.70 & 0.17 & -4.09 & $<0.001$ \\
\hline & $\begin{array}{l}\text { Northern cardinal } \\
\text { Cardinalis cardinalis }\end{array}$ & -0.01 & 0.08 & -0.17 & 0.87 & 0.03 & 0.11 & 0.29 & 0.77 & -0.11 & 0.10 & -1.03 & 0.31 \\
\hline
\end{tabular}


Figure 2. Annual interpolated distribution probability maps for ovenbirds (Seiurus aurocapilla), based on indicator kriging. GLMMs showed ovenbirds occurred in higher abundance with increasing distance from both shale gas well pads $(P=0.03)$ and linear infrastructure $(P<0.001)$. Darker red areas represent locations with higher indices of abundance. Shale gas infrastructure shown in black, for visual reference.
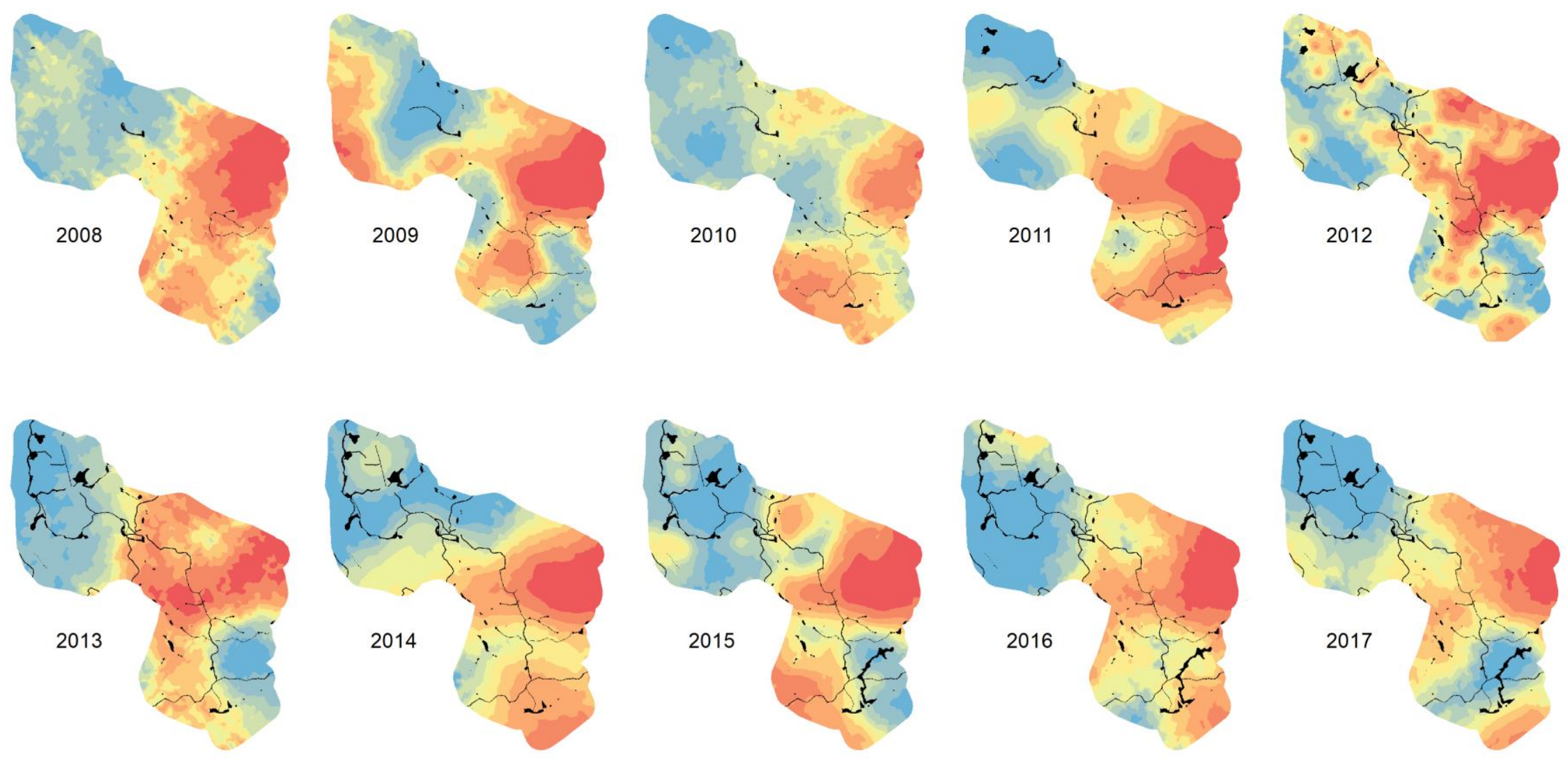
Figure 3. Annual interpolated distribution probability maps for cerulean warblers (Setophaga cerulea), based on indicator kriging. GLMMs showed cerulean warblers had higher abundances in proximity to linear shale gas infrastructure $(P<0.001)$. Darker red areas represent locations with higher indices of abundance. Shale gas infrastructure shown in black, for visual reference.
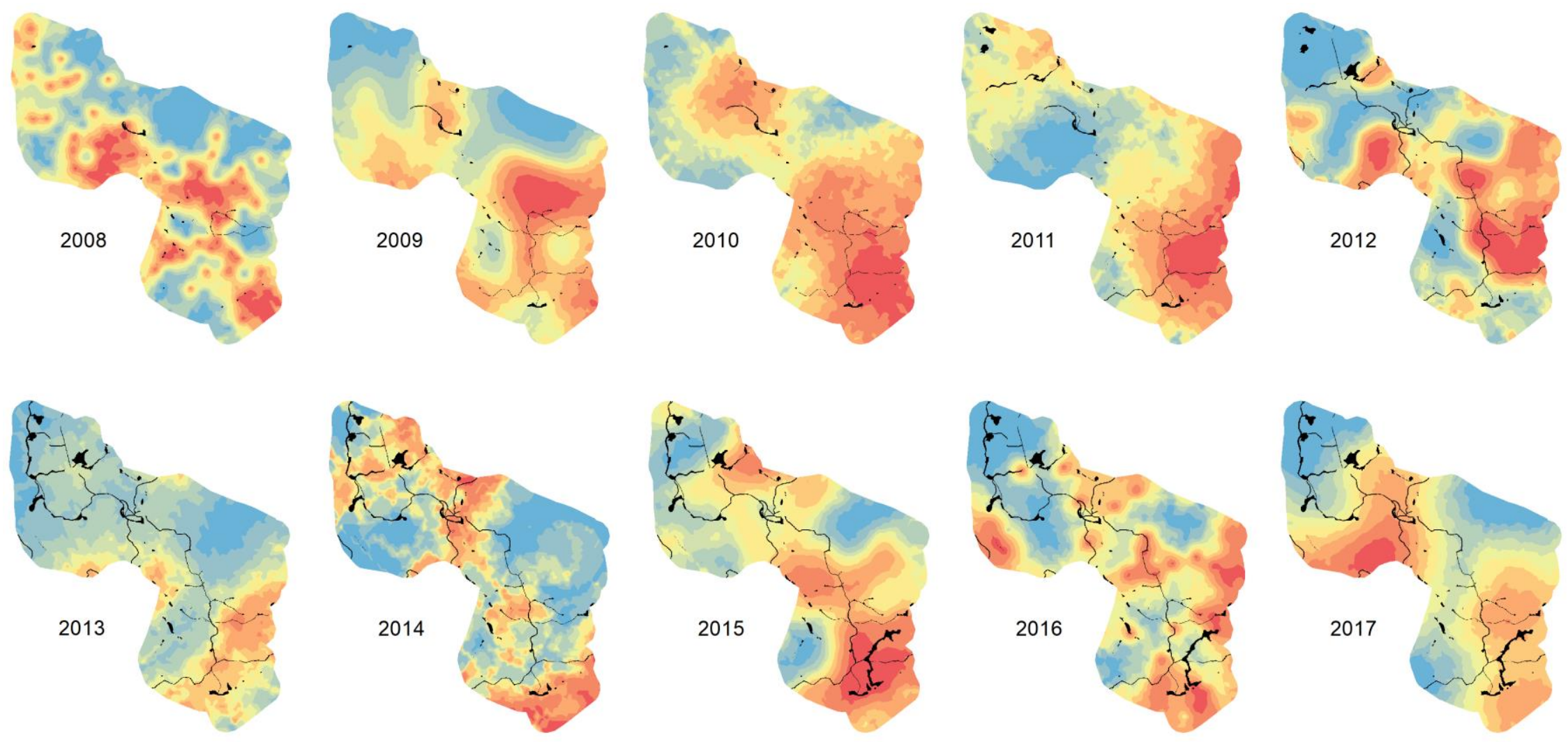
Figure 4. Annual interpolated distribution probability maps for indigo buntings (Passerina cyanea), based on indicator kriging. GLMMs showed indigo buntings occurred in higher abundances $(P=0.01)$ closer to shale gas linear infrastructure, in particular. Darker red areas represent locations with higher indices of abundance. Shale gas infrastructure shown in black, for visual reference.
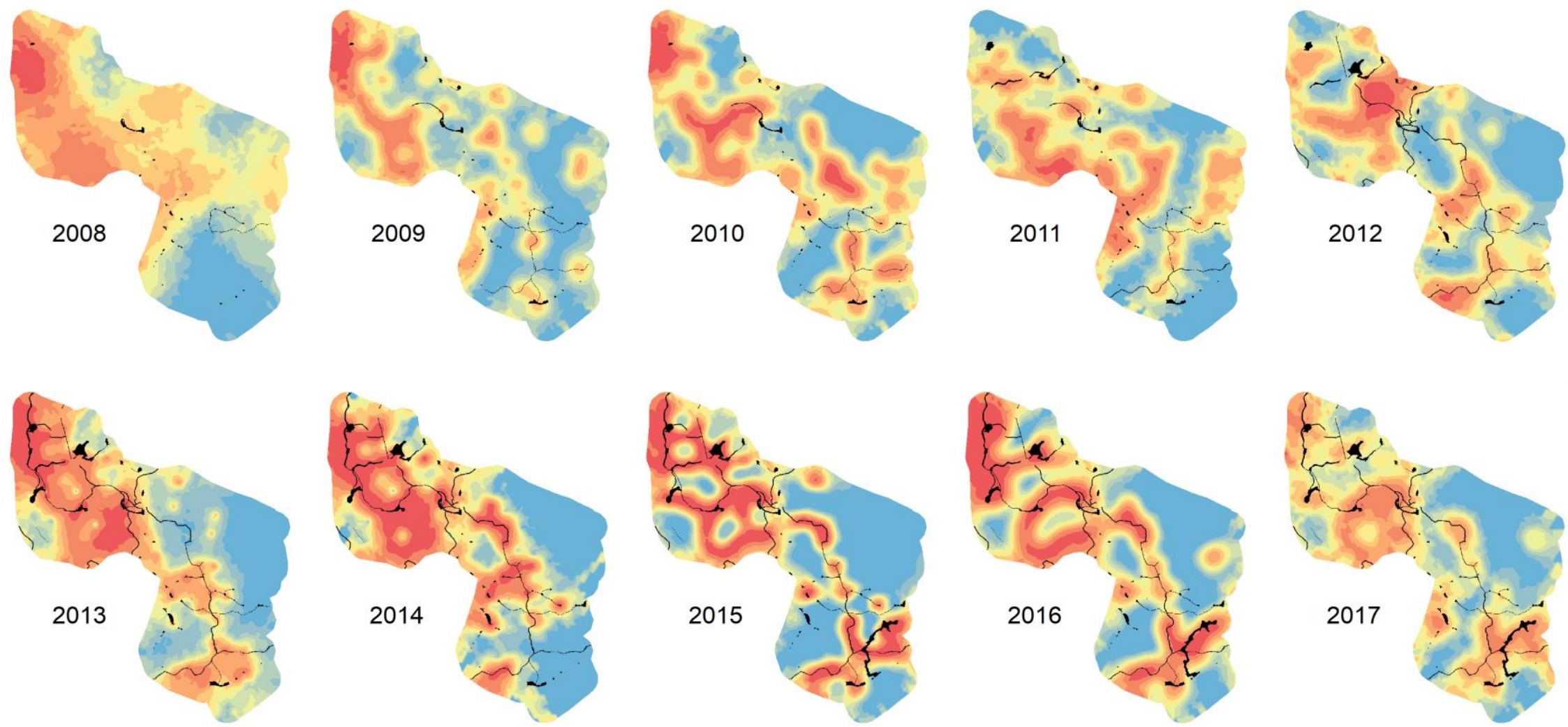
Figure 5. Annual interpolated distribution probability maps for brown-headed cowbirds (Molothrus ater), based on indicator kriging. GLMMs showed brown-headed cowbirds occurred in higher abundances with increasing proximity to both shale gas well pads $(P<$ $0.001)$ and shale gas linear infrastructure $(P<0.001)$. Darker red areas represent locations with higher indices of abundance. Shale gas infrastructure shown in black, for visual reference.
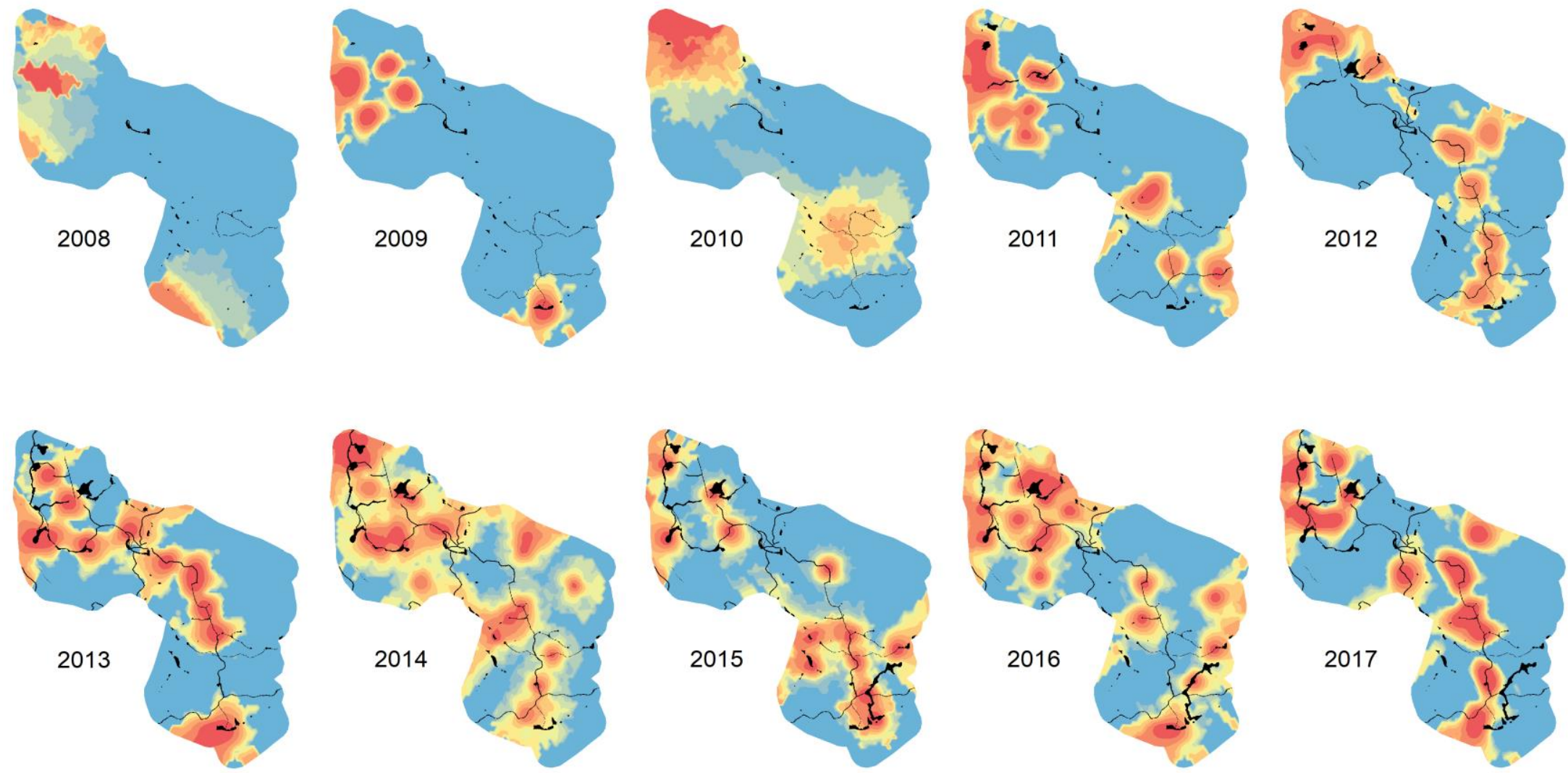
Appendix A. Sources of imagery for manual digitization of forest and non-forest cover.

\begin{tabular}{llll}
\hline Year & Platform & Season & Source \\
\hline 2003 & aerial & leaf-off & West Virginia Statewide Addressing and Mapping Board (SAMB) project \\
2007 & aerial & leaf-on & USDA National Agricultural Imagery Project (NAIP) \\
2008 & satellite & leaf-on & Landsat 7 \\
2009 & satellite & leaf-on & Quickbird \\
2010 & satellite & leaf-on & Landsat 7 \\
2011 & aerial & leaf-on & USDA National Agricultural Imagery Project (NAIP) \\
2014 & aerial & leaf-on & USDA National Agricultural Imagery Project (NAIP) \\
2016 & aerial & leaf-on & USDA National Agricultural Imagery Project (NAIP) \\
\hline
\end{tabular}


Appendix B. Model sets included in AIC analysis of factors influencing detection probabilities using (1) time removal, and (2) distance sampling. Models include intercept-only models as well as models incorporating survey-specific covariates. Tree cover is percent forest cover within a 100-m radius of each survey point.

\begin{tabular}{l} 
1. Time removal models: \\
\hline Intercept-only \\
Time since sunrise \\
Time since sunrise $+(\text { Time since sunrise })^{2}$ \\
Serial date \\
Serial date $+(\text { Serial date })^{2}$ \\
Serial date + Time since sunrise \\
Serial date $+(\text { Serial date })^{2}+$ Time since sunrise \\
Serial date + Time since sunrise $+(\text { Time since sunrise })^{2}$ \\
Serial date $+(\text { Serial date })^{2}+$ Time since sunrise $+(\text { Time since sunrise })^{2}$ \\
\hline 2. Distance sampling models: \\
\hline Intercept-only \\
Tree cover (within 100 m) \\
Observer \\
Observer + Tree cover $($ within 100 m) \\
\hline
\end{tabular}


Appendix C. Cross validation of a preliminary subset of interpolated models (2008-2016), comparing performance of three interpolation methods: inverse distance weighting (IDW), ordinary kriging, and indicator kriging. Comparison is based on root mean square errors, with error values closer to zero indicating better fit between estimated and measured values.

\begin{tabular}{|c|c|c|c|c|}
\hline & Year & IDW & Ordinary Kriging & Indicator Kriging \\
\hline \multirow[t]{9}{*}{ Ovenbird } & 2008 & 0.6461 & 0.6295 & 0.4750 \\
\hline & 2009 & 0.6226 & 0.6106 & 0.4674 \\
\hline & 2010 & 0.6419 & 0.6145 & 0.4743 \\
\hline & 2011 & 0.5678 & 0.5582 & 0.4488 \\
\hline & 2012 & 0.5075 & 0.5141 & 0.4545 \\
\hline & 2013 & 0.5932 & 0.5817 & 0.4560 \\
\hline & 2014 & 0.4402 & 0.4305 & 0.3897 \\
\hline & 2015 & 0.5360 & 0.5465 & 0.4230 \\
\hline & 2016 & 0.6078 & 0.6116 & 0.4413 \\
\hline \multirow[t]{9}{*}{ Cerulean Warber } & 2008 & 0.8188 & 0.8341 & 0.4838 \\
\hline & 2009 & 0.8752 & 0.8686 & 0.4793 \\
\hline & 2010 & 0.7451 & 0.7065 & 0.4803 \\
\hline & 2011 & 0.6427 & 0.6173 & 0.4469 \\
\hline & 2012 & 0.5725 & 0.5747 & 0.4823 \\
\hline & 2013 & 0.6265 & 0.6111 & 0.4945 \\
\hline & 2014 & 0.4340 & 0.4265 & 0.4265 \\
\hline & 2015 & 0.5634 & 0.5669 & 0.4700 \\
\hline & 2016 & 0.4863 & 0.4715 & 0.4564 \\
\hline \multirow[t]{9}{*}{ Indigo Bunting } & 2008 & 0.6034 & 0.5980 & 0.4380 \\
\hline & 2009 & 0.7601 & 0.7548 & 0.4716 \\
\hline & 2010 & 0.6609 & 0.6751 & 0.4692 \\
\hline & 2011 & 0.4693 & 0.4746 & 0.4543 \\
\hline & 2012 & 0.5900 & 0.5965 & 0.4760 \\
\hline & 2013 & 0.5874 & 0.5907 & 0.4504 \\
\hline & 2014 & 0.5105 & 0.5268 & 0.4165 \\
\hline & 2015 & 0.6426 & 0.6571 & 0.4641 \\
\hline & 2016 & 0.7512 & 0.7635 & 0.4447 \\
\hline \multirow[t]{9}{*}{ Brown-headed Cowbird } & 2008 & 0.1549 & 0.1500 & 0.1500 \\
\hline & 2009 & 0.2161 & 0.2114 & 0.2114 \\
\hline & 2010 & 0.2409 & 0.2384 & 0.2369 \\
\hline & 2011 & 0.3711 & 0.3565 & 0.2994 \\
\hline & 2012 & 0.2771 & 0.2761 & 0.2353 \\
\hline & 2013 & 0.7971 & 0.7699 & 0.4498 \\
\hline & 2014 & 0.3691 & 0.3503 & 0.3503 \\
\hline & 2015 & 1.1809 & 1.2243 & 0.3890 \\
\hline & 2016 & 0.4863 & 0.4938 & 0.3457 \\
\hline
\end{tabular}




\section{CHAPTER 4.}

\section{REGION-WIDE IMPACTS OF MARCELLUS-UTICA SHALE GAS DEVELOPMENT ON FOREST SONGBIRDS}

\section{Introduction}

Since the early 2000s, increasing energy demands combined with technological advancements in unconventional methods of extracting shale oil and gas resources - including directional drilling and hydraulic fracturing - have resulted in a boom in shale gas development in the United States. The Marcellus-Utica shale basin underlies much of the central Appalachian region, and is the largest and highest-producing unconventional gas play in the U.S. (USEIA 2018). Continued development of shale gas resources in the Marcellus-Utica region is driving total U.S. shale gas production growth and is the main source of dry natural gas (methane) production in the U.S. (USEIA 2018).

The central Appalachian region is also one of the most biologically diverse temperate ecosystems in the world, and contains some of the largest expanses of unfragmented, secondgrowth forest remaining in the eastern U.S. These large blocks of continuous forest provide important habitat for a host of forest-dependent wildlife, including numerous neotropical migratory birds and species of conservation concern (Rich et al. 2004, Steele et al. 2010, AMJV 2015). Migratory birds are facing global population declines (Robbins et al. 1989, Soykan et al. 2016, IUCN 2017), and forest loss and fragmentation are considered major drivers of these declines (Brooks et al. 2002, Gaston et al. 2003, Pimm et al. 2006). Although much is still unknown about the environmental impacts of unconventional gas development in this region (Kiviat et al. 2013, Souther et al. 2014), recent studies suggest that the rapid expansion of shale gas infrastructure is driving significant land cover change in the central Appalachians, particularly 
through fragmentation of regional forests (Johnson et al. 2010, Drohan et al. 2012, Pickell et al. 2014, Donnelly et al. 2017, Langlois et al. 2017).

Development of shale gas infrastructure results in direct loss of forest habitat through land cover conversion, but also contributes to the loss of interior or "core" forest habitat through extensive fragmentation and edge effects (Drohan et al. 2012, Farwell et al. 2016, Langlois et al. 2017). Direct mechanisms driving avian responses to changes in forested landscapes include loss of suitable habitat (Villard et al. 1999, Mortelliti et al. 2010), decreased patch size (Andren 1994, Bender et al. 1998), increased open spaces, corridors, and edges avoided by area-sensitive species (Askins 1994, Villard et al. 1999, Banks-Leite et al. 2010), and increased noise and light disturbance (Bayne et al. 2008, Kempenaers et al. 2010, Francis et al. 2011). Indirect mechanisms include increased human access and activity (Bayne and Dale 2011), increased rates of predation (Donovan et al. 1997, Jokimaki and Huhta 2000, Chalfoun et al. 2002), interspecific competition (Nee and May 1992, Shochat et al. 2010), and brood parasitism (Gates and Evans 1998, Howell et al. 2007) in isolated patches and along edges. Even relatively small changes to central Appalachian forests (as small as $4 \%$ forest loss) can alter bird communities and reduce the abundance of forest dependent birds (Becker et al. 2015). Recent studies of the impacts of Marcellus-Utica shale gas development on bird communities have documented negative effects on area-sensitive forest interior species in northcentral Pennsylvania (Barton et al. 2016, Langlois 2017) and northern West Virginia (Farwell et al. 2016). At the same time, there is some indication that early successional and disturbance-dependent species may benefit from forest disturbance associated with shale gas development (Barton et al. 2016, Farwell et al. 2016, Langlois 2017), although results vary by species and type of infrastructure. 
While these relatively localized studies documented evidence of negative impacts of shale gas infrastructure on forest interior birds in focal areas within the Marcellus-Utica region, no published study has evaluated general trends in avian response to shale gas development across the region. Given how much is still unknown about the large-scale, long-term biological impacts of shale gas development in the central Appalachians (Kiviat et al. 2013, Evans and Kiesecker 2014, Souther et al. 2014), we aimed to provide a broad snapshot assessment of region-wide avian response to Marcellus-Utica shale gas development. Our main objectives were to: (1) quantify and characterize the spatial footprint of shale gas infrastructure in forested landscapes across the region, (2) assess whether birds respond differently to shale gas development compared with other types of human development in the region, and (3) evaluate avian response to specific attributes of Marcellus-Utica shale gas infrastructure. We compared avian community similarity between gas sites and non-gas sites, and also based on patterns of public and private well pad ownership. We then evaluated patterns of community- and species-level response to land cover metrics at multiple spatial extents, including site-wide assessments of avian response to site-level landscape metrics, and point-level analyses of avian response to land cover metrics within buffers surrounding each survey point. Lastly, we evaluated how the size, shape, density, and age of shale gas infrastructure influenced the abundance and diversity of songbirds, to shed light on the effects and relative importance of specific attributes of shale gas infrastructure. Results can aid in the development of regional siting guidelines for shale gas infrastructure, with the goal of mitigating negative impacts to forest interior dependent species while potentially maximizing benefits for early successional species. Results will also provide important region-wide baseline data that can be used to monitor regional bird populations over a longer period of time. 


\section{Methods}

\subsection{Study area and site selection}

The Marcellus-Utica shale formation stretches beneath the central Appalachian Mountains, and primarily underlies 4 broad ecoregions: Western Allegheny Plateau, Central Appalachians, North Central Appalachians, and Northern Allegheny Plateau (USEPA 2013). Drilling has occurred in Pennsylvania (PA), West Virginia (WV), and eastern Ohio (OH). Although the Marcellus-Utica shale play also underlies portions of New York (NY) and western Maryland (MD), these states currently have bans in place on the practice of hydraulic fracturing.

The Marcellus-Utica shale formation stretches beneath the central Appalachian Mountains, and primarily underlies 4 broad ecoregions: the Western Allegheny Plateau, Central Appalachians, North Central Appalachians, and Northern Allegheny Plateau (USEPA 2013). Drilling has occurred in Pennsylvania (PA), West Virginia (WV), and eastern Ohio (OH). Although the Marcellus-Utica shale play also underlies portions of New York (NY) and western Maryland (MD), these states currently have bans in place on the practice of hydraulic fracturing.

We sampled a total of 190 study sites across this region during 2014-2015, including 120 sites affected by shale gas development as well as non-gas development ("gas sites") and 70 sites only affected by human development unrelated to shale gas ("non-gas sites"; Fig. 1). We used a stratified, semi-random approach to select sites across gradients of forest cover and human development, and representing both public and private land ownership (Brennan et al. 2002). We delineated site boundaries by merging 1-km buffers (314 ha) drawn around each point sampled within a site (Fig. 2). Sites ranged in area from 567 to 1,244 ha, with a mean area of 746 ha and a combined total area of 141,645 ha. Because we were most interested in ecological impacts of shale gas development on predominantly forested landscapes near a fragmentation threshold of 
approximately 60\% forest (Zuckerberg and Porter 2010, van der Hoek et al. 2013), most sites ( $n=$ 167) fell at or above $60 \%$ forest cover $(\bar{x}=79 \%$, range $=25-99 \%)$. We selected non-gas sites from the same Level IV ecoregions as gas sites (USEPA 2013), across similar ranges of forest cover, human disturbance, and land ownership. Non-gas sites had no shale gas development within a minimum 1-km radius of any point sampled, with $90 \%$ of non-gas sites having no shale gas development within $2 \mathrm{~km}$, and 79\% having no shale gas development within $3 \mathrm{~km}$. Both gas and non-gas sites were fairly evenly distributed across the study region during both years of the study, and site centroids were located at least $3 \mathrm{~km}$ apart to avoid sampling overlapping communities.

Most gas sites were centered on a focal shale gas well pad or group of well pads, as epicenters of drilling activity and infrastructure development. Well pads are large, cleared areas typically covered with compacted, crushed stone to support the weight of heavy machinery and drilling rigs. Well pads are often surrounded by secondary infrastructure, including buffer areas, retention ponds, storage lots, new or expanded gravel access roads, and gathering pipelines (Johnson et al. 2010). In two studies of shale gas land cover impacts in PA, well pads averaged 1.3-2.2 ha in size, while associated infrastructure added an average $2.3-7.7$ ha to the area directly impacted by well pad construction, for an average total footprint of 3.6-9.9 ha (Johnson et al. 2010, Langlois et al. 2017). A small number of gas sites $(n=10)$ did not contain well pads, but were centered on other types of shale gas development (i.e., pipelines, compressor stations). Gas sites contained a range of sizes, shapes, densities and ages of shale gas infrastructure. Among gas sites with well pads $(n=110), 45 \%$ had well pads located on public lands (federal, state, county or municipal), $51 \%$ had well pads located on private lands, and $4 \%$ had well pads on a mix of both public and private lands. 


\subsection{Land cover mapping and derivation of landscape metrics}

A previous regional study suggested that landscape metrics derived from 30-m resolution National Land Cover Database (NLCD) data were too coarse to effectively capture the relatively fine-resolution, spatially explicit impacts of shale gas development on bird distributions (Fearer and Klopfer 2013). Thus, we manually delineated land cover at our study sites using 1-m resolution ‘leaf-on' aerial imagery from the USDA National Agriculture Imagery Program (NAIP 2016). NAIP imagery is acquired at a 1-m ground sample distance with a horizontal accuracy that matches within $6 \mathrm{~m}$ of photo-identifiable ground control points (NAIP 2016). We imported NAIP imagery into a geographic information system (GIS) for digitization. For PA, OH, MD, and NY, we used 2013 NAIP imagery to digitize sites surveyed in 2014, and 2015 NAIP imagery for sites surveyed in 2015. For WV we used 2014 NAIP imagery for sites surveyed in both 2014 and 2015. When 2015 NAIP imagery became available for PA, OH, MD, and NY, and 2016 NAIP imagery became available for $\mathrm{WV}$, we updated site digitizations with shale gas features which did not appear in earlier images, but which were present on the landscape during avian surveys based on surveyor notes and state oil and gas well databases (OHDNR 2017, PADEP 2017, WVGES 2017).

We delineated and classified land cover at each site based on broad categories of land use, using methods similar to those detailed in a previous, localized study from northern WV (Farwell et al. 2016). Land cover classes included forest, agriculture, timber harvest, shale gas development, and other forms of human development unrelated to shale gas ("non-gas development"). We defined forest land cover as treed areas where bare ground was not visible, which had not been harvested for $\geq 19-26$ years (McDermott and Wood 2009). Conversely, timber harvests were forest stands that had been cleared within $\leq 10-12$ years. Non -gas development was 
classified separately from agriculture and timber harvests, and primarily included exurban, single family residences, rural industrial areas (e.g., surface mines, wind energy development, shallow gas wells), rural townships, and a few outlying suburban areas and industrial parks. We separately classified unconventional shale gas well pad development within specific categories (i.e., well pad, buffer, storage, retention pond, compressor). Lastly, we classified different types of linear infrastructure within categories related to shale gas development (i.e., pipelines, access roads) and categories unrelated to shale gas development (i.e., all other roads and utility corridors). We referenced state oil and gas well databases to verify locations of well pads, target shale formations, the number of individual wells drilled per pad, and "spud" dates when drilling initiated for each well (PADEP 2017, WVGES 2017, OHDNR 2017). Site digitization was conducted by 6 trained digitizers and proofed by L.S. Farwell to ensure consistency in final classification decisions.

After converting digitized maps to 1-m resolution raster land cover grids, we used FRAGSTATS v. 4.2 (McGarigal et al. 2012) to derive a number of landscape metrics at multiple spatial extents. Because sites varied in size, in site-level analyses we only included percent land cover and edge density metrics that could be compared across sites. We calculated the percent of each site occupied by forest (Forest site), well pad development (Gas pad site), and non-gas development (Non-gas site). Recent studies from the Marcellus-Utica region suggest habitat fragmentation due to expanding linear shale gas infrastructure may be a bigger driver of landscape change than habitat loss due to well pad development (Pickell et al. 2014, Donnelly et al. 2017, Langlois et al. 2017). Thus, we also calculated total edge density ( $\mathrm{m} / \mathrm{ha}$ ) of linear infrastructure related to shale gas (Linear gas site) and unrelated to shale gas (Linear non-gas site). Lastly, we calculated the density of all forest edges created by shale gas infrastructure, using the contrast- 
weighted edge density function in FRAGSTATS (McGarigal et al. 2012). Although we did not include these contrast-weighted forest edge densities in avian models because they were highly correlated with percent well pad development and total edge density of linear shale gas

infrastructure, we used them to assess trends in forest edge creation specifically due to pipelines and access roads, compared with well pad development.

To evaluate more localized effects of disturbance metrics and forest context on point-level avian response, we also calculated landscape metrics within 2 spatial extents surrounding each sampling point (Zuckerberg et al. 2012). We used disturbance metrics calculated within 500-m buffers of each point as local-scale measures of anthropogenic disturbance, including percent cover of well pad development (Gas pad 500m) and non-gas development (Non-gas 500m), edge density of linear shale gas infrastructure (Linear gas 500m), and edge density of linear infrastructure unrelated to shale gas (Linear non-gas 500m). A 500-m buffer represented an area large enough to include multiple shale gas features, but small enough to represent local-scale "neighborhoods" of songbird breeding territories (Desrochers et al. 2010). We also calculated percent forest cover within a 1-km buffer of each point (Forest $1 \mathrm{~km}$ ), as a measure of the broader forest context potentially influencing each sampling point (Kupfer et al. 2006, Smith et al. 2011). We selected metrics within these 2 point-level buffer widths to evaluate whether birds appear to respond more strongly to human impacts (gas versus non-gas) at a localized neighborhood extent, or to the surrounding forest matrix at a broader extent (Smith et al. 2011).

As a final step, we evaluated guild and focal species responses to shale gas development among gas sites only, to evaluate specific attributes that could influence siting guidelines. Again, we included edge density of linear shale gas infrastructure within 500-m of each point (Linear Gas $500 \mathrm{~m}$ ) to assess the impacts of fragmentation associated with pipelines and access roads. Then, 
we isolated 3 attributes of well pad development: (1) area-weighted mean patch area (Pad area 500m), mean patch shape (Pad shape 500m), and patch density (Pad density 500m) of well pad structures, to assess potential effects of the size, shape, and density of well pads (McGarigal et al. 2012). Lastly, we included a site-level index of 'time-since-disturbance', by calculating the number of years since the most recent shale gas development at each impacted site (Time since disturbance site . For gas sites with well pads $(n=110)$, we used the year of the most recent drilling start date to estimate time-since-disturbance. For gas sites without well pads $(n=10)$, we used historical NAIP imagery and state oil and gas databases (OHDNR 2017, PADEP 2017, WVGES 2017) to estimate the year when land cover was most recently disturbed for shale gas development.

\subsection{Avian Surveys and Detection Probability}

We conducted standard avian point count surveys (Bibby et al. 1992) at 2,590 sampling points within 190 study sites $(\bar{x}=13.5$, range $=8-20$ points per site). Typically, at gas sites we placed 2 points per site adjacent to forest edges in habitat directly disturbed by shale gas development, or in other types of human development at non-gas sites (Fig. 2). However, at sites with lower percent forest cover and more human development, we included additional points in disturbed areas adjacent to forests to better capture site-specific land cover proportions, and due to a shortage of available forest habitat to survey. We randomly distributed remaining sampling points at varying distances from the edge of disturbance into surrounding forests, within 2 clusters at each site (4-10 points per cluster) to concentrate survey efforts and minimize travel time between points on the sampling day (Wood et al. 2006). We spaced points at least $250 \mathrm{~m}$ apart to minimize double-counting individual birds, and whenever possible, at least $50 \mathrm{~m}$ from natural canopy gaps 
to reduce multiple edge effects (Paton 1994). However, point placement was also constrained by property boundaries, access, and safety issues.

We visited each site once between mid-May and early July during either 2014 or 2015, to maximize the number of sites that could be sampled (Thompson et al. 2002). We conducted 10min surveys at each sampling point between sunrise and $4 \mathrm{~h}$ after sunrise, and did not conduct surveys when weather conditions interfered with visibility or audibility of birds (Ralph et al. 1995). A total of 13 observers conducted avian surveys; all were experienced in regional bird identification and distance estimation and were trained in both prior to each field season.

First detections of all birds observed by sight or sound were recorded within 5 time intervals $(0-2,>2-4,>4-6,>6-8,>8-10 \mathrm{~min})$ and 4 distance intervals $(0-25,>25-50,>50-75,>75-100$ m) to allow for estimation of detection probability (Matsuoka et al. 2014). We employed the 'QPAD' approach (Sólymos et al. 2013), which uses time removal and distance sampling methods to estimate the 2 components of detectability: $p$ (availability, or singing rate) and $q$ (perceptibility, or the probability that an observer will detect an individual bird if it sings). QPAD provides conditional maximum likelihood estimates for $p$ and $q$, while accounting for surveyspecific covariates that might influence detection. We included serial date, time-since-sunrise, and quadratic terms of each as covariates potentially affecting $p$, and observer and percent forest cover as covariates potentially affecting $q$ (Sólymos et al. 2013). Percent forest cover within $100 \mathrm{~m}$ of each survey point was derived from 1-m resolution land cover grids, described above. We used the package 'detect' (Sólymos et al. 2016) in program R (R Version 3.4.1, www.r-project.org, accessed Dec 2017) to employ the QPAD approach and fit survey data to 9 removal models and 4 distance models (Appendix A). We used fitted models with lowest Akaike's information criterion 
(AIC) values for each species to calculate custom offsets to account for detectability in subsequent analyses (Sólymos et al. 2013).

\subsection{Avian guilds and focal species}

To evaluate patterns of community-level response to shale gas development, we grouped species a priori into 3 habitat guilds potentially impacted by human development (Table 1), based on known habitat preferences and breeding behaviors of regional birds (Rodewald 2015), and previous region-specific guild studies (Whitcomb et al. 1981, O'Connell et al. 2000, McDermott and Wood 2009, Thomas et al. 2014, Farwell et al. 2016). The habitat guilds of interest were: (1) forest interior species $(n=29)$ associated with large tracts of mature forest, $(2)$ early successional species ( $n=19)$ associated with shrubland, young forest, and/or forest edge habitat, and (3) synanthropic species $(n=15)$ known to benefit from human disturbance and to thrive in humanmodified landscapes. We excluded non-breeding migrants, species detected only once, nonpasserines and birds not effectively surveyed by point counts (i.e., gamebirds, predominantly aerial species such as swallows, and far-ranging species such as raptors, crows and ravens). Of the remaining 87 species observed within 100 m during the study (Table 1$), 72 \%(n=63)$ were placed into habitat guilds; the other $28 \%(n=24)$ did not fit clearly within a guild of interest and were thus excluded from guild analyses.

To evaluate species-level responses to shale gas development, we also analyzed abundances of 24 focal species (Table 1). Due to specific concerns regarding impacts of shale gas development on forest interior habitat (Barton et al. 2016, Farwell et al. 2016, Langlois 2017), half of these were forest birds $(n=12)$. Remaining focal species were divided between the early successional $(n=6)$ and synanthropic $(n=6)$ guilds. We chose relatively common species $(>100$ detections) to maximize model convergence. For focal species with limited range extents within 
the study region, we only included sites within species-specific range limits in analyses, as delineated in North American Breeding Bird Survey distribution maps (Sauer et al. 2017).

\subsection{Data analysis}

We used simple linear regression to evaluate general trends in the number of wells drilled per pad and the overall footprint of well pads over time, based on year of first drill date per well pad. We used Welch's two-sample $t$-tests to test whether number of wells per pad and total well pad footprint differed at sites with well pads on public versus private lands.

To compare avian community similarity at (1) gas sites versus non-gas sites, and (2) at sites with well pads on public versus private lands, we used analysis of similarities (ANOSIM), a nonparametric method for testing whether among- and within-group dissimilarities are the same on average (Clarke 1993). An ANOSIM generates an $R$ value which is scaled to lie between -1 and 1, with values close to zero indicating support for the null hypothesis of no difference between groups, and values close to 1 indicating group differences (Clarke 1993). In ANOSIM, the value of $R$ is at least as important if not more important than its statistical significance; a low $R$ value (close to 0) accompanied by a statistically significant test result indicates groups are different, but that the grouping factor had a small effect and these differences may not be ecologically important (Clarke and Warwick 2001). We calculated a rank dissimilarity matrix based on sitewide average species abundances, using the Bray-Curtis dissimilarity index for count data, and assessed significance of the test statistic with a Monte Carlo randomization test (999

permutations; Clarke 1993). Although ANOSIM can detect differences between groups, it cannot show whether these differences are the result of differences in group dispersions, differences in group locations in multivariate space, or some combination of both (Clarke 1993). Thus, we followed the ANOSIM with an analysis of variance (ANOVA) of multivariate homogeneity of 
group dispersions (Anderson 2006), to assess whether spreads of variance were different between groups. We then used non-metric multidimensional scaling (NMDS) to visually assess the relative positions of groups of sites in multivariate space (Kruskal 1964). This ranking approach is graphically precise (Ruokolainen and Salo 2006), effectively maintains scaling among objects from the original data in ordination space, and can out-perform metric multidimensional scaling when compressing distance relationships among objects into fewer than three dimensions (Legendre and Legendre 2012). We tested the significance of the NMDS stress value (goodness of fit) using a Monte Carlo randomization test (999 permutations) and plotted the correlation between fitted values and ordination distances as an $R^{2}$ linear fit.

To evaluate avian guild richness and focal species abundance across gradients of forest cover and human development at both the site and point levels, we used generalized linear mixed models (GLMMs) with a Poisson distribution and log link (Zuur et al. 2009). For site-level analyses, we evaluated site-wide guild species richness as a community-level measure of avian response, and site-averaged focal species abundances (total number of individuals counted per site divided by the number of points surveyed per site) as indices of species-level response. For pointlevel analyses, we used guild species richness and focal species abundances within a 100-m radius of each point as indices of community- and species-level response to point-level land cover metrics. We included Level IV ecoregion as a random effect in site-level analyses, to account for potential differences in avian communities among sites due to differences in biotic and abiotic conditions among fine-resolution physiographic areas (USEPA 2013, Omernik and Griffith 2014). We also included site as a random effect in all point-level analyses, to account for variability among study sites. Lastly we included percent forest cover (1-km radius) within 10 percentile categories (ranging from $0-10 \%$ to $>90-100 \%$ forest cover) as a random effect in our 
gas site-only analyses, to help isolate the specific effects of shale gas development by controlling for the influence of the surrounding forest matrix. To verify the appropriateness of models, we checked residuals for model fit (Zuur et al. 2009).

We assessed and summarized GLMM outputs using AIC with second-order bias correction $\left(\mathrm{AIC}_{\mathrm{c}}\right)$. We employed a model-averaging approach because our goal was to assess which landscape and disturbance metrics had the strongest influence on avian richness and abundance, not to rank individual models or determine the 'best' model (Burnham and Anderson 1998, Mazerolle 2006). We calculated model-averaged parameter estimates and $85 \%$ unconditional confidence intervals (Arnold 2010), and assessed the relative importance of each metric by summing $\mathrm{AIC}_{\mathrm{c}}$ weights across all models containing that term; each metric was represented an equal number of times in the full model set (Burnham and Anderson 1998).

All statistical analyses were performed in R. We used the package 'vegan' to run multivariate community analyses (Oksanen et al. 2016), 'Ime4' to conduct GLMMs (Bates et al. 2015), and 'AICcmodavg' to calculate $\mathrm{AIC}_{\mathrm{c}}$ values, model averaged parameter estimates, and relative importance values (Mazerolle 2016). We evaluated collinearity among all land cover and timesince-disturbance variables (Battin and Lawler 2006) using pairwise Pearson correlations; variables included in final models were considered uncorrelated based on a $P$-value cut-off of \pm 0.7 (Dormann et al. 2013).

\section{Results}

\subsection{Land cover metrics and the footprint of shale gas}

Forests occupied a mean $78.5 \pm 1.1 \%( \pm$ SE) of land cover across study sites (range $=25-$ 99\%). Agriculture was the next most dominant land cover type with a mean $9.5 \pm 0.9 \%$ of land 
cover $($ range $=0-65 \%)$, while timber harvests occupied a mean $1.6 \pm 0.3 \%$ of land cover (range $=$ 0-22\%). Remaining forms of non-gas human development occupied a mean $6.8 \pm 0.4 \%$ of land cover (range $=1-29 \%$ ). The combined footprint of all shale gas development (linear and nonlinear) occupied a mean $1.7 \pm 0.2 \%$ of land cover (range $=0-14 \%$, with well pad development accounting for a mean $0.7 \pm 0.1 \%$ (range $=0-10 \%)$ and linear shale gas infrastructure occupying a mean $1.0 \pm 0.1 \%$ (range $=0-7 \%$ ) of land cover. Non-gas linear infrastructure had a mean edge density of $46.1 \pm 1.5 \mathrm{~m} / \mathrm{ha}$ (range $=6.8-116.1 \mathrm{~m} / \mathrm{ha}$ ), while linear shale gas infrastructure had a mean edge density of $10.4 \pm 1.0 \mathrm{~m} / \mathrm{ha}($ range $=0-55.4 \mathrm{~m} / \mathrm{ha})$.

Among gas sites only $(n=120)$, the total footprint of linear and non-linear shale gas development occupied a mean $2.7 \pm 0.2 \%$ of land cover (range $=0-14 \%$ ), and of that combined footprint, linear shale gas infrastructure made up a mean of $1.5 \pm 0.1 \%$ (range $=0-7 \%$ ) while well pad development only accounted for a mean of $1.2 \pm 0.1 \%$ (range $=0-10 \%)$. Linear shale gas infrastructure had a mean edge density of $16.4 \pm 1.0 \mathrm{~m} / \mathrm{ha}$ (range $=0-55.4 \mathrm{~m} / \mathrm{ha})$ at gas sites. In terms of new forest edges specifically created by shale gas development at gas sites, well pad development had a mean forest edge density of $2.2 \pm 0.1 \mathrm{~m} / \mathrm{ha}($ range $=0-9.8 \mathrm{~m} / \mathrm{ha})$, while linear shale gas infrastructure had a mean forest edge density of $9.9 \pm 0.6 \mathrm{~m} / \mathrm{ha}$ (range $=0-40.7 \mathrm{~m} / \mathrm{ha}$ ).

Among gas sites that contained well pads $(n=110)$, we found a mean well pad density of 2.6 \pm 0.2 pads per site (range $=1-14$ pads). Although the majority of well pads $(60 \%)$ had just $1-2$ individual wells drilled, we did see a significant increase over time in average number of wells drilled per pad based on the year each pad was first drilled, from 1 well drilled per pad in 2005 to $4.3 \pm 0.9$ wells per pad in $2015\left(F_{1,279}=33.61, P \leq 0.001\right)$. We also saw a significant increase in the overall footprint of well pads and associated infrastructure, over time, from $0.5 \pm 0.2$ ha in 2005 to $5.8 \pm 1.4$ ha in $2015\left(F_{1,279}=64.25, P \leq 0.001\right)$. The mean area of shale gas well pads $(n=$ 
265 ) at our study sites was $0.8 \pm 0.03 \mathrm{ha}$ (range $=0.01-3.0 \mathrm{ha}$ ), and associated non-linear infrastructure (e.g., buffers, retention ponds, storage areas) on average occupied an additional 2.5 \pm 0.2 ha (range $=0-18.2$ ). The combined footprint of well pads and related infrastructure occupied a mean of $3.2 \pm 0.2 \mathrm{ha}($ range $=0.01-19.5 \mathrm{ha})$.

The number of individual wells drilled per pad varied slightly based on land ownership, with $2.9 \pm 0.2$ wells drilled per pad (range $=1-13$ ) on public lands, and $2.6 \pm 0.2$ wells drilled per pad (range $=1-10)$ on private lands. Additionally, the mean footprint of pads and associated infrastructure was slightly smaller $(3.0 \pm 0.3 \mathrm{ha}$, range $=0.03-17.7 \mathrm{ha})$ on public lands compared with private lands $(3.5 \pm 0.3 \mathrm{ha}$, range $=0.01-19.5 \mathrm{ha})$. However, differences in number of wells drilled per pad $\left(t_{251}=-1.10, P=0.27\right)$ and well pad footprint $\left(t_{251}=1.27, P=0.24\right)$ were not

statistically significant, based on surface ownership of well pads. Also, the sites we sampled with well pads on private lands generally occurred in less heavily forested landscapes and represented a broader range of forest cover $(\bar{x}=68.1 \pm 2.2 \%$, range $=25-91 \%)$ compared with the sites we sampled with well pads on public lands $(\bar{x}=84.7 \pm 1.4 \%$, range $=55-97 \%)$.

\subsection{Avian community similarity}

Site-level analysis of similarity (ANOSIM) indicated there was little difference between avian communities at gas sites and non-gas sites, based on site-wide average species abundances $(R=$ $0.04, P=0.01)$. An ANOVA test of multivariate homogeneity of group dispersions showed there was not a difference in multivariate dispersion between gas and non-gas sites $\left(F_{1,188}=0.39, P=\right.$ 0.54), suggesting the slight difference between groups was driven by separation in multivariate space. An NMDS ordination did show some separation in multivariate locations of the groups, though there was also substantial overlap (Fig. 3a). The ordination resulted in a stress value $<0.2$ $(0.19, P=0.01)$ and an $R^{2}$ linear fit value of 0.90 , indicating an appropriate NMDS solution. All 3 
habitat guilds had significant loadings on the ordination axes $(P=0.01)$, as did land cover types (forest, shale gas and non-gas development; $P=0.01$ ). The separation in multivariate locations of gas sites versus non-gas sites was consistent with higher abundances of forest birds at non-gas sites, and higher abundances of early successional and synanthropic birds at gas sites. These trends were also consistent with higher forest cover at non-gas sites and more shale gas development and non-gas human development at gas sites. However, 2 outlying non-gas sites with high percent forest cover (88\% and 99\%) appeared to be heavily influencing the separation.

We found some evidence of differences in avian communities between sites with well pads on public lands versus private lands, although the ANOSIM $R$ value of $0.29(P \leq 0.001)$ was still relatively low. This indicates a slight difference between groups accompanied by some degree of overlap (Clarke 1993). A test of multivariate homogeneity of group dispersions showed a difference in spreads of variance between sites with well pads on public versus private lands $\left(F_{1,103}=5.58, P=0.02\right)$. An NMDS ordination also showed a small difference in multivariate locations of the 2 groups of sites, although there was also substantial overlap (Fig. 3b). The slight separation in multivariate space was consistent with more early successional and synanthropic birds at sites with private well pads, and more forest interior birds at sites with public well pads. These patterns were also consistent with higher percent development surrounding privately owned well pads, compared with higher percent forest cover surrounding well pads on public lands. All 3 habitat guilds had significant loadings on the ordination axes $(P=0.01)$. However only percent forest and percent non-gas development had significant loadings $(P=0.01)$; percent shale gas development did not $(P=0.12)$. The NMDS had a stress value of $0.19(P=0.01)$, and a $R^{2}$ linear fit value of 0.89 . 


\subsection{Avian guilds and focal species}

We report both guild-level and species-level results; however, to conserve space we provide summary tables for guild-level models only (Tables 2-4). Summary tables for 24 focal species are provided in supplementary materials (Appendices B-G).

Forest interior guild and species.-At the site level, forest cover had a positive effect on forest interior guild species richness and the highest relative importance (Table 2). At the point level, forest cover within $1 \mathrm{~km}$ also had a positive effect and high relative importance, although well pad development and non-gas development within $500 \mathrm{~m}$ were also important point-level predictors and had negative effects on forest interior guild richness (Table 3). When we limited our analyses to specific attributes of shale gas development across points at gas sites only, the area occupied by well pad development had a negative effect on forest interior guild species richness and had highest relative importance, followed closely by a positive effect of time-sincedisturbance (Table 4).

These general patterns held true for most forest interior focal species, which typically occurred in higher abundance with increasing forest cover and lower abundance relative to human development (Appendices B-D). However, we observed some differential species-specific effects of shale gas development compared with non-gas human development. For example, at the site level non-gas linear development had more positive effects on abundance of forest interior birds (6 out of 12 focal species) than negative effects ( 3 species), whereas shale gas linear development had more negative effects on forest birds ( 7 out of 12 focal species) than positive effects ( 3 species; Appendix B). It is also worth noting that although most forest interior focal species (9 out of 12) showed consistently higher abundance relative to forest cover at both the site and point level (within $1 \mathrm{~km}$ ), 3 species did not. Site-level forest cover negatively influenced abundance of 
hooded warblers and wood thrush and had no effect on abundance of Kentucky warblers (see Table 1 for scientific names of all species), and point-level forest cover had little effect on all 3 species (Appendix B, C). Disturbance metrics at both the site and point level were more important for these 3 species than forest cover.

Additionally, multiple forest interior species showed scale-dependent responses to disturbance metrics. For example, at the site level 9 out of 12 focal species occurred in higher abundance relative to at least one disturbance metric (either related to shale gas or not; Appendix B), whereas no forest interior focal species occurred in higher abundance relative to any point-level disturbance metric (Appendix C). Abundance of cerulean warbler, a species of high conservation concern (Table 1), was positively affected by forest cover and all disturbance metrics except well pad development, with equal relative importance values at the site level (Appendix B). At the point level, however, cerulean warbler abundance was only positively influenced by forest cover (Appendix C). Similarly, at the site level worm-eating warbler, another priority conservation species (Table 1), occurred in higher abundance relative to site-level forest cover, edge density of linear non-gas and linear shale gas infrastructure, and had lower abundance with increasing well pad development (Appendix B). However, at the point level worm-eating warbler abundance was only influenced by a positive effect of forest cover (Appendix C).

In keeping with guild-level effects among gas sites only, well pad area had a negative effect on 8 out of 12 focal species within the forest interior guild, while time-since-disturbance had a positive effect on 8 out of 12 forest interior species; for 5 of those 8 species time-sincedisturbance also had the highest relative importance (Appendix D). Edge density of linear shale gas infrastructure had a negative influence on abundance of 5 forest interior species. No forest interior focal species occurred in higher abundances relative to point-level edge density of linear 
shale gas infrastructure (Appendix C, D), although the same metric positively influenced abundances of 3 forest interior species (black-throated blue warblers, cerulean warblers, wormeating warblers) at the site level (Appendix B).

Early successional guild and species. - At the site level, forest cover had the highest relative importance for the early successional guild, with lower guild species richness relative to forest cover (Table 2). At the point level, forest cover within $1 \mathrm{~km}$ still had high relative importance and negative influenced early successional guild species richness (Table 3). However, all 4 point-level disturbance metrics were also relatively important and positively influenced early successional guild species richness, at the point level (Table 3). Among gas sites only, linear shale gas infrastructure had a positive effect on early successional guild richness and highest relative importance, followed by a negative effect of time-since-disturbance, and positive effects of well pad area and well pad shape (Table 4).

Responses of early successional focal species were generally consistent with overall guildlevel response, but we did see species-specific variability in the influence of shale gas development compared with non-shale gas development, and in the influence of disturbance metrics when evaluated at different spatial extents (Appendices E-G). For example, at the site level 3 out of 6 early successional focal species were positively affected by non-gas development, but not by well pad development (Appendix E). Conversely, at the site level 2 out of 6 focal species were positively affected by shale gas development, but not by non-gas development: chestnut-sided warbler abundance was positively affected by well pad development but not by non-gas development, and common yellowthroat abundance was positively affected by linear shale gas infrastructure but not by non-gas linear infrastructure (Appendix E). At the point level, abundances of more early successional focal species were positively affected by non-gas 
development ( 4 out of 6 species) than by well pad development ( 2 out of 6 species), while more focal species were positively affected by linear shale gas infrastructure (4 out of 6 species) than by non-gas linear infrastructure (3 out of 6 species; Appendix F). Well pad development and linear shale gas development had positive effects on indigo bunting abundance at the point level, but not at the site level (Appendix E, F). Blue-winged warbler, a species of conservation concern, was the only early successional species to occur in lower abundances relative to well pad development at both the site and point level, while non-gas development positively affected bluewinged warbler abundance, at both spatial extents (Appendix E, F).

Also in keeping with guild-level effects, 4 out of 6 early successional focal species occurred in higher abundance relative to linear shale gas infrastructure among gas sites only, although this variable had highest relative importance for only 1 species, eastern towhee (Appendix G). Well pad area had a positive effect on abundance of chestnut-sided warbler and indigo bunting and was the variable with highest relative importance for both species in gas site-only models (Appendix G). Lastly, time-since-disturbance had a negative effect on 2 early successional focal species, with highest relative importance: common yellowthroat and field sparrow (Appendix G).

Synanthropic guild and species. - Forest cover had a negative effect on synanthropic guild species richness and was also the variable with highest relative importance at both the site-level and the point-level (Table 2, 3). Linear shale gas infrastructure had a positive effect on synanthropic guild richness at both the site level and the point level, while well pad development and linear non-gas infrastructure only had positive effects and high relative importance values, at the point-level (Table 2, 3). Among gas sites only, time-since-disturbance had the strongest influence and a negative effect on synanthropic guild richness, while well pad shape had a positive influence on synanthropic guild species richness (Table 4). 
Again, despite species-specific variability, effects on abundance of synanthropic focal species were generally consistent with guild-level effects (Appendices E-G). Forest cover had a negative influence on abundance of 5 out of 6 synanthropic species at both the site and point level; chipping sparrow was the only exception, with a positive effect of forest cover at the site level and no effect at the point level (Appendix E, F). Linear shale gas development positively affected abundance of 5 out of 6 synanthropic focal species at the site level, but only had a positive effect on 3 of those species at the point level (Appendix E, F). Non-gas development positively affected abundance of 4 out of 6 synanthropic species at the site level, but only 3 of these species were also positively influenced by site-level well pad development (Appendix E). At the site level, blue jay was the only synanthropic species with lower abundance relative to non-gas development, but occurred in higher abundances relative to both gas and non-gas linear infrastructure (Appendix E). However, at the point level blue jay occurred in lower abundances relative to both gas and non-

gas development (Appendix F). Only 3 species were positively influenced by point-level well pad development: brown headed cowbird, chipping sparrow, and song sparrow (Appendix F).

Among gas sites only, time-since-disturbance had a negative effect on 5 out of 6 synanthropic focal species and was the shale gas variable with highest relative importance for 3 of these species: American robin, blue jay, and northern cardinal (Appendix G). Well pad area had a positive effect on and was the most important variable for the remaining synanthropic focal species: brown-headed cowbird, chipping sparrow, and song sparrow (Appendix G).

\section{Discussion}

Natural gas from the Marcellus-Utica shale has emerged as one of the fastest growing and most important contributors to the U.S. energy portfolio (USEIA 2018). As demand for natural 
gas continues to grow, there is a need to improve our understanding of the environmental impacts associated with the extraction and transportation of unconventional shale resources, while opportunities still remain to mitigate consequences for area-sensitive species and important core forest habitat (Kiviat et al. 2013, Brittingham et al. 2014). We have provided a timely, regionwide assessment of shale gas impacts on land cover and specific landscape metrics that influence avian communities, across a heavily forested region experiencing rapid growth in shale gas development.

\section{1. Shale gas footprint}

We found that the footprint of shale gas development directly only affected $2.7 \%$ of impacted landscapes, on average, and that linear shale gas infrastructure $(1.5 \%)$ comprised a greater proportion of that overall footprint than well pad development (1.2\%). Furthermore, linear shale gas development created more than 4 times the amount of new forest edges $(9.8 \mathrm{~m} / \mathrm{ha})$ compared with well pads and associated infrastructure $(2.2 \mathrm{~m} / \mathrm{ha})$. Our results were consistent with other recent localized studies finding that linear shale gas infrastructure poses a larger potential threat to forest habitat than well pad development, both in terms of forest loss and fragmentation (Moran et al. 2015, Farwell et al. 2016, Donnelly et al. 2017, Langlois et al. 2017). Despite the relatively small direct footprint of shale gas development on landscapes in the Marcellus-Utica shale region, much of this development is taking place in predominantly forested landscapes, many of which comprise core, interior forest habitat. This suggests the continuing expansion of shale gas infrastructure is likely to reduce regional forest cover, but perhaps more importantly may leave remaining forests heavily fragmented (Drohan et al. 2012, Donnelly et al. 2017, Langlois et al. 2017). We would expect this to have ecological impacts disproportionate to the direct footprint of disturbance, due to increased edge and isolation effects associated with shale gas infrastructure in 
forest habitat (Pickell et al. 2014, Racicot et al. 2014, Moran et al. 2015, Farwell et al. 2016, Donnelly et al. 2017, Langlois et al. 2017).

Our assessment of the average footprint of well pad development was comparable to findings from an earlier study of Marcellus-Utica well pads in PA (Johnson et al. 2010), which found well pads averaged 1.3 ha in size with an additional 2.3 ha in associated infrastructure, for an average total footprint of 3.6 ha. However, a more recent study of shale gas development across Lycoming County in northcentral PA (Langlois et al. 2017) found that well pads developed from 2010-2016 averaged 2.2 ha in size, with an additional 7.7 ha of associated infrastructure, for an average total footprint of 9.9 ha. Although these local averages are substantially larger than our regional averages, they are still within the range of well pad areas we measured and are also consistent with our finding that more recently constructed well pads were significantly larger in size. Similarly, Donnelly et al. (2017) found that wells drilled in the more recently developed Carroll County in eastern $\mathrm{OH}$ (since 2011) were nearly $20 \%$ larger on average than wells in the earlier developed Washington County in southwestern PA (since 2003).

Our regional results regarding the average number of individual wells drilled per pad also confirm findings from other recent studies. Johnson et al. (2010) reported that as of 2010 the average was 2 wells per pad in PA, while Drohan et al. (2012) found that as of 2011, over $75 \%$ of wells drilled in PA had only 1-2 wells drilled per pad. Drohan et al. (2012) also found a slight increasing trend in number of wells per pad, based on the year pads were built. In keeping with this general pattern, Langlois et al. (2017) reported a significant increase in number of wells per pad in northcentral PA, with an average 2.2 wells per pad in 2010 and 4.4 wells per pad in 2016. This is consistent with the region-wide increase in wells per pad we measured over time, with an 
average of 1.0 well per pad among pads first drilled in 2005-2006 and 4.3 wells per pad among pads first drilled in 2015 .

Lastly, the non-significant trends we observed of slightly smaller well pad footprints and more individual wells drilled per pad on public lands compared with privately owned lands was consistent with trends found in northcentral PA, although the differences reported by Langlois et al. (2017) were significant, whereas ours were not. This may in part be a function of differences in the age range of well pads we evaluated. We sampled well pads from across the region drilled from 2005-2015, which included a number of smaller, older pads with fewer wells per pad, relative to the newer, larger well pads assessed by Langlois et al. (2017). While surface ownership does not necessarily reflect ownership of mineral rights (Drohan et al. 2012), the slightly higher average number of wells drilled per pad and slightly smaller average footprint of pads on publicly owned lands may be related to increased oversight and better management practices implemented on public versus private lands (Cox et al. 2017, Langlois et al. 2017, Stauffer et al. 2017).

\subsection{Avian response}

We found little difference in the overall avian community at gas sites compared with non-gas sites, which indicates that avian communities may be responding in a similar way to shale gas development as they do to other forms of human development. This suggests that land cover conversion for shale gas development is not necessarily unique in terms of broad impacts on avian communities, and that we can take advantage of the substantial body of research on the environmental impacts of comparable forms of anthropogenic forest disturbance (e.g., road and powerline construction, exurban development, mining and other forms of energy development) to help predict the effects of shale gas infrastructure on forest systems. 
The slight differences we detected in overall avian community at sites with well pads on public lands versus sites with well pads on privately owned lands were characterized by higher abundances of forest interior birds at public sites and higher abundances of early successional and synanthropic birds at private sites. This suggests that differences in well pad construction and/or management based on surface ownership may have had a differential effect on habitat attributes affecting birds. Our regional results are consistent with localized studies that observed differential impacts of shale gas development on forest habitat on public lands compared with privately owned lands (Cox et al. 2017, Langlois et al. 2017). However, it is also important to note that the private sites we sampled generally occurred in landscapes with lower mean percent forest cover ( $68 \%$ forest) compared with the public sites we sampled ( $84 \%$ forest). This makes it difficult to assess whether the differences we detected in avian communities were a result of basic differences in habitat, disparate management practices based on land ownership, or some combination of both. Stauffer et al. (2017) found that although targeted management on public lands in PA may improve habitat for individual species, general differences in avian communities on private versus public lands are more likely a function of broad-scale habitat differences than localized differences in management practices. Future studies could focus on differential impacts of shale gas development and site management on avian habitat and community response, based on surface and/or mineral ownership.

Our broad community-level comparisons were binary (i.e., gas/non-gas, public/private) and quite coarse, by design. However, in our finer-grain analyses of avian guild and species responses to shale gas infrastructure compared with other forms of non-gas development, we did detect unique guild- and species-specific responses to land cover disturbance associated with shale gas development compared with non-gas development. This was despite the relatively small 
proportion of land cover occupied by shale gas development $(\bar{x}=1.7 \%$, range $=0-14 \%)$ across the landscapes we evaluated. We also found that the relative effects of forest amount versus anthropogenic disturbance were scale-dependent. Differences in the effects and relative importance of landscape variables at different scales reflect underlying ecological processes affected by landscape structure which also operate at multiple spatial scales (e.g., territory selection, foraging, predation, dispersal; Smith et al. 2011).

For the forest interior guild and most forest interior focal species, the overall amount of available forest habitat was the most important driver of guild species richness and species abundance, at both a landscape extent (site-level) and a local extent (point-level). However, at the point level, the footprint of well pad development and non-gas human development also were important factors and had negative effects on forest interior birds. This is not surprising given what we know about the habitat preferences of this group of birds; however, it does emphasize that at a more localized spatial extent, habitat disturbance and fragmentation effects became increasingly influential relative to the effect of overall forest amount for forest interior birds. For the early successional and synanthropic guilds, percent forest cover was also the most important variable with a negative effect on both guilds, at both the site level and the point level. This suggests the availability of disturbed, non-forest habitat was the most important factor for these two groups of birds. However, point-level disturbance metrics were also important and had a positive effect on both the early successional and synanthropic guilds at the more localized extent, which indicates that the influence of point-level disturbance metrics also increased for early successional and synanthropic birds, compared to the overall amount of non-forest habitat.

Despite species-specific variability, most forest interior focal species were positively affected by overall forest context, and negatively affected by shale gas disturbance (either linear or well 
pad-related, or both). The region-wide pattern of response we documented in forest interior species confirms patterns observed in more localized studies within the Marcellus-Utica shale region (Barton et al. 2016, Farwell et al. 2016, Langlois 2017). Our results are also consistent with patterns of forest interior bird response to other forms of human development in eastern forests, including exurban development (Kluza et al. 2000, Glennon and Kretser 2013, Lumpkin and Pearson 2013), mountaintop removal coal mining (Becker et al. 2015), and conventional gas development (Thomas et al. 2014). However, there were some exceptions to this general pattern of response within the forest interior guild: 5 out of 12 focal species occurred in higher abundances relative to shale gas development at a landscape extent, but not at a local extent. This may partly reflect variable responses to canopy gaps among forest interior species. Within mature forest landscapes, the relatively small footprint of forest loss for construction of shale gas infrastructure may resemble natural canopy openings (Buchanan and Hart 2012). At the site level, these openings may attract some forest interior species known to prefer small canopy gaps within large areas of forest, such as black-and-white warblers and cerulean warblers (Boves et al. 2013, Perkins and Wood 2014, Farwell et al. 2016). Cerulean warblers in particular do not avoid internal forest edges such as open-canopy roads (Weakland and Wood 2005) and linear shale gas infrastructure (Farwell et al. 2016).

Additionally, forest cover negatively influenced abundances of hooded warblers and wood thrush at the site level, and disturbance metrics had a stronger influence on both species than amount of forest habitat at both spatial extents. This suggests there may be additional factors we did not measure influencing some forest interior birds, or that some forest interior birds may be attracted by some quality of forest loss due to human development. However, lower abundances of both hooded warblers and wood thrush relative to local-scale disturbance metrics indicate 
neither species is directly attracted to anthropogenic disturbance. Thus, it is more likely that we simply did not measure factors which are driving or limiting certain species. For example, both hooded warblers and wood thrush are shrub-nesting birds that prefer a moderate understory of saplings and shrubs, and are often associated with moist woodlands typical of lower elevations or slope positions (Rodewald 2015), where there also tends to be more human development (Stauffer et al. 2017). However, we could not account for fine-resolution habitat metrics such as these in our analyses.

Other local studies have indicated that some early successional, disturbance-dependent species may benefit from shale gas disturbance of forests in the Marcellus-Utica region (Barton et al. 2016, Farwell et al. 2016, Langlois 2017). Although we did not find a guild-level response to shale gas development at the site level, well pad development and linear shale gas infrastructure positively influenced early successional guild species richness, at the point level. However, this positive guild-level effect was not unique to shale gas development, with non-gas development and non-gas linear infrastructure also having positive influence on guild species richness with similar relative importance values. Conversely, some early successional focal species exhibited unique trends relative to shale gas development compared with non-gas development, especially at the site level. The patterns we observed of point-level linear shale gas development effects on early successional guild richness and 4 of 6 focal species are consistent with findings from local studies. Farwell et al. (2016) found early successional guild richness and focal species abundances were higher relative to forest edges created by shale gas infrastructure, while Langlois (2017) found early successional guild richness and focal species abundances were highest in forest edges created by pipelines compared with either core forest areas or habitat directly within pipeline corridors. 
Previous localized studies also suggest synanthropic birds respond positively to shale gas development in the Marcellus-Utica region. Barton et al. (2016) found synanthropic species were more abundant at sites with well pads at both a point level (within $3 \mathrm{ha}$ ) and at a neighborhood scale (within 25 ha), compared with reference sites. Farwell et al. (2016) found a significantly increasing trend in synanthropic guild species richness over an 8-year period (2008-2015) at a long-term study site impacted by shale gas in northern WV, and that synanthropic focal species responded positively to forest edges created by shale gas development and to the overall footprint of shale gas development, at a point level (within 3 ha). Langlois (2017) also found that synanthropic species were abundant in pipeline corridors and responded positively to forest edges created by shale gas pipelines, although this response varied according to pipeline type. Our region-wide findings for synanthropic birds were consistent with these localized studies, with the synanthropic guild and all 6 focal species occurring in higher abundances relative to well pad development or linear shale gas infrastructure, or both. However, these responses were scaledependent for the guild and all synanthropic focal species except chipping sparrows, which were more abundant relative to well pad and linear shale gas infrastructure, at both spatial extents.

Higher abundances of blue jays relative to site-level well pad development and higher abundances of brown-headed cowbirds relative to point-level well pad and site-level linear shale gas infrastructure are of potential concern. Both species are common nest predators of other songbird species, and are known to be attracted to forest edges created by human disturbance (Gates and Evans 1998, Miller and Hobbs 2000, Howell et al. 2007, Friesen et al. 2013, DeGregorio et al. 2014). Brown-headed cowbirds are also brood parasites that have been implicated in declines of other songbirds (Robinson et al. 1995) and multiple species of conservation concern (Eckrich et al. 1999, Kus 1999, DeCapita 2000). Increased abundance of 
nest predators and brood parasites facilitated by anthropogenic forest disturbance (Gates and Evans 1998, Friesen et al. 2013, DeGregorio et al. 2014), raises the question of whether areas disturbed by shale gas development may serve as sink habitat or ecological traps for early successional species (Askins et al. 2012, Friesen et al. 2013, Shipley et al. 2013, DeGregorio et al. 2014) and forest interior gap specialists (Boves et al. 2013). Given that our study is based entirely on species richness and abundance data, it is important to note that these are not necessarily accurate measures of habitat quality, since animals can gather or be forced into low-quality areas (VanHorne 1983). For example, recent studies found that Louisiana waterthrush had lower productivity and reproductive success in breeding territories impacted by shale gas development (Frantz et al. 2018) and showed higher accumulation of heavy metals associated with hydraulic fracturing in impacted watersheds (Latta el al. 2015), compared to controls. Further studies of demographic parameters such as reproductive success and survivorship in areas disturbed by shale gas development will improve our understanding of underlying habitat quality in areas impacted by shale gas (Bock and Jones 2004).

When we focused on specific attributes of shale gas development in impacted landscapes only, well pad area negatively affected forest interior guild richness and positively affected early successional guild richness. Conversely, time-since-disturbance was positively related to forest interior guild species richness and negatively influenced both early successional and synanthropic guild species richness. Edge density of linear shale gas infrastructure was negatively related to abundance of several forest interior focal species, but was positively related to early successional guild richness and abundances of most early successional focal species. Well pad shape also had a positive effect on both the early successional and synanthropic guilds, and was more important than overall well pad area. This suggests that efforts to reduce the overall footprint of well pads 
and, to a lesser extent, efforts to keep the shape of well pad development as compact (round or square) as possible, may benefit forest interior species both by reducing forest disturbance and by limiting increasing abundances of disturbance-dependent species (i.e., potential competitors, nest predators and brood parasites). The importance of time-since-disturbance on all 3 guilds is likely a surrogate for the effect of (a) successional changes in resource availability over time (Conner and Adkisson 1975, Helle and Monkkonen 1990, Mooney 2011, Wood and Ammer 2015), and (b) reduced human activity, truck traffic, industrial noise and light disturbance associated with well pad construction and drilling (Frid and Dill 2002, Kempenaers et al. 2010, Bayne and Dale 2011, Ware et al. 2015). This suggests that over time, some forest interior birds may return to forested areas impacted by shale gas, although the time-since-disturbance 'clock' may be reset by subsequent re-drilling of existing well pads.

Even though linear shale gas infrastructure did not have a guild-level effect on forest interior birds, it did have a negative effect on abundance of several forest interior focal species, including wood thrush, a species of regional and global conservation concern (Near Threatened category; IUCN 2017). Conversely, we found that cerulean warblers were more abundant relative to edge density of linear shale gas infrastructure at the site level, which supports previous findings that cerulean warblers responded positively to roads in forested landscapes (Weakland and Wood 2005) and to forest edges created by shale gas development (Farwell et al. 2016). This is of particular concern given that this is a species of high conservation concern (Vulnerable category; IUCN 2017) that is experiencing dramatic regional and global declines (Sauer et al. 2017). Cerulean warblers declined by $35 \%$ over an 8-yr period (2008-2015) at a site impacted by shale gas development in northern WV (Farwell et al. 2016), which again suggests that pipelines and access roads may potentially function as ecological traps for some forest interior gap specialists. 
The current study adds to a growing body of evidence that a major biological consequence of expanding shale gas infrastructure on birds in this region is the restructuring of avian communities, particularly within forested environments (Barton et al. 2016, Farwell et al. 2016, Langlois 2017). The evidence indicates that forest interior specialists decline in forests near gas infrastructure while habitat generalists and edge-associated species increase, in a process known as biotic homogenization (McKinney and Lockwood 1999). Biotic homogenization leads to loss of endemic species and the ecosystem services they provide, loss of regional ecological distinctness, and decreased functional and genetic biodiversity (McKinney and Lockwood 1999, Olden et al. 2004). By gradually shifting the composition of species in regional forests, community turnover due to shale gas disturbance poses a threat to native biodiversity, and warrants further investigation (Gutzwiller et al. 2015, McGill et al. 2015).

Lastly, it is important to consider that shale gas development in this region is occurring within the context of a long history of anthropogenic forest disturbance and removal in the eastern U.S. The mixed mesophytic forests of Appalachia are almost entirely second growth, with the majority of forests regenerating since the implementation of forest management practices in the 1920s and 1930s (MacCleery 2011). The central Appalachian region has experienced and continues to experience forest loss and fragmentation due to agriculture, urban development, silviculture, coal mining, conventional oil and gas development, and most recently, wind farm development and shale gas exploration (Drummond and Loveland 2010, Evans and Kiesecker 2014). There are valid concerns about the long-term, cumulative effects of multiple anthropogenic stressors on a given landscape (Hegmann et al. 1999). The combined effects of human-facilitated disturbances are often greater than expected, since disturbances may interact to prevent biological communities from recovering as they would to natural levels of disturbance (Paine et al. 1998, Brook et al. 
2008). While we did not find that shale gas development differed from other types of human development in terms of overall avian community response at a broad scale, the rapid expansion of shale gas infrastructure combined with other forms of human forest disturbance may compound the negative effects we observed for area-sensitive, forest interior dependent birds, in particular.

\section{Management implications}

The continued removal and fragmentation of forests for the construction of shale gas infrastructure is likely unavoidable in the heavily forested Marcellus-Utica shale region. However, coordinated efforts among policy-makers and resource managers to avoid, reduce, and mitigate forest disturbance may help conserve native bird communities in this ecoregion of high importance for global biodiversity (Gillian and Kiviat 2012, Kiviat 2013).

To avoid forest disturbance, some of the largest remaining areas of core, interior forest could be exempted from future development. Although this may be easier to do on public lands from a policy standpoint, it should also be encouraged on private lands through policy and outreach efforts (Drohan et al. 2012, Stauffer et al. 2017). In addition to protecting undeveloped core forests, careful design and placement of shale gas infrastructure can prevent unnecessary forest disturbance. Given the extensive horizontal reach of directionally drilled wells $(1.5-3 \mathrm{~km})$, there is considerable flexibility regarding placement of well pads relative to target shale formations (Johnson et al. 2010, Abrahams et al. 2015). Requiring new well pads to be sited in alreadydisturbed areas and/or close to existing pipelines and access roads would minimize new forest disturbance (Milt et al. 2016, Langlois et al. 2017), although this practice must be balanced with potential impacts to water resources (Milt et al. 2016). Given that linear infrastructure is the largest contributor to forest loss and fragmentation from shale gas development - particularly 
gathering pipelines that transport gas from well pads to larger transmission lines - requiring new pipelines to be consolidated with existing pipelines and collocated with existing roads whenever possible would prevent substantial forest fragmentation (Abrahams et al. 2015, Milt et al. 2016, Langlois et al. 2017). Consolidating pipeline corridors would also create fewer but potentially wider corridors of early successional habitat, providing larger areas of non-forest habitat that may benefit early successional species (Askins 1994, Askins et al. 2012). However, this would require policies mandating coordination or "unitization" among different pipeline operators, and potentially mandating pooling of privately owned lands for pipeline easements, neither of which are easy policy-making tasks (Abrahams et al. 2015). Nevertheless, avoidance of forest disturbance whenever possible may be the most effective strategy for minimizing negative impacts, since once constructed these disturbances are functionally permanent features on the landscape.

To reduce forest disturbance, the footprint of well pads could be reduced and the number of wells per pad can be increased (Johnson et al. 2010, Drohan et al. 2012, Abrahams et al. 2013). Well pad area had a negative impact on forest interior birds in our region-wide study, yet we found an increasing trend in size of the overall footprint of well pads across the region over time. This trend was primarily driven by the increasing area occupied by secondary infrastructure associated with well pad development (i.e., buffers, retention ponds, staging areas), rather than the actual well pads. Minimizing the sprawl or "project creep" of secondary infrastructure during well pad construction and drilling would substantially reduce the footprint of disturbance. Requiring additional wells to be drilled on existing well pads in a given area before new well pads can be constructed would further reduce the footprint of shale gas disturbance, not only by reducing the 
number of well pads on the landscape but also by reducing the amount of supporting infrastructure (Johnson et al. 2010, Abrahams et al. 2015, Thompson et al. 2015).

To mitigate forest disturbance, a straightforward but important solution is to limit the timing of construction and drilling of well pads and clearing and maintenance of pipelines to avoid critical nesting periods. Additionally, non-essential shale gas infrastructure can be reclaimed as soon as drilling is complete. We found that retention ponds, in particular, often occupied an area as large as (and in some cases larger than) the well pad, itself. Additional storage and buffer areas could also be reclaimed soon after drilling is completed. Requiring operators to promptly fill and reclaim these areas may help mitigate some of the negative effects of well pad area on forest interior birds. Seeding these areas with native mixes and planting native shrubs may also benefit early successional species, some of which showed a positive response to well pad and pipeline development in our regional study. Lastly, improved management of vegetation in pipeline rightsof-way (ROW) could also help mitigate some of the negative effects of linear shale gas infrastructure on forest interior birds, while improving habitat for early successional species along these corridors (Langlois 2017). There are well-established best management practices for vegetation management along electric utility ROW, as well as a body of research on the impacts of linear corridors and effectiveness of different management strategies (e.g., Bramble and Byrnes 1983, Askins 1994, Bramble et al. 1994, De Blois et al. 2004, Yahner et al. 2004, Askins et al. 2012, Miller 2014, Richardson et al. 2017). Specific strategies include planting low-growing native shrubs on the sides of corridors to soften hard forest edges while suppressing tree growth, and using selective mowing and herbicide treatments to control invasive plants while promoting establishment of native grasses and forbs along the pipeline itself (i.e., "pipe-zone-border-zone" method). Many of these strategies are cost-effective, sustainable, require less-frequent cycles of 
mowing, remove the need for broadcast herbicide spraying, and may help mitigate some negative impacts of ROW on wildlife (Bramble and Byrnes 1983, Bramble et al. 1994, Yahner et al. 2004).

Given the relative novelty of the shale gas industry in the central Appalachian region combined with how much is still unknown about long-term environmental consequences, we suggest that continued research and monitoring of the efficacy of management strategies is also important. Natural gas is projected to be the fastest-growing fossil fuel in international energy consumption - second in demand only to renewable resources (USEIA 2017). Thus, recent studies of fragmentation impacts on interior forest habitat and wildlife communities in the Marcellus-Utica shale region carry not just regional but global implications, especially when we consider that many of the world's shale gas resources underlie global forests (USEIA 2015).

\section{Acknowledgments}

This research was funded by the U.S. Fish and Wildlife Service in collaboration with the Appalachian Mountains Joint Venture, and by a dissertation fellowship from the Southern Regional Education Board. We are grateful to the Western Pennsylvania Conservancy, D. Pitcock and the WV Host Farms Program, B. Hughes, D. LeVasseur and many other landowners who helped identify potential study sites and provided access to private property. We thank the many surveyors who collected field data, and the mapping assistants who helped digitize land cover. $\mathrm{T}$. M. Fearer, J. T. Anderson, D. J. Brown, B. E. McNeil, G. T. Merovich, and J. Sheehan provided guidance during project design and helpful comments on an earlier version of this manuscript. Special thanks to M. W. Frantz, R. D. Davis, K. R. Aldinger, and G. E. Nareff for input during project development and data analysis. We thank the WV Division of Natural Resources, PA Department of Conservation and Natural Resources, and PA Game Commission for support in the field and access to field housing. We also thank L. A. Langlois and B. M. Gamble for help and guidance early in the study, and for shared use of field housing in northern PA. Any use of trade, firm, or product names is for descriptive purposes only and does not imply endorsement by the U.S. Government. 


\section{References}

Abrahams, L. S., W. M. Griffin, and H. S. Matthews. 2015. Assessment of policies to reduce core forest fragmentation from Marcellus shale development in Pennsylvania. Ecological Indicators 52:153-160.

Appalachian Mountains Joint Venture [AMJV]. 2015. Priority Landbird Species. <http://amjv.org/documents/Priority_Landbird_Species.pdf> Accessed Aug 2015.

Anderson, M. J. 2006. Distance-based tests for homogeneity of multivariate dispersions. Biometrics 62:245-253.

Anderson, M. J. 2013. PERMANOVA, ANOSIM, and the Mantel test in the face of heterogeneous dispersions: what null hypothesis are you testing? Ecological Monographs 83:557-574

Andren, H. 1994. Effects of habitat fragmentation on birds and mammals in landscapes with different proportions of suitable habitat: a review. Oikos 71:355-366.

Arnold, T. W. 2010. Uninformative parameters and model selection using Akaike's Information Criterion. Journal of Wildlife Management 74:1175-1178.

Askins, R. A. 1994. Open corridors in a heavily forested landscape: impact on shrubland and forest-interior birds. Wildlife Society Bulletin 22:339-347.

Askins, R. A., C. M. Folsom-O'Keefe, and M. C. Hardy. 2012. Effects of vegetation, corridor width and regional land use on early successional birds on powerline corridors. PLoS ONE 7:e31520.

Banks-Leite, C., R. M. Ewers, and J. P. Metzger. 2010. Edge effects as the principal cause of area effects on birds in fragmented secondary forest. Oikos 119:918-926.

Barton, E. P., S. E. Pabian, and M. C. Brittingham. 2016. Bird community response to Marcellus shale gas development. Journal of Wildlife Management 80:1301-1313.

Bates, D., M. Maechler, B. Bolker, and S. Walker. 2015. Fitting linear mixed-effects models using lme4. Journal of Statistical Software 67:1-48.

Battin, J. 2004. When good animals love bad habitats: ecological traps and the conservation of animal populations. Conservation Biology 18:1482-1491.

Battin, J. and J. J. Lawler. 2006. Cross-scale correlations and the design and analysis of avian habitat selection studies. Condor 108:59-70.

Bayne, E. M., L. Habib, and S. Boutin. 2008. Impacts of chronic anthropogenic noise from energy-sector activity on abundance of songbirds in the Boreal forest. Conservation Biology 22:1186-1193.

Bayne, E. M., and B. C. Dale. 2011. Effects of energy development on songbirds. Pages 95-114 in D. E. Naugle, editor. Energy development and wildlife conservation in western North America. Island Press, Washington, D.C., USA.

Becker, D. A., P. B. Wood, M. P. Strager, and C. Mazzarella. 2015. Impacts of mountaintop mining on terrestrial ecosystem integrity: identifying landscape thresholds for avian species in the central Appalachians, United States. Landscape Ecology 30:339-356. 
Bélisle M, and C. C. St. Clair. 2002. Cumulative effects of barriers on the movements of forest birds. Conservation Ecology 5:9.

Bender, D. J., T. A. Contreras, and L. Fahrig. 1998. Habitat loss and population decline: a metaanalysis of the patch size effect. Ecology 79:517-533.

Bibby, C. J., N. D. Burgess, and D. A. Hill. 1992. Bird Census Techniques. Academic Press, London, United Kingdom.

Bock, C. E., and Z. F. Jones. 2004. Avian habitat evaluation: should counting birds count? Frontiers in Ecology and the Environment 2:403-410.

Boves, T. J., D. A. Buehler, J. Sheehan, P. B. Wood, A. D. Rodewald, J. L. Larkin, P. D. Keyser, F. L. Newell, G. A. George, M. H. Bakermans, A. Evans, T. A. Beachy, M. E. McDermott, K. A. Perkins, M. White, and T. B. Wigley. 2013. Emulating natural disturbances for declining late-successional species: a case study of the consequences for Cerulean Warblers (Setophaga cerulea). PLoS ONE 8: e52107.

Bramble, W. C., and W. R. Byrnes. 1983. Thirty years of research on development of plant cover on an electric transmission right-of-way. Journal of Arboriculture 9:67-74.

Bramble, W. C., R. H. Yahner, and W. R. Byrnes. 1994. Nesting of breeding birds on an electric utility right-of-way. Journal of Arboriculture 20:124-129.

Brennan, J. M., D. J. Bender, T. A. Contreras, and L. Fahrig. 2002. Focal patch landscape studies for wildlife management. Pages 68-91 in J. Wu, and W. W. Taylor, editors. Optimizing sampling effort across scales: integrating landscape ecology into natural resource management. Cambridge University Press, Cambridge, United Kingdom.

Brittingham, M. C., K. O. Maloney, A. M. Farag, D. D. Harper, and Z. H. Bowen. 2014. Ecological risks of shale oil and gas development to wildlife, aquatic resources and their habitats. Environmental Science and Technology 48:11034-11047.

Brook, B. W., N. S. Sodhi, and C. J. A. Bradshaw. 2008. Synergies among extinction drivers under global change. Trends in Ecology and Evolution 23:453-460.

Brooks, T. M., R. A. Mettermeier, C. G. Mittermeier, G. A. B. da Fonseca, A. B. Rylands, W. R. Konstant, P. Flick, J. Pilgrim, S. Oldfield, G. Magin, and C. Hilton-Taylor. 2002. Habitat loss and extinction in the hotspots of biodiversity. Conservation Biology 16:909-923.

Buchanan, M. L., and J. L. Hart. 2012. Canopy disturbance history of old-growth Quercus alba sites in the eastern United States: examination of long-term trends and broad-scale patterns. Forest Ecology and Management 267:28-39

Burnham, K. P., and D. R. Anderson. 1998. Model selection and inference: a practical information-theoretic approach. Springer-Verlag, New York, USA.

Chalfoun, A. D., Thompson, F. R., Ratnaswamy, M. J. 2002. Nest predators and fragmentation: a review and meta-analysis. Conservation Biology 16:306-18.

Clarke, K. R. 1993. Non-parametric multivariate analyses of changes in community structure. Australian Journal of Ecology 18:117-143. 
Clarke, K. R., and R. M. Warwick. 2001. Change in marine communities: an approach to statistical analysis and interpretation. Second edition. PRIMER-E, Plymouth, United Kingdom.

Conner, R. N., and C. S. Adkisson. 1975. Effects of clearcutting on diversity of breeding birds. Journal of Forestry 73:781-785.

Cox, A. B., N. T. Taylor, M. A. Rebein, M. Song, M. D. Moran, and M. R. McClung. 2017. Land use changes from unconventional gas development in public lands of the Fayetteville Shale. Natural Areas Journal 37:233-239.

De Blois, S., J. Brisson, and A. Bouchard. 2004. Herbaceous covers to control tree invasion in rights-of-way: ecological concepts and applications. Environmental Management 33:606-619.

DeCapita, M. E. 2000. Brown-headed cowbird control on Kirtland's warbler nesting areas in Michigan, 1972-1995. Pages 333-341 in J. N. M. Smith, T. L. Cook, S. I. Rothstein, S. K. Robinson, and S. G. Sealy, editors. Ecology and management of cowbirds and their hosts: studies in the conservation of North American passerine birds. University of Texas Press, Austin, Texas, USA.

DeGregorio, B. A., P. J. Weatherhead, and J. H. Sperry. 2014. Power lines, roads, and avian nest survival: effects on predator identity and predation intensity. Evolution and Ecology 4:15891600 .

Desrochers, A., C. Renaud, W. M. Hochachka, and M. Cadman. 2010. Area-sensitivity by forest songbirds: theoretical and practical implications of scale-dependency. Ecography 33:921-931.

Donnelly, S., I. C. Wilson, and J. O. Appiah. 2017. Comparing land change from shale gas infrastructure development in neighboring Utica and Marcellus regions, 2006-2015. Journal of Land Use Science 12:338-350.

Donovan, T. M., P. W. Jones, E. M. Annand, and F. R. Thompson. 1997. Variation in local-scale edge effects: mechanisms and landscape context. Ecology 78:2064-2075.

Dormann, C. F., J. Elith, S. Bacher, C. Buchmann, G. Carl, G. Carre, J. R. G. Marquez, B. Gruber, B. Lafourcade, P. J. Leitao, T. Munkemuller, C. McClean, P. E. Osborne, B. Reineking, B. Schroder, A. K. Skidmore, D. Zurell, and S. Lautenbach. 2013. Collinearity: a review of methods to deal with it and a simulation study evaluating their performance. Ecography 36:27-46.

Drohan, P. J., M. C. Brittingham, and J. Bishop. 2012. Early trends in landcover change and forest fragmentation due to shale-gas development in Pennsylvania: a potential outcome for the northcentral Appalachians. Environmental Management 49:1061-1075.

Drummond, M. A., and T. R. Loveland. 2010. Land-use pressure and a transition to forest-cover loss in the Eastern United States. BioScience 60:286-298.

Eckrich, G. H., J. A. Koloszar, and M. D. Goering. 1999. Effective landscape management of brown-headed cowbirds at Fort Hood, Texas. Studies in Avian Biology 18:267-274.

Evans, J. S., and J. M. Kiesecker. 2014. Shale gas, wind and water: assessing the potential cumulative impacts of energy development on ecosystem services within the Marcellus play. PLoS One 9:e89210. 
Farwell, L. S., P. B. Wood, J. Sheehan, G. A. George. 2016. Shale gas development effects on the songbird community in a central Appalachian forest. Biological Conservation 201:78-91.

Fearer, T., and S. Klopfer. 2013. Examining the relationship between forest characteristics and bird distribution at the landscape scale: potential impacts of Marcellus shale development in Pennsylvania. Appalachian Mountains Joint Venture, Blacksburg, Virginia, USA.

Francis, C. D., J. Paritsis, C. P. Ortega, and A. Cruz. 2011. Landscape patterns of avian habitat use and nest success are affected by chronic gaswell compressor noise. Landscape Ecology 26:1269-1280.

Frantz, M. W., P. B. Wood, J. Sheehan, and G. A. George. 2018. Demographic response of Louisiana Waterthrush, a stream obligate songbird of conservation concern, to shale gas development. Condor 120:265-282.

Frid, A., and L. Dill. 2002. Human-caused disturbance stimuli as a form of predation risk. Conservation Ecology 1:11.

Friesen, L. E., G. Casbourn, V. Martin, and R. J. Mackay. 2013. Nest predation in an anthropogenic landscape. Wilson Journal of Ornithology 125:562-569.

Gates, J. E., and D. R. Evans. 1998. Cowbirds breeding in the central Appalachians: spatial and temporal patterns and habitat selection. Ecological Applications 8:27-40.

Gillen, J. L., and E. Kiviat. 2012. Hydraulic fracturing threats to species with restricted geographic ranges in the Eastern United States. Environmental Practice 14:320-331.

Glennon, M. J., and H. E. Kretser. 2013. Size of the ecological effect zone associated with exurban development in the Adirondack Park, NY. Landscape and Urban Planning 112:1017.

Gutzwiller, K. J., S. K. Riffell, and C. H. Flather. 2015. Avian abundance thresholds, humanaltered landscapes, and the challenge of assemblage-level conservation. Landscape Ecology 30:2095-2110.

Hegmann, G., C. Cocklin, R. Creasey, S. Dupuis, A. Kennedy, L. Kingsley, W. Ross, H. Spaling, and D. Stalker. 1999. Cumulative Effects Assessment Practitioners Guide. AXYS Environmental Consulting and the CEA Working Group for the Canadian Environmental Assessment Agency, Hull, Quebec, Canada.

Helle, P., and M. Monkkonen. 1990. Forest successions and bird communities: theoretical aspects and practical implications. Pages 299-318 in A. Keast, editor. Biogeography and ecology of forest bird communities. SPB Academic Publishing, The Hague, Netherlands.

Howell, C. A., W. D. Dijak, and F. R. Thompson. 2007. Landscape context and selection for forest edge by breeding brown-headed cowbirds. Landscape Ecology 22:273-284.

International Union for Conservation of Nature and Natural Resources [IUCN]. 2017. The IUCN red list of threatened species. Version 2017-1. <http://www.iucnredlist.org> Accessed Oct 2017.

Johnson, N., T. Gagnolet, R. Ralls, E. Zimmerman, B. Eichelberger, C. Tracey, G. Kreitler, S. Orndorff, J. Tomlinson, S. Bearer, and S. Sargent. 2010. Pennsylvania energy impacts 
assessment, report 1: Marcellus shale natural gas and wind. The Nature Conservancy, Pennsylvania Chapter, Harrisburg, Pennsylvania, USA.

Jokimaki,J., and E. Huhta. 2000. Artificial nest predation and abundance of birds along an urban gradient. Condor 102:838-847.

Kempenaers, B., P. Borgstrom, P. Loes, E. Schlicht, and M. Valcu. 2010. Artificial night lighting affects dawn song, extra-pair siring success, and lay date in songbirds. Current Biology 20:1735-1739.

Kiviat, E. 2013. Risks to biodiversity from hydraulic fracturing for natural gas in the Marcellus and Utica shales. Annals of the New York Academy of Sciences 1286:1-14.

Kluza, D. A., C. R. Griffin, and R. M. DeGraaf. 2000. Housing developments in rural New England: effects on forest birds. Animal Conservation 3:15-26.

Kruskal, J. 1964. Nonmetric multidimensional scaling: a numerical method. Psychometrika 29:115-129.

Kupfer, J. A., G. P. Malanson, and S. B. Franklin. 2006. Not seeing the ocean for the islands: the mediating influence of matrix-based processes on forest fragmentation effects. Global Ecology and Biogeography 15:8-20.

Kus, B. E. 1999. Impacts of brown-headed cowbird parasitism on productivity of the endangered Least Bell's Vireo. Studies in Avian Biology 18:160-166.

Langlois, L. A. 2017. Effects of Marcellus shale gas infrastructure on forest fragmentation and bird communities in northcentral Pennsylvania. Dissertation, Pennsylvania State University, State College, USA.

Langlois, L. A., P. J. Drohan, and M. C. Brittingham. 2017. Linear infrastructure drives habitat conversion and forest fragmentation associated with Marcellus shale gas development in a forested landscape. Journal of Environmental Management 197:167-176.

Latta, S. C., L. C. Marshall, M. W. Frantz, and J. D. Toms. 2015. Evidence from two shale gas regions that a riparian songbird accumulates metals associated with hydraulic fracturing. Ecosphere 6:art144.

Legendre, P., and L. Legendre. 2012. Numerical ecology. Third edition. Elsevier, Amsterdam, Netherlands.

Lumpkin, H. A., and S. M. Pearson. 2013. Effects of exurban development and temperature on bird species in the southern Appalachians. Conservation Biology 27:1069-1078.

MacCleery, D. W. 2011. American forests: a history of resiliency and recovery. The Forest History Society, Durham, North Carolina, USA.

Matsuoka, S. M., C. L. Mahon, C. M. Handel, P. Sólymos, E. M. Bayne, P. C. Fontaine, and C. J. Ralph. 2014. Reviving common standards in point-count surveys for broad inference across studies. Condor 116:599-608.

Mazerolle, M. J. 2006. Improving data analysis in herpetology: using Akaike's Information Criterion (AIC) to assess the strength of biological hypotheses. Amphibia-Reptilia 27:169180. 
Mazerolle, M. J. 2016. AICcmodavg: model selection and multimodel inference based on (Q)AIC(c). R package version 2.0-4. 〈http://CRAN.R-project.org/package=AICcmodavg> Accessed Mar 2016.

McDermott, M. E., and P. B. Wood. 2009. Short- and long-term implications of clearcut and twoage silviculture for conservation of breeding forest birds in the central Appalachians, USA. Biological Conservation 142:212-220.

McGarigal, K., S. A. Cushman, and E. Ene. 2012. FRAGSTATS v4: Spatial Pattern Analysis Program for Categorical and Continuous Maps. University of Massachusetts, Amherst. Amherst, MA. <http://www.umass.edu/landeco/research/fragstats/fragstats.html > Accessed Jul 2017.

McGill, B. J., M. Dornelas, N. J.Gotelli, and A. E. Magurran. 2015. Fifteen forms of biodiversity trend in the Anthropocene. Trends in Ecology and Evolution 30:104-113.

McKinney, M. L., and J. L. Lockwood. 1999. Biotic homogenization: a few winners replacing many losers in the next mass extinction. Trends in Ecology and Evolution 14:450-453.

Miller, J. R., and N. T. Hobbs. 2000. Recreational trails, human activity, and nest predation in lowland riparian areas. Landscape and Urban Planning 50:227-236.

Miller, R. H. 2014. Best management practices: integrated vegetation management. Second edition. International Society of Arboriculture, Champaign, Illinois, USA.

Milt, A. W., T. Gagnolet, and P. R. Armsworth. 2016. Synergies and tradeoffs among environmental impacts under conservation planning of shale gas infrastructure. Environmental Management 57:21-30.

Mooney, P. F. 2011. The effect of human disturbance on site habitat diversity and avifauna community composition in suburban conservation areas. Pages 13-25 in Y. Villacampa, and C. A. Brebbia, editors. Ecosystems and sustainable development VIII. WIT Press, Ashurst, United Kingdom.

Moran, M. D., A. B. Cox, R. L. Wells, C. C. Benichou, and M. R. McClung. 2015. Habitat loss and modification due to gas development in the Fayetteville Shale. Environmental Management 55:1276-1284.

Mortelliti, A., S. Fagiani, and C. Battisti. 2010. Independent effects of habitat loss, habitat fragmentation and structural connectivity on forest-dependent birds. Diversity and Distributions 16:941-951.

National Agriculture Imagery Program [NAIP]. 2016. U.S. Department of Agriculture Farm Service Agency: NAIP Imagery. <https://www.fsa.usda.gov/programs-and-services/aerialphotography/imagery-programs/naip-imagery/> Accessed Jun 2017.

Nee, S., and R. M. May. 1992. Dynamics of metapopulations: habitat destruction and competitive coexistence. Journal of Animal Ecology 61:37-40.

O’Connell, T. J., L. E. Jackson, and R. P. Brooks. 2000. Bird guilds as indicators of ecological condition in the central Appalachians. Ecological Applications 10:1706-1721.

Ohio Department of Natural Resources [OHDNR]. 2017. Ohio oil and gas well database. <http://apps.ohiodnr.gov/oilgas/rbdmsreports/Reports_Completions.aspx> Accessed Jul 2017. 
Oksanen, J., F. Guillaume Blanchet, R. Kindt, P. Legendre, P. R. Minchin, R. B. O'Hara, G. L. Simpson, P. Sólymos, M. Henry, H. Stevens, and H. Wagner. 2016. vegan: Community ecology package. R package version 2.3-3. <https://CRAN.R-project.org/package=vegan> Accessed Feb 2016.

Olden, J. D., N. L. Poff, M. R. Douglas, M. E. Douglas, and K. D. Fausch. 2004. Ecological and evolutionary consequences of biotic homogenization. Trends in Ecology and Evolution $19: 18-24$.

Omernik, J. M., and G. E. Griffith. 2014. Ecoregions of the conterminous United States: evolution of a hierarchical spatial framework. Environmental Management 54:1249-1266.

Pennsylvania Department of Environmental Protection [PADEP]. 2017. Pennsylvania oil and gas mapping. <http://www.depgis.state.pa.us/PaOilAndGasMapping/OilGasWellsStrayGasMap.html> Accessed Jul 2017.

Paine, R. T., M. J. Tegner, and E. A. Johnson. 1998. Compounded perturbations yield ecological surprises. Ecosystems 1:535-545.

Paton, P. W. C. 1994. The effects of edge on avian nest success: how strong is the evidence? Conservation Biology 8:17-26.

Perkins, K. A., and P. B. Wood. 2014. Selection of forest canopy gaps by male cerulean warblers in West Virginia. Wilson Journal of Ornithology 126:288-297.

Pickell, P., S. Gergel, N. Coops, and D. Andison. 2014. Monitoring forest change in landscapes undergoing rapid energy development: challenges and new perspectives. Land 3:617-638.

Pimm, S., P. Raven, A. Peterson, C. H. Sekercioglu, and P. R. Ehrlich. 2006. Human impacts on the rates of recent, present, and future bird extinctions. Proceedings of the National Academy of Sciences of the United States of America 103:10941-10946.

Racicot, A., V. Babin-Roussel, J.-F. Dauphinais, J. S. Joly, P. Noel, and C. Lavoie. 2014. A framework to predict the impacts of shale gas infrastructures on the forest fragmentation of an agroforest region. Environmental Management 53:1023-1033.

Ralph, C. J., S. Droege, J. R. Sauer. 1995. Managing and monitoring birds using point counts: standards and applications. USDA Forest Service General Technical Report PSW-GTR-149: 161-168. USDA Forest Service Pacific Southwest Research Station, Albany, California, USA.

Rich, T. D., C. J. Beardmore, H. Berlanga, P. J. Blancher, M. S. W. Bradstreet, G. S. Butcher, D. W. Demarest, E. H. Dunn, W. C. Hunter, E. E. Inigo-Elias, J. A. Kennedy, A. M. Martell, A. O. Panjabi, D. N. Pashley, K. V. Rosenberg, C. M. Rustay, J. S. Wendt, and T. C. Will. 2004. Partners in Flight North American landbird conservation plan. Cornell Lab of Ornithology, Ithaca, New York, USA.

Richardson, M. L., B. A. Wilson, D. A. S. Aiuto, J. E. Crosby, A. Alonso, F. Dallmeier, and G. K. Golinski. 2017. A review of the impact of pipelines and power lines on biodiversity and strategies for mitigation. Biodiversity and Conservation 26:1801-1815. 
Robbins, C. S., J. R. Sauer, R. S. Greenberg, and S. Droege. 1989. Population declines in North American birds that migrate to the neotropics. Proceedings of the National Academy of Sciences of the United States of America 86:7658-7662.

Robinson, S. K., F. R. Thompson, T. M. Donovan, D. R. Whitehead, and J. Faaborg. 1995. Regional forest fragmentation and the nesting success of migratory birds. Science 267:19871990.

Rodewald, P. G., editor. 2015. The birds of North America. Cornell Laboratory of Ornithology, Ithaca, New York, USA.

Ruokolainen, L., and K. Salo. 2006. Differences in performance of four ordination methods on a complex vegetation dataset. Annales Botanici Fennici 43:269-275.

Sauer, J. R., D. K. Niven, J. E. Hines, K. L. Pardieck, J. E. Fallon, W. A. Link, and D. J. Ziolkowski, Jr. 2017. The North American Breeding Bird Survey, results and analysis 19662015. Version 12.23.2015. USGS Patuxent Wildlife Research Center, Laurel, Maryland, USA.

Shipley, A. A., M. T. Murphy, and A. H. Elzinga. 2013. Residential edges as ecological traps: post-fledging survival of a ground-nesting passerine in a forested urban park. Auk 130:501511.

Shochat, E., S. B. Lerman, J. M. Anderies, P. S. Warren, S. H. Faeth, and C. H. Nilon. 2010. Invasion, competition, and biodiversity loss in urban ecosystems. Bioscience 60:199-208.

Smith, A. C., L. Fahrig, and C. M Francis. 2011. Landscape size affects the relative importance of habitat amount, habitat fragmentation, and matrix quality on forest birds. Ecography 34:103113.

Sólymos, P., S. M. Matsuoka, E. M. Bayne, S. R. Lele, P. Fontaine, S. G. Cummings, D. Stralberg, F. K. A. Schmiegelow, and S. J. Song. 2013. Calibrating indices of avian density from non-standardized survey data: making the most of a messy situation. Methods in Ecology and Evolution 4:1047-1058.

Sólymos, P., M. Moreno, and S. R. Lele. 2016. detect: Analyzing wildlife data with detection error. R package version 0.4-0. <https://CRAN.R-project.org/package=detect > Accessed Apr 2016.

Souther, S, M. W. Tingley, V. D. Popescu, D. T. S. Hayman, M. E. Ryan, T. A. Graves, B. Harth, and K. Terrell. 2014. Biotic impacts of energy development from shale: research priorities and knowledge gaps. Frontiers in Ecology and the Environment 12: 330-338.

Soykan, C. U., J. Sauer, J. G. Schuetz, G. S. LeBaron, K. Dale, and G. M. Langham. Population trends for North American winter birds based on hierarchical models. Ecosphere 7:e01351.

Stauffer, G. E., D. A. W. Miller, A. M. Wilson, M. C. Brittingham, and D. W. Brauning. 2017. Stewardship responsibility of Pennsylvania public and private lands for songbird conservation. Biological Conservation 213:185-193.

Steele, M. A., M. C. Brittingham, T. J. Maret, and J. F. Merritt. 2010. Terrestrial vertebrates of Pennsylvania: a complete guide to species of conservation concern. Johns Hopkins University Press, Baltimore, Maryland, USA. 
Thomas, E. H., M. C. Brittingham, and S. H. Stoleson. 2014. Conventional oil and gas development alters forest songbird communities. Journal of Wildlife Management 78:293306.

Thompson, F. R., D. E. Burhans, and B. Root. 2002. Effects of point count protocol on bird abundance and variability estimates and power to detect population trends. Journal of Field Ornithology 73:141-150.

Thompson, S. J., D. H. Johnson, N. D. Niemuth, and C. A. Ribic. 2015. Avoidance of unconventional oil wells and roads exacerbates habitat loss for grassland birds in the North American great plains. Biological Conservation 192:82-90.

U.S. Energy Information Administration [USEIA]. 2015. World shale resource assessments. <https://www.eia.gov/analysis/studies/worldshalegas/> Accessed Oct 2015.

U.S. Energy Information Administration [USEIA]. 2018. Annual energy outlook. <https://www.eia.gov/outlooks/aeo/> Accessed Feb 2018.

U.S. Energy Information Administration [USEIA]. 2017. International energy outlook. $<$ https://www.eia.gov/outlooks/ieo/> Accessed Oct 2017.

U.S. Environmental Protection Agency [USEPA]. 2013. Level III and IV ecoregions of the continental United States: Corvallis, Oregon, U.S. EPA - National Health and Environmental Effects Research Laboratory, map scale 1:7,500,000. <https://www.epa.gov/ecoresearch/level-iii-and-iv-ecoregions-continental-united-states> Accessed Aug 2016.

van der Hoek, Y., R. Renfrew, and L. L. Manne. 2013. Assessing regional and interspecific variation in threshold responses of forest breeding birds through broad scale analyses. PLoS ONE 8:e55996.

Van Horne, B. 1983. Density as a misleading indicator of habitat quality. 1983. Journal of Wildlife Management 47:893-901.

Villard, M., M. K. Trzcinski, and G. Merriam. 1999. Fragmentation effects on forest birds: relative influence of woodland cover and configuration on landscape occupancy. Conservation Biology 13:774-783.

Ware, H. E., C. J. W. McClure, J. D. Carlisle, and J. R. Barber. 2015. A phantom road experiment reveals traffic noise is an invisible source of habitat degradation. Proceedings of the National Academy of Sciences of the United States of America 112:12105-12109.

Weakland, C. A., and P. B. Wood. 2005. Cerulean warbler (Dendroica cerulea) microhabitat and landscape-level habitat characteristics in southern West Virginia. Auk 122:497-508.

Whitcomb, R. F., C. S. Robbins, J. F. Lynch, B. L. Klimkiewicz, and D. Bystrak. 1981. Effects of forest fragmentation on avifauna of the eastern deciduous forest. Pages 125-206 in R. L. Burgess, and D. M. Sharpe, editors. Forest island dynamics in man-dominated landscapes. Springer-Verlag, New York, USA.

Wood, P. B., S. Bosworth, and R. Dettmers. 2006. Cerulean warbler abundance and occurrence relative to large-scale edge and habitat characteristics. Condor 108:154-165. 
Wood, P. B., and F. K. Ammer. 2015. Grasshopper sparrow reproductive success and habitat use on reclaimed surface mines varies by age of reclamation. Wildlife Society Bulletin 39:512520 .

West Virginia Geological and Economic Survey [WVGES]. 2017. Pipeline: West Virginia oil and gas well database. <http://www.wvgs.wvnet.edu/oginfo/pipeline/pipeline2.asp> Accessed Jul 2017.

Yahner, R. H., B. D. Ross, R. T. Yahner, R. J. Hutnik, and S. A. Liscinsky. 2004. Long-term effects of rights-of-way maintenance via the wire-border zone method on bird nesting ecology. Journal of Arboriculture 30:288-294.

Zuckerberg, B., and W. F. Porter. 2010. Thresholds in the long-term responses of breeding birds to forest cover and fragmentation. Biological Conservation 143:952-962.

Zuckerberg, B., A. Desrochers, W. M. Hochachka, D. Fink, W. D. Koenig, and J. L. Dickinson. 2012. Overlapping landscapes: a persistent, but misdirected concern when collecting and analyzing ecological data. Journal of Wildlife Management 76:1072-1080.

Zuur, A. F., E. N. Ieno, N. J. Walker, A. A. Saveliev, and G. M. Smith. 2009. Mixed effects models and extensions in ecology with R. Springer, New York, USA. 
Figure 1. Map of study region. Sites were surveyed in 5 states: Pennsylvania, West Virginia, Ohio, Maryland, and New York. Black triangles represent shale gas sites, white dots represent non-gas sites. Extent of Marcellus shale play shaded in gray.

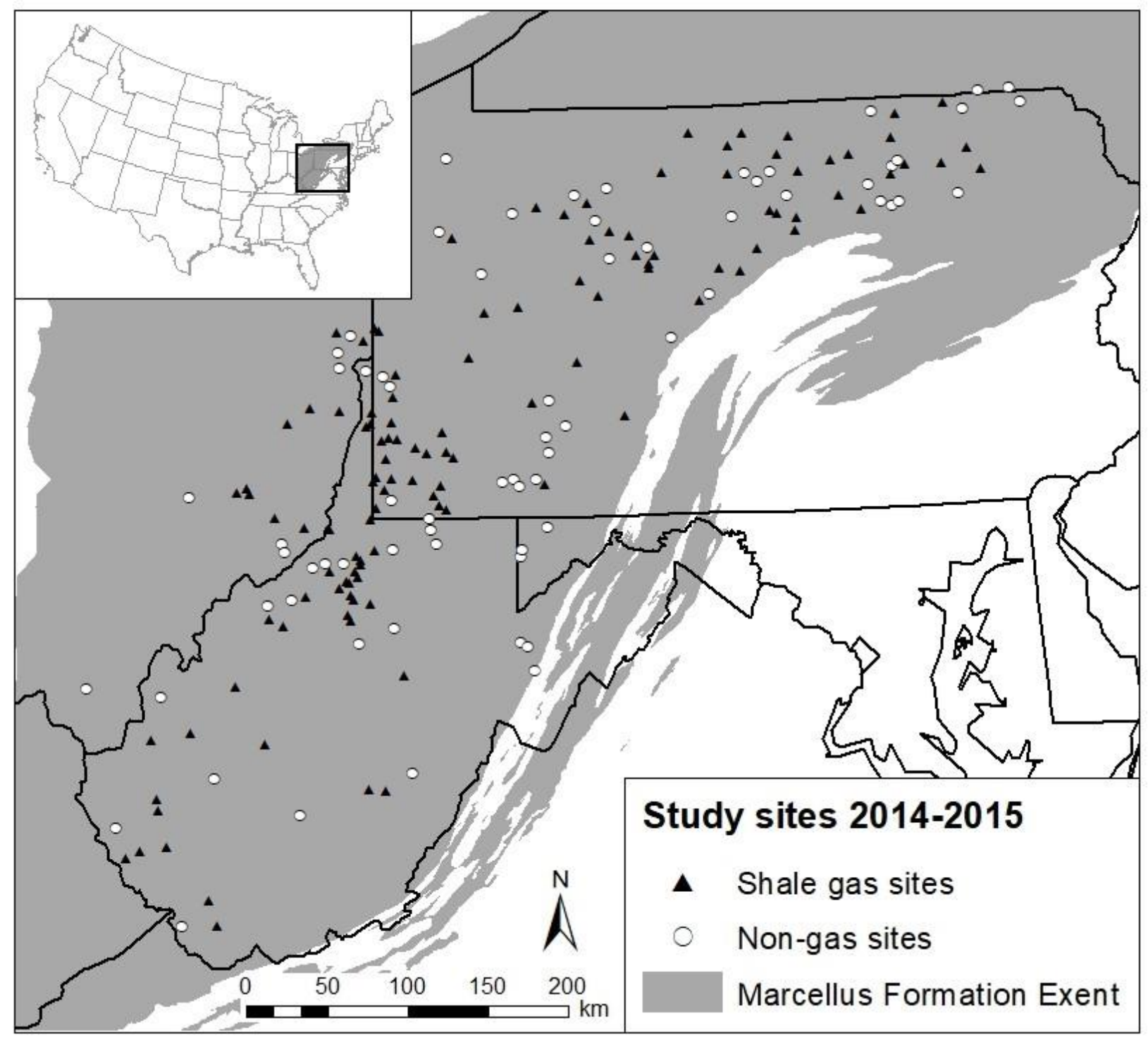


Figure 2. Land cover maps of 3 shale gas sites representing a gradient of forest cover: (a) low $37 \%$ forest, (b) moderate - $66 \%$ forest, and (c) high - 94\% forest. Forest cover shown in green, shale gas infrastructure in red, non-gas development in black, agriculture in light green. White dots represent point count locations. Non-gas sites had similar gradients of forest cover and human development but had no shale gas development.
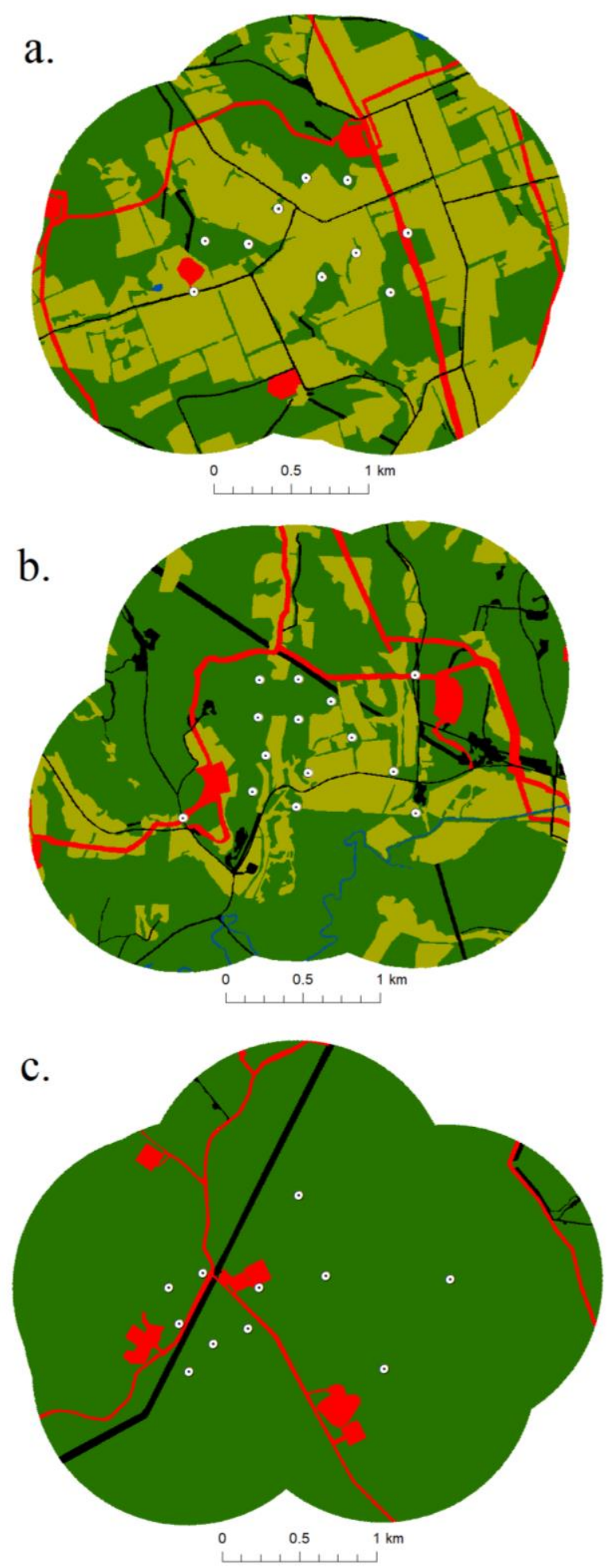
Figure 3. Site-level NMDS ordinations of sites (individual dots) based on avian community similarity, for (a) non-gas sites (bounded by white polygon) and shale gas sites (bounded by gray polygon); (b) shale gas sites with well pads on public lands (white polygon) versus private lands (gray polygon). Sites closer together in ordination space are more similar in overall species composition. For reference only, vectors labeled with large black text show the loadings of species richness within 3 avian guilds on the ordination axes: forest interior (FI), early successional (ES) and synanthropic (SYN). Vectors labeled with smaller gray text show the loadings of land cover: percent forest (FOREST), percent non-gas development (DEVELOP), and percent shale gas development (GAS). GAS was significant in (a) and non-significant in (b).
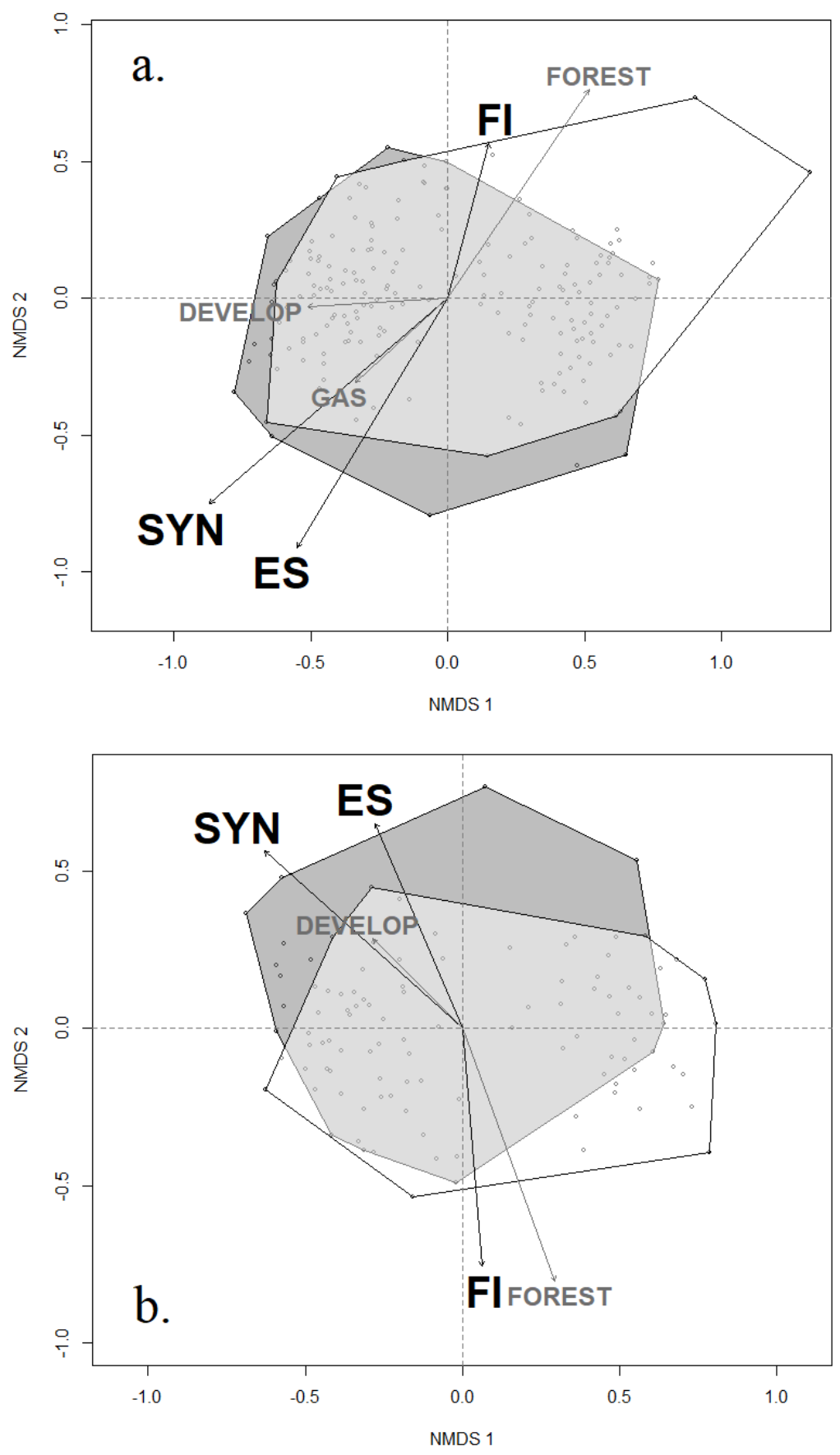
Table 1. Species surveyed during 2014-2015, grouped into three guilds potentially affected by human development: forest interior, early successional, and synanthropic species. Birds with no clear habitat guild were excluded from guild analyses. Focal species shown in bold.

\begin{tabular}{|c|c|c|c|}
\hline Forest Interior & Early Successional & Synanthropic & No Assigned Guild \\
\hline $\begin{array}{l}\text { Acadian flycatcher }{ }^{2} \\
\text { Empidonax virescens }\end{array}$ & $\begin{array}{l}\text { Blue-winged warbler }{ }^{2, b} \\
\text { Vermivora cyanoptera }\end{array}$ & $\begin{array}{l}\text { American goldfinch } \\
\text { Spinus tristis }\end{array}$ & $\begin{array}{l}\text { Alder flycatcher } \\
\text { Empidonax alnorum }\end{array}$ \\
\hline $\begin{array}{l}\text { American redstart } \\
\text { Setophaga ruticilla }\end{array}$ & $\begin{array}{l}\text { Brown thrasher" } \\
\text { Toxostoma rufum }\end{array}$ & $\begin{array}{l}\text { American robin } \\
\text { Turdus migratorius }\end{array}$ & $\begin{array}{l}\text { Black-billed cuckoo" } \\
\text { Coccyzus enythropthalmus }\end{array}$ \\
\hline $\begin{array}{l}\text { Black-and-white warbler } \\
\text { Mniotilta varia }\end{array}$ & $\begin{array}{l}\text { Chestnut-sided warbler } \\
\text { Setophaga pensylvanica }\end{array}$ & $\begin{array}{l}\text { Baltimore oriole } \\
\text { Icterus galbula }\end{array}$ & $\begin{array}{l}\text { Black-capped chickadee } \\
\text { Poecile atricapillus }\end{array}$ \\
\hline $\begin{array}{l}\text { Blackburnian warbler } \\
\text { Setophaga fusca }\end{array}$ & $\begin{array}{l}\text { Common yellowthroat } \\
\text { Geothlypis trichas }\end{array}$ & $\begin{array}{l}\text { Blue jay } \\
\quad \text { Cyanocitta cristata }\end{array}$ & $\begin{array}{l}\text { Blve-gray gnatcatcher } \\
\text { Polioptila caerulea }\end{array}$ \\
\hline $\begin{array}{l}\text { Black-throated blue warbler } \\
\text { Setophaga caerulescens }\end{array}$ & $\begin{array}{l}\text { Eastern blvebird } \\
\text { Sialia sialis }\end{array}$ & $\begin{array}{l}\text { Brown-headed cowbird } \\
\text { Molothrus ater }\end{array}$ & $\begin{array}{l}\text { Bobolink } \\
\text { Dolichonyx onyzivorus }\end{array}$ \\
\hline $\begin{array}{l}\text { Black-throated green warbler } \\
\text { Setophaga virens }\end{array}$ & $\begin{array}{l}\text { Eastern kingbird } \\
\text { Tyrannus tyrannus }\end{array}$ & $\begin{array}{l}\text { Carolina wren } \\
\text { Thyothorus ludovicianus }\end{array}$ & $\begin{array}{l}\text { Carolina chickadee } \\
\text { Poecile carolinensis }\end{array}$ \\
\hline $\begin{array}{l}\text { Blve-headed vireo } \\
\text { Vireo solitarius }\end{array}$ & $\begin{array}{l}\text { Eastern towhee } \\
\quad \text { Pipilo enythrophthalmus }\end{array}$ & $\begin{array}{l}\text { Chipping sparrow } \\
\text { Spizella passerina }\end{array}$ & $\begin{array}{l}\text { Cedar waxwing } \\
\text { Bombycilla cedrorum }\end{array}$ \\
\hline $\begin{array}{l}\text { Brown creeper } \\
\text { Certhia americana }\end{array}$ & $\begin{array}{l}\text { Field sparrow }{ }^{2} \\
\quad \text { Spizella pusilla }\end{array}$ & $\begin{array}{l}\text { Common grackle } \\
\text { Quiscalus quiscula }\end{array}$ & $\begin{array}{l}\text { Dark-eyed junco } \\
\text { Junco hyemalis }\end{array}$ \\
\hline $\begin{array}{l}\text { Canada warbler }{ }^{2, b} \\
\text { Cardellina canadensis }\end{array}$ & $\begin{array}{l}\text { Golden-winged warbler } \\
\text { Vermivora chyysoptera }\end{array}$ & $\begin{array}{l}\text { Eastern phoebe } \\
\text { Sayornis phoebe }\end{array}$ & $\begin{array}{l}\text { Eastern meadowlark } \\
\text { Stumella magna }\end{array}$ \\
\hline $\begin{array}{l}\text { Cerulean warbler }{ }^{2, \text { the }} \\
\text { Setophaga cerulea }\end{array}$ & $\begin{array}{l}\text { Gray catbird } \\
\text { Dumetella carolinensis }\end{array}$ & $\begin{array}{l}\text { European starling } \\
\text { Stumus vulgaris }\end{array}$ & $\begin{array}{l}\text { Grasshopper sparrow" } \\
\text { Ammodramus savannarum }\end{array}$ \\
\hline $\begin{array}{l}\text { Eastern wood pewee } \\
\text { Contopus virens }\end{array}$ & $\begin{array}{l}\text { Indigo bunting }{ }^{a} \\
\text { Passerina cyanea }\end{array}$ & $\begin{array}{l}\text { House wren } \\
\text { Troglodytes aedon }\end{array}$ & $\begin{array}{l}\text { Great-crested flycatcher } \\
\text { Myiarchus crinitus }\end{array}$ \\
\hline $\begin{array}{l}\text { Hermit Thrush } \\
\text { Catharus guttatus }\end{array}$ & $\begin{array}{l}\text { Mourning warbler } \\
\text { Geothlypis philadelphia }\end{array}$ & $\begin{array}{l}\text { Mourning dove } \\
\text { Zenaida macroura }\end{array}$ & $\begin{array}{l}\text { Northern parula }{ }^{a} \\
\quad \text { Setophaga americana }\end{array}$ \\
\hline $\begin{array}{l}\text { Hooded warbler }{ }^{2} \\
\text { Setophaga citrina }\end{array}$ & $\begin{array}{l}\text { Nashville warbler } \\
\text { Oreothlypis ruficapilla }\end{array}$ & $\begin{array}{l}\text { Northern cardinal } \\
\text { Cardinalis cardinalis }\end{array}$ & $\begin{array}{l}\text { Pine warbler } \\
\text { Setophaga pinus }\end{array}$ \\
\hline $\begin{array}{l}\text { Kentucky warbler }{ }^{2, b} \\
\text { Geothlypis formosa }\end{array}$ & $\begin{array}{l}\text { Orchard oriole } \\
\text { Icterus spurius }\end{array}$ & $\begin{array}{l}\text { Northern mockingbird } \\
\text { Mimus polyglottos }\end{array}$ & $\begin{array}{l}\text { Purple finch } \\
\text { Haemorhous purpureus }\end{array}$ \\
\hline $\begin{array}{l}\text { Least flycatcher } \\
\text { Parkesia motacilla }\end{array}$ & $\begin{array}{l}\text { Prairie warbler } \\
\text { Setophaga discolor }\end{array}$ & $\begin{array}{l}\text { Song sparrow } \\
\text { Melospiza melodia }\end{array}$ & $\begin{array}{l}\text { Red-breasted nuthatch } \\
\text { Sitta canadensis }\end{array}$ \\
\hline $\begin{array}{l}\text { Lovisiana waterthrush" } \\
\text { Parkesia motacilla }\end{array}$ & $\begin{array}{l}\text { Warbling vireo } \\
\text { Vireo gilvus }\end{array}$ & & $\begin{array}{l}\text { Red-winged blackbird } \\
\text { Agelaius phoeniceus }\end{array}$ \\
\hline $\begin{array}{l}\text { Magnolia warbler } \\
\text { Setophaga magnolia }\end{array}$ & $\begin{array}{c}\text { White-eyed vireo } \\
\text { Vireo griseus }\end{array}$ & & $\begin{array}{l}\text { Ruby-throated hummingbird } \\
\text { Archilochus colubris }\end{array}$ \\
\hline $\begin{array}{l}\text { Ovenbird } \\
\quad \text { Seiurus aurocapilla }\end{array}$ & $\begin{array}{l}\text { Willow flycatcher, } \\
\text { Empidonax traillii }\end{array}$ & & $\begin{array}{l}\text { Savannah sparrow } \\
\text { Passerculus sandwichensis }\end{array}$ \\
\hline $\begin{array}{l}\text { Red-eyed vireo } \\
\text { Vireo olvaceus }\end{array}$ & $\begin{array}{l}\text { Yellow-breasted chat } \\
\text { Icteria virens }\end{array}$ & & $\begin{array}{l}\text { Summer tanager } \\
\text { Piranga rubra }\end{array}$ \\
\hline $\begin{array}{l}\text { Rose-breasted grosbeak } \\
\text { Pheucticus ludovicianus }\end{array}$ & & & $\begin{array}{l}\text { Tufted titmouse } \\
\text { Basolophus bicolor }\end{array}$ \\
\hline $\begin{array}{l}\text { Scarlet tanager } \\
\quad \text { Piranga olvivacea }\end{array}$ & & & $\begin{array}{l}\text { White-breasted nuthatch } \\
\text { Sitta carolinensis }\end{array}$ \\
\hline $\begin{array}{l}\text { Swainson's thrush } \\
\text { Catharus ustulatus }\end{array}$ & & & $\begin{array}{l}\text { Yellow warbler } \\
\quad \text { Setophaga petechia }\end{array}$ \\
\hline $\begin{array}{l}\text { Swainson's warbler" } \\
\text { Limnothlypis stainsonii }\end{array}$ & & & $\begin{array}{l}\text { Yellow-billed cuckoo' } \\
\text { Coccyzus americanus }\end{array}$ \\
\hline $\begin{array}{l}\text { Veery } \\
\text { Catharus fuscescens }\end{array}$ & & & $\begin{array}{l}\text { Yellow-throated vireo" } \\
\text { Vireo flavifions }\end{array}$ \\
\hline \multicolumn{4}{|l|}{$\begin{array}{l}\text { Winter wren } \\
\text { Troglodytes hiemalis }\end{array}$} \\
\hline \multicolumn{4}{|l|}{$\begin{array}{l}\text { Wood thrush } \\
\text { Hylocichla mustelina }\end{array}$} \\
\hline \multicolumn{4}{|l|}{$\begin{array}{l}\text { Worm-eating warbler }{ }^{2, b} \\
\text { Helmitheros vermivorum }\end{array}$} \\
\hline \multicolumn{4}{|l|}{$\begin{array}{l}\text { Yellow-rumped warbler } \\
\text { Setophaga coronata }\end{array}$} \\
\hline $\begin{array}{c}\text { Yellow-throated warbler } \\
\text { Setophaga dominica }\end{array}$ & & & \\
\hline
\end{tabular}


Table 2. Summary results of generalized linear mixed models relating avian guild species richness with site-level land cover metrics ( $n=190$ sites), after model-averaging.

\begin{tabular}{lcccccc}
\hline Habitat guild: & & Forest sice & Gas Pad sile & Non-gas sile & Linear gas sire & Linear non-gas sice \\
\hline Forest interior & Est. & 0.12 & 0.002 & -0.01 & 0.02 & 0.01 \\
& (C.I.) & $(0.08,0.15)$ & $(-0.03,0.04)$ & $(-0.05,0.02)$ & $(-0.01,0.05)$ & $(-0.02,0.04)$ \\
& Rel. Imp. & 1.00 & 0.27 & 0.29 & 0.33 & 0.29 \\
Early successional & Est. & -0.16 & -0.002 & 0.01 & -0.01 & 0.01 \\
& (C.I.) & $(-0.21,-0.11)$ & $(-0.05,0.05)$ & $(-0.03,0.06)$ & $(-0.06,0.05)$ & $(-0.04,0.06)$ \\
& Rel. Imp. & 1.00 & 0.26 & 0.27 & 0.26 & 0.27 \\
Synanthropic & Est. & -0.12 & 0.01 & 0.02 & 0.07 & -0.02 \\
& (C.I.) & $(-0.17,-0.06)$ & $(-0.05,0.06)$ & $(-0.03,0.07)$ & $(0.02,0.12)$ & $(-0.07,0.03)$ \\
& Rel. Imp. & 0.97 & 0.28 & 0.30 & 0.69 & 0.30 \\
\hline
\end{tabular}

*85\% unconditional confidence intervals provided, following Arnold (2010).

Table 3. Summary results of generalized linear mixed models relating habitat guild species richness with point-level land cover metrics ( $n=2,590$ points), after model-averaging.

\begin{tabular}{lcccccc}
\hline Habitat guild: & & Forest $_{\mathrm{llm}}$ & Gas Pad $_{500 \mathrm{~m}}$ & Non-gas soom & Linear gas soom & Linear non-gas soom \\
\hline Forest interior & Est. & 0.14 & -0.04 & -0.04 & -0.005 & -0.01 \\
& (C.I.) & $(0.11,0.16)$ & $(-0.06,-0.03)$ & $(-0.06,-0.02)$ & $(-0.03,0.02)$ & $(-0.03,0.01)$ \\
& Rel. Imp. & 1.00 & 0.99 & 0.99 & 0.28 & 0.32 \\
Early successional & Est. & -0.18 & 0.06 & 0.08 & 0.13 & 0.11 \\
& (C.I.) & $(-0.23,-0.13)$ & $(0.03,0.09)$ & $(0.04,0.11)$ & $(0.09,0.17)$ & $(0.07,0.15)$ \\
& Rel. Imp. & 1.00 & 0.92 & 0.99 & 1.00 & 1.00 \\
Synanthropic & Est. & -0.21 & 0.05 & 0.001 & 0.07 & 0.05 \\
& (C.I.) & $(-0.25,-0.16)$ & $(0.02,0.09)$ & $(-0.03,0.03)$ & $(0.03,0.11)$ & $(0.02,0.09)$ \\
& Rel. Imp. & 1.00 & 0.83 & 0.27 & 0.84 & 0.81 \\
\hline
\end{tabular}

* $85 \%$ unconditional confidence intervals provided, following Arnold (2010).

Table 4. Summary results of generalized linear mixed models relating habitat guild species richness with point-level shale gas development metrics at points at gas sites only $(n=1,612$ points), after modelaveraging.

\begin{tabular}{lcccccc}
\hline Habitat guild: & & Linear gas so0m & Pad area $500 \mathrm{~m}$ & Pad shape $500 \mathrm{~m}$ & Pad density soom & $\begin{array}{c}\text { Time since } \\
\text { disturbance }\end{array}$ \\
\hline Forest Interior & Est. & -0.01 & -0.06 & 0.003 & 0.01 & 0.05 \\
& (C.I.) & $(-0.03,0.02)$ & $(-0.09,-0.04)$ & $(-0.02,0.03)$ & $(-0.02,0.03)$ & $(0.02,0.08)$ \\
& Rel. Imp. & 0.29 & 1.00 & 0.27 & 0.28 & 0.82 \\
Early Successional & Est. & 0.11 & 0.06 & 0.08 & 0.02 & -0.13 \\
& (C.I.) & $(0.07,0.16)$ & $(0.01,0.10)$ & $(0.03,0.14)$ & $(-0.03,0.08)$ & $(-0.21,-0.05)$ \\
& Rel. Imp. & 0.99 & 0.69 & 0.84 & 0.33 & 0.87 \\
Synanthropic & Est. & 0.04 & 0.03 & 0.10 & 0.02 & -0.16 \\
& (C.I.) & $(-0.003,0.09)$ & $(-0.01,0.07)$ & $(0.05,0.14)$ & $(-0.03,0.07)$ & $(-0.23,-0.10)$ \\
& Rel. Imp. & 0.47 & 0.38 & 0.96 & 0.31 & 1.00 \\
\hline
\end{tabular}

*8\% unconditional confidence intervals provided, following Arnold (2010). 
Appendix A. Model sets included in AIC analysis of factors influencing detection probabilities using (1) time removal, and (2) distance sampling. Models include intercept-only models as well as models incorporating survey-specific covariates. Tree cover is percent forest cover within a 100-m radius of each survey point.

\begin{tabular}{l} 
5. Time removal models: \\
\hline Intercept-only \\
Time since sunrise \\
Time since sunrise $+(\text { Time since sunrise })^{2}$ \\
Serial date \\
Serial date + (Serial date $)^{2}$ \\
Serial date + Time since sunrise \\
Serial date $+(\text { Serial date })^{2}+$ Time since sunrise \\
Serial date + Time since sunrise $+(\text { Time since sunrise })^{2}$ \\
Serial date $+(\text { Serial date })^{2}+$ Time since sunrise $+(\text { Time since sunrise })^{2}$ \\
\hline 6. Distance sampling models: \\
\hline Intercept-only \\
Tree cover (within 100 m) \\
Observer \\
Observer + Tree cover $($ within 100 m) \\
\hline
\end{tabular}


Appendix B. Summary results of generalized linear mixed models relating forest interior focal species abundances with site-level land cover metrics $(n=190)$, after model-averaging.

\begin{tabular}{|c|c|c|c|c|c|c|}
\hline $\begin{array}{l}\text { Forest interior } \\
\text { species: }\end{array}$ & & Forest sile & Gas $\mathrm{Pad}_{\text {sile }}$ & Non-gas sile & Linear gas sile & Linear non-gas sit \\
\hline Acadian flycatcher & $\begin{array}{c}\text { Est. } \\
\text { (C.I.) } \\
\text { Rel. Imp. }\end{array}$ & $\begin{array}{c}0.08 \\
(0.05,0.11) \\
1.00\end{array}$ & $\begin{array}{c}0.01 \\
(-0.01,0.03) \\
0.31\end{array}$ & $\begin{array}{c}-0.06 \\
(-0.08,-0.04) \\
1.00\end{array}$ & $\begin{array}{c}-0.06 \\
(-0.08,-0.03) \\
0.99\end{array}$ & $\begin{array}{c}-0.01 \\
(-0.04,0.01) \\
0.37\end{array}$ \\
\hline $\begin{array}{l}\text { Black-and-white } \\
\text { warbler }\end{array}$ & $\begin{array}{c}\text { Est. } \\
\text { (C.I.) } \\
\text { Rel. Imp. }\end{array}$ & $\begin{array}{c}0.56 \\
(0.51,0.60) \\
1.00\end{array}$ & $\begin{array}{c}0.20 \\
(0.17,0.22) \\
1.00\end{array}$ & $\begin{array}{c}-0.28 \\
(-0.32,-0.25) \\
1.00\end{array}$ & $\begin{array}{c}0.004 \\
(-0.03,0.04) \\
0.26\end{array}$ & $\begin{array}{c}-0.04 \\
(-0.06,-0.01) \\
0.79\end{array}$ \\
\hline $\begin{array}{l}\text { Black-throated } \\
\text { blue warbler }\end{array}$ & $\begin{array}{c}\text { Est. } \\
\text { (C.I.) } \\
\text { Rel. Imp. }\end{array}$ & $\begin{array}{c}0.44 \\
(0.38,0.49) \\
1.00\end{array}$ & $\begin{array}{c}-0.15 \\
(-0.22,-0.08) \\
0.98\end{array}$ & $\begin{array}{c}-0.19 \\
(-0.24,-0.15) \\
1.00\end{array}$ & $\begin{array}{c}0.15 \\
(0.11,0.19) \\
1.00\end{array}$ & $\begin{array}{c}-0.19 \\
(-0.23,-0.15) \\
1.00\end{array}$ \\
\hline $\begin{array}{l}\text { Black-throated } \\
\text { green warbler }\end{array}$ & $\begin{array}{c}\text { Est. } \\
\text { (C.I.) } \\
\text { Rel. Imp. }\end{array}$ & $\begin{array}{c}0.50 \\
(0.47,0.53) \\
1.00\end{array}$ & $\begin{array}{c}-0.02 \\
(-0.07,0.03) \\
0.34\end{array}$ & $\begin{array}{c}-0.07 \\
(-0.10,-0.04) \\
1.00\end{array}$ & $\begin{array}{c}-0.04 \\
(-0.07,-0.02) \\
0.82\end{array}$ & $\begin{array}{c}0.12 \\
(0.10,0.14) \\
1.00\end{array}$ \\
\hline Cerulean warbler & $\begin{array}{c}\text { Est. } \\
\text { (C.I.) } \\
\text { Rel. Imp. }\end{array}$ & $\begin{array}{c}0.60 \\
(0.54,0.65) \\
1.00\end{array}$ & $\begin{array}{c}0.01 \\
(-0.03,0.04) \\
0.26\end{array}$ & $\begin{array}{c}0.11 \\
(0.07,0.15) \\
1.00\end{array}$ & $\begin{array}{c}0.16 \\
(0.13,0.20) \\
1.00\end{array}$ & $\begin{array}{c}0.09 \\
(0.06,0.12) \\
1.00\end{array}$ \\
\hline Hooded warbler & $\begin{array}{c}\text { Est. } \\
\text { (C.I.) } \\
\text { Rel. Imp. }\end{array}$ & $\begin{array}{c}-0.04 \\
(-0.06,-0.02) \\
0.89\end{array}$ & $\begin{array}{c}-0.10 \\
(-0.13,-0.08) \\
1.00\end{array}$ & $\begin{array}{c}-0.14 \\
(-0.16,-0.12) \\
1.00\end{array}$ & $\begin{array}{c}-0.13 \\
(-0.16,-0.11) \\
1.00\end{array}$ & $\begin{array}{c}0.01 \\
(-0.01,0.03) \\
0.34\end{array}$ \\
\hline Kentucky warbler & $\begin{array}{c}\text { Est. } \\
\text { (C.I.) } \\
\text { Rel. Imp. }\end{array}$ & $\begin{array}{c}0.03 \\
(-0.03,0.08) \\
0.31\end{array}$ & $\begin{array}{c}-0.10 \\
(-0.16,-0.04) \\
0.86\end{array}$ & $\begin{array}{c}-0.01 \\
(-0.06,0.03) \\
0.27\end{array}$ & $\begin{array}{c}-0.13 \\
(-0.19,-0.07) \\
0.99\end{array}$ & $\begin{array}{c}0.05 \\
(0.01,0.09) \\
0.58\end{array}$ \\
\hline Ovenbird & $\begin{array}{c}\text { Est. } \\
\text { (C.I.) } \\
\text { Rel. Imp. }\end{array}$ & $\begin{array}{c}0.30 \\
(0.28,0.31) \\
1.00\end{array}$ & $\begin{array}{c}-0.05 \\
(-0.07,-0.03) \\
1.00\end{array}$ & $\begin{array}{c}-0.06 \\
(-0.07,-0.04) \\
1.00\end{array}$ & $\begin{array}{c}-0.02 \\
(-0.03,0.002) \\
0.44\end{array}$ & $\begin{array}{c}0.08 \\
(0.07,0.09) \\
1.00\end{array}$ \\
\hline Red-eyed vireo & $\begin{array}{c}\text { Est. } \\
\text { (C.I.) } \\
\text { Rel. Imp. }\end{array}$ & $\begin{array}{c}0.08 \\
(0.06,0.09) \\
1.00\end{array}$ & $\begin{array}{c}-0.04 \\
(-0.05,-0.02) \\
1.00\end{array}$ & $\begin{array}{c}0.004 \\
(-0.01,0.02) \\
0.29\end{array}$ & $\begin{array}{c}-0.05 \\
(-0.06,-0.03) \\
1.00\end{array}$ & $\begin{array}{c}0.07 \\
(0.06,0.08) \\
1.00\end{array}$ \\
\hline Scarlet tanager & $\begin{array}{c}\text { Est. } \\
\text { (C.I.) } \\
\text { Rel. Imp. }\end{array}$ & $\begin{array}{c}0.11 \\
(0.08,0.13) \\
1.00\end{array}$ & $\begin{array}{c}-0.07 \\
(-0.09,-0.05) \\
1.00\end{array}$ & $\begin{array}{c}-0.07 \\
(-0.09,-0.05) \\
1.00\end{array}$ & $\begin{array}{c}-0.01 \\
(-0.03,0.01) \\
0.29\end{array}$ & $\begin{array}{c}0.02 \\
(-0.003,0.03) \\
0.42\end{array}$ \\
\hline Wood thrush & $\begin{array}{c}\text { Est. } \\
\text { (C.I.) } \\
\text { Rel. Imp. }\end{array}$ & $\begin{array}{c}-0.03 \\
(-0.05,-0.01) \\
0.75\end{array}$ & $\begin{array}{c}0.07 \\
(0.05,0.08) \\
1.00\end{array}$ & $\begin{array}{c}-0.04 \\
(-0.06,-0.03) \\
1.00\end{array}$ & $\begin{array}{c}-0.15 \\
(-0.17,-0.13) \\
1.00\end{array}$ & $\begin{array}{c}-0.12 \\
(-0.14,-0.11) \\
1.00\end{array}$ \\
\hline $\begin{array}{l}\text { Worm-eating } \\
\text { warber }\end{array}$ & $\begin{array}{c}\text { Est. } \\
\text { (C.I.) } \\
\text { Rel. Imp. }\end{array}$ & $\begin{array}{c}0.96 \\
(0.85,1.06) \\
1.00\end{array}$ & $\begin{array}{c}-0.09 \\
(-0.17,-0.001) \\
0.51\end{array}$ & $\begin{array}{c}-0.08 \\
(-0.16,-0.01) \\
0.53\end{array}$ & $\begin{array}{c}0.12 \\
(0.05,0.19) \\
0.93\end{array}$ & $\begin{array}{c}0.38 \\
(0.33,0.43) \\
1.00\end{array}$ \\
\hline
\end{tabular}

*85\% unconditional confidence intervals provided, following Arnold (2010). 
Appendix C. Summary results of generalized linear mixed models relating forest interior focal species abundances with point-level land cover metrics ( $n=2,590$ points), after model-averaging.

\begin{tabular}{|c|c|c|c|c|c|c|}
\hline $\begin{array}{l}\text { Forest interior } \\
\text { species: }\end{array}$ & & Forest ${ }_{1 \mathrm{~km}}$ & Gas Pad ${ }_{s 00 m}$ & Non-gas $500 \mathrm{~m}$ & Linear gas $500 \mathrm{~m}$ & Linear non-gas soom \\
\hline Acadian flycatcher & $\begin{array}{c}\text { Est. } \\
\text { (C.I.) } \\
\text { Rel. Imp. }\end{array}$ & $\begin{array}{c}-0.21 \\
(-0.25,-0.16) \\
0.98\end{array}$ & $\begin{array}{c}0.05 \\
(0.02,0.09) \\
0.86\end{array}$ & $\begin{array}{c}0.001 \\
(-0.03,0.03) \\
0.38\end{array}$ & $\begin{array}{c}0.07 \\
(0.03,0.11) \\
0.42\end{array}$ & $\begin{array}{c}0.05 \\
(0.02,0.09) \\
0.40\end{array}$ \\
\hline $\begin{array}{l}\text { Black-and-white } \\
\text { warbler }\end{array}$ & $\begin{array}{c}\text { Est. } \\
\text { (C.I.) } \\
\text { Rel. Imp. }\end{array}$ & $\begin{array}{c}0.36 \\
(0.24,0.49) \\
1.00\end{array}$ & $\begin{array}{c}0.03 \\
(-0.04 .0 .10) \\
0.30\end{array}$ & $\begin{array}{c}-0.17 \\
(-0.27,-0.06) \\
0.85\end{array}$ & $\begin{array}{c}-0.002 \\
(-0.08,0.08) \\
0.27\end{array}$ & $\begin{array}{c}0.01 \\
(-0.07,0.09) \\
0.27\end{array}$ \\
\hline $\begin{array}{l}\text { Black-throated } \\
\text { blue warbler }\end{array}$ & $\begin{array}{c}\text { Est. } \\
\text { (C.I.) } \\
\text { Rel. Imp. }\end{array}$ & $\begin{array}{c}0.60 \\
(0.41,0.79) \\
1.00\end{array}$ & $\begin{array}{c}-0.15 \\
(-0.27,-0.03) \\
0.66\end{array}$ & $\begin{array}{c}-0.15 \\
(-0.26,-0.04) \\
0.72\end{array}$ & $\begin{array}{c}-0.06 \\
(-0.17,0.04) \\
0.37\end{array}$ & $\begin{array}{c}-0.23 \\
(-0.33,-0.12) \\
0.98\end{array}$ \\
\hline $\begin{array}{l}\text { Black-throated } \\
\text { green warbler }\end{array}$ & $\begin{array}{c}\text { Est. } \\
\text { (C.I.) } \\
\text { Rel. Imp. }\end{array}$ & $\begin{array}{c}0.42 \\
(0.29,0.55) \\
1.00\end{array}$ & $\begin{array}{c}-0.17 \\
(-0.27,-0.06) \\
0.84\end{array}$ & $\begin{array}{c}-0.17 \\
(-0.25,-0.08) \\
0.96\end{array}$ & $\begin{array}{c}-0.13 \\
(-0.23,-0.03) \\
0.68\end{array}$ & $\begin{array}{c}-0.04 \\
(-0.11,0.02) \\
0.36\end{array}$ \\
\hline Cerulean warbler & $\begin{array}{c}\text { Est. } \\
\text { (C.I.) } \\
\text { Rel. Imp. }\end{array}$ & $\begin{array}{c}0.58 \\
(0.39,0.78) \\
1.00\end{array}$ & $\begin{array}{c}0.04 \\
(-0.06,0.13) \\
0.31\end{array}$ & $\begin{array}{c}-0.01 \\
(-0.14,0.12) \\
0.27\end{array}$ & $\begin{array}{c}0.08 \\
(-0.03,0.18) \\
0.39\end{array}$ & $\begin{array}{c}-0.01 \\
(-0.11,0.10) \\
0.27\end{array}$ \\
\hline Hooded warbler & $\begin{array}{c}\text { Est. } \\
\text { (C.I.) } \\
\text { Rel. Imp. }\end{array}$ & $\begin{array}{c}0.10 \\
(0.01,0.20) \\
0.56\end{array}$ & $\begin{array}{c}-0.23 \\
(-0.31,-0.15) \\
1.00\end{array}$ & $\begin{array}{c}-0.08 \\
(-0.14,-0.01) \\
0.60\end{array}$ & $\begin{array}{c}-0.03 \\
(-0.12,0.06) \\
0.29\end{array}$ & $\begin{array}{c}-0.01 \\
(-0.08,0.05) \\
0.28\end{array}$ \\
\hline Kentucky warbler & $\begin{array}{c}\text { Est. } \\
\text { (C.I.) } \\
\text { Rel. Imp. }\end{array}$ & $\begin{array}{c}0.10 \\
(-0.06,0.27) \\
0.35\end{array}$ & $\begin{array}{c}-0.23 \\
(-0.39,-0.08) \\
0.81\end{array}$ & $\begin{array}{c}-0.07 \\
(-0.20,0.06) \\
0.33\end{array}$ & $\begin{array}{c}0.03 \\
(-0.12,0.19) \\
0.29\end{array}$ & $\begin{array}{c}-0.01 \\
(-0.13,0.11) \\
0.27\end{array}$ \\
\hline Ovenbird & $\begin{array}{c}\text { Est. } \\
\text { (C.I.) } \\
\text { Rel. Imp. }\end{array}$ & $\begin{array}{c}0.27 \\
(0.20,0.34) \\
1.00\end{array}$ & $\begin{array}{c}-0.08 \\
(-0.13,-0.04) \\
0.91\end{array}$ & $\begin{array}{c}-0.01 \\
(-0.06,0.04) \\
0.28\end{array}$ & $\begin{array}{c}-0.02 \\
(-0.08,0.03) \\
0.32\end{array}$ & $\begin{array}{c}0.02 \\
(-0.02,0.06) \\
0.31\end{array}$ \\
\hline Red-eyed vireo & $\begin{array}{c}\text { Est. } \\
\text { (C.I.) } \\
\text { Rel. Imp. }\end{array}$ & $\begin{array}{c}0.11 \\
(0.06,0.15) \\
1.00\end{array}$ & $\begin{array}{c}-0.04 \\
(-0.08,0.0001) \\
0.52\end{array}$ & $\begin{array}{c}-0.001 \\
(-0.03,0.03) \\
0.27\end{array}$ & $\begin{array}{c}-0.07 \\
(-0.11,-0.03) \\
0.89\end{array}$ & $\begin{array}{c}0.03 \\
(-0.002,0.06) \\
0.47\end{array}$ \\
\hline Scarlet tanager & $\begin{array}{l}\text { Est. } \\
\text { (C.I.) } \\
\text { Rel. Imp. }\end{array}$ & $\begin{array}{c}0.17 \\
(0.11,0.23) \\
1.00\end{array}$ & $\begin{array}{c}-0.11 \\
(-0.17,-0.05) \\
0.92\end{array}$ & $\begin{array}{c}-0.02 \\
(-0.07,0.04) \\
0.29\end{array}$ & $\begin{array}{c}-0.04 \\
(-0.11,0.03) \\
0.36\end{array}$ & $\begin{array}{c}-0.02 \\
(-0.07,0.03) \\
0.31\end{array}$ \\
\hline Wood thrush & $\begin{array}{c}\text { Est. } \\
\text { (C.I.) } \\
\text { Rel. Imp. }\end{array}$ & $\begin{array}{c}-0.03 \\
(-0.11,0.04) \\
0.32\end{array}$ & $\begin{array}{c}-0.13 \\
(-0.19,-0.07) \\
0.99\end{array}$ & $\begin{array}{c}-0.02 \\
(-0.07,0.03) \\
0.31\end{array}$ & $\begin{array}{c}-0.08 \\
(-0.15,-0.01) \\
0.60\end{array}$ & $\begin{array}{c}-0.10 \\
(-0.15,-0.05) \\
0.94\end{array}$ \\
\hline $\begin{array}{l}\text { Worm-eating } \\
\text { warber }\end{array}$ & $\begin{array}{c}\text { Est. } \\
\text { (C.I.) } \\
\text { Rel. Imp. }\end{array}$ & $\begin{array}{c}0.82 \\
(0.54,1.09) \\
1.00\end{array}$ & $\begin{array}{c}-0.10 \\
(-0.31,0.10) \\
0.33\end{array}$ & $\begin{array}{c}0.01 \\
(-0.19,0.21) \\
0.27\end{array}$ & $\begin{array}{c}0.06 \\
(-0.14,0.26) \\
0.29\end{array}$ & $\begin{array}{c}-0.05 \\
(-0.22,0.12) \\
0.29\end{array}$ \\
\hline
\end{tabular}

* $85 \%$ unconditional confidence intervals provided, following Arnold (2010). 
Appendix D. Summary results of generalized linear mixed models relating forest interior focal species abundances with point-level shale gas development metrics at gas sites only $(n=1,612$ points), after model-averaging.

\begin{tabular}{|c|c|c|c|c|c|c|}
\hline $\begin{array}{l}\text { Forest interior } \\
\text { species: }\end{array}$ & & Linear gas $500 \mathrm{~m}$ & Pad area $500 m$ & Pad shape $s 00 m$ & Pad density $500 m$ & $\begin{array}{l}\text { Time since } \\
\text { disturbance }_{\text {sile }}\end{array}$ \\
\hline Acadian flycatcher & $\begin{array}{c}\text { Est. } \\
\text { (C.I.) } \\
\text { Rel. Imp. }\end{array}$ & $\begin{array}{c}-0.04 \\
(-0.13,0.05) \\
0.31\end{array}$ & $\begin{array}{c}-0.14 \\
(-0.22,-0.06) \\
0.91\end{array}$ & $\begin{array}{c}0.06 \\
(-0.03,0.15) \\
0.37\end{array}$ & $\begin{array}{c}0.02 \\
(-0.07,0.11) \\
0.29\end{array}$ & $\begin{array}{c}0.11 \\
(0.01,0.21) \\
0.57\end{array}$ \\
\hline $\begin{array}{l}\text { Black-and-white } \\
\text { warbler }\end{array}$ & $\begin{array}{c}\text { Est. } \\
\text { (C.I.) } \\
\text { Rel. Imp. }\end{array}$ & $\begin{array}{c}-0.03 \\
(-0.14,0.08) \\
0.30\end{array}$ & $\begin{array}{c}-0.08 \\
(-0.19,0.03) \\
0.41\end{array}$ & $\begin{array}{c}0.08 \\
(-0.03,0.19) \\
0.40\end{array}$ & $\begin{array}{c}0.11 \\
(0.005,0.22) \\
0.52\end{array}$ & $\begin{array}{c}0.29 \\
(0.10,0.47) \\
0.78\end{array}$ \\
\hline $\begin{array}{l}\text { Black-throated } \\
\text { blue warbler }\end{array}$ & $\begin{array}{c}\text { Est. } \\
\text { (C.I.) } \\
\text { Rel. Imp. }\end{array}$ & $\begin{array}{c}-0.07 \\
(-0.19,0.05) \\
0.35\end{array}$ & $\begin{array}{c}-0.10 \\
(-0.28,0.08) \\
0.36\end{array}$ & $\begin{array}{c}-0.15 \\
(-0.30,0.002) \\
0.52\end{array}$ & $\begin{array}{c}-0.15 \\
(-0.31,0.01) \\
0.49\end{array}$ & $\begin{array}{c}0.41 \\
(0.09,0.72) \\
0.65\end{array}$ \\
\hline $\begin{array}{l}\text { Black-throated } \\
\text { green warbler }\end{array}$ & $\begin{array}{c}\text { Est. } \\
\text { (C.I.) } \\
\text { Rel. Imp. }\end{array}$ & $\begin{array}{c}-0.22 \\
(-0.33,-0.12) \\
0.97\end{array}$ & $\begin{array}{c}-0.12 \\
(-0.24,-0.005) \\
0.53\end{array}$ & $\begin{array}{c}-0.01 \\
(-0.12,0.10) \\
0.29\end{array}$ & $\begin{array}{c}0.003 \\
(-0.11,0.11) \\
0.28\end{array}$ & $\begin{array}{c}0.63 \\
(0.42,0.84) \\
1.00\end{array}$ \\
\hline Cerulean warbler & $\begin{array}{c}\text { Est. } \\
\text { (C.I.) } \\
\text { Rel. Imp. }\end{array}$ & $\begin{array}{c}0.07 \\
(-0.06,0.20) \\
0.34\end{array}$ & $\begin{array}{c}-0.04 \\
(-0.16,0.08) \\
0.30\end{array}$ & $\begin{array}{c}-0.13 \\
(-0.28,0.02) \\
0.46\end{array}$ & $\begin{array}{c}0.16 \\
(0.02,0.30) \\
0.60\end{array}$ & $\begin{array}{c}0.20 \\
(-0.02,0.41) \\
0.46\end{array}$ \\
\hline Hooded warbler & $\begin{array}{c}\text { Est. } \\
\text { (C.I.) } \\
\text { Rel. Imp. }\end{array}$ & $\begin{array}{c}-0.06 \\
(-0.16,0.03) \\
0.36\end{array}$ & $\begin{array}{c}-0.24 \\
(-0.34,-0.14) \\
0.99\end{array}$ & $\begin{array}{c}-0.02 \\
(-0.11,0.08) \\
0.28\end{array}$ & $\begin{array}{c}0.01 \\
(-0.08,0.10) \\
0.27\end{array}$ & $\begin{array}{c}0.02 \\
(-0.12,0.16) \\
0.27\end{array}$ \\
\hline Kentucky warbler & $\begin{array}{c}\text { Est. } \\
\text { (C.I.) } \\
\text { Rel. Imp. }\end{array}$ & $\begin{array}{c}0.06 \\
(-0.14,0.25) \\
0.29\end{array}$ & $\begin{array}{c}-0.23 \\
(-0.43,-0.03) \\
0.41\end{array}$ & $\begin{array}{c}0.01 \\
(-0.21,0.23) \\
0.30\end{array}$ & $\begin{array}{c}-0.04 \\
(-0.23,0.16) \\
0.28\end{array}$ & $\begin{array}{c}0.28 \\
(0.06,0.50) \\
0.66\end{array}$ \\
\hline Ovenbird & $\begin{array}{c}\text { Est. } \\
\text { (C.I.) } \\
\text { Rel. Imp. }\end{array}$ & $\begin{array}{c}-0.05 \\
(-0.11,0.01) \\
0.43\end{array}$ & $\begin{array}{c}-0.15 \\
(-0.23,-0.08) \\
0.98\end{array}$ & $\begin{array}{c}0.09 \\
(0.03,0.15) \\
0.77\end{array}$ & $\begin{array}{c}0.03 \\
(-0.04,0.10) \\
0.34\end{array}$ & $\begin{array}{c}0.09 \\
(-0.02,0.20) \\
0.41\end{array}$ \\
\hline Red-eyed vireo & $\begin{array}{c}\text { Est. } \\
\text { (C.I.) } \\
\text { Rel. Imp. }\end{array}$ & $\begin{array}{c}-0.08 \\
(-0.13,-0.03) \\
0.80\end{array}$ & $\begin{array}{c}-0.07 \\
(-0.11,-0.02) \\
0.78\end{array}$ & $\begin{array}{c}-0.03 \\
(-0.09,0.03) \\
0.38\end{array}$ & $\begin{array}{c}0.06 \\
(0.01,0.12) \\
0.66\end{array}$ & $\begin{array}{c}0.05 \\
(0.0002,0.11) \\
0.51\end{array}$ \\
\hline Scarlet tanager & $\begin{array}{c}\text { Est. } \\
\text { (C.I.) } \\
\text { Rel. Imp. }\end{array}$ & $\begin{array}{c}-0.01 \\
(-0.08,0.06) \\
0.28\end{array}$ & $\begin{array}{c}-0.09 \\
(-0.16,-0.01) \\
0.64\end{array}$ & $\begin{array}{c}-0.01 \\
(-0.09,0.07) \\
0.30\end{array}$ & $\begin{array}{c}-0.04 \\
(-0.12,0.03) \\
0.35\end{array}$ & $\begin{array}{c}0.08 \\
(0.01,0.16) \\
0.59\end{array}$ \\
\hline Wood thrush & $\begin{array}{c}\text { Est. } \\
\text { (C.I.) } \\
\text { Rel. Imp. }\end{array}$ & $\begin{array}{c}-0.11 \\
(-0.19,-0.03) \\
0.68\end{array}$ & $\begin{array}{c}-0.19 \\
(-0.27,-0.12) \\
1.00\end{array}$ & $\begin{array}{c}0.11 \\
(0.04,0.18) \\
0.79\end{array}$ & $\begin{array}{c}0.03 \\
(-0.05,0.12) \\
0.33\end{array}$ & $\begin{array}{c}-0.02 \\
(-0.14,0.10) \\
0.27\end{array}$ \\
\hline $\begin{array}{l}\text { Worm-eating } \\
\text { warber }\end{array}$ & $\begin{array}{c}\text { Est. } \\
\text { (C.I.) } \\
\text { Rel. Imp. }\end{array}$ & $\begin{array}{c}0.17 \\
(-0.08,0.43) \\
0.38\end{array}$ & $\begin{array}{c}-0.12 \\
(-0.40,0.16) \\
0.31\end{array}$ & $\begin{array}{c}-0.07 \\
(-0.28,0.15) \\
0.29\end{array}$ & $\begin{array}{c}-0.12 \\
(-0.38,0.14) \\
0.32\end{array}$ & $\begin{array}{c}0.59 \\
(0.29,0.90) \\
0.98\end{array}$ \\
\hline
\end{tabular}

* $85 \%$ unconditional confidence intervals provided, following Arnold (2010). 
Appendix E. Summary results of generalized linear mixed models relating early successional and synanthropic focal species abundances with site-level land cover metrics ( $n=190$ sites), after model-averaging.

\begin{tabular}{|c|c|c|c|c|c|c|}
\hline $\begin{array}{l}\text { Early successtional } \\
\text { species: }\end{array}$ & & Forest sile & $\mathrm{Gas}^{\mathrm{Pad}} \mathrm{sic}_{\mathrm{sic}}$ & Non-gas sile & Linear gas sile & Linear non-gas sile \\
\hline $\begin{array}{l}\text { Blue-winged } \\
\text { warbler }\end{array}$ & $\begin{array}{c}\text { Est. } \\
\text { (C.I.) } \\
\text { Rel. Imp. }\end{array}$ & $\begin{array}{c}0.04 \\
(-0.02,0.10) \\
0.37\end{array}$ & $\begin{array}{c}-0.16 \\
(-0.22,-0.10) \\
1.00\end{array}$ & $\begin{array}{c}0.05 \\
(0.01,0.10) \\
0.61\end{array}$ & $\begin{array}{c}-0.13 \\
(-0.19,-0.07) \\
0.98\end{array}$ & $\begin{array}{c}-0.01 \\
(-0.05,0.04) \\
0.27\end{array}$ \\
\hline $\begin{array}{l}\text { Chestnut-sided } \\
\text { warbler }\end{array}$ & $\begin{array}{l}\text { Est. } \\
\text { (C.I.) } \\
\text { Rel. Imp. }\end{array}$ & $\begin{array}{c}-0.01 \\
(-0.05,0.04) \\
0.26\end{array}$ & $\begin{array}{c}0.38 \\
(0.33,0.44) \\
1.00\end{array}$ & $\begin{array}{c}-0.12 \\
(-0.16,-0.08) \\
1.00\end{array}$ & $\begin{array}{c}-0.09 \\
(-0.13,-0.05) \\
0.99\end{array}$ & $\begin{array}{c}-0.14 \\
(-0.17,-0.10) \\
1.00\end{array}$ \\
\hline $\begin{array}{l}\text { Common } \\
\text { yellowthroat }\end{array}$ & $\begin{array}{l}\text { Est. } \\
\text { (C.I.) } \\
\text { Rel. Imp. }\end{array}$ & $\begin{array}{c}-0.28 \\
(-0.31,-0.26) \\
1.00\end{array}$ & $\begin{array}{c}0.01 \\
(-0.02,0.04) \\
0.27\end{array}$ & $\begin{array}{c}-0.12 \\
(-0.15,-0.10) \\
1.00\end{array}$ & $\begin{array}{c}0.14 \\
(0.12,0.17) \\
1.00\end{array}$ & $\begin{array}{c}-0.06 \\
(-0.09,-0.03) \\
0.98\end{array}$ \\
\hline Eastern Towhee & $\begin{array}{l}\text { Est. } \\
\text { (C.I.) } \\
\text { Rel. Imp. }\end{array}$ & $\begin{array}{c}-0.10 \\
(-0.12,-0.08) \\
1.00\end{array}$ & $\begin{array}{c}-0.004 \\
(-0.02,0.01) \\
0.28\end{array}$ & $\begin{array}{c}0.07 \\
(0.05,0.08) \\
1.00\end{array}$ & $\begin{array}{c}0.04 \\
(0.02,0.06) \\
0.97\end{array}$ & $\begin{array}{c}-0.10 \\
(-0.12,-0.08) \\
1.00\end{array}$ \\
\hline Field Sparrow & $\begin{array}{l}\text { Est. } \\
\text { (C.I.) } \\
\text { Rel. Imp. }\end{array}$ & $\begin{array}{c}-0.56 \\
(-0.60,-0.52) \\
1.00\end{array}$ & $\begin{array}{c}0.03 \\
(-0.003,0.06) \\
0.45\end{array}$ & $\begin{array}{c}-0.04 \\
(-0.07,-0.003) \\
0.57\end{array}$ & $\begin{array}{c}-0.21 \\
(-0.26,-0.16) \\
1.00\end{array}$ & $\begin{array}{c}-0.08 \\
(-0.12,-0.04) \\
0.95\end{array}$ \\
\hline Indigo Bunting & $\begin{array}{c}\text { Est. } \\
\text { (C.I.) } \\
\text { Rel. Imp. }\end{array}$ & $\begin{array}{c}-0.19 \\
(-0.21,-0.16) \\
1.00\end{array}$ & $\begin{array}{c}-0.01 \\
(-0.03,0.01) \\
0.30\end{array}$ & $\begin{array}{c}0.07 \\
(0.05,0.09) \\
1.00\end{array}$ & $\begin{array}{c}-0.01 \\
(-0.03,0.02) \\
0.27\end{array}$ & $\begin{array}{c}0.16 \\
(0.13,0.18) \\
1.00 \\
\end{array}$ \\
\hline $\begin{array}{l}\text { Synanthropic } \\
\text { species: }\end{array}$ & & Forest sile & Gas Pad sile & Non-gas sile & Linear gas sile & Linear non-gas sice \\
\hline American Robin & $\begin{array}{c}\text { Est. } \\
\text { (C.I.) } \\
\text { Rel. Imp. }\end{array}$ & $\begin{array}{c}-0.05 \\
(-0.09,-0.02) \\
0.88\end{array}$ & $\begin{array}{c}0.08 \\
(0.05,0.10) \\
1.00\end{array}$ & $\begin{array}{c}0.05 \\
(0.02,0.07) \\
0.96\end{array}$ & $\begin{array}{c}0.04 \\
(0.01,0.07) \\
0.66\end{array}$ & $\begin{array}{c}-0.04 \\
(-0.07,-0.01) \\
0.81\end{array}$ \\
\hline Blue Jay & $\begin{array}{l}\text { Est. } \\
\text { (C.I.) } \\
\text { Rel. Imp. }\end{array}$ & $\begin{array}{c}-0.08 \\
(-0.10,-0.05) \\
1.00\end{array}$ & $\begin{array}{c}0.01 \\
(-0.01,0.03) \\
0.31\end{array}$ & $\begin{array}{c}-0.06 \\
(-0.08,-0.04) \\
1.00\end{array}$ & $\begin{array}{c}0.03 \\
(0.01,0.05) \\
0.67\end{array}$ & $\begin{array}{c}0.04 \\
(0.02,0.06) \\
0.87\end{array}$ \\
\hline $\begin{array}{l}\text { Brown-headed } \\
\text { cowbird }\end{array}$ & $\begin{array}{l}\text { Est. } \\
\text { (C.I.) } \\
\text { Rel. Imp. }\end{array}$ & $\begin{array}{c}-0.26 \\
(-0.29,-0.23) \\
1.00\end{array}$ & $\begin{array}{c}-0.02 \\
(-0.05,0.002) \\
0.49\end{array}$ & $\begin{array}{c}0.05 \\
(0.02,0.07) \\
0.95\end{array}$ & $\begin{array}{c}0.05 \\
(0.01,0.08) \\
0.79\end{array}$ & $\begin{array}{c}-0.08 \\
(-0.10,-0.05) \\
1.00\end{array}$ \\
\hline Chipping Sparrow & $\begin{array}{l}\text { Est. } \\
\text { (C.I.) } \\
\text { Rel. Imp. }\end{array}$ & $\begin{array}{c}0.31 \\
(0.25,0.37) \\
1.00\end{array}$ & $\begin{array}{c}0.17 \\
(0.14,0.21) \\
1.00\end{array}$ & $\begin{array}{c}0.07 \\
(0.03,0.12) \\
0.91\end{array}$ & $\begin{array}{c}0.14 \\
(0.09,0.18) \\
1.00\end{array}$ & $\begin{array}{c}0.07 \\
(0.03,0.11) \\
0.85\end{array}$ \\
\hline Northern Cardinal & $\begin{array}{l}\text { Est. } \\
\text { (C.I.) } \\
\text { Rel. Imp. }\end{array}$ & $\begin{array}{c}-0.33 \\
(-0.35,-0.30) \\
1.00\end{array}$ & $\begin{array}{c}0.05 \\
(0.03,0.07) \\
0.99\end{array}$ & $\begin{array}{c}0.03 \\
(0.01,0.05) \\
0.77\end{array}$ & $\begin{array}{c}-0.15 \\
(-0.18,-0.12) \\
1.00\end{array}$ & $\begin{array}{c}-0.05 \\
(-0.07,-0.02) \\
0.97\end{array}$ \\
\hline Song Sparrow & $\begin{array}{c}\text { Est. } \\
\text { (C.I.) } \\
\text { Rel. Imp. }\end{array}$ & $\begin{array}{c}-0.64 \\
(-0.68,-0.60) \\
1.00\end{array}$ & $\begin{array}{c}-0.02 \\
(-0.05,0.01) \\
0.34\end{array}$ & $\begin{array}{c}-0.004 \\
(-0.03,0.03) \\
0.27\end{array}$ & $\begin{array}{c}0.07 \\
(0.03,0.11) \\
0.92\end{array}$ & $\begin{array}{c}-0.01 \\
(-0.05,0.04) \\
0.26\end{array}$ \\
\hline
\end{tabular}

*85\% unconditional confidence intervals provided, following Arnold (2010). 
Appendix F. Summary results of generalized linear mixed models relating early successional and synanthropic focal species abundances with point-level land cover metrics ( $n=2,590$ points), after model-averaging.

\begin{tabular}{|c|c|c|c|c|c|c|}
\hline $\begin{array}{l}\text { Early successtional } \\
\text { species: }\end{array}$ & & Forest $1 \mathrm{lbm}$ & Gas Pad $500 m$ & Non-gas $500 m$ & Linear gas $500 \mathrm{~m}$ & Linear non-gas $500 \mathrm{~m}$ \\
\hline $\begin{array}{l}\text { Blue-winged } \\
\text { warbler }\end{array}$ & $\begin{array}{c}\text { Est. } \\
\text { (C.I.) } \\
\text { Rel. Imp. }\end{array}$ & $\begin{array}{c}-0.11 \\
(-0.30,0.08) \\
0.35\end{array}$ & $\begin{array}{c}-0.11 \\
(-0.27,0.05) \\
0.39\end{array}$ & $\begin{array}{c}0.25 \\
(0.13,0.38) \\
0.94\end{array}$ & $\begin{array}{c}-0.01 \\
(-0.19,0.17) \\
0.27\end{array}$ & $\begin{array}{c}0.08 \\
(-0.07,0.24) \\
0.33\end{array}$ \\
\hline $\begin{array}{l}\text { Chestnut-sided } \\
\text { warbler }\end{array}$ & $\begin{array}{c}\text { Est. } \\
\text { (C.I.) } \\
\text { Rel. Imp. }\end{array}$ & $\begin{array}{c}0.15 \\
(-0.03,0.33) \\
0.44\end{array}$ & $\begin{array}{c}0.25 \\
(0.13,0.36) \\
0.97\end{array}$ & $\begin{array}{c}0.08 \\
(-0.02,0.18) \\
0.41\end{array}$ & $\begin{array}{c}0.15 \\
(0.04,0.26) \\
0.72\end{array}$ & $\begin{array}{c}0.22 \\
(0.11,0.32) \\
0.97\end{array}$ \\
\hline $\begin{array}{l}\text { Common } \\
\text { yellowthroat }\end{array}$ & $\begin{array}{c}\text { Est. } \\
\text { (C.I.) } \\
\text { Rel. Imp. }\end{array}$ & $\begin{array}{c}-0.34 \\
(-0.43,-0.25) \\
1.00\end{array}$ & $\begin{array}{c}0.01 \\
(-0.07,0.09) \\
0.28\end{array}$ & $\begin{array}{c}0.05 \\
(-0.01,0.12) \\
0.40\end{array}$ & $\begin{array}{c}0.16 \\
(0.09,0.23) \\
0.98\end{array}$ & $\begin{array}{c}0.10 \\
(0.02,0.17) \\
0.66\end{array}$ \\
\hline Eastern Towhee & $\begin{array}{c}\text { Est. } \\
\text { (C.I.) } \\
\text { Rel. Imp. }\end{array}$ & $\begin{array}{c}-0.07 \\
(-0.15,0.005) \\
0.48\end{array}$ & $\begin{array}{c}-0.01 \\
(-0.07,0.04) \\
0.29\end{array}$ & $\begin{array}{c}0.08 \\
(0.03,0.12) \\
0.77\end{array}$ & $\begin{array}{c}0.10 \\
(0.05,0.16) \\
0.90\end{array}$ & $\begin{array}{c}-0.07 \\
(-0.13,-0.01) \\
0.56\end{array}$ \\
\hline Field Sparrow & $\begin{array}{c}\text { Est. } \\
\text { (C.I.) } \\
\text { Rel. Imp. }\end{array}$ & $\begin{array}{c}-0.64 \\
(-0.78,-0.50) \\
1.00\end{array}$ & $\begin{array}{c}0.06 \\
(-0.04,0.16) \\
0.35\end{array}$ & $\begin{array}{c}0.09 \\
(-0.004,0.19) \\
0.48\end{array}$ & $\begin{array}{c}0.22 \\
(0.10,0.34) \\
0.90\end{array}$ & $\begin{array}{c}0.12 \\
(-0.01,0.24) \\
0.49\end{array}$ \\
\hline Indigo Bunting & $\begin{array}{c}\text { Est. } \\
\text { (C.I.) } \\
\text { Rel. Imp. }\end{array}$ & $\begin{array}{c}-0.24 \\
(-0.33,-0.15) \\
1.00\end{array}$ & $\begin{array}{c}0.21 \\
(0.15,0.27) \\
1.00 \\
\end{array}$ & $\begin{array}{c}0.13 \\
(0.07,0.19) \\
0.97 \\
\end{array}$ & $\begin{array}{c}0.14 \\
(0.06,0.21) \\
0.89 \\
\end{array}$ & $\begin{array}{c}0.26 \\
(0.20,0.33) \\
1.00 \\
\end{array}$ \\
\hline $\begin{array}{l}\text { Synanthropic } \\
\text { species: }\end{array}$ & & Forest ${ }_{1 \mathrm{~lm}}$ & Gas Pad ${ }_{500 m}$ & Non-gas soom & Linear gas $500 \mathrm{~m}$ & Linear non-gas s00m \\
\hline American Robin & $\begin{array}{l}\text { Est. } \\
\text { (C.I.) } \\
\text { Rel. Imp. }\end{array}$ & $\begin{array}{c}-0.22 \\
(-0.31,-0.12) \\
0.98\end{array}$ & $\begin{array}{c}0.03 \\
(-0.03,0.10) \\
0.34\end{array}$ & $\begin{array}{c}0.10 \\
(0.04,0.17) \\
0.77\end{array}$ & $\begin{array}{c}0.10 \\
(0.02,0.18) \\
0.66\end{array}$ & $\begin{array}{c}-0.01 \\
(-0.09,0.07) \\
0.27\end{array}$ \\
\hline Blue Jay & $\begin{array}{l}\text { Est. } \\
\text { (C.I.) } \\
\text { Rel. Imp. }\end{array}$ & $\begin{array}{c}-0.17 \\
(-0.25,-0.10) \\
0.98\end{array}$ & $\begin{array}{c}-0.07 \\
(-0.14,-0.004) \\
0.56\end{array}$ & $\begin{array}{c}-0.08 \\
(-0.14,-0.01) \\
0.62\end{array}$ & $\begin{array}{c}0.04 \\
(-0.04,0.11) \\
0.34\end{array}$ & $\begin{array}{c}-0.11 \\
(-0.17,-0.05) \\
0.89\end{array}$ \\
\hline $\begin{array}{l}\text { Brown-headed } \\
\text { cowbird }\end{array}$ & $\begin{array}{c}\text { Est. } \\
\text { (C.I.) } \\
\text { Rel. Imp. }\end{array}$ & $\begin{array}{c}-0.44 \\
(-0.55,-0.34) \\
1.00\end{array}$ & $\begin{array}{c}0.16 \\
(0.10,0.22) \\
0.99\end{array}$ & $\begin{array}{c}-0.05 \\
(-0.14,0.03) \\
0.36\end{array}$ & $\begin{array}{c}0.003 \\
(-0.09,0.10) \\
0.27\end{array}$ & $\begin{array}{c}-0.08 \\
(-0.18,0.01) \\
0.46\end{array}$ \\
\hline Chipping Sparrow & $\begin{array}{c}\text { Est. } \\
\text { (C.I.) } \\
\text { Rel. Imp. }\end{array}$ & $\begin{array}{c}0.05 \\
(-0.11,0.21) \\
0.29\end{array}$ & $\begin{array}{c}0.37 \\
(0.27,0.47) \\
1.00\end{array}$ & $\begin{array}{c}0.08 \\
(-0.04,0.21) \\
0.37\end{array}$ & $\begin{array}{c}0.24 \\
(0.11,0.37) \\
0.92\end{array}$ & $\begin{array}{c}0.35 \\
(0.22,0.47) \\
1.00\end{array}$ \\
\hline Northern Cardinal & $\begin{array}{c}\text { Est. } \\
\text { (C.I.) } \\
\text { Rel. Imp. }\end{array}$ & $\begin{array}{c}-0.27 \\
(-0.35,-0.18) \\
1.00\end{array}$ & $\begin{array}{c}-0.03 \\
(-0.09,0.03) \\
0.31\end{array}$ & $\begin{array}{c}0.04 \\
(-0.03,0.10) \\
0.33\end{array}$ & $\begin{array}{c}-0.03 \\
(-0.11,0.04) \\
0.31\end{array}$ & $\begin{array}{c}0.11 \\
(0.04,0.18) \\
0.82\end{array}$ \\
\hline Song Sparrow & $\begin{array}{c}\text { Est. } \\
\text { (C.I.) } \\
\text { Rel. Imp. }\end{array}$ & $\begin{array}{c}-0.65 \\
(-0.76,-0.55) \\
1.00 \\
\end{array}$ & $\begin{array}{c}0.23 \\
(0.14,0.31) \\
1.00 \\
\end{array}$ & $\begin{array}{c}0.06 \\
(-0.03,0.14) \\
0.37 \\
\end{array}$ & $\begin{array}{c}0.15 \\
(0.04,0.26) \\
0.73 \\
\end{array}$ & $\begin{array}{c}0.13 \\
(0.02,0.24) \\
0.63 \\
\end{array}$ \\
\hline
\end{tabular}

*85\% unconditional confidence intervals provided, following Arnold (2010). 
Appendix G. Summary results of generalized linear mixed models relating early successional and synanthropic focal species abundances with point-level shale gas development metrics at gas sites only ( $n=1,612$ points), after model-averaging.

\begin{tabular}{|c|c|c|c|c|c|c|}
\hline $\begin{array}{l}\text { Early successtional } \\
\text { species: }\end{array}$ & & Linear gas $500 m$ & Pad area $500 m$ & Pad shape $500 m$ & Pad density $500 m$ & $\begin{array}{c}\text { Time since } \\
\text { disturbance } \\
\text { sile }\end{array}$ \\
\hline $\begin{array}{l}\text { Blue-winged } \\
\text { warbler }\end{array}$ & $\begin{array}{c}\text { Est. } \\
\text { (C.I.) } \\
\text { Rel. Imp. }\end{array}$ & $\begin{array}{c}-0.03 \\
(-0.25,0.18) \\
0.28\end{array}$ & $\begin{array}{c}-0.15 \\
(-0.36,0.06) \\
0.41\end{array}$ & $\begin{array}{c}0.23 \\
(-0.02,0.47) \\
0.52\end{array}$ & $\begin{array}{c}-0.30 \\
(-0.57,-0.02) \\
0.62\end{array}$ & $\begin{array}{c}0.02 \\
(-0.19,0.24) \\
0.27\end{array}$ \\
\hline $\begin{array}{l}\text { Chestnut-sided } \\
\text { warbler }\end{array}$ & $\begin{array}{c}\text { Est. } \\
\text { (C.I.) } \\
\text { Rel. Imp. }\end{array}$ & $\begin{array}{c}0.20 \\
(0.08,0.31) \\
0.89\end{array}$ & $\begin{array}{c}0.27 \\
(0.14,0.40) \\
0.97\end{array}$ & $\begin{array}{c}-0.12 \\
(-0.29,0.05) \\
0.39\end{array}$ & $\begin{array}{c}0.02 \\
(-0.13,0.17) \\
0.29\end{array}$ & $\begin{array}{c}0.33 \\
(0.05,0.61) \\
0.57\end{array}$ \\
\hline $\begin{array}{l}\text { Common } \\
\text { yellowthroat }\end{array}$ & $\begin{array}{c}\text { Est. } \\
\text { (C.I.) } \\
\text { Rel. Imp. }\end{array}$ & $\begin{array}{c}0.13 \\
(0.04,0.21) \\
0.75\end{array}$ & $\begin{array}{c}0.03 \\
(-0.07,0.13) \\
0.31\end{array}$ & $\begin{array}{c}0.11 \\
(0.01,0.21) \\
0.56\end{array}$ & $\begin{array}{c}-0.07 \\
(-0.19,0.05) \\
0.39\end{array}$ & $\begin{array}{c}-0.31 \\
(-0.45,-0.17) \\
0.98\end{array}$ \\
\hline Eastern Towhee & $\begin{array}{c}\text { Est. } \\
\text { (C.I.) } \\
\text { Rel. Imp. }\end{array}$ & $\begin{array}{c}0.10 \\
(0.03,0.17) \\
0.72\end{array}$ & $\begin{array}{c}-0.02 \\
(-0.08,0.05) \\
0.30\end{array}$ & $\begin{array}{c}0.09 \\
(0.01,0.16) \\
0.61\end{array}$ & $\begin{array}{c}0.04 \\
(-0.04,0.12) \\
0.36\end{array}$ & $\begin{array}{c}-0.08 \\
(-0.20,0.03) \\
0.38\end{array}$ \\
\hline Field Sparrow & $\begin{array}{c}\text { Est. } \\
\text { (C.I.) } \\
\text { Rel. Imp. }\end{array}$ & $\begin{array}{c}0.22 \\
(0.07,0.37) \\
0.75\end{array}$ & $\begin{array}{c}0.04 \\
(-0.09,0.17) \\
0.30\end{array}$ & $\begin{array}{c}0.25 \\
(0.11,0.39) \\
0.86\end{array}$ & $\begin{array}{c}0.03 \\
(-0.11,0.17) \\
0.30\end{array}$ & $\begin{array}{c}-0.35 \\
(-0.56,-0.15) \\
0.86\end{array}$ \\
\hline Indigo Bunting & $\begin{array}{c}\text { Est. } \\
\text { (C.I.) } \\
\text { Rel. Imp. }\end{array}$ & $\begin{array}{c}0.08 \\
(-0.02,0.19) \\
0.43\end{array}$ & $\begin{array}{c}0.16 \\
(0.08,0.24) \\
0.95 \\
\end{array}$ & $\begin{array}{c}0.17 \\
(0.06,0.29) \\
0.79 \\
\end{array}$ & $\begin{array}{c}0.15 \\
(0.06,0.25) \\
0.81 \\
\end{array}$ & $\begin{array}{c}-0.04 \\
(-0.17,0.09) \\
0.18\end{array}$ \\
\hline $\begin{array}{l}\text { Synanthropic } \\
\text { species: }\end{array}$ & & Linear gas soom & Pad area $500 m$ & Pad shape & Pad density $500 m$ & $\begin{array}{c}\text { Time since } \\
\text { disturbance }_{\text {sile }}\end{array}$ \\
\hline American Robin & $\begin{array}{c}\text { Est. } \\
\text { (C.I.) } \\
\text { Rel. Imp. }\end{array}$ & $\begin{array}{c}0.02 \\
(-0.08,0.12) \\
0.29\end{array}$ & $\begin{array}{c}0.03 \\
(-0.04,0.11) \\
0.31\end{array}$ & $\begin{array}{c}0.08 \\
(-0.02,0.18) \\
0.43\end{array}$ & $\begin{array}{c}0.11 \\
(0.03,0.20) \\
0.67\end{array}$ & $\begin{array}{c}-0.27 \\
(-0.40,-0.14) \\
0.97\end{array}$ \\
\hline Blue Jay & $\begin{array}{c}\text { Est. } \\
\text { (C.I.) } \\
\text { Rel. Imp. }\end{array}$ & $\begin{array}{c}0.05 \\
(-0.03,0.13) \\
0.37\end{array}$ & $\begin{array}{c}-0.09 \\
(-0.17,-0.01) \\
0.58\end{array}$ & $\begin{array}{c}-0.03 \\
(-0.12,0.07) \\
0.32\end{array}$ & $\begin{array}{c}-0.04 \\
(-0.12,0.05) \\
0.32\end{array}$ & $\begin{array}{c}-0.15 \\
(-0.24,-0.06) \\
0.87\end{array}$ \\
\hline $\begin{array}{l}\text { Brown-headed } \\
\text { cowbird }\end{array}$ & $\begin{array}{c}\text { Est. } \\
\text { (C.I.) } \\
\text { Rel. Imp. }\end{array}$ & $\begin{array}{c}0.03 \\
(-0.08,0.14) \\
0.29\end{array}$ & $\begin{array}{c}0.19 \\
(0.11,0.27) \\
0.98\end{array}$ & $\begin{array}{c}0.10 \\
(-0.02,0.23) \\
0.45\end{array}$ & $\begin{array}{c}0.11 \\
(0.02,0.20) \\
0.59\end{array}$ & $\begin{array}{c}-0.15 \\
(-0.29,-0.003) \\
0.51\end{array}$ \\
\hline Chipping Sparrow & $\begin{array}{c}\text { Est. } \\
\text { (C.I.) } \\
\text { Rel. Imp. }\end{array}$ & $\begin{array}{c}0.15 \\
(-0.01,0.32) \\
0.47\end{array}$ & $\begin{array}{c}0.35 \\
(0.25,0.46) \\
1.00\end{array}$ & $\begin{array}{c}0.14 \\
(-0.05,0.33) \\
0.39\end{array}$ & $\begin{array}{c}0.27 \\
(0.13,0.42) \\
0.92\end{array}$ & $\begin{array}{c}-0.23 \\
(-0.43,-0.03) \\
0.60\end{array}$ \\
\hline Northern Cardinal & $\begin{array}{c}\text { Est. } \\
\text { (C.I.) } \\
\text { Rel. Imp. }\end{array}$ & $\begin{array}{c}-0.07 \\
(-0.15,0.01) \\
0.44\end{array}$ & $\begin{array}{c}0.01 \\
(-0.06,0.08) \\
0.27\end{array}$ & $\begin{array}{c}0.021 \\
(-0.06,0.10) \\
0.29\end{array}$ & $\begin{array}{c}0.00 \\
(-0.08,0.08) \\
0.28\end{array}$ & $\begin{array}{c}-0.20 \\
(-0.29,-0.11) \\
0.98\end{array}$ \\
\hline Song Sparrow & $\begin{array}{c}\text { Est. } \\
\text { (C.I.) } \\
\text { Rel. Imp. }\end{array}$ & $\begin{array}{c}0.19 \\
(0.06,0.31) \\
0.72\end{array}$ & $\begin{array}{c}0.20 \\
(0.10,0.30) \\
0.94\end{array}$ & $\begin{array}{c}0.12 \\
(-0.04,0.28) \\
0.40\end{array}$ & $\begin{array}{c}0.09 \\
(-0.04,0.23) \\
0.38\end{array}$ & $\begin{array}{c}0.03 \\
(-0.13,0.20) \\
0.27\end{array}$ \\
\hline
\end{tabular}

*85\% unconditional confidence intervals provided, following Arnold (2010). 


\section{CHAPTER 5.}

\section{THRESHOLD RESPONSES OF SONGBIRDS WITHIN FORESTED LANDSCAPES DISTURBED BY MARCELLUS-UTICA SHALE GAS DEVELOPMENT}

\section{Introduction}

The extraction of natural gas from deep, low-permeability shale formations has increased dramatically since the early 2000s, when the combined use of horizontal drilling and hydraulic fracturing technologies increased the economic viability of previously untapped shale resources. These advances in 'unconventional' drilling practices opened new regions to shale gas development, including the Marcellus-Utica shale region in the eastern United States, which holds one of the largest shale gas reserves in North America. The Marcellus-Utica region also encompasses large expanses of core forest habitat of high conservation value. Emerging patterns of land use change due to shale gas development suggest the industry is driving substantial forest fragmentation in the central Appalachian region, raising concern about potential ecological consequences for forest dependent species and regional biodiversity (Kiviat 2013, Souther et al. 2014, Brittingham et al. 2014, Langlois et al. 2017). Improving our understanding of the impacts of this relatively new form of energy development on wildlife and species diversity is key to the development of effective and sustainable land management and conservation strategies.

Theoretical models and a growing body of research support the existence of ecological thresholds (i.e., tipping points or change points), beyond which ecological processes show a disproportionate, non-linear response to an incremental change in environmental pressures (Lande 1987, Betts et al. 2007, Bestelmeyer et al. 2011, Gutzwiller et al. 2015). The ecological effects of forest loss and fragmentation can lead to thresholds of landscape change at which additional losses can have dramatic effects on biological communities (Fahrig 1999, Luck 2005). In fragmented landscapes, habitat generalists are likely to possess sufficient behavioral plasticity to 
persist in highly variable forest configurations (Leonard et al. 2008). However, we would expect forest interior species with narrower habitat requirements to exhibit threshold responses to changes in forest cover (Villard 1999). At the local or patch scale, we might see species-specific thresholds in forest loss or fragmentation beyond which individuals cannot persist (Hanski et al. 1995, Radford et al. 2005). At a landscape or regional scale, there may be population thresholds in the proportion of forest habitat to the surrounding matrix at which point recolonizations can no longer compensate for emigrations and local extinctions (Hanski et al. 1995, Andren 1996, Boulinier et al. 2001). Identification of threshold responses of species and communities to forest loss and fragmentation can be invaluable to adaptive management efforts (Bestelmeyer 2006, Foley et al. 2015). The existence of such thresholds among large numbers of forest dependent species in the Marcellus-Utica region would have important conservation implications.

Terrestrial birds are useful and effective indicators of habitat change and complex community response to human-modified landscapes (Canterbury et al. 2000, O'Connell et al. 2007). They are relatively easy to survey, and exhibit a range of space-use behaviors (Leonard et al. 2008) and habitat associations across multiple spatial scales (Warren et al. 2005, Mitchell et al. 2006). Birds are also facing dramatic regional and global declines (Gaston et al. 2003, IUCN 2017), including several species of conservation concern whose breeding ranges overlap the Marcellus-Utica shale region. Recent studies from this region have documented negative effects of shale gas development on forest interior dependent birds, in particular (Barton et al. 2016, Farwell et al. 2016, Langlois 2017). Conversely, some disturbance dependent and synanthropic birds appear to benefit from land cover change resulting from shale gas development, although responses vary by species and type of infrastructure (Barton et al. 2016, Farwell et al. 2016, Langlois 2017). 
However, little is known about potential nonlinear, threshold responses of birds to forest disturbance in landscapes altered by shale gas development.

Our objective was to assess whether birds exhibited threshold responses to anthropogenic forest disturbance in the Marcellus-Utica shale region. First, we assessed potential distance thresholds from forest edges created by human development, and whether distance thresholds differed between forest edges created by shale gas infrastructure compared with other forms of human development. Second, we evaluated thresholds in overall forest cover and core forest cover in landscapes altered by Marcellus-Utica shale gas development. We used Threshold Indicator Taxa Analysis (TITAN; Baker and King 2010, 2013) to identify change points in bird abundances at varying distances from anthropogenic forest edges, and across gradients of forest cover within 1-km radius landscapes surrounding avian sampling points. We calculated threshold responses for the overall avian community, within habitat guilds, and for individual species within each guild.

\section{Methods}

\subsection{Study area and site selection}

The study area encompassed regions in Pennsylvania (PA), West Virginia (WV), and eastern Ohio $(\mathrm{OH})$ where unconventional drilling for Marcellus-Utica shale gas has occurred (Fig. 1). During 2014-2015, we sampled 120 sites impacted by shale gas development as well as other types of human development ("gas sites") and 70 sites impacted only by human development unrelated to shale gas ("non-gas sites"). Most gas sites were centered on a focal gas well pad or cluster of gas well pads; 10 out of 120 gas sites did not contain gas well pads but were centered on other types of shale gas infrastructure (i.e., pipelines, gas compressor stations). Non-gas sites 
had no shale gas development within a minimum 1-km radius of any point sampled; $90 \%$ of control sites had no shale gas development within $2 \mathrm{~km}$ of any point sampled, and $79 \%$ had no shale gas within $3 \mathrm{~km}$. We selected both gas sites and non-gas sites from the same Level IV ecoregions (USEPA 2013) and across comparable ranges of forest cover and anthropogenic disturbance using a stratified, semi-random sampling approach (Brennan et al. 2002, Farwell et al. 2018). Although sites were selected across a broad gradient of forest cover (range $=25-99 \%$ ), most sites (167 out of 190$)$ fell at or above $60 \%$ forest cover $(\bar{x}=79 \%)$, since our aim was to identify threshold responses of birds to human development in predominantly forested landscapes (Zuckerberg et al. 2012, van der Hoek et al. 2013).

\subsection{Distance and land cover metrics}

We manually delineated land cover within broad land use categories by importing temporally appropriate, 1-m resolution aerial imagery from the USDA National Agriculture Imagery Program (NAIP 2016) into a geographic information system (Farwell et al. 2018). NAIP digital orthoimagery is leaf-on and acquired at a 1-m ground sample distance with a horizontal accuracy of $\pm 6.0 \mathrm{~m}$ to true ground (NAIP 2016). Primary land cover classes of interest were: (1) forest, (2) shale gas well pad development, (3) non-shale gas human development (i.e., residential, commercial, industrial), (4) linear shale gas infrastructure (i.e., pipelines, access roads), and (5) non-shale gas linear infrastructure (i.e., all other roads and utility rights-of-way).

We calculated distances from avian sampling points within forested areas to nearest anthropogenic disturbance, using the 'near' function in ArcGIS 10.4 (ESRI 2016). We then separated points into those closest to the four classes of human development we were most interested in evaluating: areas developed for shale gas well pads ("well pads"), developed areas unrelated to shale gas ("non-gas development"), linear infrastructure related to shale gas ("linear 
gas"), and linear infrastructure unrelated to shale gas ("linear non-gas"). We ensured each class of development was the closest anthropogenic edge to points placed in each group. Thus, a linear gas point located $70 \mathrm{~m}$ from a shale gas pipeline would have no other human development within a 70-m radius. For our distance threshold analyses, we excluded points for which the closest edge was related to silviculture, since the impacts of forest disturbance due to regenerating timber harvests are likely to differ from the more permanent, static types of development that were the focus of this study (Schmiegelow et al. 1997, Marzluff and Ewing 2001, Lichstein et al. 2002).

We then converted digitized vector maps to raster grids, and calculated land cover metrics within 1-km radius buffers of each avian sampling point using Fragstats 4.2 (McGarigal et al. 2012), including percent forest and percent core forest cover, using a 100-m edge depth (Robbins et al. 1989a, Howell et al. 2007, Drohan et al. 2012, Farwell et al. 2016). We selected a 1-km radius landscape ( $314 \mathrm{ha}$ ) surrounding each sampling point because this is an area large enough to capture multiple human development features on the landscape (Farwell et al. 2018), while also representing multiple 'neighborhoods' of breeding songbird territories (Desrochers et al. 2010) and an area feasibly visited during daily movements by songbirds (Kremetnz and Powell 2000, Lang et al. 2002). Although there is some overlap in 1-km radius buffers, the avian survey data are independent and landscape metrics relate to avian data at each individual point (Zuckerberg et al. 2012, Becker et al. 2015).

\subsection{Avian surveys and detection probability}

We conducted avian surveys at 2,576 sampling points, distributed among 190 sites across the study region $(\bar{x}=13.6$ points; range $=8-20$ points per site). We placed at least 2 sampling points in areas directly disturbed by shale gas development at gas sites, and by other types of human development at non-gas sites. At sites with lower percent forest cover, we placed additional 
sampling points in human-disturbed areas to better represent site-specific land cover ratios. Remaining points at each site were randomly distributed in surrounding forests within 2 'clusters' (4-10 points per cluster) to minimize travel time between points, while ensuring points were $\geq$ $250 \mathrm{~m}$ apart to maintain statistical independence (Wood et al. 2006, Farwell et al. 2018). Forest points were located at varying distances from human development, and placed $\geq 50 \mathrm{~m}$ from natural canopy gaps when possible to reduce multiple edge effects (Paton 1994). Sampling locations were also constrained by mosaic property boundaries, accessibility, and safety issues.

We counted birds using standard 10-min avian point count surveys (Ralph et al. 1995, Bibby et al. 2000) during 12 May-3 July in 2014 and 15 May-6 July in 2015. Each sample point was surveyed once in either 2014 or 2015 by one of 13 observers experienced in regional bird identification and distance estimation. We conducted surveys between sunrise and $4 \mathrm{~h}$ after sunrise, when weather conditions did not interfere with audibility or visibility of birds. We recorded first detections of birds seen or heard within 5 time intervals $(0-2,>2-4,>4-6,>6-8$, $>8-10 \mathrm{~min})$ and 4 distance bands $(0-25,>25-50,>50-75,>75-100 \mathrm{~m})$, to allow for estimation of detection probability using a combined time removal and distance sampling approach (Sólymos et al. 2013). This approach provides conditional maximum likelihood estimates for the two components of detectability: availability (the probability that a bird will sing) and perceptibility (the probability that a bird will be detected). We included serial date, time-since-sunrise, and their quadratic terms as visit-level covariates potentially affecting singing rates (availability) and observer and tree cover as visit-level covariates potentially affecting perceptibility. Tree cover was percent forest calculated within $100 \mathrm{~m}$ buffers of each survey point, using raster land cover data described above. We only included species in our analyses with sufficient observations to run detection probability models; based on trial-and-error, and as demonstrated in Sólymos et al. 
(2013), we found approximately 75 detections to be sufficient to run detection models and subsequent analyses. For each species with $\geq 75$ detections, we fitted 9 removal models and 4 distance sampling models, including intercept-only models (Appendix A), using the package 'detect' (Sólymos et al. 2016) in program R version 3.4.1 (R Core Team 2017). Using fitted models with lowest Akaike's information criterion (AIC) values, we calculated custom offsets to account for detection probability and used adjusted abundances in subsequent analyses (Sólymos et al. 2013).

\subsection{Threshold analysis}

We used TITAN (Baker and King 2010, 2013) to analyze adjusted avian abundances, using the 'TITAN2' package (Baker et al. 2015) in R version 3.4.1 (R Core Team 2017). TITAN uses a combination of change-point analysis (King and Richardson 2003, Qian et al. 2003) and indicator species analysis (Dufrene and Legendre 1997) to identify abrupt changes in relative abundance and frequency of occurrence of taxa across an environmental gradient. TITAN evaluates midpoints between values along a continuous environmental gradient as potential thresholds, iteratively partitioning observations into two groups and using change-point analysis to maximize a deviance reduction statistic that compares within-group and between-group dissimilarity. However, in place of the aggregate community dissimilarity response used in change-point analysis, TITAN uses taxon-specific indicator value scores to assess the strength of association between each taxon and the environmental gradient. Indicator value scores are the product of cross-group relative abundance and within-group frequency of occurrence; occurrence frequency within each group is used to weight the relative abundance of each taxon such that a large abundance within a sample group only results in a higher score if the taxon also frequently occurs within that group. Indicator value scores are normalized on a scale from 0-100\%, allowing for 
cross-taxa comparisons. The relative strength of indicator value scores on either side of candidate change points indicates whether each taxon shows a negative response $(Z-)$ or positive response $(Z+)$ to the environmental gradient.

TITAN calculates the probability $(p)$ of randomly obtaining indicator value scores equal to or larger than observed values, using 500 random permutations. To assess uncertainty around change-points, the original data is then bootstrapped (500 replicates) and change-points are recalculated with each permutation; uncertainty is expressed as quantiles of change-point distribution. Narrow intervals between upper and lower change-point quantiles (i.e., 5-95\%) reflect sharp, nonlinear responses in taxon abundance, whereas broad quantile intervals indicate linear or more gradual responses. Two diagnostic indices of indicator response quality are obtained from bootstrap resampling: indicator purity and reliability. Purity is the percent of bootstrap replicates with the same change-point response directions (positive or negative) as the observed response. Reliability is the percent of bootstrapped change-point indicator value scores that consistently have $p$-values below defined probability levels (i.e., $p \leq 0.05$ ). We considered taxa as indicators if their purity and reliability indices were $\geq 95 \%$, as in Baker and King (2010). TITAN calculates overall community and species threshold responses based on all species included, but also calculates filtered responses based on indicator species responses, only. Because we were most interested in pure and reliable responses of taxa to environmental gradients, here we only report filtered community responses and indicator species responses $(Z)$. We calculated threshold responses for the overall avian community, within 3 habitat guilds likely to be affected by anthropogenic forest disturbance: forest interior, early successional, and synanthropic (Barton et al. 2016, Farwell et al. 2016, Langlois 2017), and for individual species within each of these guilds. 


\section{Results}

\subsection{Distance and land cover metrics}

Out of 2,576 points sampled, 2,042 points fell closest to anthropogenic forest edges related either to shale gas infrastructure or non-gas development (excluding agriculture and timber harvests). Of these, 211 points were closest to a well pad $(\bar{x}=85 \mathrm{~m}$, range $=0-414 \mathrm{~m}), 572$ points were closest to non-gas development $(\bar{x}=197 \mathrm{~m}$, range $=0-1273 \mathrm{~m}), 288$ points were closest to linear gas infrastructure $(\bar{x}=95 \mathrm{~m}$, range $=0-750 \mathrm{~m})$, and 971 points were closest to linear nongas infrastructure $(\bar{x}=145 \mathrm{~m}$, range $=0-823 \mathrm{~m})$.

We calculated percent forest and percent core forest cover within 1,504 landscapes surrounding avian sampling points (1-km radius) that contained shale gas development. Forest cover occupied a mean $75.7 \pm 0.4 \%( \pm \mathrm{SE})$ of these landscapes (range $=16.7-99.5 \%)$, while core forest cover occupied a mean $33.7 \pm 0.5 \%$ of landscapes (range $=0.04-95.2 \%$ ). In general, the footprint of shale gas infrastructure within these landscapes was relatively small, occupying a mean $3.5 \pm 0.1 \%$ land cover $($ range $=0.001-26.0 \%)$. Of these landscapes, $97 \%$ contained $<10 \%$ shale gas cover, and $75 \%$ contained $<5 \%$ shale gas cover.

\subsection{Avian surveys}

We detected 133 species within $100 \mathrm{~m}$ of our 2,590 sampling points, but excluded species detected only once, non-breeding migrants, and species not reliably sampled using point counts (e.g., gamebirds and other non-passerines, predominantly aerial species, and far-ranging species such as raptors and ravens). Of the 92 remaining species of passerines and near-passerines observed during surveys, 54 had sufficient detections $(n \geq 75)$ for estimation of detection probability $(28,181$ total detections, range $=79-3,460$ per species $)$. Based on natural histories of 
each species (Rodewald 2015) and previous regional studies of avian habitat guilds (Thomas et al. 2014, Barton et al. 2016, Farwell et al. 2016), we placed 23 species in the forest interior habitat guild, 8 in the early successional guild, and 9 in the synanthropic guild (Table 1). We included the remaining 14 species with no clear habitat guild in threshold analyses of the overall avian community, but excluded these from guild-specific analyses (Table 1).

\subsection{Distance thresholds}

When we evaluated threshold responses of indicator species to distance from all anthropogenic forest edges grouped together (gas and non-gas, linear and non-linear), the overall avian community (all species combined) had a positive threshold response at $107.0 \mathrm{~m}$ (Table 2), indicating birds that occurred in higher abundances with greater distance from anthropogenic edge showed a change point at this distance. This positive threshold response within the overall avian community was largely driven by birds within the forest interior guild, which generally occurred in higher abundance and frequency of occurrence at greater distance from anthropogenic forest disturbance and showed a change point at $116.8 \mathrm{~m}$. However, the 5-95\% quantile intervals for positive thresholds were quite broad and extended up to $220.4 \mathrm{~m}$ from anthropogenic edges for the overall avian community and $218.7 \mathrm{~m}$ for the forest interior guild, and well past this distance for individual species (as far as 410.7-740.7 m). Neither the early successional or synanthropic guild showed a positive response in abundance with increasing distance from edges of all development combined, reflecting a general lack of species increasing in abundance with distance from edges, within these guilds (Table 2).

Negative threshold responses to distance from all anthropogenic forest edges combined generally occurred at shorter distances from edges and had narrower quantile intervals than positive responses. Within the overall avian community, birds that occurred in lower abundance 
and frequency of occurrence at greater distance from human development showed a change point at $57.0 \mathrm{~m}$. This community-level response was primarily driven by birds within the early successional and synanthropic guilds, which showed negative threshold change points at $56.4 \mathrm{~m}$ and $33.1 \mathrm{~m}$, respectively, and extended up to 57.9-60.1 $\mathrm{m}$ into surrounding forests. This indicates that disturbance-dependent and human-adapted species declined abruptly beyond a distance of approximately $60 \mathrm{~m}$ from human development.

When we evaluated threshold responses separately for the four categories of anthropogenic edges (Table 2; well pad, non-gas development, linear gas, linear non-gas), the forest interior guild showed positive threshold change points at closer distances to shale gas well pads $(60.4 \mathrm{~m})$ and linear shale gas infrastructure $(61.9 \mathrm{~m})$ compared to non-gas development $(229.6 \mathrm{~m})$ and nongas linear infrastructure $(182.3 \mathrm{~m})$. This indicates that edge effects of non-gas development generally extended further into adjacent forest areas than the effects of edges associated with shale gas development, for forest interior species. However, quantile intervals for shale gas development extended up to $100.9 \mathrm{~m}$ from shale gas well pads and $348.0 \mathrm{~m}$ from linear shale gas infrastructure for the forest interior guild, and much further for individual species (up to $227.1 \mathrm{~m}$ from well pads and $505.1 \mathrm{~m}$ from linear shale gas infrastructure).

We did observe a negative threshold response to non-gas development within the forest interior guild that was considerably higher $(250.5 \mathrm{~m})$ than that of the overall community $(58.6 \mathrm{~m})$. This indicates that negative indicator species within the forest interior guild for distance to nongas development - Acadian flycatcher, cerulean warbler, wood thrush, yellow-throated warbler were more abundant and occurred with greater frequency closer to forest edges associated with non-gas development, compared with other types of human development, and that positive effects for these species of edges associated with non-gas development extended upwards of $250 \mathrm{~m}$ into 
altered forests. Only cerulean warblers and yellow-throated warblers were also negative indicator species for non-gas linear infrastructure. There were no negative indicator species for distance from either shale gas well pad development or linear shale gas infrastructure within the forest interior guild.

In contrast, there were no positive indicator species for distance from any category of human development within the early successional guild, while blue jays were the only positive indicator species for distance to shale gas well pads, within the synanthropic guild. This suggests there was some quality of shale gas well pads that caused blue jays to occur in higher abundances at greater distance from well pads. While both the early successional and synanthropic guilds showed negative distance thresholds to all four categories of human development, change points within the synanthropic guild occurred much closer to shale gas-related development, in particular, compared with change points for shale gas development within the early successional guild. This suggests that species within the synanthropic guild were not able to penetrate as far into forest edges adjacent to shale gas development compared with areas altered by other types of human development.

\subsection{Land cover thresholds}

Among landscapes altered by shale gas development, indicator species within the overall avian community increased in abundance and frequency of occurrence above a threshold of $83.7 \%$ forest cover, with a narrow quantile interval that indicates an abrupt change point between 77.9-84.1\% forest cover (Table 3). The overall avian community also increased in abundance above a threshold of $33.4 \%$ core forest cover, with a quantile interval ranging from $31.8-40.8 \%$

core forest cover. In general, positive responses to both percent forest and percent core forest had narrow 5-95\% quantile intervals within the overall avian community, among habitat guilds, and 
for most individual species evaluated, which indicates confidence in the existence of threshold responses among birds to changes in forest land cover. These positive thresholds largely reflected indicator species responses within the forest interior guild as well as chestnut-sided warblers, an early successional woodland species (Rodewald 2015). Among positive indicator species, thresholds occurred from $45.4-91.1 \%$ forest cover and $2.5-69.7 \%$ core forest cover.

Generally, negative responses to percent forest cover and core forest cover occurred at lower thresholds compared with positive responses (Table 3). The overall avian community decreased in abundance and frequency of occurrence above thresholds of $62.5 \%$ forest cover and $18.8 \%$ core forest cover. Again, these community-level negative responses to forest cover were primarily driven by species within the early successional and synanthropic guilds, although some forest interior species also showed negative threshold responses to either percent forest or percent core forest cover, or both.

The early successional and synanthropic guilds showed similar negative threshold responses to percent forest cover at $60.0 \%$ and $63.9 \%$, and to and percent core forest cover $25.7 \%$ and $20.1 \%$, respectively (Table 3 ). Aside from the positive response to forest cover and core forest cover within the early successional guild, which was driven by chestnut-sided warblers, no other indicator species from the early successional or synanathropic guilds showed positive threshold responses to either percent forest or percent core forest cover. 


\section{Discussion}

\subsection{Distance thresholds}

Our results support the occurrence of some nonlinear avian responses to distance from anthropogenic edges among indicator species, although change point quantile intervals for distance thresholds were generally quite broad - for the overall avian community, within habitat guilds, and among indicator species. This indicates that distance threshold responses were typically gradual rather than sharply nonlinear. This may be a reflection of the wide range of sizes, shapes, and configurations of human development we evaluated, and varying species responses to qualities of anthropogenic edges other than distance, alone. In general, species that increased in abundance and frequency of occurrence along a gradient of distance from human development showed change points at greater distances than species that declined at greater distances from human development. This suggests that the benefits of anthropogenic disturbance for edge-associated species do not extend as far into altered forests as negative edge effects extend, for forest dependent species. For certain area-sensitive, forest interior species (e.g., blackand-white warbler, blue-headed vireo, blackburnian warbler, veery), negative effects of anthropogenic edges extended $>600 \mathrm{~m}$ into affected forests.

We also saw differences in threshold responses among the different categories of human development we evaluated, particularly in threshold responses to forest edges created by shale gas infrastructure (both linear and non-linear) compared to edges associated with other types of nongas development. Species within the forest interior guild, in particular, increased in abundance at change points closer to forest edges associated with shale gas development relative to non-gas development. This may reflect the smaller overall footprint of shale gas infrastructure compared with the other categories of human development we evaluated. However, it is worth noting that 
the forest interior guild showed a positive threshold response at a slightly greater distance from linear gas infrastructure than from well pad development, even though linear shale gas impacts tend to be narrower than land cover impacts associated with well pad development. This suggests that shale gas pipelines and access roads have equal if not greater edge effects on forest interior species than well pad development.

Conversely, the early successional guild decreased in abundance at a change point further from well pad development compared with other types of human development. This suggests there is some quality of edge effects associated with well pad development that this particular habitat guild may be exploiting. The synanthropic guild, on the other hand, decreased abruptly in abundance at change points very close to edges associated with shale gas development, compared with other categories of development evaluated. This indicates that synanthropic birds are not generally occurring in higher abundance or frequency of occurrence within forest edges adjacent to shale gas development to the extent that they are in forest edges created by other types of human development.

\subsection{Land cover thresholds}

Our land cover analyses identified threshold responses to the proportion of forest cover and core forest cover in landscapes altered by shale gas development. Some of these threshold responses were quite abrupt with narrow quantile intervals, particularly for positive threshold responses within the overall avian community at $83.7 \%$ and the forest interior guild at $81.6 \%$. These change point values suggest that forest associated birds increased abruptly in abundance and frequency of occurrence at relatively high levels of overall forest cover, within the landscapes we evaluated. These findings are consistent with other studies from this region, which documented declines in abundance and richness of forest interior birds in response to 
anthropogenic forest disturbance, even at relatively low levels of forest loss (Suarez et al. 2013, Becker et al. 2015, Farwell et al. 2016, Langlois 2017).

Positive threshold responses to core forest habitat occurred at lower proportions of land cover than overall percent forest cover, for both the overall avian community at $33.4 \%$ and the forest interior guild at $39.0 \%$. This suggests that while the overall amount of forest cover is a driving factor for forest bird abundance and frequency of occurrence (Fahrig 2003), at least some degree of intactness, or configuration of forest habitat within large, undisturbed patches, is also an important factor for many forest interior birds (Banks-Leite et al. 2010). Lower positive threshold responses to percent core forest compared with overall percent forest cover may partly reflect the attraction of some forest dependent species to canopy openings within large areas of mature forest, such as cerulean warblers and American redstarts (Buchanan and Hart 2012, Perkins and Wood 2014).

Conversely, negative threshold responses to percent forest cover and core forest cover only occurred at lower proportions of forest cover. These negative responses to forest cover may be interpreted as positive responses to increasing anthropogenic disturbance and availability of nonforest habitat. Negative responses to percent forest cover and core forest cover consistently occurred at lower thresholds than positive responses, which indicates forest birds were negatively impacted by forest loss before early successional and synanthropic species benefitted. This is similar to avian threshold responses of birds in landscapes altered by mountaintop removal mining in the Appalachian region (Becker et al. 2015).

\subsection{Management implications}

By evaluating potential threshold responses in birds to anthropogenic forest disturbance across the Marcellus-Utica shale region, we sought to address a knowledge gap in a region experiencing 
rapid expansion of shale gas infrastructure. We detected thresholds of bird abundance and frequency of occurrence as functions of distance from forest edges associated with shale gas and non-gas development, and as functions of the amount and degree of intactness of forest habitat within landscapes affected by shale gas development. Such thresholds are predicted to occur in theoretical models (Lande 1987, Fahrig 1998, With and King 1999) and have been supported by regional studies of impacts of exurban development (Suarez-Rubio et al. 2013) and mountaintop removal mining (Becker et al. 2015) on forested landscapes, but had not been assessed in the context of unconventional shale gas development.

Our results support the existence of threshold responses to anthropogenic forest disturbance, and indicate that species abundance and frequency of occurrence do not always decline linearly to habitat change. Such threshold responses can be used by conservation practitioners and resource managers to help identify particularly sensitive or vulnerable species, and/or to help predict the point at which landscapes may be on the verge of rapid ecological change (van der Hoek et al. 2015). However, the wide range of threshold values we observed among individual species underscores the fallacy of searching for a single, 'one-size-fits-all' threshold value for edge effects and land cover change (With and King 1999, Lindenmeyer and Luck 2005, Zuckerberg and Porter 2010). Rather than managing for minimum threshold values at which point large numbers of sensitive species will be lost, preventative management efforts will focus on managing landscapes above thresholds that will support the most sensitive species and species of highest conservation concern (Robbins et al. 1989b, Betts et al. 2007, van der Hoek et al. 2015). Landscapes maintained at these target levels of forest cover are also likely to benefit less sensitive species. For example, we found that forested landscapes with at least $81.6 \%$ forest cover supported most forest interior species, although some sensitive species increased in abundance 
and frequency of occurrence at higher thresholds ranging from $83.8-91.1 \%$ forest cover. In contrast, species in the early successional and synanthropic guilds declined in abundance and frequency of occurrence in landscapes with $60.0-63.9 \%$ forest cover, suggesting these species are not likely to benefit optimally from anthropogenic disturbance in heavily forest landscapes above these thresholds of forest cover.

Lastly, our analyses were based on survey data collected during a 2-year period, and were intended as a preliminary assessment of potential nonlinear responses in birds to the relatively novel land cover disturbance associated with unconventional shale gas development in the Marcellus-Utica region. Future studies could focus on longer-term abundance data and could also test for thresholds in demographic responses (i.e., reproductive success, survival).

\section{Acknowledgments}

This research was funded by the U.S. Fish and Wildlife Service in collaboration with the Appalachian Mountains Joint Venture, and by a dissertation fellowship from the Southern Regional Education Board. We are grateful to the Western Pennsylvania Conservancy, D. Pitcock and the WV Host Farms Program, B. Hughes, D. LeVasseur and many other landowners who helped identify potential study sites and provided access to private property. We thank the many surveyors who collected field data, and mapping assistants who helped digitize land cover. T. M. Fearer, J. T. Anderson, D. J. Brown, B. E. McNeil, G. T. Merovich, and J. Sheehan provided guidance during project design and helpful comments on an earlier version of this manuscript. XX anonymous reviewers also provided valuable feedback and manuscript edits. Special thanks to D. Becker for advice during data analysis. We thank the WV Division of Natural Resources, PA Department of Conservation and Natural Resources, and PA Game Commission for support in the field and access to field housing. We also thank L. A. Langlois and B. M. Gamble for help and guidance early in the study, and for shared use of field housing in northern PA. Any use of trade, firm, or product names is for descriptive purposes only and does not imply endorsement by the U.S. Government. 


\section{References.}

Andren, H. 1996. Population responses to habitat fragmentation: statistical power and the random sample hypothesis. Oikos 76:235-242.

Askins, R.A. 1995. Hostile landscapes and the decline of migratory songbirds. Science 267:19561957.

Baker, M.E., and R.S. King. 2010. A new method for detecting and interpreting biodiversity and ecological community thresholds. Methods in Ecology and Evolution 1:25-37.

Baker, M.E., and R.S. King. 2013. Of TITAN and straw men: an appeal for greater understanding of community data. Freshwater Science 32:489-506.

Baker, M.E., R.S. King and D. Kahle. 2015. TITAN2: Threshold Indicator Taxa Analysis. R package version 2.1 .

Banks-Leite, C., R.M. Ewers, and J.-P. Metzger. 2010. Edge effects as the principal cause of area effects on birds in fragmented secondary forest. Oikos 119(6):918-926.

Barton, E.P., S.E. Pabian, and M.C. Brittingham. 2016. Bird community response to Marcellus shale gas development. Journal of Wildlife Management 80:1301-1313.

Becker, D.A., P.B. Wood, M.P. Strager, and C. Mazzarella. 2015. Impacts of mountaintop mining on terrestrial ecosystem integrity: identifying landscape thresholds for avian species in the central Appalachians, United States. Landscape Ecology 30:339-356

Bestelmeyer, B.T. 2006. Threshold concepts and their use in rangeland management and restoration: the good, the bad, and the insidious. Restoration Ecology 14(3):325-329.

Bestelmeyer, B.T., A.M. Ellison, W.R. Fraser, K.B. Gorman, S.J. Holbrook, C.M. Laney, M.D. Ohman, D.P.C. Peters, F.C. Pillsbury, A. Rassweiler, R.J. Schmitt, and S. Sharma. 2011. Analysis of abrupt transitions in ecological systems. Ecosphere 2(12):129.

Betts, M.G., G.J. Forbes, and A.W. Diamond. 2007. Thresholds in songbird occurrence in relation to landscape structure. Conservation Biology 21(4):1046-1058.

Bibby, C.J., N.D. Burgess, and D.A. Hill. 1992. Bird Census Techniques. Academic Press, London, United Kingdom.

Boulinier, T., J.D. Nichols, J.E. Hines, J.R.Sauer, C.H. Flather, and K.H. Pollock. 2001. Forest fragmentation and bird community dynamics: inference at regional scales. Ecology 82(4):1159-1169.

Brennan, J.M., D.J. Bender, T.A. Contreras, and L. Fahrig. 2002. Focal patch landscape studies for wildlife management. Pages 68-91 in J. Wu, and W. W. Taylor, editors. Optimizing sampling effort across scales: integrating landscape ecology into natural resource management. Cambridge University Press, Cambridge, United Kingdom.

Brittingham, M.C., K.O. Maloney, A.M. Farag, D.D. Harper, and Z.H. Bowen. 2014. Ecological risks of shale oil and gas development to wildlife, aquatic resources and their habitats. Environmental Science and Technology 48:11034-11047. 
Buchanan, M.L., and J.L. Hart. 2012. Canopy disturbance history of old-growth Quercus alba sites in the eastern United States: examination of long-term trends and broad-scale patterns. Forest Ecology and Management 267:28-39.

Canterbury, G.E., T.E. Martin, D.R. Petit, L.J. Petit, and D.F. Bradford. Bird communities and habitat as ecological indicators of forest condition in regional monitoring. Conservation Biology 14:544-558.

Drohan, P.J., M.C. Brittingham, and J. Bishop. 2012. Early trends in landcover change and forest fragmentation due to shale-gas development in Pennsylvania: a potential outcome for the northcentral Appalachians. Environmental Management 49:1061-1075.

Dufrene, M., and P. Legendre. 1997. Species assemblages and indicator species: the need for a flexible asymmetrical approach. Ecological Monographs 67:345-366.

ESRI (Environmental Research Systems Institute). 2016. ArcGIS Desktop: Release 10.4. Redlands, CA, USA.

Fahrig, L. 1998. When does fragmentation of breeding habitat affect population survival? Ecological Modelling 105:273-292.

Fahrig, L. 1999. Forest loss and fragmentation: which has the greater effect on persistence of forest-dwelling animals? Pp: 87-95. In: Rochelle, J.A., L. A. Lehmann, and J. Wisniewski (eds.) Forest Fragmentation: Wildlife and Management Implications. Brill Academic Publishing, Leiden, Netherlands.

Fahrig, L. 2003. Effects of habitat fragmentation on biodiversity. Annual Review of Ecology, Evolution, and Systematics 34:487-515.

Farwell, L.S., P.B. Wood, J. Sheehan, and G.A. George. 2016. Shale gas development effects on the songbird community in a central Appalachian forest. Biological Conservation 201:78-91.

Farwell, L.S., P.B. Wood, R. Dettmers, and M.C. Brittingham. 2018 (in review). Region-wide impacts of Marcellus-Utica shale gas development on forest songbirds.

Foley, M.M., R.G. Martone, M.D. Fox, C.V. Kappel, L.A. Mease, A.L. Erickson, B.S. Halpern, K.A. Selkoe, P. Taylor, and C. Scarborough. 2015. Using ecological thresholds to inform resource management: current options and future possibilities. Frontiers in Marine Science 2:95.

Gaston, K.J., T.M. Blackburn, and K.K. Goldewijk. 2003. Habitat conversion and global avian biodiversity loss. Proceedings of the Royal Society B 270(1521):1293-1300.

Gutzwiller, K.J., S.K. Riffell, and C.H. Flather. 2015. Avian abundance thresholds, human-altered landscapes, and the challenge of assemblage-level conservation. Landscape Ecology 30(1):2095-2110.

Hanski, I., and P. Hammond. 1995. Biodiversity in boreal forests. Trends in Ecology and Evolution 10(1):5-6.

Howell, C.A., W.D. Dijak, and F.R. Thompson. 2007. Landscape context and selection for forest edge by breeding brown-headed cowbirds. Landscape Ecology 22:273-284. 
IUCN (International Union for Conservation of Nature and Natural Resources). 2017. The IUCN red list of threatened species. Version 2017-3. <http://www.iucnredlist.org> Accessed Dec 2017.

King, R.S., and C.J. Richardson. 2003. Integrating bioassessment and ecological risk assessment: an approach to developing numerical water-quality criteria. Environmental Management 31:795-809.

Kiviat, E. 2013. Risks to biodiversity from hydraulic fracturing for natural gas in the Marcellus and Utica shales. Annals of the New York Academy of Sciences 1286:1-14.

Krementz, D.G., and L.A. Powell. 2000. Breeding season demography and movements of eastern towhees at the Savannah River Site, South Carolina. Wilson Bulletin 112:243-248.

Lande, R. 1987. Extinction thresholds in demographic models of territorial populations. American Naturalist 130:624-635.

Lang, J.D., L.A. Powell, D.G. Krementz, and M.J. Conroy. 2002. Wood thrush movements and habitat use: effects of forest management for red-cockaded woodpeckers. Auk 119:109-124.

Langlois, L.A. 2017. Effects of Marcellus shale gas infrastructure on forest fragmentation and bird communities in northcentral Pennsylvania. Dissertation, Pennsylvania State University, State College, USA.

Langlois, L.A., P.J. Drohan, and M.C. Brittingham. 2017. Linear infrastructure drives habitat conversion and forest fragmentation associated with Marcellus shale gas development in a forested landscape. Journal of Environmental Management 197:167-176.

Leonard, T.D., P.D. Taylor, and I.G. Warkentin. 2008. Landscape structure and spatial scale affect space use by songbirds in naturally patchy and harvested boreal forests. Condor 110(3):467-481.

Lichstein, J.W., Simons, T.R., and Franzreb, K.E. 2002. Landscape effects on breeding songbird abundance in managed forests. Ecological Applications 12(3):836-857.

Lindenmayer, D.B., and G. Luck. 2005. Synthesis: thresholds in conservation and management. Biological Conservation 124:351-354.

Luck, G.W. 2005. An introduction to ecological thresholds. Landscape Ecology 124:299-300.

Marzluff, J.M., and K. Ewing. 2001. Restoration of fragmented landscapes for the conservation of birds: a general framework and specific recommendations for urbanizing landscapes.

Restoration Ecology 9:280-292.

McGarigal, K., S.A. Cushman, and E. Ene. 2012. FRAGSTATS v4: Spatial Pattern Analysis Program for Categorical and Continuous Maps. University of Massachusetts, Amherst. Amherst, MA. <http://www.umass.edu/landeco/research/fragstats/fragstats.html> Accessed Jul 2017.

Mitchell, M.S., S.H. Rutzmoser, T. Bently Wigley, C. Loehle, J.A. Gerwin, P.D. Keyser, R.A. Lancia, R.W. Perry, C.J. Reynolds, R.E. Thill, R. Weih, D. White, and P.B. Wood. 2006. Relationships between avian richness and landscape structure at multiple scales using multiple landscapes. Forest Ecology and Management 221:155-169. 
National Agriculture Imagery Program (NAIP). 2016. U.S. Department of Agriculture Farm Service Agency: NAIP Imagery. <https://www.fsa.usda.gov/programs-and-services/aerialphotography/imagery-programs/naip-imagery/> Accessed Jun 2017.

O’Connell, T.J., J.A.Bishop, R.P. Brooks. 2007. Sub-sampling data from the North American Breeding Bird Survey for application to the Bird Community Index, an indicator of ecological condition. Ecological Indicators 7:679-691.

Paton, P.W.C. 1994. The effects of edge on avian nest success: how strong is the evidence? Conservation Biology 8:17-26.

Perkins, K.A., and P.B. Wood. 2014. Selection of forest canopy gaps by male cerulean warblers in West Virginia. Wilson Journal of Ornithology 126:288-297.

Qian, S.S., R.S. King, and C.J. Richardson. 2003. Two methods for the detection of environmental thresholds. Ecological Modelling 166:87-97.

R Core Team. 2017. R: A language and environment for statistical computing. R Foundation for Statistical Computing, Vienna, Austria. <https://www.R-project.org/> Accessed Dec 2017.

Ralph, C.J., S. Droege, J.R. Sauer. 1995. Managing and monitoring birds using point counts: standards and applications. USDA Forest Service General Technical Report PSW-GTR-149: 161-168. USDA Forest Service Pacific Southwest Research Station, Albany, California, USA.

Robbins, C.S., J.R. Sauer, R.S. Greenberg, and S. Droege. 1989a. Population declines in North American birds that migrate to the neotropics. Proceedings of the National Academy of Sciences of the United States of America 86:7658-7662.

Robbins, C.S., Dawson, D.K., Dowell, B.A. 1989b. Habitat area requirements of breeding forest birds of the Middle Atlantic States. Wildlife Monographs 103:3-34.

Rodewald, P. G., editor. 2015. The birds of North America. Cornell Laboratory of Ornithology, Ithaca, New York, USA.

Schmiegelow, F.K.A., Machtans, C.S., and Hannon, S.J. 1997. Are boreal birds resilient to forest fragmentation? An experimental study of short-term community responses. Ecology 78(6):1914-1932.

Sólymos, P., S.M. Matsuoka, E.M. Bayne, S.R. Lele, P. Fontaine, S.G. Cummings, D. Stralberg, F.K.A. Schmiegelow, and S.J. Song. 2013. Calibrating indices of avian density from nonstandardized survey data: making the most of a messy situation. Methods in Ecology and Evolution 4:1047-1058

Sólymos, P., M. Moreno, and S.R. Lele. 2016. detect: Analyzing wildlife data with detection error. R package version $0.4-0$.

Souther, S, M. W. Tingley, V.D. Popescu, D.T.S. Hayman, M.E. Ryan, T.A. Graves, B. Harth, and K. Terrell. 2014. Biotic impacts of energy development from shale: research priorities and knowledge gaps. Frontiers in Ecology and the Environment 12: 330-338.

Suarez-Rubio, M., S. Wilson, P. Leimgruber, and T. Lookingbill. 2013. Threshold responses of forest birds to landscape changes around exurban development. PLoS ONE 8:e67593. 
Thomas, E.H., M.C. Brittingham, and S.H. Stoleson. 2014. Conventional oil and gas development alters forest songbird communities. Journal of Wildlife Management 78:293-306.

USEPA (U.S. Environmental Protection Agency). 2013. Level III and IV ecoregions of the continental United States: Corvallis, Oregon, U.S. EPA - National Health and Environmental Effects Research Laboratory, map scale 1:7,500,000. <https://www.epa.gov/ecoresearch/level-iii-and-iv-ecoregions-continental-united-states> Accessed Aug 2016.

van der Hoek, Y., R. Renfrew, L.L. Manne. 2013. Assessing regional and interspecific variation in threshold responses of forest breeding birds through broad scale analyses. PLoS ONE 8:e55996.

van der Hoek, Y., B. Zuckerberg, and L.L. Manne. 2015. Application of habitat thresholds in conservation: considerations, limitations, and future directions. Global Ecology and Conservation 3:736-743.

With, K.A., and A.W. King. 1999. Dispersal success on fractal landscapes: a consequence of lacunarity thresholds. Landscape Ecology 14:73-82.

Warren, T.L., M.G. Betts, A.W. Diamond, and G.J. Forbes. 2005. The influence of local habitat and landscape composition on cavity-nesting birds in a forested mosaic. Forest Ecology and Management 214:331-343.

Wood, P.B., S. Bosworth, and R. Dettmers. 2006. Cerulean warbler abundance and occurrence relative to large-scale edge and habitat characteristics. Condor 108:154-165.

Zuckerberg, B., and W.F. Porter. 2010. Thresholds in the long-term responses of breeding birds to forest cover and fragmentation. Biological Conservation 143:952-962.

Zuckerberg, B., A. Desrochers, W.M. Hochachka, D. Fink, W.D. Koenig, and J.L. Dickinson. 2012. Overlapping landscapes: a persistent, but misdirected concern when collecting and analyzing ecological data. Journal of Wildlife Management 76:1072-1080. 
Figure 1. Map of study region. Sites were surveyed in 5 states: Pennsylvania, West Virginia, Ohio, Maryland, and New York. Black triangles represent shale gas sites, white dots represent non-gas sites. Extent of Marcellus shale play shaded in gray.

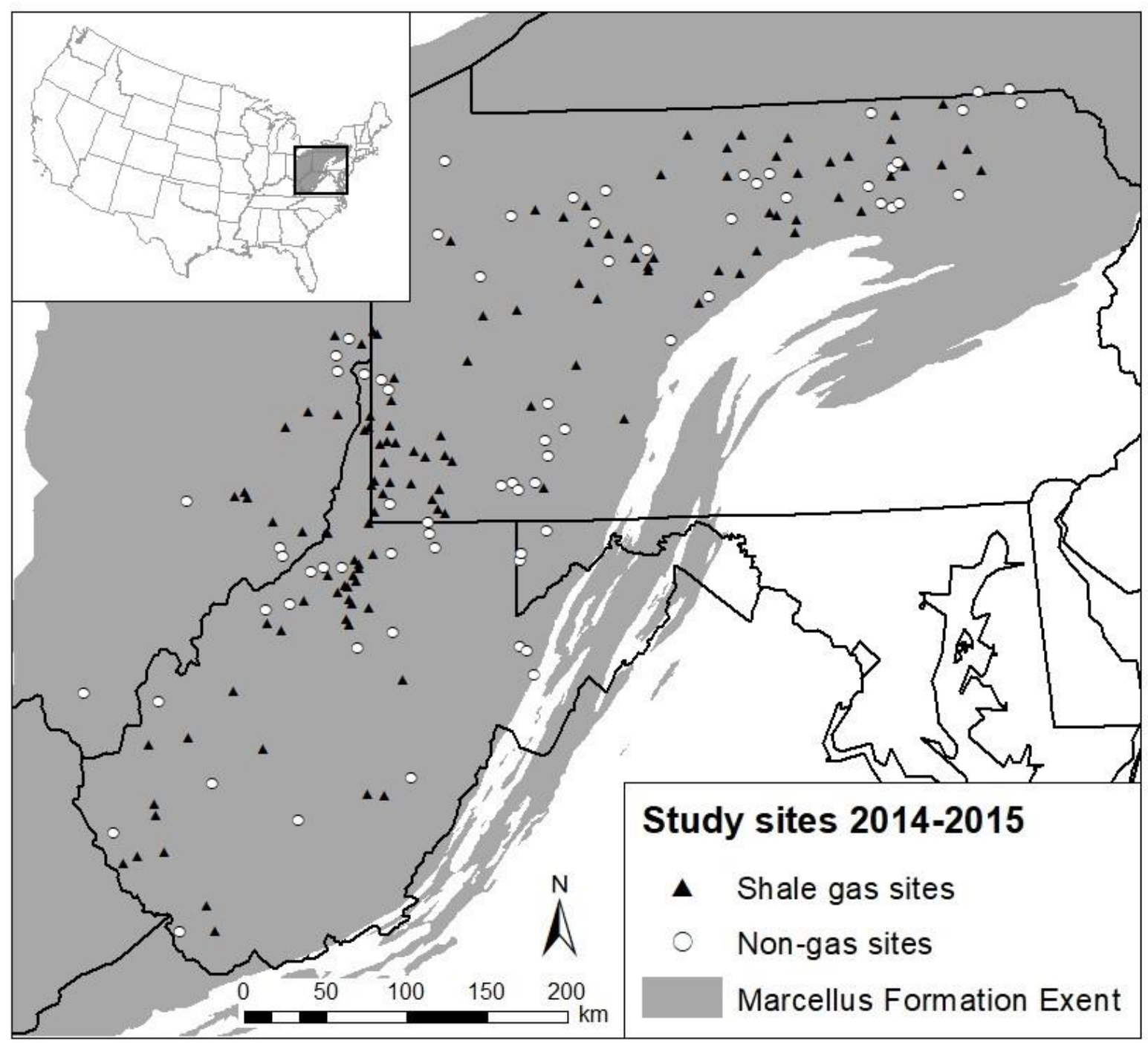


Table 1. Species included in threshold analyses, grouped into three guilds potentially impacted by human development: forest interior, early successional, and synanthropic species. Birds with no clear habitat guild were excluded from guild-specific analyses. Species of conservation concern shown in bold.

\begin{tabular}{|c|c|c|c|}
\hline Forest interior & Early successional & Synanthropic & No assigned guild \\
\hline Acadian flycatcher ${ }^{\mathrm{a}}$ & Blue-winged warbler ${ }^{\mathrm{a}, \mathrm{b}}$ & American robin & Black-capped chickadee \\
\hline Empidonax virescens & Vermivora cyanoptera & Turdus migratorius & Poecile atricapillus \\
\hline American redstart & Chestnut-sided warbler & Baltimore oriole & Blue-gray gnatcatcher \\
\hline Setophaga ruticilla & Setophaga pensylvanica & Icterus galbula & Polioptila caerulea \\
\hline Black-and-white warbler ${ }^{a}$ & Common yellowthroat & Blue jay & Carolina chickadee \\
\hline Mniotilta varia & Geothlypis trichas & Cyanocitta cristata & Poecile carolinensis \\
\hline Blackburnian warbler ${ }^{\text {a }}$ & Eastern towhee $^{a}$ & Brown-headed cowbird & Cedar waxwing \\
\hline Setophaga fusca & Pipilo erythrophthalmus & Molothrus ater & Bombycilla cedrorum \\
\hline Black-throated blue warbler & Field sparrow $^{\mathrm{a}}$ & Carolina wren & Dark-eyed junco \\
\hline Setophaga caerulescens & Spizella pusilla & Thryothorus ludovicianus & Junco hyemalis \\
\hline $\begin{array}{l}\text { Black-throated green warbler } \\
\text { Setophaga virens }\end{array}$ & $\begin{array}{l}\text { Gray catbird } \\
\text { Dumetella carolinensis }\end{array}$ & $\begin{array}{l}\text { Chipping sparrow } \\
\text { Spizella passerina }\end{array}$ & $\begin{array}{l}\text { Downy woodpecker } \\
\text { Picoides pubescens }\end{array}$ \\
\hline Blue-headed vireo & Indigo bunting ${ }^{\mathrm{a}}$ & Mourning dove & Northern flicker ${ }^{\mathrm{a}}$ \\
\hline Vireo solitarius & Passerina cyanea & Zenaida macroura & Colaptes auratus \\
\hline Cerulean warbler ${ }^{a, b, c}$ & White-eyed vireo & Northern cardinal & Northern parula ${ }^{a}$ \\
\hline Setophaga cerulea & Vireo griseus & Cardinalis cardinalis & Setophaga americana \\
\hline Eastern wood peewee ${ }^{a}$ & & Song sparrow & Red-bellied woodpecker \\
\hline Contopus virens & & Melospiza melodia & Melanerpes carolinus \\
\hline Hairy woodpecker & & & Tufted titmouse \\
\hline Picoides villosus & & & Baeolophus bicolor \\
\hline Hooded warbler ${ }^{\mathrm{a}}$ & & & White-breasted nuthatch \\
\hline Setophaga citrina & & & Sitta carolinensis \\
\hline Kentucky warbler ${ }^{a, b}$ & & & Yellow warbler \\
\hline Geothlypis formosa & & & Setophaga petechia \\
\hline Magnolia Warbler & & & Yellow-billed cuckoo $^{\text {b }}$ \\
\hline Setophaga magnolia & & & Coccyzus americanus \\
\hline Ovenbird & & & Yellow-throated vireo ${ }^{a}$ \\
\hline Seiurus aurocapilla & & & Vireo flavifrons \\
\hline \multicolumn{4}{|l|}{ Pileated woodpecker } \\
\hline Dryocopus pileatus & & & \\
\hline \multicolumn{4}{|l|}{ Red-eyed vireo } \\
\hline \multicolumn{4}{|l|}{ Vireo olivaceus } \\
\hline \multicolumn{4}{|l|}{ Rose-breasted grosbeak } \\
\hline \multicolumn{4}{|l|}{ Pheucticus ludovicianus } \\
\hline \multicolumn{4}{|l|}{ Scarlet tanager } \\
\hline \multicolumn{4}{|l|}{ Piranga olivacea } \\
\hline \multicolumn{4}{|l|}{ Veery } \\
\hline \multicolumn{4}{|l|}{ Catharus fuscescens } \\
\hline \multicolumn{4}{|l|}{ Wood thrush ${ }^{\mathrm{a}, \mathrm{b}, \mathrm{c}}$} \\
\hline \multicolumn{4}{|l|}{ Hylocichla mustelina } \\
\hline \multicolumn{4}{|l|}{ Worm-eating warbler ${ }^{\mathrm{a}, \mathrm{b}}$} \\
\hline \multicolumn{4}{|l|}{ Helmitheros vermivorum } \\
\hline \multicolumn{4}{|l|}{ Yellow-bellied sapsucker ${ }^{\mathrm{a}}$} \\
\hline \multicolumn{4}{|l|}{ Sphyrapicus varius } \\
\hline \multicolumn{4}{|l|}{ Yellow-throated warbler ${ }^{\mathrm{a}}$} \\
\hline \multicolumn{4}{|l|}{ Setophaga dominica } \\
\hline
\end{tabular}


Table 2. Distance thresholds: negative ( $\mathrm{Z}-$ ) and positive $(\mathrm{Z}+)$ threshold responses $(\mathrm{CP}=$ change point) and 5-95\% change point quantiles, to distance $(\mathrm{m})$ to closest edge for all anthropogenic edge types combined, and grouped separately by closest edge type. Responses are filtered using only indicator taxa (purity and reliability $\geq 95 \%$ ). Results are listed for all species combined, by habitat guild, and for indictor species within each guild.

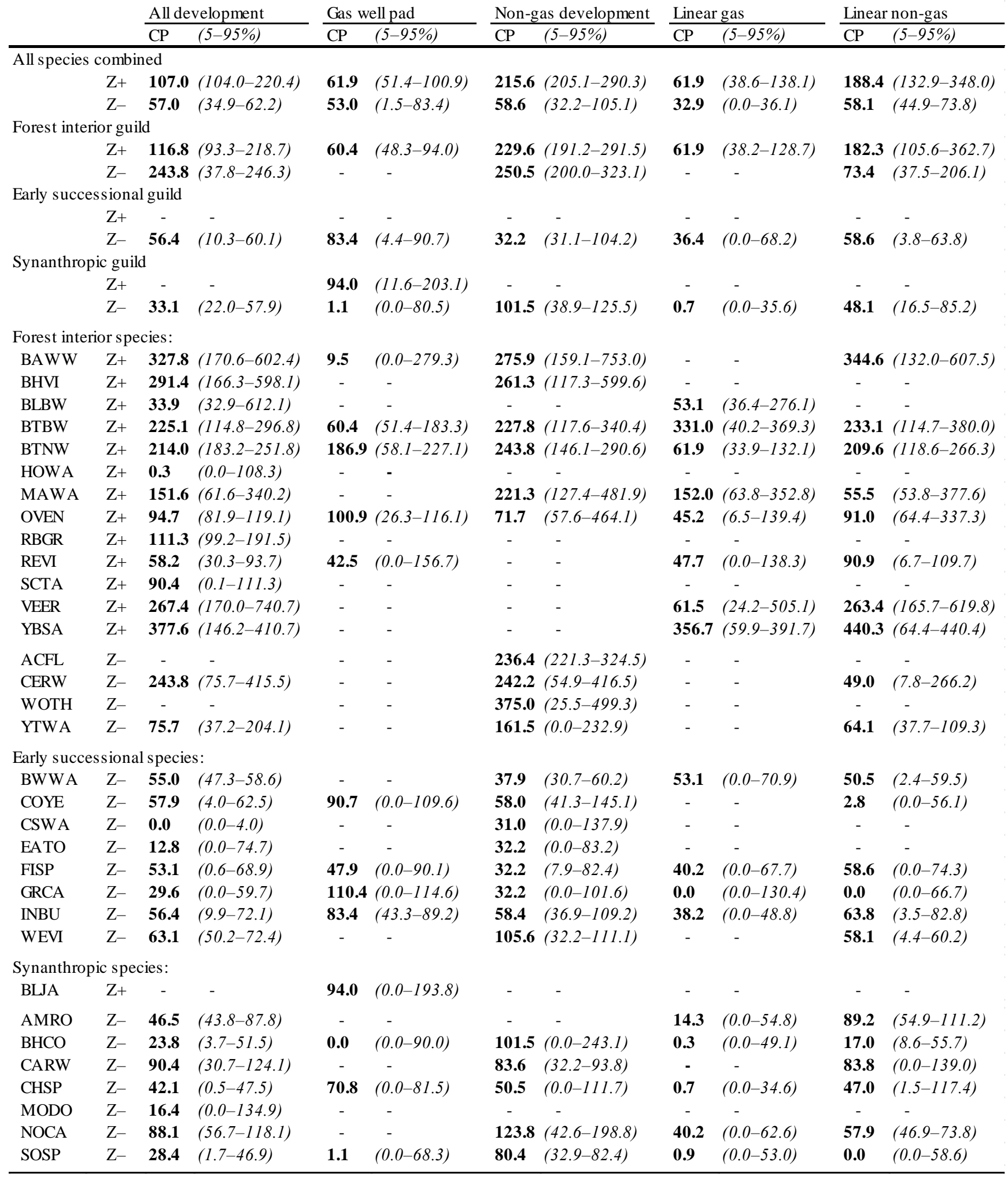


Table 3. Forest cover thresholds: negative $(\mathrm{Z}-)$ and positive $(\mathrm{Z}+)$ threshold responses $(\mathrm{CP}=$ change point $)$ and 595\% CP quantiles, to forest and core forest cover within 1-km radius landscapes altered by shale gas development. Responses are filtered using only indicator taxa (purity and reliability $\geq 95 \%$ ).

\begin{tabular}{|c|c|c|c|c|c|}
\hline & & \multicolumn{2}{|c|}{ Forest cover $(\%)$} & \multicolumn{2}{|c|}{ Core forest cover $(\%$} \\
\hline & & $\overline{\mathrm{CP}}$ & $(5-95 \%)$ & $\overline{\mathrm{CP}}$ & $(5-95 \%)$ \\
\hline \multirow[t]{2}{*}{ All species combined } & $\mathrm{Z}+$ & 83.7 & $(77.9-84.1)$ & 33.4 & $(31.8-40.8)$ \\
\hline & $Z_{-}$ & 62.5 & $(60.0-70.5)$ & 18.8 & $(14.5-25.9)$ \\
\hline \multirow[t]{2}{*}{ Forest interior guild } & $\mathrm{Z}+$ & 81.6 & $(74.9-84.3)$ & 39.0 & $(31.7-43.0)$ \\
\hline & $Z_{-}$ & 77.9 & $(44.7-80.9)$ & 21.9 & $(14.5-34.1)$ \\
\hline \multirow[t]{2}{*}{ Early successional guild } & $Z_{+}$ & 82.7 & $(78.7-90.9)$ & 36.8 & $(31.6-58.8)$ \\
\hline & Z- & 60.0 & $(58.3-71.3)$ & 25.7 & $(14.3-26.9)$ \\
\hline \multirow[t]{2}{*}{ Synanthropic guild } & $\mathrm{Z}+$ & - & - & - & - \\
\hline & $Z_{-}$ & 63.9 & $(54.8-79.2)$ & 20.1 & $(12.3-24.0)$ \\
\hline \multicolumn{6}{|l|}{ Forest interior species: } \\
\hline AMRE & $\mathrm{Z}_{+}$ & 90.3 & $(82.5-93.4)$ & 2.5 & $(2.2-63.3)$ \\
\hline BAWW & $Z_{+}$ & 77.1 & $(74.6-89.4)$ & 51.7 & $(31.9-61.2)$ \\
\hline BHVI & $\mathrm{Z}+$ & 84.3 & $(72.5-97.4)$ & 31.6 & $(31.3-40.5)$ \\
\hline BLBW & $Z_{+}$ & 89.8 & $(80.3-93.8)$ & 69.7 & $(24.8-71.1)$ \\
\hline BTBW & $Z_{+}$ & 84.3 & $(82.9-92.5)$ & 45.4 & $(34.6-61.7)$ \\
\hline BTNW & $Z_{+}$ & 81.6 & $(73.8-88.9)$ & 39.0 & $(34.7-42.4)$ \\
\hline CERW & $\mathrm{Z}_{+}$ & 80.2 & $(77.8-97.1)$ & 9.6 & $(6.3-62.5)$ \\
\hline MAWA & $Z_{+}$ & 76.0 & (69.3-97.9) & 33.0 & $(28.6-75.9)$ \\
\hline OVEN & $\mathrm{Z}_{+}$ & 74.5 & $(65.2-78.6)$ & 33.6 & $(16.5-35.2)$ \\
\hline REVI & $\mathrm{Z}+$ & 63.0 & $(51.1-87.9)$ & - & - \\
\hline VEER & $Z_{+}$ & 91.1 & $(77.8-94.6)$ & 42.2 & $(31.4-47.5)$ \\
\hline WEWA & $Z_{+}$ & 83.8 & $(72.1-86.9)$ & 24.8 & $(14.6-59.3)$ \\
\hline YBSA & $\mathrm{Z}+$ & 74.5 & $(66.6-93.9)$ & 44.0 & $(34.4-48.4)$ \\
\hline YTWA & $\mathrm{Z}+$ & 81.3 & $(78.7-97.5)$ & 38.3 & $(15.6-62.7)$ \\
\hline ACFL & $Z_{-}$ & - & - & 18.4 & (13.6-39.7) \\
\hline EAWP & $Z_{-}$ & 45.4 & $(43.9-58.4)$ & 5.7 & $(4.7-8.0)$ \\
\hline HOWA & $Z_{-}$ & 78.4 & $(66.6-80.6)$ & 25.9 & $(22.7-30.8)$ \\
\hline RBGR & $Z_{-}$ & 87.9 & $(23.8-89.9)$ & - & - \\
\hline SCTA & $Z_{-}$ & - & - & 34.6 & $(3.6-64.9)$ \\
\hline WOTH & Z- & 78.8 & $(58.4-81.5)$ & 21.6 & $(7.4-37.0)$ \\
\hline \multicolumn{6}{|c|}{ Early successional species: } \\
\hline CSWA & $Z_{+}$ & 80.6 & $(74.3-90.7)$ & 36.8 & $(31.6-58.8)$ \\
\hline BWWA & $Z_{-}$ & 74.1 & $(60.0-90.7)$ & 25.7 & $(23.4-46.0)$ \\
\hline COYE & $Z_{-}$ & 59.1 & $(37.4-63.9)$ & - & - \\
\hline EATO & $Z_{-}$ & 60.8 & $(58.0-77.7)$ & - & - \\
\hline FISP & $Z_{-}$ & 60.4 & $(58.8-71.3)$ & 22.9 & $(11.5-27.5)$ \\
\hline GRCA & Z- & 54.9 & $(31.2-55.4)$ & 14.3 & $(0.7-14.6)$ \\
\hline INBU & $Z_{-}$ & 70.6 & $(66.7-76.3)$ & 27.9 & $(19.2-31.9)$ \\
\hline WEVI & $Z_{-}$ & 66.2 & $(46.6-69.7)$ & 27.0 & $(6.7-38)$. \\
\hline \multicolumn{6}{|l|}{ Synanthropic species: } \\
\hline AMRO & $Z_{-}$ & 83.8 & $(61.1-84.3)$ & 24.7 & $(21.8-34.0)$ \\
\hline BAOR & $Z_{-}$ & 59.7 & $(50.1-65.8)$ & 12.0 & $(9.3-15.6)$ \\
\hline $\mathrm{BHCO}$ & $Z_{-}$ & 70.3 & $(55.3-79.1)$ & 16.4 & $(9.5-33.7)$ \\
\hline BLJA & $Z_{-}$ & 84.0 & $(31.0-93.8)$ & 19.5 & $(1.0-58.5)$ \\
\hline CARW & $Z_{-}$ & 62.0 & $(40.3-63.8)$ & 10.8 & $(2.3-20.3)$ \\
\hline MODO & Z- & 83.0 & $(21.8-83.7)$ & 0.8 & $(0.4-46.4)$ \\
\hline NOCA & $Z_{-}$ & 70.4 & $(66.4-81.4)$ & 23.5 & $(17.5-37.5)$ \\
\hline SOSP & $Z_{-}$ & 50.1 & $(38.5-66.5)$ & 5.6 & $(2.9-22.2)$ \\
\hline
\end{tabular}


Appendix A. Model sets included in AIC analysis of factors influencing detection probabilities using (1) time removal, and (2) distance sampling. Models include intercept-only models as well as models incorporating survey-specific covariates. Tree cover is percent forest cover within a 100-m radius of each survey point.

\begin{tabular}{l} 
7. Time removal models: \\
\hline Intercept-only \\
Time since sunrise \\
Time since sunrise $+(\text { Time since sunrise })^{2}$ \\
Serial date \\
Serial date $+(\text { Serial date })^{2}$ \\
Serial date + Time since sunrise \\
Serial date $+(\text { Serial date })^{2}+$ Time since sunrise \\
Serial date + Time since sunrise $+(\text { Time since sunrise })^{2}$ \\
Serial date $+(\text { Serial date })^{2}+$ Time since sunrise $+(\text { Time since sunrise })^{2}$ \\
\hline 8. Distance sampling models: \\
\hline Intercept-only \\
Tree cover (within 100 m) \\
Observer \\
Observer + Tree cover $($ within 100 m) \\
\hline
\end{tabular}

